\title{
Rules for tools
}

Citation for published version (APA):

Dreesens, D. H. H. (2020). Rules for tools: Knowledge translation tools in health care: a case of consilience. [Doctoral Thesis, Maastricht University]. Maastricht University. https://doi.org/10.26481/dis.20201104dd

Document status and date:

Published: 01/01/2020

DOI:

10.26481/dis.20201104dd

Document Version:

Publisher's PDF, also known as Version of record

\section{Please check the document version of this publication:}

- A submitted manuscript is the version of the article upon submission and before peer-review. There can be important differences between the submitted version and the official published version of record.

People interested in the research are advised to contact the author for the final version of the publication, or visit the DOI to the publisher's website.

- The final author version and the galley proof are versions of the publication after peer review.

- The final published version features the final layout of the paper including the volume, issue and page numbers.

Link to publication

\footnotetext{
General rights rights.

- You may freely distribute the URL identifying the publication in the public portal. please follow below link for the End User Agreement:

www.umlib.nl/taverne-license

Take down policy

If you believe that this document breaches copyright please contact us at:

repository@maastrichtuniversity.nl

providing details and we will investigate your claim.
}

Copyright and moral rights for the publications made accessible in the public portal are retained by the authors and/or other copyright owners and it is a condition of accessing publications that users recognise and abide by the legal requirements associated with these

- Users may download and print one copy of any publication from the public portal for the purpose of private study or research.

- You may not further distribute the material or use it for any profit-making activity or commercial gain

If the publication is distributed under the terms of Article $25 \mathrm{fa}$ of the Dutch Copyright Act, indicated by the "Taverne" license above, 


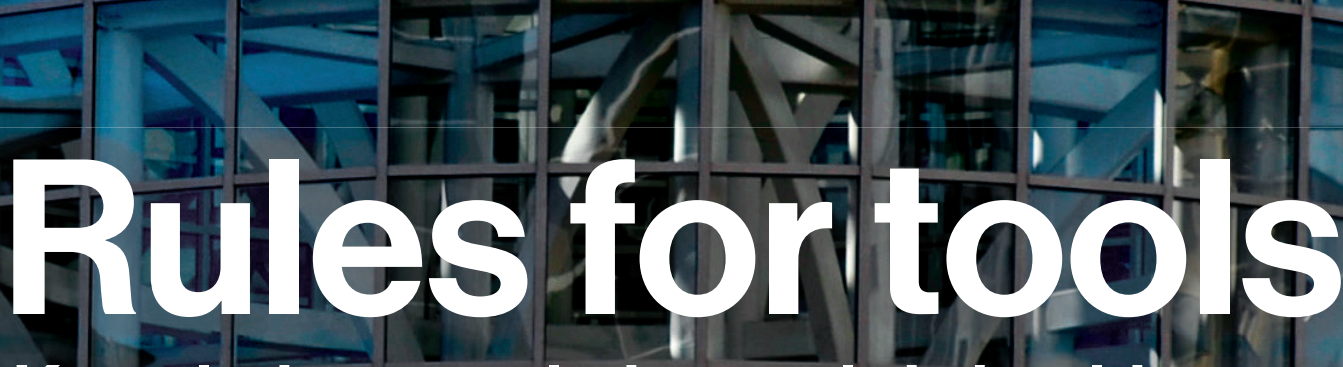

Knowledge translation tools in health care: a case of consilience

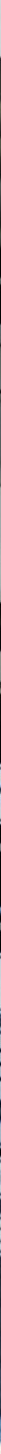





\section{Rules for tools}

Knowledge translation tools in health care: a case of consilience

Dunja Dreesens 
The research presented in this thesis was conducted at CAPHRI Care and Public Health Research Institute, department of Family Practice at Maastricht University. CAPHRI participates in the Netherlands School of Public Health and Care Research (CaRe).

The studies in this thesis were supported by grants from and in kind by:

- ZonMw, the Netherlands organization for health research and development - grant for the project Development of patient information and patient decision aids alongside clinical practice guidelines, (project number 0-83900-98-350) for chapter four and the valorisation chapter, and in kind;

- Zorginstituut Nederland (National Institute of Health Care) - financial contributions for chapters three and four, and in kind;

- Kennisinstituut van Medisch Specialisten - financial contribution for chapter four, and in kind;

- Synmind - in kind contribution to chapter three.

\section{Colofon}

Cover photo: Dunja Dreesens, Salt Lake City, USA, 2017

Cover design and lay out: www.verapost.nl

Printing: Ridderprint | www.ridderprint.nl

(C) Copyright: Dunja Dreesens, Maastricht 2020

ISBN: 978-94-6416-175-5 


\section{Rules for tools}

Knowledge translation tools in health care:

a case of consilience

\section{Proefschrift}

Ter verkrijging van de graad van doctor aan de Universiteit Maastricht, op gezag van Rector Magnificus, prof. dr. Rianne M. Letschert, volgens het besluit van het College van Decanen, in het openbaar te verdedigen op woensdag 4 november om 16 uur

door

Dunja H.H. Dreesens 


\section{Promotores}

Prof. dr. T. van der Weijden

Prof. dr. A.A.E. Verhagen (UMCG, RUG)

Prof. dr. L.C. Kremer (Amsterdam UMC)

\section{Beoordelingscommissie}

Prof. dr. D. Ruwaard (voorzitter)

Prof. dr. K. Horstman

Prof. dr. J.M.P. Kleijnen

Prof. dr. D.M.J. Delnoij (Erasmus Universiteit Rotterdam)

Dr. J.J.E. van Everdingen (Nederlandse Vereniging voor Dermatologie en Venereologie) 
"De grenzen van mijn taal

betekenen de grenzen van mijn wereld."

- Ludwig Wittgenstein 



\section{Content manuscript}

\section{Propositions / Stellingen}

11 Abbreviations

13 Chapter 1 General introduction

25 Chapter 2 The Dutch chaos case: a scoping review of knowledge and decision support tools available to clinicians in the Netherlands

45 Chapter 3 Lost in definitions: reducing duplication and clarifying definitions of knowledge and decision support tools. A RAND-modified Delphi consensus study

65 Chapter 4 A conceptual framework for patient-directed knowledge tools to support patient-centred care: Results from an evidence-informed consensus meeting

85 Chapter 5 Different knowledge, different styles of reasoning: a challenge for guideline development

99 Chapter 6 The clinical practice guideline Palliative care for children and other strategies to enhance shared decision-making in pediatric palliative care: pediatricians' critical reflections

121 Chapter 7 General discussion

141 List of references

159 Summary

165 Samenvatting

171 Valorisation chapter Developing quality criteria for patient-directed knowledge tools related to clinical practice guidelines. A development and consensus study

191 Bibliography of author

195 Dankwoord / Acknowledgements

199 About the author 



\section{Propositions/Stellingen}

- By trying to solve the information overload of Dutch clinicians we inundate them with knowledge and decision support tools (this thesis).

- National experts agreed that to support knowledge translation and (shared) decisionmaking five tool types should be sufficient: clinical practice guideline, summary, flowchart, patient information and patient decision aid (this thesis).

- Next to be trained in GRADE (Grading of Recommendations Assessment, Development and Evaluation), guideline developers and members of guideline working groups should be trained in, or at least introduced to, the art of reasoning as well, to conceptualise and contextualise knowledge better (this thesis, also with a tip of the hat to Inez de Beaufort, professor Health ethics at ErasmusMC).

- Shared-decision making involves more than (developing) tools; it requires training, skill, a supportive environment and according to some interviewed paediatricians it is part of the art of medicine (this thesis).

- You gather more information, learn more by asking questions than by talking (all the time).

- Healthcare knowledge translation ( $\approx$ implementation) should receive at least the same amount of attention and means as knowledge production.

- Dutch clinical practice guidelines unfortunately seem to focus on one goal of knowledge translation ('improve health') instead of addressing the other goals as well: provide more effective health services and products, and strengthen the healthcare system.

- As was done with clinical practice guidelines in the so-called Dutch AQUA committee, stakeholders managed to agree on quality criteria to ensure the development (and governance) of more uniform and trustworthy patient decision aids and patient information in the Netherlands. We need to integrate these quality criteria sets to increase impact.

- Time to change GIN (Guidelines International Network) to Guidelines Implementation Network.

- Dingen slecht benoemen, is de wereld nog slechter maken (Albert Camus)

- The meaning of Corona will never be the same. 


\section{Abbreviations}

\begin{tabular}{|c|c|}
\hline AlWH & Australian Institute of Health and Welfare \\
\hline AHRQ & Agency for Healthcare Research and Quality \\
\hline ÄZQ & Ärztliches Zentrum für Qualität in der Medizin \\
\hline CCCG & Cochrane Consumer \& Communication Group \\
\hline $\mathrm{ClHR}$ & Canadian Institutes of Health Research \\
\hline CPG & Clinical Practice Guideline \\
\hline DCGP & Dutch College of General Practitioners \\
\hline DECIDE & Developing and Evaluating Communication strategies to support Informed \\
\hline & Decisions and practice based on Evidence \\
\hline EBHC & International Society for Evidence Based Health Care \\
\hline EBM & Evidence-based Medicine \\
\hline ePDA & Encounter Patient Decision Aid \\
\hline EU & European Union \\
\hline GIN & Guidelines International Network \\
\hline GRADE & Grading of Recommendations Assessment, Development and Evaluation \\
\hline IGJ & Dutch Health and Youth Care Inspectorate \\
\hline IHTSDO & International Health Terminology Standards Development Organisation \\
\hline IOM & Institute of Medicine \\
\hline IPDAS & International Patient Decision Aid Standards \\
\hline ISDM & International (society of) Shared Decision Making \\
\hline IVM & Institute of Responsible Medicine Use \\
\hline KT & Knowledge Translation \\
\hline LOINC & Logical Observation, Identifiers, Names and Codes \\
\hline NHS & National Health Service \\
\hline $\mathrm{NIH}$ & National Institutes of Health \\
\hline NICE & The National Institute for Health and Care Excellence \\
\hline NKP & Network of Clinical Pathways \\
\hline PDA & Patient Decision Aid \\
\hline PCFC & Palliative Care For Children (guideline) \\
\hline QPL & Question Prompt List \\
\hline $\mathrm{RCT}$ & Randomized Clinical Trial \\
\hline SDM & Shared Decision Making \\
\hline SGB & Foundation Drug Bulletin \\
\hline WHO & World Health Organization \\
\hline
\end{tabular}




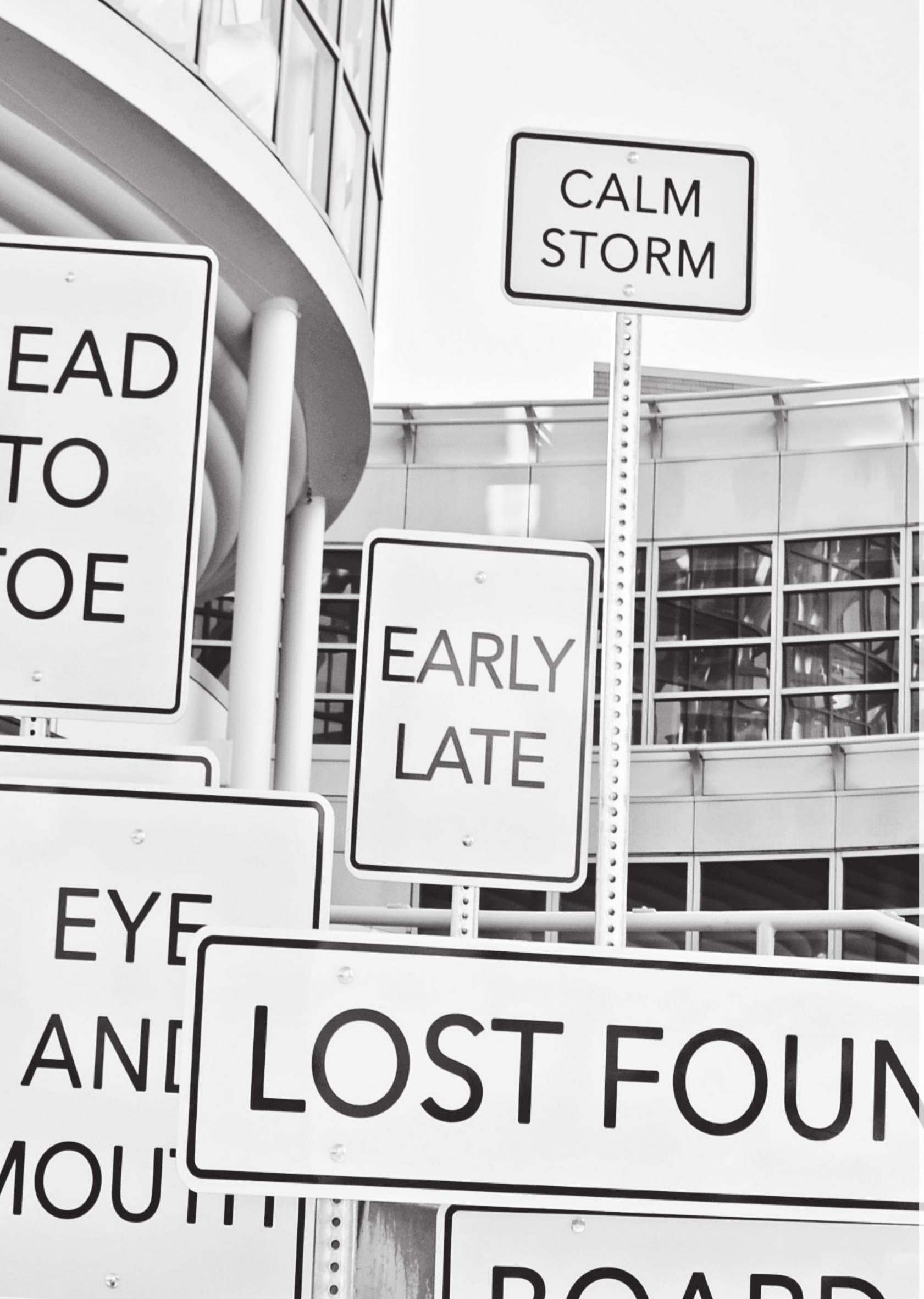


Chapter 1

General introduction

PREVENT CURE 
14 | Chapter 1 


\section{General introduction}

My first introduction to clinical practice guidelines was in 2006. During my studies at Erasmus School of Health Policy \& Management (Rotterdam), I had to write a critical reflection paper on the subject. Later that same year, I switched jobs and started as programme manager with ZonMw, the Netherlands Organisation for Health Research and Development. One of the programmes I was responsible for was the so-called KKCZ-programme (Kennisbeleid, Kwaliteit Curatieve Zorg (Knowledge management, Quality Curative Care)) which was chaired by professor Ton Casparie. He was responsible for bringing the quality (management) movement and clinical practice guidelines to the Netherlands. The KKCZ-programme entailed the development of multidisciplinary clinical practice guidelines while also introducing innovative elements as patient involvement, taking into account the social and labour participation by patients, as well cost effectiveness of the recommendation. Up until then clinical practice guidelines, further referred to by the acronym CPG, were mainly characterized by a monodisciplinary approach and patient participation was virtually non-existent. The Dutch Ministry of Health, wellbeing and sports thought it important that CPGs should reflect the everincreasing multidisciplinary setting of (health) care (delivery) and the added value of patient involvement. In addition, the Ministry of Social Affairs and Employment felt that CPGs should regard health from a broader perspective than just curative care aspects $(2,3)$. Therefore, both ministries commissioned and funded this guideline programme.

Adding patient involvement and the effect of health care on labour and social participation to clinical practice guidelines, turned out for me to be an early introduction to patient engagement, and maybe even shared decision-making (SDM). However, the concept of shared decisionmaking and its abbreviation SDM were not mainstream in the Netherlands yet.

As a follow-up, the Ministry of Health installed the Council for the Quality of Care in 2009. This was an advisory board to the Minister of Health for which I was - together with Jannes van Everdingen - executive secretary. The task of the Council for the Quality of Care was to:

- Enter on the agenda bottlenecks concerning clinical practice guideline development and implementation;

- Support healthcare professional associations by providing guidance in CPG development and developing procedures to solve the bottlenecks mentioned above;

- Encourage healthcare professional associations in dealing with these bottlenecks (4).

One of the bottlenecks was that the development of CPGs in the Netherlands was being left to the own accord of the parties involved. Besides the agreement that guideline development should be evidence-based (5), there was no nationwide consensus on the criteria which had to be met when developing clinical practice guidelines. To tackle this, the Working Group Guideline for Guidelines was formed by the Council. Members of the working group were representatives from the various care domains, such as long term care, public health, primary and secondary care, as well as experts on guideline development and implementation. Some of the represented domains were forerunners in CPG development, such as the Dutch College of General Practitioners and the medical specialists. The main legacy of the working group is the 


\section{6 | Chapter 1}

'Guideline for Guidelines', which stipulates 20 criteria for the development and implementation of clinical practice guidelines. The working group also more or less addressed shared decisionmaking; criterion 16 states that the guideline development project delivers products that are tuned to the needs of the healthcare professionals as well as patients, and which enhance the use of said guideline. Examples are: a patient version of the guideline, patient decision aids, patient materials to inform and educate, and other tools that promote self-management and shared decision-making by the professional and patient (6).

The Working Group Guideline for Guidelines also adapted the existing Dutch 'Haamstede'definition of a CPG, stemming from 2004: "A CPG is a document with recommendations, advice and acting instructions to support the decision-making of healthcare professionals and patients, based on the results of scientific research and subsequent discussion and forming of opinion, aimed at making effective and efficient clinical care explicit." (7). The members of the working group decided to align it more with the international consensus on what a CPG is, and updated the new definition using the one from Institute of Medicine (IOM) (2011). The new 'Brummelen'definition of a CPG was: "A CPG is a document with recommendations, aimed at improving the quality of care, based upon systematic summaries of scientific research and the assessment of pros and cons of the various care options, supplemented with the expertise and experience of healthcare professionals and patients." (6). By doing so, the working group intended to shift the focus of CPGs from predominantly research evidence to include clinical practice and patient preferences as well. They decided to do this partly because a review of 62 CPGs commissioned by the Council showed that CPGs had low(er) AGREE-scores (Appraisal of Guidelines Research and Evaluation instrument) when less hard scientific evidence was available, as is often the case with input generated by patient involvement or other end users, and with topics related to organisation of care (8).

Another bottleneck the Council recognized was a lack of consistency in the language and terminology being used regarding quality of care. The Council assembled a glossary of 1,000 words used in the quality of care discourse and added descriptions (9). Together with the participants of the Keizer Karel conference in 2009100 from those 1,000 words were chosen as the most important ones (10) and both lists were published so that everybody working in care could get acquainted with these terms and definitions. The online glossary also provided the possibility to comment on the descriptions and add new words (11), as any language is dynamic; meanings change, words disappear and new ones are introduced.

SDM was not mainstream in 2006, but since then it had picked up pace and in 2011 the international conference on SDM took place in the Netherlands: 'Bridging the gap towards SDM: patient pull or clinician push?'. However, at the end of the ISDM-conference, the Dutch participants had to conclude that the Netherlands were not ready for nationwide implementation of shared decision-making. Before this was possible, concerted action was needed. For example, by educating professionals, further empowering of patients and making high quality decision support tools such as patient decision aids (PDAs) publicly accessible. At the end of 2012, it became clear that the Ministry of Health persevered in merging several councils and platforms dedicated to improving the quality of care. The Council for the Quality 
of Care and the other platforms were merged with the then Health Care Insurance Board (CVZ) resulting in the new National Health Care Institute (ZIN). This institute was assigned to maintain the quality, accessibility and affordability of health care in the Netherlands. Specifically, for the task health care quality, which was where I was assigned to, it had - and has - to contribute to good health care by helping the parties involved to continually improve health care and help patients find their way to good-quality care. The institute therefore:

Encourages and supports healthcare parties responsible to develop quality standards, such as CPGs, and relevant measurement tools;

- Encourages healthcare parties to comply with these quality standards;

- Provides insight into the quality of care provided. This information helps patients make choices in health care and facilitates the supervision of health care (12).

- At the institute, I was lead of the project with the aim to develop a long-term agenda for clinical practice guideline development and implementation in the Netherlands (also known as Meerjarenagenda).

Looking back, 2011/2012 turned out to be a pivotal year. Six years after being introduced to the world of clinical practice guidelines, it had been expanded with the worlds such as knowledge, quality of care, evidence-based medicine, shared decision-making and implementation. It had also sparked my interest in (the effect of) language.

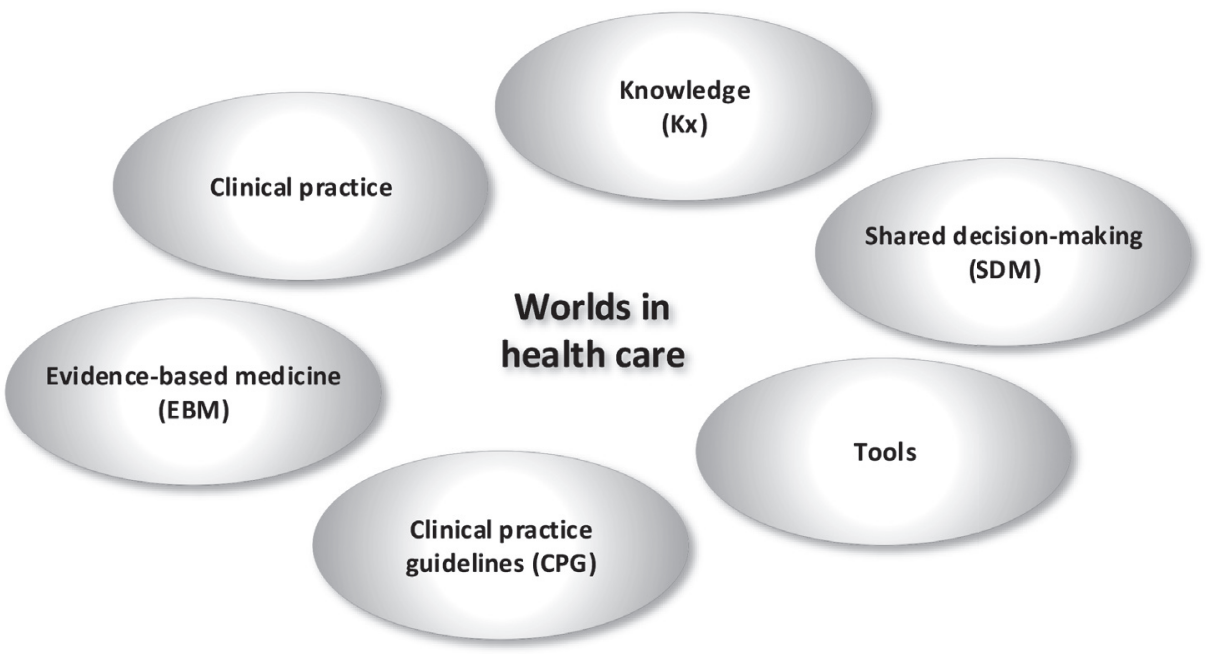

Figure 1: Worlds in health care

During those years, I have had the chance to work with a multitude of people and parties from various backgrounds such as healthcare professionals, patients, payers, administrators, and politicians. Moreover, I encountered them in various settings: research, policy and practice. People and parties with different expertise as knowledge production, tool development, implementation, monitoring, quality improvement and communication, but also people and parties with their own perspectives, stakes, expectations and terminology. For me these worlds felt as one, but while navigating these worlds I noticed this was not the case for everyone. In the next part, I will offer a glimpse into these worlds (see figure 1). 


\section{8 | Chapter 1}

\section{The world of knowledge}

A lot of research is carried out in health care. This research aims primarily to find out new knowledge that could lead to changes in treatments, policies or care. Many different types of research exist: from studies in a scientific laboratory to those that observe and examine people with different conditions, and to develop new treatments. Researchers look into preventing or curing disease, promoting good health, or finding out patients' experience of different care services and support in the community (13). All this research leads to a vast knowledge base. And this knowledge base accumulates fast daily. Bastian, Glasziou and Chalmers showed in 2007 that every day 75 trials and 11 systematic reviews are published (see figure 2) (14). Since then, these numbers have been increasing steadily $(15,16)$.

All Articles

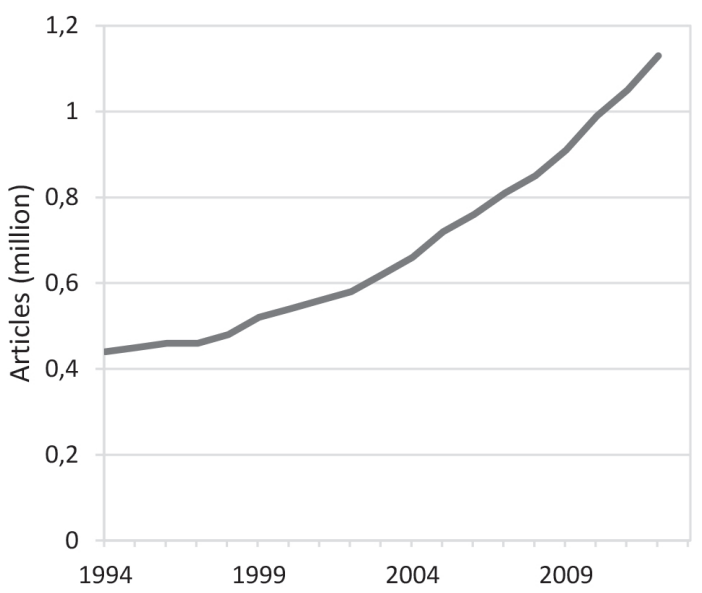

\section{Systematic Reviews}

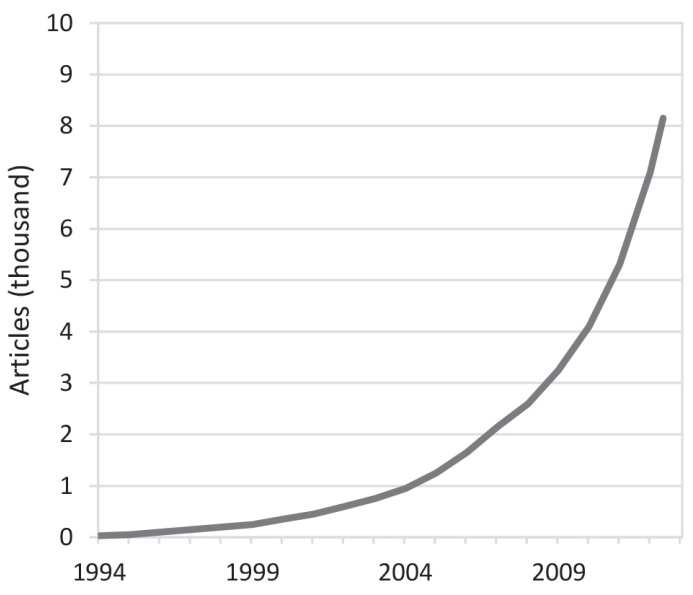

Articles and systematic reviews indexed in Medline (PubMed), 1994-2013 (17)

Figure 2: The increasing volume of research evidence (based on: Grattan Institute, report Questionable care, 2015)

For example, if a cardiac imaging specialist wants to stay up to date she or he needs to read 30 papers a week on echocardiography or 43 a week on multimodality imaging. Time that cannot be spent with patients. Sackett et al indicated already over 30 years ago that it would be impossible for clinicians to stay abreast of the developments in their field (16). That clinicians have been indicating for years that they feel overburdened by information should therefore be no surprise $(18,19)$. The 'phrase information overload' was already coined in 1970 (15); a more modern typology could be that healthcare professionals suffer from 'info-besitas' (20).

One of the best-known responses to this information overload was the founding of the Cochrane Collaboration in 1993. It was named after the Scottish clinician and epidemiologist Archie Cochrane who called for a critical summary of all relevant randomised controlled trials (RCT) that is adapted periodically. Realizing that most of the information was of poor quality, to him it made no sense for healthcare professionals to try and read everything. Therefore, they should be able to rely on critical summaries $(16,21)$. 
Furthermore, research has shown that it usually takes approximately 17 years before research results find their way into healthcare practice $(22,23)$. Meaning that the translation, or implementation of this knowledge, takes 17 years before it is used in practice and reaches

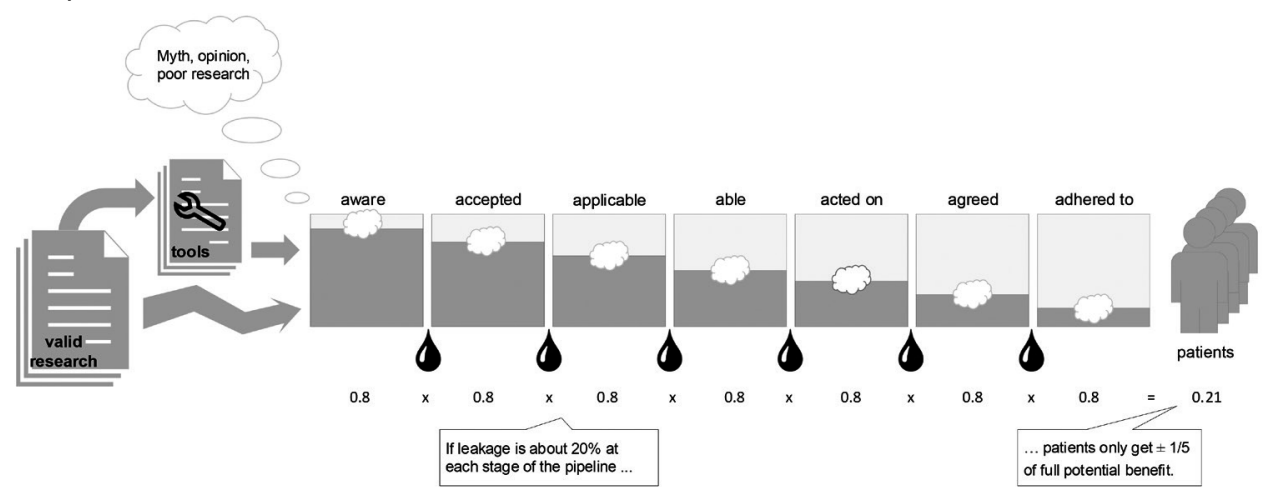

Figure 3: Leaks in the evidence pipeline from research to daily practice (based on Glasziou \& Haynes, BMJ Evidence-based Nursing, 2005)

To make matters worse, other research pointed out that the pipeline through which the knowledge flows is a leaking pipeline. At every step of the knowledge translation process due to various reasons and blockages knowledge drips away and does not reach daily practice (see figure 3) $(24,25)$. The starting point of 'valid research' in figure 2 is essential as will become clear in the next world.

\section{The world of evidence-based medicine}

Another world in health care is evidence-based medicine (EBM). EBM is nowadays omnipresent in health care. Sackett et al in 1996 described evidence-based medicine as integrating "the best external evidence with individual clinical expertise and patients' choice" (see figure 4) (26). Over the years, however, it has become clear that EBM did not completely deliver on its promise. The pillar 'research evidence' has received much more emphasis than the other two pillars, especially in evidence-based clinical practice guidelines. This emphasis on research evidence is troublesome for several reasons. One reason being that certain patient groups, such as women, minorities, children, and the elderly, were and still are often underrepresented or excluded from research trials. Another reason is that multi-morbidity is not taken into account (27). The applicability of the research results for certain patient groups is therefore limited. Contrary to Sackett et al's intentions, a hierarchy of evidence has (unintentionally) evolved in EBM. Perhaps influenced by Cochrane's emphasis on summarizing RCTs, most in the EBM-community

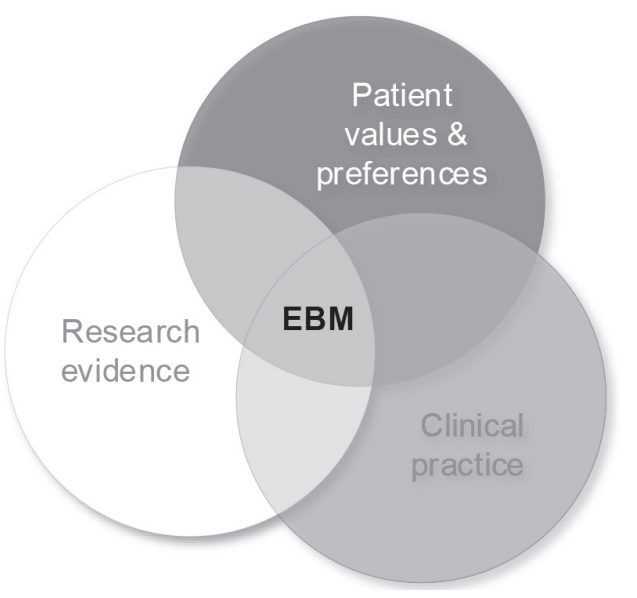

Figure 4: Three pillars of evidence-based medicine (based on Sackett et al, BMJ, 1996) 


\section{0 | Chapter 1}

regard systematic reviews and randomized clinical trials as the highest level of evidence. This has led to a disregard of other evidence, such as qualitative research. Another reason for the overreliance on research evidence is that research has shown that a very low percentage of studies in most medical journals meet the strict scientific standards. loannidis claimed in 2005 that most published research findings were false $(28,29)$. Chalmers et al added to this that patients and healthcare professionals are not involved in setting the research agenda, which means that research questions relevant to these groups are not being studied (as much) and important outcomes to patients and professionals are not addressed. Moreover, there exists a publication bias. In 2011, Schunemann et al reported that over half of the studies has never been published in full and studies with disappointing results were underreported $(30,31)$. The research evidence we use is biased. That makes the other pillars in EBM even more important. In addition, because e.g. not everything can be studied in a RCT, it is hard for clinicians to predict the preferences of patients whilst deciding about their care (32), and in daily practice, it is essential to be able to translate the knowledge to the individual patient using also clinical expertise.

\section{The world of clinical practice guidelines}

Another approach to translate knowledge into practice are clinical practice guidelines. CPGs distil, synthesize and interpret the best available evidence. The tool clinical practice guideline serves several purposes. The most important one being, as stated by the loM in 1990: “... to assist practitioner and patient [making] decisions about appropriate health care for specific clinical circumstances" (33). A lot of medical associations regard CPGs as a way to professionalize and to lay a sound foundation for their quality of care (34). This way, CPGs contribute to 1 / maintaining the level of quality of care; 2 / the warranted uniformization of care nationwide (by decreasing unwarranted practice variation (35)); and $3 /$ make more effective use of health care resources (36). The adherence to CPGs can be assessed during peer reviews or medical audits, which makes CPGs part of the quality (improvement) cycle (PDCA-cycle). Professionals can be held accountable for their performance by their peers and management (37). Other parties can also employ CPGs. The government can decide on reimbursement and health coverage using CPGs, and healthcare insurers can use them for contracting healthcare providers. However, not everybody is pleased when CPGs are being used for other purposes than the intended ones $(38,39)$.

Even though the earliest developed clinical practice guidelines are completely different from the recent ones - progressing from consensus guidelines to evidence-based guidelines - and despite all the CPG-improvements over the years regarding content and methodology (40) (41), the implementation of CPGs still leaves room for improvement $(35,42,43)$. Possible reasons are that healthcare professionals e.g. worry that CPGs are conducive to "cookbook medicine", decrease their autonomy and income, conflicts of interests are not always made transparent, and increase medico-legal liability. Furthermore, CPGs can rarely define optimal care with certainty, due to poor science, imperfect analytic processes, and differences in patients (44). These concerns were voiced in the early 1990s and still echo in 2010s (45). The earlier mentioned review of 62 clinical practice guidelines also showed that not all knowledge sources are used when developing CPGs, begging the question how evidence-based and applicable 
they really are. This outcome led to the establishment of a new G-I-N Working Group: WG Appraising and Including Different (AID) Knowledge. This working group aims to identify methods and promising initiatives for appraising and including a wider range of knowledge sources in CPGs (46-48). Another outcome of the review was the lack of public and patient involvement in CPG development and implementation. This issue is addressed by the G-I-N Working Group Public which already exists longer (49).

The dissatisfaction with CPGs, and other drawbacks such as keeping CPGs up to date, lack of patient perspective, and attention to organisation of care, has led to the development of other types of tools for knowledge translation and decision support. Some examples: care standards are written from a patient perspective and include organisation of care (50); clinical pathways are local complex interventions for mutual decision making and care processes (51); viewpoints offer quickly developed guidance when the evidence is not (fully) available yet (52); and patient decision aids help patients to become involved in decision making about their care and/or treatment by providing information about the options and outcomes, and clarify personal values (53).

\section{The world of shared decision-making}

Shared decision-making has been advocated as the ideal model of decision-making in the medical encounter (54-56). The concept got a boost in 1999 when Charles et al described three approaches to decision-making: paternalistic, shared and informed. In the first one, the clinician provides information about the options, deliberates and decides. In the latter, the clinician provides information about the options, but the patient deliberates and decides. In the shared approach both exchange information - the clinician about the options, the patient about what matters most to her or him -, both consider the pros and cons, and the final decision involves the patient as much as possible (and as much as the patient desires) (57). Other boosts were the (repeated) Cochrane reviews of patient decision aids showing the benefits of these tools towards SDM (58) and the realisation of the International Patient Decision Aid Standards (IPDAS) by O'Connor et al $(59,60)$. O'Connor and Wennberg pushed matters further along when they made a plea for informed patient choice (instead of informed consent). Governments took a keen interest as research showed that PDAs not only improve the quality of decision making but might also have an effect on health costs as informed patients in general chose more conservatively $(35,61)$. Governments, however, also acknowledged that if they wanted to pay tribute to all the domains of quality of care, and especially the domain patient-centeredness (62), formal patient engagement is essential (63-65) and SDM is one way to achieve this.

Patient-centeredness is "providing care respectful of and responsive to individual patient preferences, needs, and values, and ensuring that patient values guide all clinical decisions" (62). Furthermore, patients were adamantly calling for a power shift in health care (66). Especially because even though SDM was receiving more attention and gaining momentum, considering patient preferences and values was still not standard operating procedure yet, although most clinicians thought they were involving patients in deciding about their care $(63,67-69)$. The increased attention to the involvement of patients in the care process and decision-making has led to new tools. Examples of these include patient decision aids, option grids, decision boxes, question prompt lists, patient education, and patient versions of clinical practice guidelines (7). 


\section{The world of tools}

To deal with the vast accumulating knowledge, tools are being developed. Tools such as systematic reviews, evidence summaries and meta-analyses mean that healthcare professionals do no longer need to read and interpret all the articles and research themselves. To help them further, clinical practice guidelines are developed. This tool type not only distils and synthesises knowledge it also interprets it. To help inform, educate, engage and support the patient and healthcare professionals to use the knowledge during patient encounters (patient) decision aids are developed as tools. The previous paragraphs have already mentioned several different tool types. However, if you look at a random website of a health profession association or ask around, one encounters more tool types. That begs the questions: how many tool types to support knowledge translation and support (shared) decision-making are out there?; are they different tool types, or just clad with different names; what purposes do they serve?; do professionals and patients know all these tools exist, and if yes, how do they deal with all these tools or tool types? Research into the tool type 'clinical pathway' revealed 84 names for tools with a similar meaning (70). Research into patient decision aids showed similar results (58). Are we, trying to resolve the information and knowledge overload by swamping our healthcare professionals, and maybe even the patients nowadays, with all sorts of knowledge translation and decision support tool types?

Another dimension of the tools is their development process and the criteria they must meet to be regarded as trustworthy. For the development of the tool types, CPGs and PDAs rules and international criteria are available $(6,59,71)$. But how about the other tool types? Moreover, are the existing tool types interconnected with each other?

\section{The world of clinical practice}

From bench to bedside is a well-known phrase in health care. It refers to "the process by which the results of research done in the laboratory are directly used to develop new ways to treat patients" (72). It is mainly used in the biomedical domain, but the phrase could be expanded to the broader knowledge base and knowledge sources (73). Researchers, epidemiologists, administrative and policy workers, tool developers, and implementation experts mainly inhabit the worlds described above. Even though we acknowledge that healthcare professionals and patients should be more involved in setting research agendas, developing tools, and implementation strategies, the ones that are involved make up only a small proportion of the ones that are out in the real world. It is up to all those in the real world to try stay abreast of all the knowledge, and use it accordingly, with or without the help of tools. The latter being almost impossible. Despite all efforts, it still takes knowledge ('bench') a long time to reach practice ('bedside'), as was mentioned before, and the use of available tools in daily practice is lagging. There still seems to be a gap between research, tools and practice.

\section{Aim and research questions}

How can we make all the knowledge in health care available to healthcare professionals and patients in a timely matter and in such a way that it is easy to digest and apply? Which tool types to translate knowledge and support (shared) decision-making do we need and are suitable? How do we develop them so that target users know that they can rely on them? 
Moreover, how do we best disclose the knowledge and the tools? Compared to the $20^{\text {th }}$ century, there are much more opportunities now with the internet and ICT. The aim of this $\mathrm{PhD}$-research is fourfold. Firstly, tool types are no longer developed without a clear definition and use. Secondly, there exists a common terminology when referring to tool types. Thirdly, to make better use of the different knowledge sources available, and finally provide healthcare professionals and patients, and possibly other users such as policy advisors and insurers, with a set of pragmatic tools that covers their needs in knowledge translation and (shared) decision support.

This has led to the following research questions:

1. What tool types to translate knowledge and support (shared) decision-making are available to healthcare professionals (and patients) in the Netherlands?

2. How are these tool types defined and does consensus exist on the definitions across the healthcare domains in the Netherlands?

3. Which criteria do these tool types need to meet and which purposes do they serve so that healthcare professionals and patients consider them trustworthy and useful?

4. Do we consider all knowledge sources when developing tools, and what does that mean for tool development?

5. What are healthcare professionals' needs using tools for knowledge translation and shared decision-making?

\section{Outline of thesis}

This thesis exists of several chapters. After this introduction, the second chapter describes the results of the scoping review into tool types available to healthcare professionals and patients that support knowledge transfer and (shared) decision-making (research question 1 and 2). The Delphi study carried out after the review aimed to limit the number of tool types and to achieve national consensus on the definitions of these tools and is covered in chapter three (research question 2 and 3). Chapter four presents the conceptual framework on patient-directed knowledge tools - detailing purposes and core elements of these tools - which was developed by a group of international experts during a consensus-based evidence informed meeting (research question 3). Chapter five explores the different kinds of knowledge being used in clinical practice guidelines and how this affects, or should affect the development of clinical practice guidelines (research question 4). In chapter six, interviewed paediatricians reflect firstly on the clinical practice guideline 'Palliative care for children' that attempted to integrate shared decision-making into the guideline, and secondly on other strategies in which guidelines can be adapted to enhance shared decision-making (research question 5). Finally, chapter seven provides a summary of findings and contains the general discussion addressing the outcomes and implications for daily practice, as well as suggestions for future research. 


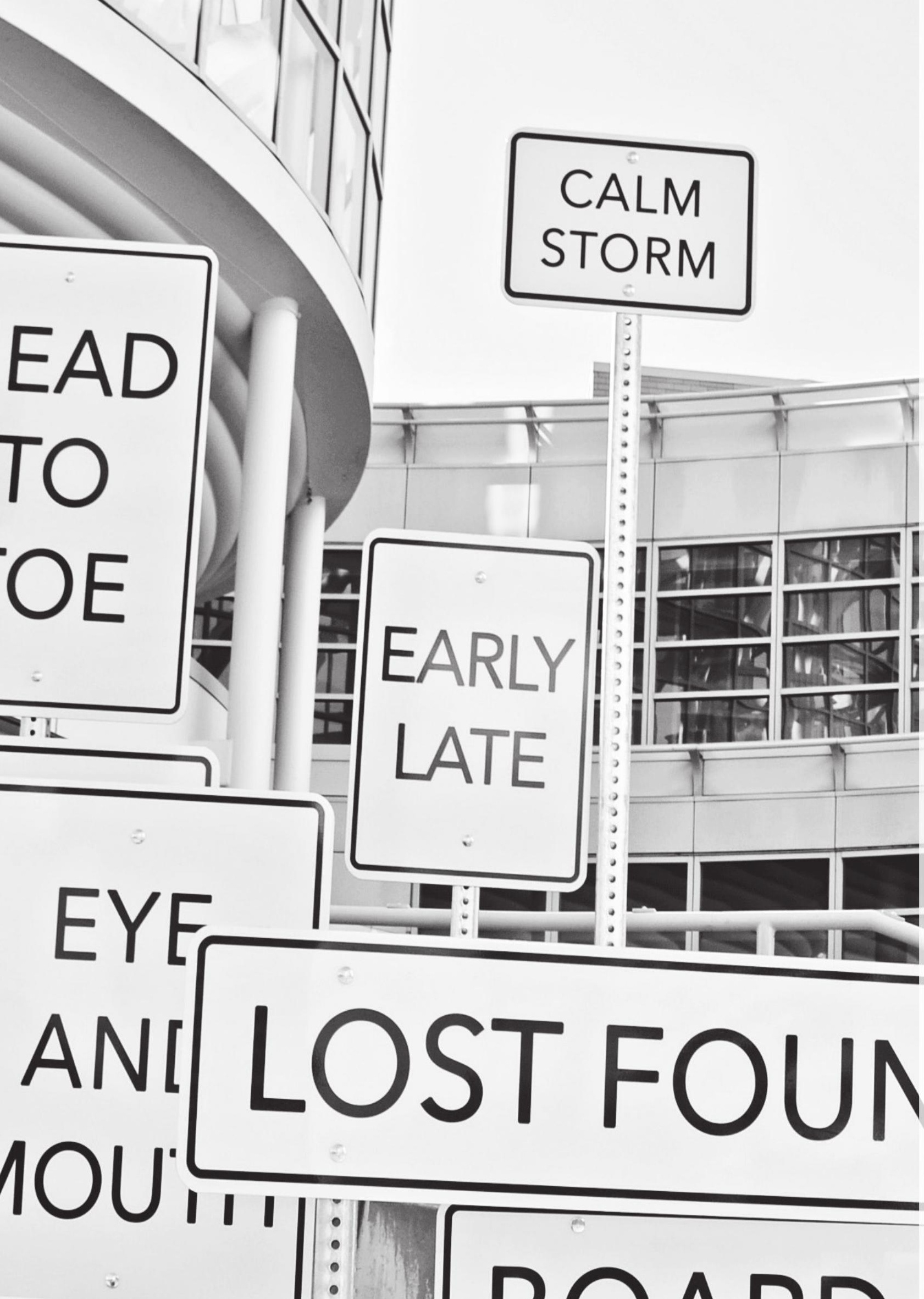


Chapter 2

The Dutch chaos case: a scoping review of knowledge and decision support tools available to clinicians in the Netherlands

Dunja Dreesens

Leontien Kremer

Trudy van der Weijden 


\section{6 | Chapter 2}

\section{Abstract}

\section{Background}

To keep clinicians up-to-date with the latest evidence, clinical practice and patient preferences, more and more knowledge tools - aiming to synthesise knowledge and support (shared) decision-making - are being developed. Unfortunately, it seems that in the Netherlands, and possibly elsewhere, the amount of different knowledge tool types makes it difficult to see the forest through the trees.

\section{Methods}

A scoping review, exploring types of knowledge tools available to Dutch clinicians (and patients) and how these tools are described. The search terms were collected from thesauri and textbooks, and used to search the websites and documents of selected national tool developing organisations.

\section{Results}

The review yielded 126 tool types. We included 67 different tool types, such as guidelines, protocols, standards and clinical pathways. Half of those tool types were aimed at clinicians, 14 at patients and 18 at both. In general, descriptions of the tool types were hard to find or incomplete.

\section{Conclusions}

There exists a myriad of knowledge tool types and their descriptions are mostly unclear. The information overload experienced by clinicians is not addressed effectively by developing numerous unclearly defined knowledge tools. We recommend limiting the number of tool types and making a greater effort in clearly defining them. This abundance of poorly defined tools does not seem to be restricted to the Netherlands.

\section{Keywords}

guidelines; tools; knowledge; decision-making; definitions; review 


\section{Background}

Doctors have been signalling for years that they feel overburdened by information $(18,19,74)$ and that they are suffering from 'infobesity' (16). Sackett indicated more than 20 years ago that it is impossible for doctors to stay abreast of the developments in their field (75). The already vast knowledge in health care is expanding daily - in 2010, 11 systematic reviews were published every day (14) - so that keeping up with developments is a challenge $(15,24)$. The development of so-called knowledge tools is intended to support clinicians (and patients) to keep pace and to improve their decision-making $(76,77)$. In addition to knowledge tool types such as evidence-based clinical practice guidelines (CPG), however, protocols, guidance, standards, clinical pathways and many other tool types have been developed over the years. With the rising importance of shared decision-making (61) and the increasing call for a patient revolution (66), further tool types have been added to the mix, including decision aids, question prompt lists and option grids $(78,79)$.

Is the image of the clinician bogged down in information being replaced with one of the clinician bogged down in a myriad of knowledge tools (80)? This image is probably not exclusive to the Netherlands, as there appears to be a 'widespread view [...] that work effectiveness is impaired by information overload' $(18,19)$. Moreover, even though tool types such as CPGs, standards, pathways and decision aids are used in other countries as well (81-87), are all these tools really different in terms of content and purpose $(76,88)$ ?

Research into knowledge and decision support tools has been conducted within several countries. Such research, however, seems to focus on one tool type, for example clinical pathways $(70,89,90)$, CPGs or patient decision aids $(58,88,91)$. Research into clinical pathways yielded an overview of 84 similar tools adorned with different names. Another focus in this research was the use, methodology of development (92) and implementation (42) of these tools. To our knowledge, no overview exists at a national level of current knowledge and decision support tool types used by clinicians or patients.

The objective of this review article is to identify the different types of knowledge and decision support tools which are available at a national level to clinicians and patients in the Netherlands and to gain insight in how these tool types are described or defined. We looked at it from a national policy perspective, concentrating on tool types developed by national organisations. For reasons of feasibility, we focused on Dutch national organisations that develop and implement these tools. A scoping review identifies the range and nature of existing knowledge tools by summarising what is there and might reveal if something is missing. The review therefore also serves as a basis for conducting further research and defining relevant research questions related to tools, knowledge use and translation. 


\section{8 | Chapter 2}

\section{Methods}

\section{General design}

This study is a descriptive scoping review of knowledge tool types developed by Dutch national healthcare organisations and tools that support clinicians or patients with knowledge transfer and shared decision-making. The general purpose for conducting scoping reviews is to identify and map the available evidence, in this case tool types. Arksey \& O'Malley, and Levac et al, also described several reasons why scoping reviews are conducted. We chose this kind of review because we wanted to examine the amount and range of available tool types, and gain insight into the provided definitions $(93,94)$.

\section{Data sources}

The websites, documents and links to other sources on the websites of purposive sampled Dutch healthcare organisations known to develop and disseminate knowledge tools were used as data sources. Organisations that solely fund or research such tools were excluded. Because of the multitude of organisations in the Netherlands developing and disseminating knowledge tools, the authors selected seventeen of them: three medical specialists associations, two allied healthcare organisations, five guideline agencies, one umbrella organisation for professionals, five government agencies and one umbrella organisation for patients (see appendix A).

\section{Inclusion criteria for the tool types}

Included in this review were those tool types which are being developed and made available by Dutch nationwide non-commercial healthcare organisations; are related to care content; for which an evidence-based approach was followed; which are intended for knowledge transfer and decision support; are publicly accessible and which concern cure and/or palliative care (figure 1).

We used the following definition of a tool: a tool distils, synthesizes and interprets the highest quality knowledge and research to serve knowledge translation and support (shared) decision-making (95). Related, secondary tools that are based on these primary tools, with the main purpose to educate and/or implement were, albeit contributing to knowledge translation, excluded.

\section{Identification, selection of tools and data extraction}

A scan of the selected organisations was undertaken to reveal which search terms to use in order to identify knowledge tools (see appendix B). These terms were then processed through two thesauri $(9,96)$ to find synonyms and related terms. The list of terms was entered into the search engines on the websites of the organisations. If a website did not support searches for compound terms (for example, 'evidence table'), the yield of hits for the separate search terms was checked for their combination. In cases of various spellings for the same term, e.g. 'shared decision-making' and 'shared decision making', both spellings were used. If a website did not provide a search engine, the terms were searched on the webpages by the first author with the help of the web browser search function and by manual inspection. 
An iterative approach was used when searching these websites. The hits were checked for relevant descriptions and information by the first author. The information was copied and pasted into a crude data file, including web address and the time and date of the search. When there were more than 100 hits, only the first 100 were checked. In cases where the hits redirected to other websites (see appendix A) these links were followed, as were links to reports and articles ('snowballing' method). When reports or publications were unavailable on the website, the organisation was contacted in order to obtain a copy of the report or article. If it could not provide the document, it was obtained through the National Library of the Netherlands. In the case of unclear or unavailable descriptions, Google was used to find more information on the term in combination with the organisation. If Google yielded no or insufficient information, the organisation was contacted by email to ask for the missing information. If no clarification could be provided by email, a phone call or physical appointment was undertaken to retrieve the missing information. Both the emails and the notes of the telephone conversations were added to the crude data file. If the email or follow-up was not successful after two attempts, the researchers limited themselves to the available data from the websites.

\section{Data analysis}

Statements describing or defining the knowledge tool types formed our primary interest. Each tool type found was entered into a table together with the full or partial descriptions identified per data source. All the tools identified were subsequently scored along the inclusion criteria (see figure 1) by the first author. To decide if a tool type had followed an evidence-based approach we checked if it was developed in a transparent and systematic way, and searched and synthesized evidence according to the rules of evidence-based practice (26).

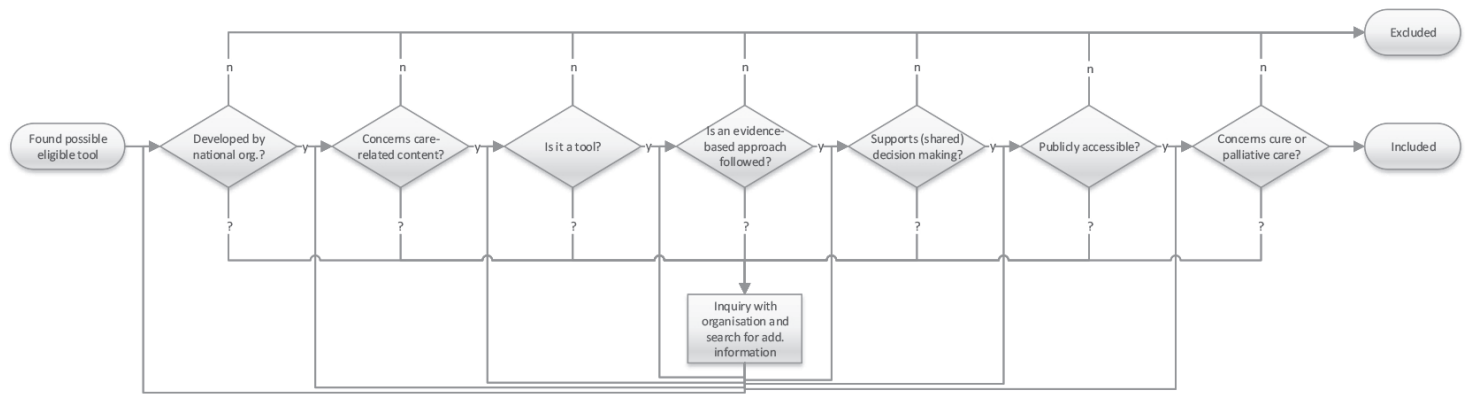

Figure 1: Inclusion flow chart for the final tool selection

The scoring by the first author was verified by the authors TvdW and LK, by systematically scoring every tenth tool listed, with TvdW starting from 5 and LK from 10 (so rows 5, 15, 25, 35 , etc. and rows $10,20,30$, etc.). When scores varied, we discussed these until we reached consensus on the scoring. The first author then entered the final scores for all tools.

The tool types preliminarily included were copied into a new crude data table. Information received from additional searches and inquiries with the organisations were added to this table. On the basis of the additional information, we made a decision on final inclusion. The final table was structured by organisation to provide insight into the number of organisations in the Netherlands active in developing and disseminating knowledge tools, and the different names of 


\section{0 | Chapter 2}

the tools assigned. The tool types were described according to the following characteristics, if available, extracted from the data sources:

- Definition or description of tool is available on the website;

- Target group of knowledge tool:

- Patients, healthcare professionals, both, or others such as policy advisors, government and insurers?

- If targeted at healthcare professionals, mono- or multidisciplinary?

- Development process:

- Patient or public involved?

- Authorisation process described or mentioned?

- Publicly accessible?

The aim was to characterise the tool as generic or specific - generic means that the tool can be used or reused for different care subjects and is developed by various organisations; specific means that the tool is limited in its options for use or reuse by others or is developed by one organisation only. As this proved difficult to indicate in a table, we decided to reflect on the characteristics of these tools in the running text.

Again, the co-authors verified the subset of the data extraction. They each selected at least 15 tools at random and checked the scoring. In case of disagreement, we discussed the extraction until we reached a consensus. The first author then entered the final scores for all tools.

\section{Results}

The search yielded 126 tool types, of which we included 67 in the review.

\section{Data sources}

We started by searching the websites of the 17 selected organisations. During this search, 10 additional organisations were found via snowballing; three of those organisations that met the selection criteria of the purposive sampled organisations were added to the search and their websites were subsequently searched.

\section{Identification, selection of tools and data extraction}

The search started with 48 search terms. During the search, which took place from September 2012 to April 2013, we added six related terms (marked with an asterisk in appendix B). Hits were listed numerically per organisation, together with the source and description if available. This led to a list containing 126 tool types. Hits which appeared to represent a tool were tentatively put on the list. Descriptions of the tools were either limited or not always available on the websites. Additional inquiries with the organisations, data sources and Google search were used to fill the gaps, but sometimes information remained unknown. After applying the inclusion criteria of the flow chart, 74 tool types remained. However, seven of these were considered synonymous and were removed, leaving 67 tool types (figure 2). The inclusion reliability and data extraction verification by the co-authors did not lead to any discrepancies.

This lack of information, even after additional searches and inquires meant that it was not always possible to extract the tools' characteristics. Information on characteristics such as authorisation and patient or public involvement were the most difficult to determine. 
Sometimes the organisations only mentioned the name of the tool and offered little or no description. In several cases, the information was retrieved by looking at documents on the website or in hard-copy papers obtained from the organisation itself. Moreover, not all tools were accessible via the Internet; some were only available to organisation members or upon payment. In this case, we attempted to obtain a demo version which might yield a description of the tool. Most organisations that we contacted were willing to offer additional information and made demos of their tools available free of charge. These demos, however, did not always yield descriptions either. Some organisations did not describe the tool on their website, while others offered more than one description. On several websites compound terms were mentioned but only the simple term was explained. For instance, the website of the Federation Medical Specialists explains the term 'guideline' but does not explain the term 'multidisciplinary guideline'. What is meant by 'multidisciplinary' is left to the reader: more than two disciplines of medical specialists, other healthcare professionals, or even other parties such as insurers, providers and patients?

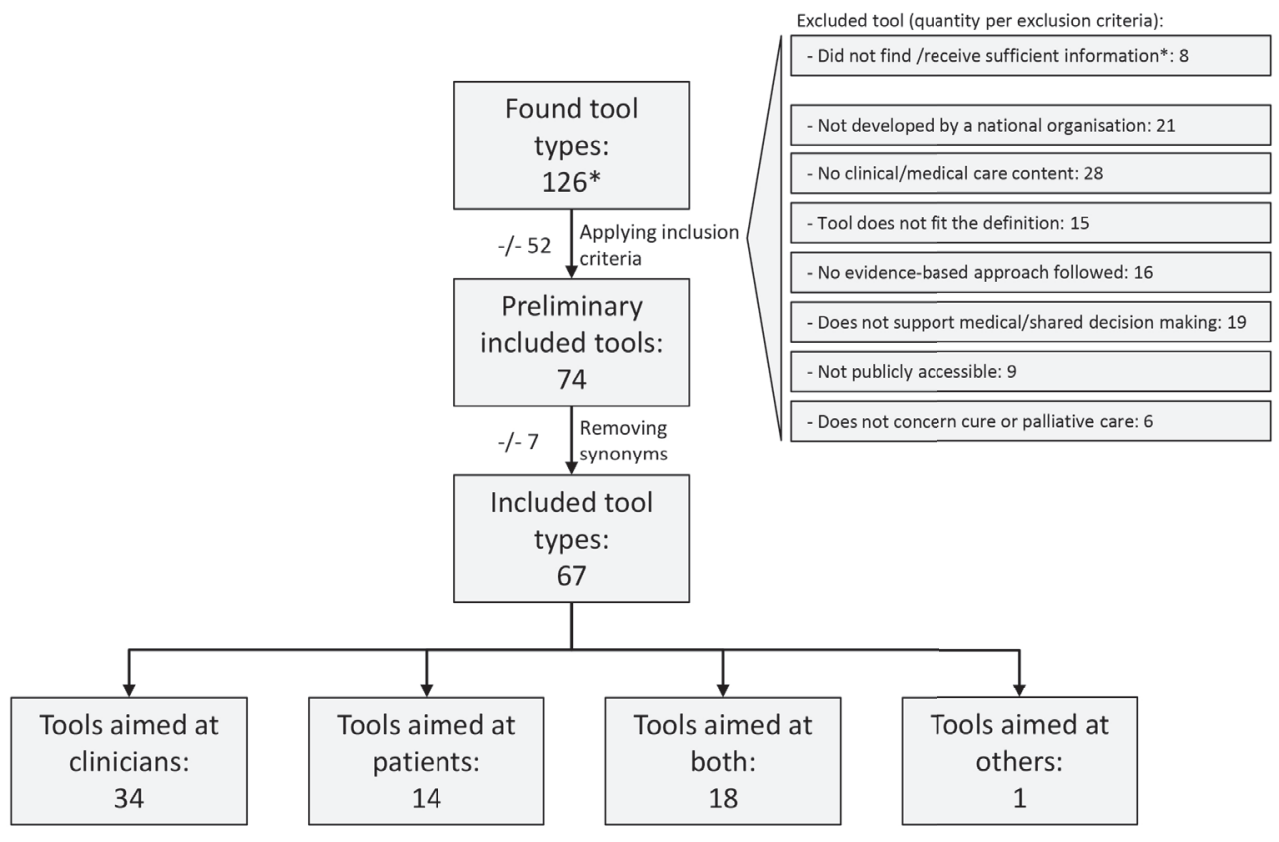

* For 54 tools we needed to go the extra length to find or acquire additional information ** Tool types could be excluded on more than one criteria.

Figure 2: Tool types found

As mentioned above, the characteristic of public or patient involvement during tool development was difficult to determine. This was apparent in 28 descriptions of tool types, of which five mentioned explicitly that there was no patient or public involvement, and for 34 tools this could not be ascertained. These figures were almost the same as those for the characteristic 'authorized' or 'legitimatised' by the organisation(s) involved in the development of the tool: 26 tools were authorised, three were not, and for 38 tools this could not be determined. Four tools were deemed limited accessible; these were difficult to find online at the time of the review. 
Table 1: Included tool types, and tool characteristics

\begin{tabular}{|c|c|c|c|c|c|c|c|c|}
\hline & \multirow[b]{3}{*}{ ORGANISATION } & \multirow[b]{3}{*}{ TOOL TYPE } & \multicolumn{6}{|c|}{ CHARACTERISTICS } \\
\hline & & & & \multicolumn{3}{|c|}{ TARGET USER GROUPS } & \multicolumn{2}{|c|}{$\begin{array}{l}\text { DEVELOPMENT \& } \\
\text { DISSEMINATION } \\
\end{array}$} \\
\hline & & & 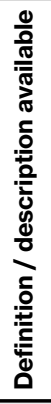 & 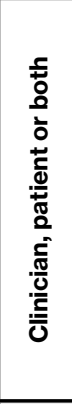 & 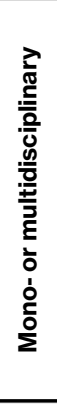 & 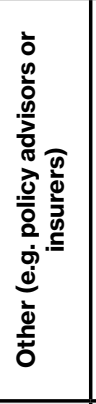 & 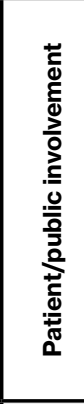 & 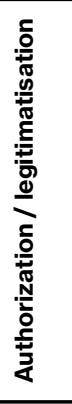 \\
\hline 1 & \multirow{7}{*}{$\begin{array}{l}\text { Royal Dutch } \\
\text { Society } \\
\text { for Physical } \\
\text { Therapy }\end{array}$} & Decision tree/flow chart & $x$ & c & mo & $x$ & $?$ & $\checkmark$ \\
\hline 2 & & Evidence statement & $\checkmark$ & c & mo & $x$ & $?$ & $\checkmark$ \\
\hline 3 & & $\begin{array}{l}\text { National primary care } \\
\text { cooperation agreement }\end{array}$ & $\checkmark$ & c & mo & $x$ & $?$ & $\checkmark$ \\
\hline 4 & & Multidisciplinary guideline & $\checkmark$ & c & $\mathrm{mu}$ & $x$ & $\checkmark$ & $\checkmark$ \\
\hline 5 & & $\begin{array}{l}\text { Patient version of the } \\
\text { guideline }\end{array}$ & $\checkmark$ & $\mathrm{p}$ & $\mathrm{n} / \mathrm{a}$ & $x$ & $\checkmark$ & $?$ \\
\hline 6 & & Practice guideline & $\approx$ & c & mo & $x$ & $\checkmark$ & $\checkmark$ \\
\hline 7 & & Standard & $\approx$ & c & mo & $x$ & $?$ & $\checkmark$ \\
\hline 8 & \multirow{9}{*}{$\begin{array}{l}\text { Dutch College of } \\
\text { General } \\
\text { Practitioners } \\
\text { (DCGP) }\end{array}$} & $\begin{array}{l}\text { Pharmacotherapeutic } \\
\text { guideline }\end{array}$ & $\approx$ & c & $\mathrm{b}$ & $x$ & $?$ & $?$ \\
\hline 9 & & $\begin{array}{l}\text { Information brochure (for } \\
\text { the clinician) }\end{array}$ & $\approx$ & c & $\mathrm{n} / \mathrm{a}$ & $x$ & $\checkmark$ & $\checkmark$ \\
\hline 10 & & Multidisciplinary guideline & $x$ & $\mathrm{~b}$ & $\mathrm{mu}$ & $x$ & $\checkmark$ & $?$ \\
\hline 11 & & Network guideline & $x$ & $\mathrm{~b}$ & $\mathrm{mu}$ & $x$ & $\checkmark$ & $?$ \\
\hline 12 & & Patient letter & $x$ & $\mathrm{p}$ & $\mathrm{n} / \mathrm{a}$ & $x$ & $?$ & $?$ \\
\hline 13 & & DCGP standard & $x$ & c & mo & $x$ & $?$ & $\checkmark$ \\
\hline 14 & & Viewpoint & $x$ & c & mo & $x$ & $x$ & $?$ \\
\hline 15 & & $\begin{array}{l}\text { 'Thuisarts.nl (Homedoctor. } \\
\text { nl)' }\end{array}$ & $\approx$ & $\mathrm{p}$ & $\mathrm{n} / \mathrm{a}$ & $x$ & $?$ & $?$ \\
\hline 16 & & Clinical description & $x$ & $\mathrm{p}$ & $\mathrm{n} / \mathrm{a}$ & $x$ & $?$ & $?$ \\
\hline 17 & \multirow{6}{*}{$\begin{array}{l}\text { Netherlands } \\
\text { Society of } \\
\text { Occupational } \\
\text { Medicine }\end{array}$} & Blueprint & $\checkmark$ & c & $\mathrm{mu}$ & $x$ & $?$ & $\checkmark$ \\
\hline 18 & & $\begin{array}{l}\text { Patient translation of the } \\
\text { guideline }\end{array}$ & $\approx$ & $\mathrm{p}$ & $\mathrm{n} / \mathrm{a}$ & $x$ & $?$ & $?$ \\
\hline 19 & & Guideline & $\checkmark$ & b & b & $x$ & $\checkmark$ & $\checkmark$ \\
\hline 20 & & Viewpoint & $\approx$ & c & mo & $x$ & $x$ & $\checkmark$ \\
\hline 21 & & Employer version & $x$ & $\mathrm{n} / \mathrm{a}$ & $\mathrm{n} / \mathrm{a}$ & $x$ & $?$ & $?$ \\
\hline 22 & & Employee version & $x$ & $\mathrm{p}$ & $n / a$ & $x$ & ? & $?$ \\
\hline
\end{tabular}




\begin{tabular}{lll|l|lll|lll}
\hline 23 & Dutch Paediatric & Clinical guideline & $\checkmark$ & $\mathrm{b}$ & $\mathrm{b}$ & $\mathrm{X}$ & $?$ & $\checkmark$ \\
24 & Association & Viewpoint & $\checkmark$ & $\mathrm{c}$ & $\mathrm{mo}$ & $\mathrm{X}$ & $?$ & $?$ \\
\hline 25 & Dutch Nurses & Information folder & $\mathrm{X}$ & $\mathrm{p}$ & $\mathrm{n} / \mathrm{a}$ & $\mathrm{X}$ & $?$ & $?$ \\
26 & Association & Quick reference guide/ & $\mathrm{X}$ & $\mathrm{c}$ & $\mathrm{mo}$ & $\mathrm{X}$ & $?$ & $?$ \\
& & summary (sheet) & Guideline & $\checkmark$ & $\mathrm{b}$ & $\mathrm{b}$ & $\mathrm{X}$ & $?$ & $\checkmark$ \\
\hline
\end{tabular}

\begin{tabular}{|c|c|c|c|c|c|c|c|c|}
\hline 28 & \multirow{5}{*}{$\begin{array}{l}\text { Dutch Institute for } \\
\text { Healthcare } \\
\text { Improvement } \\
\text { (CBO) }\end{array}$} & Indicator & $\approx$ & b & $b$ & $\checkmark$ & $\checkmark$ & $\checkmark$ \\
\hline 29 & & Patient decision aid & $\checkmark$ & $p$ & $\mathrm{n} / \mathrm{a}$ & $x$ & $?$ & $?$ \\
\hline 30 & & Patient version & $\checkmark$ & $p$ & $\mathrm{n} / \mathrm{a}$ & $x$ & $?$ & $?$ \\
\hline 31 & & Guideline & $\checkmark$ & c & $b$ & $x$ & $\checkmark$ & $?$ \\
\hline 32 & & Guidance & $\approx$ & $b$ & $\mathrm{mu}$ & $\checkmark$ & $\checkmark$ & $\checkmark$ \\
\hline 33 & \multirow{6}{*}{$\begin{array}{l}\text { Quality Institute } \\
\text { for Oncological } \\
\text { and Palliative } \\
\text { Research and } \\
\text { Practice (IKNL) }\end{array}$} & Decision disk & $\checkmark$ & c & b & $x$ & $?$ & $?$ \\
\hline 34 & & Helping hand & $\checkmark$ & c & mo & $x$ & $?$ & $?$ \\
\hline 35 & & $\begin{array}{l}\text { Integral oncological care } \\
\text { path }\end{array}$ & $\approx$ & c & $\mathrm{mu}$ & $x$ & $?$ & $?$ \\
\hline 36 & & Patient folder & $\checkmark$ & $p$ & $\mathrm{n} / \mathrm{a}$ & $x$ & $?$ & $?$ \\
\hline 37 & & Guideline & $\approx$ & b & b & $x$ & $\checkmark$ & $\checkmark$ \\
\hline 38 & & $\begin{array}{l}\text { Compounded information } \\
\text { on side effects }\end{array}$ & $\checkmark$ & b & b & $x$ & $?$ & $?$ \\
\hline 39 & \multirow{3}{*}{$\begin{array}{l}\text { Federation } \\
\text { Medical } \\
\text { Specialists }\end{array}$} & $\begin{array}{l}\text { Information brochure (for } \\
\text { the clinician) }\end{array}$ & $\checkmark$ & c & $\mathrm{n} / \mathrm{a}$ & $x$ & $\checkmark$ & $\checkmark$ \\
\hline 40 & & Guiding principle & $\approx$ & c & $\mathrm{mu}$ & $x$ & $?$ & $\checkmark$ \\
\hline 41 & & Guideline & $\checkmark$ & $b$ & $b$ & $x$ & $?$ & $\checkmark$ \\
\hline 42 & \multirow{2}{*}{$\begin{array}{l}\text { TNO research } \\
\text { organisation }\end{array}$} & Guideline & $\approx$ & c & b & $x$ & $\checkmark$ & $?$ \\
\hline 43 & & WStandard & $x$ & c & b & $x$ & $\checkmark$ & $?$ \\
\hline 44 & \multirow{2}{*}{$\begin{array}{l}\text { Trimbos Institute } \\
\text { of Mental Health }\end{array}$} & Patient decision aid & $\approx$ & $\mathrm{p}$ & $\mathrm{n} / \mathrm{a}$ & $x$ & $\checkmark$ & $?$ \\
\hline 45 & & Multidisciplinary guideline & $\checkmark$ & c & $\mathrm{mu}$ & $x$ & $?$ & $?$ \\
\hline 46 & \multirow{6}{*}{$\begin{array}{l}\text { Royal Dutch } \\
\text { Medical } \\
\text { Association } \\
\text { Dutch Patient } \\
\text { Organisations } \\
\text { Federation }\end{array}$} & Helping hand & $\approx$ & c & $\mathrm{mu}$ & $x$ & $?$ & $?$ \\
\hline 47 & & Guideline & $\approx$ & c & $\mathrm{mu}$ & $\checkmark$ & $\checkmark$ & $?$ \\
\hline 48 & & Patient brochure & $\approx$ & $p$ & $\mathrm{n} / \mathrm{a}$ & $x$ & $\checkmark$ & $?$ \\
\hline 49 & & Patient version & $\approx$ & $\mathrm{p}$ & $\mathrm{n} / \mathrm{a}$ & $x$ & $\checkmark$ & $?$ \\
\hline 50 & & Guideline & $\approx$ & c & $b$ & $x$ & $\checkmark$ & $?$ \\
\hline 51 & & Care standard & $\approx$ & $b$ & $\mathrm{mu}$ & $\checkmark$ & $\checkmark$ & $?$ \\
\hline
\end{tabular}

\begin{tabular}{|c|c|c|c|c|c|c|c|c|}
\hline 52 & \multirow{6}{*}{$\begin{array}{l}\text { National Health } \\
\text { Care Institute }\end{array}$} & Decision tree & $\checkmark$ & c & mo & $x$ & ? & ? \\
\hline 53 & & Pharmaceutical compass & $\approx$ & C & $\mathrm{mu}$ & $x$ & $X$ & $x$ \\
\hline 54 & & $\begin{array}{l}\text { Quality / professional } \\
\text { standard }\end{array}$ & $\approx$ & b & $b$ & $\checkmark$ & $\checkmark$ & $\checkmark$ \\
\hline 55 & & (indication) protocol & $\checkmark$ & c & mo & $x$ & $?$ & $?$ \\
\hline 56 & & Guideline & $x$ & $b$ & $b$ & $\checkmark$ & $\checkmark$ & $\checkmark$ \\
\hline 57 & & Care standard & $x$ & $b$ & $\mathrm{mu}$ & $\checkmark$ & $\checkmark$ & $\checkmark$ \\
\hline 58 & \multirow{2}{*}{$\begin{array}{l}\text { Health Council of } \\
\text { the Netherlands }\end{array}$} & Guideline & $\checkmark$ & $b$ & $\mathrm{mu}$ & $x$ & $?$ & $\checkmark$ \\
\hline 59 & & $\begin{array}{l}\text { Occupational health benefit } \\
\text { insurance protocol }\end{array}$ & $\checkmark$ & c & mo & $x$ & ? & $\checkmark$ \\
\hline
\end{tabular}




\begin{tabular}{|c|c|c|c|c|c|c|c|c|}
\hline $\begin{array}{l}60 \\
61\end{array}$ & $\begin{array}{l}\text { Choosing } \\
\text { better.nl }\end{array}$ & $\begin{array}{l}\text { Decision aid } \\
\text { Guideline }\end{array}$ & $\begin{array}{l}\approx \\
\approx\end{array}$ & $\begin{array}{l}\mathrm{p} \\
\mathrm{c}\end{array}$ & $\begin{array}{c}n / a \\
b\end{array}$ & $\begin{array}{l}x \\
x\end{array}$ & $\begin{array}{l}\checkmark \\
\checkmark\end{array}$ & $\begin{array}{l}? \\
?\end{array}$ \\
\hline 62 & $\begin{array}{l}\text { Health and Youth } \\
\text { Care Inspectorate }\end{array}$ & Field norm & $x$ & $b$ & $b$ & $x$ & $\checkmark$ & ? \\
\hline 63 & IVM $^{1}$ & Medicine Balance sheet & $\checkmark$ & c & $\mathrm{mu}$ & $x$ & $x$ & $x$ \\
\hline $\begin{array}{l}64 \\
65\end{array}$ & $\begin{array}{l}\text { Coordination } \\
\text { Platform Care } \\
\text { Standards }\end{array}$ & $\begin{array}{l}\text { Care module } \\
\text { Care standard }\end{array}$ & $\checkmark$ & $\begin{array}{l}\mathrm{b} \\
\mathrm{b}\end{array}$ & $\begin{array}{l}\mathrm{mu} \\
\mathrm{mu}\end{array}$ & $\begin{array}{l}\checkmark \\
\checkmark\end{array}$ & $\checkmark$ & $\checkmark$ \\
\hline 66 & $\mathrm{SGB}^{2}$ & $\begin{array}{l}\text { 'GeneesmiddelenBulletin } \\
\text { (Drug Bulletin)' }\end{array}$ & $\approx$ & c & $\mathrm{mu}$ & $x$ & $x$ & $x$ \\
\hline 67 & $\mathrm{NKP}^{3}$ & Clinical pathway & $\sqrt{ }$ & c & $\mathrm{mu}$ & $x$ & $?$ & $?$ \\
\hline
\end{tabular}

\section{Legend table 1}

- Definition/description of tool type available on website? No $(X)$, yes $(\checkmark)$, incomplete $(\approx)$

- Tool type targeted at which group? Clinician/healthcare professional (c), patient (p) or both (b)

- Monodisciplinary (mo), multidisciplinary (mu) tool, both (b) or not applicable (n/a)

- Tool types also mentions other target groups? No $(X)$, yes $(\checkmark)$

- Mentioning of patient and/or public involvement in developing the instrument? Yes $(\checkmark)$, no $(X)$, unclear (?)

- Authorization or legitimatization process mentioned? Yes $(\checkmark)$, no $(X)$, unclear (?)

- Publicly accessible? Limited $(\approx)$, yes $(\checkmark)$

\section{Abbreviations table 1}

IIVM: Institute of Responsible Medicine Use (Instituut Verantwoord Geneesmiddelengebruik)

2 SGB: Foundation Drug Bulletin (Stichting Geneesmiddelen Bulletin)

${ }^{3}$ NKP: Clinical Pathway Network (Netwerk Klinische Paden)

Of the 67 tool types/names, 33 appeared to refer to unique tool types. 'Patient translation of guideline' and 'patient version of guideline' were considered similar terms, just as 'multidisciplinary', 'network' and 'practice guideline' were considered to be similar to the 'plain' 'guideline'. To show the abundance of names given to the tool types and possible differences in data extraction, we transported all included tools to the final table for data extraction (see table 1) describing their characteristics.

\section{Target users and interrelatedness of tools}

Despite the increased attention for patient engagement in decision-making and tools enabling this, it appeared that most tool types $(n=34)$ were primarily aimed at healthcare professionals; 14 were aimed solely at patients; and 18 at both. One tool type was targeted at a different user group: helping employers deal with employees who have health problems. Six tool types also mentioned other target users, such as governments and healthcare insurers.

Flow charts, summaries and patient versions of CPGs are generally regarded as derivatives of guidelines (97). We consider decision aids and CPGs to be linked as well, since patient decision aids are mostly based, or should be based on CPGs (98). The criteria of Option Grid ${ }^{\mathrm{TM}}$ even required these to be based on clinical practice guidelines (99). However, interpretations differ among organisations and expected links are missing. For instance, the Netherlands Society of Occupational Medicine (NVAB) and the Royal Dutch Society for Physical Therapy do not regard flow charts and guideline summaries as knowledge tools in themselves - to be used 
independently from the guideline - but as an integral part of the guideline. By contrast, the Nurses Association does regard a summary (sheet) of the guideline as a tool that can be used independently. Patient versions of guidelines were mostly viewed as tools to be used independently. With other tools, however, links were expected, as they cover the same subject and are probably based on the same knowledge. For example, CPGs and patient decision aids developed by the Dutch Institute for Healthcare Improvement were not always developed in concordance with each other, as the CPG for a specific subject was updated but the corresponding decision aid was not. Figure 3 provides a rendering of how different tool types in our view could be (inter)connected or related to each other.

Figure 3: A rendering of how tool types could be (inter)connected or related to each other

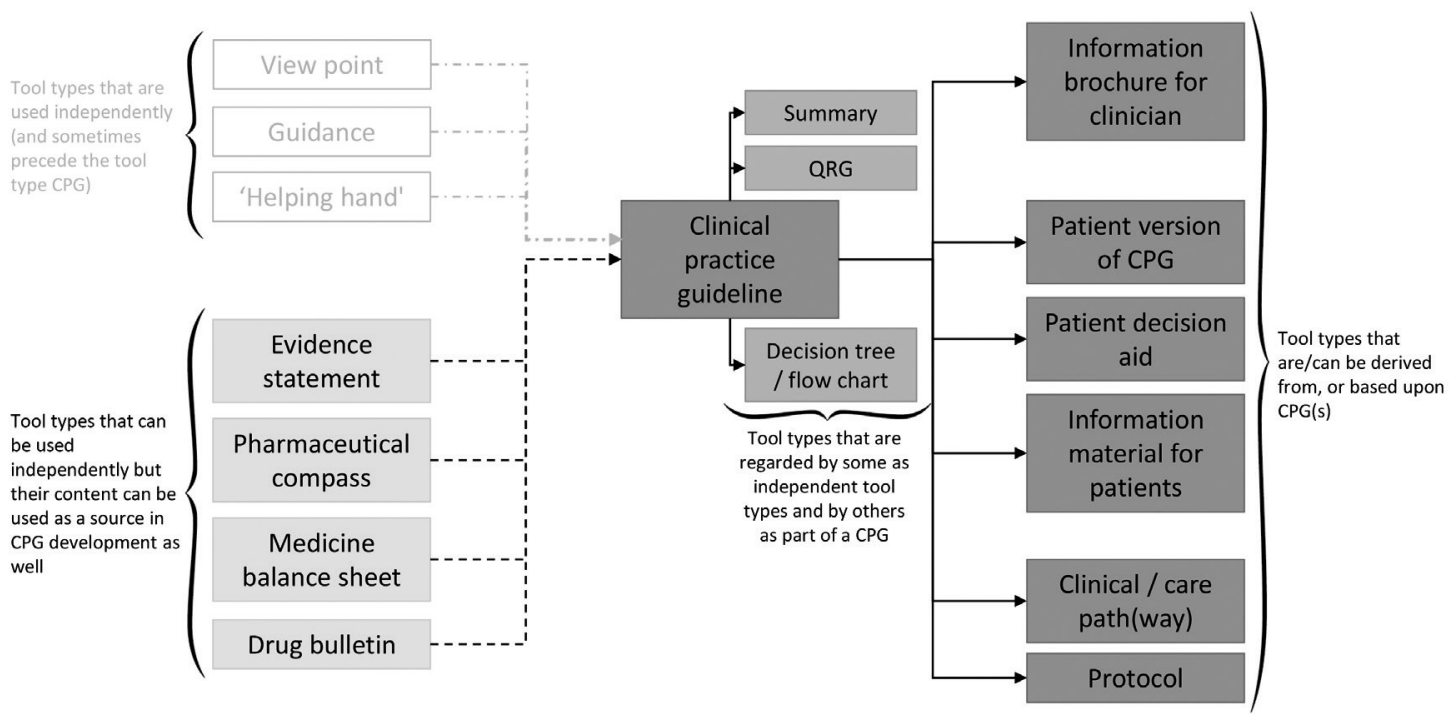

Abbreviations figure 3

- QRG: quick reference guide

- CPG: clinical practise guideline

\section{Discussion}

The aim of the review was to assess the number of tool types available to clinicians or patients, by identifying the existing national-level tools that support knowledge translation and (shared) decision-making. We included 67 tools published by 20 organisations. So, does the real-life situation correspond to the picture of chaos painted in the introduction, with doctors bogged down in a myriad of tools? Notwithstanding the fact that the review only included tools from a limited number of national organisations that develop and disseminate knowledge tools, we suggest that the answer is yes. There is an abundance of tool types available and the definitions of these tools are mostly vague or incomplete. This made it difficult to assess whether these tools differ in terms of content or purpose. 


\section{6 | Chapter 2}

Moreover, there are even more knowledge tools available than we could include. For example, tool types such as 'process guideline' and 'modular guidelines' were gaining momentum at the time of the review but were excluded. Based on the name, we decided that the tool type 'process guideline' would probably address care processes and not care content. After inquiry, 'modular guidelines' seemed to refer more to the development process of clinical practice guidelines, and it was therefore excluded. Moreover, we also disregarded tools developed at regional and local levels, just as tools in the domain of long-term care. Also excluded were tools developed at an international level $(79,100)$, some of which were not yet mainstream in the Netherlands at the time of the review, and tools from (more) commercial organisations such as pharmaceutical companies. This means that there are even more tool types available to clinicians and patients than we mentioned in this article, and we doubt if these are all clearly defined.

As a number of definitions were incomplete, data extraction was more difficult than we had anticipated. Textbooks $(7,101,102)$, which were consulted to determine search terms, seemed more conscientious about the terms they used than the websites. The books mostly contained definitions or descriptions, but these were sometimes in contradiction with the terms found on the websites. One could argue that the gap identified between the textbooks and the websites perhaps mirrors the gap between theory and practice (101).

Most tools were primarily aimed at healthcare professionals. This could be due to the leeway of patient involvement in this area and in developing these tools to catch up. There are other users of these tools, such as the Dutch Health and Youth Care Inspectorate and healthcare insurers. These are, however, not considered to be target groups; that is, they are not mentioned in the descriptions of the majority of the tools. This might reflect the opinion of some developers in the Netherlands that these groups use the tools for other purposes then the ones for which they are intended, e.g. contracting healthcare services or enforcement. These are considered inappropriate uses, which leads to friction between these parties (39). In one of the discussions among the authors, the question surfaced whether information on target users should be part of the definition. What is the hallmark of a good definition and what needs to be included in the definition to describe a tool clearly?

An interesting question related to the digital age is whether anything is ever lost or forgotten nowadays. Even though tool types and tools become obsolete or their content becomes outdated, they can often still be found on the Internet (or on PCs). This could mean that tools no longer in use are never completely forgotten, clogging up the already bulging pipeline of tool types. Another aspect of the digital age is that the tool and its medium are becoming increasingly interlinked and inseparable; apps on smartphones are a powerful example (103, 104). Tools are nowadays readily available in different forms and on different media. Looking to the (near) future, we see a digital age with an abundance of access possibilities via apps, social media and the internet, with '[u]nlimited information on limited human bandwidth.' (105).

One could raise the question whether it is chaos we are looking at, or evolution. Like organisms, tools come into existence and gradually evolve into different 'species'. In time, some become 
extinct, while the ones that fit best survive. Alternatively, one could put it into more economic terms, as the Dutch healthcare system has undergone a shift from government regulated to a market regulated construct. As a result, organisations apply strategies of differentiation and diversification to advance themselves and to try to distinguish their products from those of other organisations (106). The National Health Care Institute recently introduced the 'care tree' tool (107). This is in effect a digital flow chart, but such a name would not attract the attention desired by the institute (108). The DCGP (Dutch College of General Practitioners) already applied this marketing technique a long time ago by calling its guidelines 'standards'. This implies that when their guidelines are developed according to their strict, predetermined criteria, they are entitled to be called 'standards'. Consequently, DCGP Standard could be considered the 'brand name' for their guidelines.

As mentioned above, the description of a tool was not always immediately clear. This does not necessarily mean that there is no understanding of the tools within or outside the organisation. For example, the DCPG Standards have already been in use for almost thirty years. The DCPG Standard and its meaning might therefore be considered to be common knowledge in healthcare practice.

The tool types of the Dutch Health and Youth Care Inspectorate (IGJ) proved to be an ambiguous case. The Inspectorate mentioned seven tool types on its site but no definitions were provided. In general, the Inspectorate refers to these tool types as 'field norms', as they are preferably developed by the healthcare field. One of the tasks of the Health Care Inspectorate is monitoring; when it detects an inadequacy, it will call upon the relevant healthcare organisations to address this problem, for example by developing a tool. A clear explanation of these tools would therefore have been expected; in failing to provide these, the expectations of the Inspectorate remain unclear. Some parties, including the Health and Youth Care Inspectorate itself, might say that in this manner it grants organisations room to manoeuvre and decide for themselves which tool is appropriate. At the same time, the Inspectorate fosters expectations of the tool in question and its use for monitoring and enforcement, which congruent with the purposes of the healthcare organisations developing the tool, and whether this organisation employs a clear definition of the tool or not. We decided to include the general term 'field norm' as it can refer to all tool types developed and used by healthcare organisations.

The example mentioned above underlines the importance of clear and precise definitions of tools. Norma Lang phrased it boldly in 1992: 'If we cannot name it, we cannot control it, practice it, teach it, finance it, or put in into practice' (109-112).

Another reason for this might be that health care is multidisciplinary, although the real meaning of 'multidisciplinary' seems to become apparent and sink in only now. Apart from different kinds of healthcare professionals, patients are added to the healthcare equation, while insurers, government agencies are also (getting) involved $(113,114)$. Maybe these do not all play a pivotal role in the decision-making process between patient and clinician, but they do use the tools. To better understand each other it is therefore necessary to use and speak the same language (115). As Ubel states in his book 'Critical decisions': 'For any pair of people to communicate effectively, it helps enormously if they share a common language.' (116). At the moment, we 


\section{8 | Chapter 2}

appear to speak a common language regarding knowledge tools in the Netherlands, using terms that sound and look alike. However, because these terms are not always defined explicitly, we do not always attach the same meaning to them or use them in the same way, and we get lost in translation.

We have not yet even looked beyond the national borders, even though increasing cooperation between clinicians and patients from different countries (117-119) means additional languages, additional tools and terms, and additional meanings. Some recognise the need to have a common language within and outside the knowledge domain. In 2012, an international study group explored the notion of developing a common terminology for knowledge translation interventions. The rationale for doing this was that 'a wide range of diverse and inconsistent terminology exists in the field of knowledge translation. This limits the conduct of evidence syntheses, impedes communication and collaboration, and undermines knowledge translation.' (120). At an even more fundamental level, organisations have started to work together towards a shared terminology. An international consortium consisting of WHO (ICD10), IHTSDO (SNOMED $\mathrm{CT}$ ) and LOINC, worrying about the confusion of tongues regarding data collection in (health) care for the use of research and policy development, worked out a framework describing core concepts using concise process descriptions (121).

Is the chaos restricted to the Netherlands? A search on foreign websites and PubMed yielded no information or articles on chaos regarding knowledge tools. At the same time, no overviews or frameworks of tool types - which state definitions and possible links between them - were found either for other countries. Glossaries, definitions, A to Z's, jargon busters and taxonomies found (search took place in April 2013) on the websites of e.g. AIWH (Australia), NIH, Informed Medical Decisions Foundation, AHRQ (US), CIHR (Canada), NHS, NICE (UK), ÄZQ (Germany), Cochrane Collaboration, EU and WHO mainly dealt with words and terms related to medicine/ health (adverse event, condition), epidemiology (absolute risk), research (abstract), quality (patient safety terms) and organisation of care domains (advocacy) (122-136). The document that came closest to an explanation of tool types was found on the AHRQ website and concerned a collaboration between Russia and the United States, dating from 1999. It listed under the heading 'Quality standards' terms such as 'practice guidelines', 'clinical path', 'critical path', 'standard' and 'quality standard' (137).

Our suspicion that the chaos case was not limited solely to the Netherlands was confirmed when we presented the preliminary results of the review at the Guidelines International Network (GIN) Conference (138) and International Shared Decision Making (ISDM) Conference (139). The conclusion that there are too many tools was endorsed, together with the notion that the links between the tools are often lost. The DECIDE project (Developing and Evaluating Communication strategies to support Informed Decisions and practice based on Evidence) - funded by the European Union - has tried to address these issues, by increasing the accessibility and use of tools such as clinical practice guidelines, linking interconnected tools such as decision aids in a more visible way and updating them (140).

The website of the European Union makes it clear that health care is not the only area 
struggling with definition issues: 'It is not possible to use one definition to cover all circumstances. Similarly, the word 'standards' is employed in a variety of ways across Europe [...]. The words also have very different meanings in the local contexts of national higher education systems.' (136)

\section{Strengths and limitations}

Because we made the choice to include tools even though their definition or description was not fully complete - incompleteness was deemed an interesting result by itself - it could mean that somebody else might decide differently on the inclusion or exclusion of the tools that we found. The aim of the review was to show that there were many tool types available in the Netherlands for knowledge transfer and decision-making. Although another person might have chosen different organisations or different tools, we feel that the outcome would have been roughly the same. Because of the national policy perspective, we limited the scoping review to tool types being developed by national agencies. Including locally developed, internationally developed tool types and tool types developed by commercial organisations probably would have generated an even larger range of available tool types, but we would not have been able to look into these tool types in detail as we did in this approach.

\section{Conclusions}

In the Netherlands, but also in other countries, there is a myriad of tool types available to healthcare professionals (and patients). Tools that are developed to facilitate, ensure knowledge translation, and to provide healthcare professionals with support whilst making decisions. But because the tool types are not defined clearly and precise, misunderstanding about their use and purpose can arise. As can miscomprehension between disciplines and domains. We also might be duplicating efforts, and wasting (public) means when developing these tool types. Also, because the dependencies or interconnectedness between some of the tool types is poorly indicated as well. And we still add new ones before we have established that the old ones do not work. By doing so, we seem to be creating, despite our best intentions, a tool overload instead of solving the information overload.

\section{Recommendations}

As existing tool types do not seem to deliver the results for which they are intended or do not live up to the full expectations of their target users, one response is to develop new ones (107, 141). We should ask, however, if this is the right response, or whether we need to take a closer look at the tools already available and how they are being used, need adaptation, as well as paying attention to improving (in providing) the definition of these tool types and their intended use.

We have shown that there exists a myriad of tool types, most of which are poorly defined and unclear as well as to their mutual relations. This abundance of tool types might affect their usefulness raising the important question how to deal with all these tools, their different formats and sometimes their contradictory contents. The review underpins what parties have been advocating for a number of years now (88): a trimming down of the number of tool types or terms used and a clear(er) definition of tools. We recommend that parties on either a national or 


\section{0 | Chapter 2}

preferably an international level try, first, to reach agreement on a core set of knowledge tools; second, to reach consensus on the definitions and terms used for these tools; and third, to develop a conceptual framework showing the relations between the tools. This tool issue seems to be an exemplification of the tenet that 'less is more'. However, as we did not systematically invest Dutch clinicians' and/or patients' views on this issue, we would recommend that follow-up research is carried out to find out if Dutch healthcare professionals and patients are aware of the multitude of tool types, how they perceive this availability and how they deal with it.

Another paper features our report on a Delphi process intended to reach a consensus on the number of tool types and their definitions at a national level in the Netherlands. This Delphi process (2015) was followed by an invitational meeting with international experts (2016) aiming to develop a framework of related knowledge tools, their purposes and characteristics (142). 


\section{Appendix A - Searched websites}

\begin{tabular}{|c|c|c|}
\hline \# & WEBSITE / ORGANISATION (DUTCH) & WEBSITE / ORGANISATION (ENGLISH) \\
\hline 1 & $\mathrm{CBO}$ & Dutch Institute for Healthcare Improvement \\
\hline 2 & CPZ - Coördinatie Platform Zorgstandaarden & Coordination Platform Care Standards \\
\hline 3 & FMS - Federatie Medisch Specialisten & Federation Medical Specialists \\
\hline 4 & Gezondheidsraad & Health Council of the Netherlands \\
\hline 5 & IKNL - Integrale Kankercentrum Nederland & $\begin{array}{l}\text { Quality Institute for Oncological and Palliative } \\
\text { Research and Practice }\end{array}$ \\
\hline 6 & IGJ - Inspectie Gezondheidszorg en Jeugd & Health and Youth Care Inspectorate \\
\hline 7 & Kiesbeter.nl & Kiesbeter.nl (Choosing Better) \\
\hline 8 & $\begin{array}{l}\text { KNGF - Koninklijk Nederlands Genootschap } \\
\text { voor Fysiotherapie }\end{array}$ & Royal Dutch Society for Physical Therapy \\
\hline 9 & $\begin{array}{l}\text { KNMG - Koninklijke Nederlandsche } \\
\text { Maatschappij tot bevordering der Geneeskunst }\end{array}$ & Royal Dutch Medical Association \\
\hline 10 & NHG - Nederlands Huisartsengenootschap & Dutch College of General Practitioners (DCGP) \\
\hline 11 & Patiëntenfederatie Nederland & Dutch Patient Organisations' Federation \\
\hline 12 & $\begin{array}{l}\text { NVAB - Nederlandse Vereniging voor Arbeids- } \\
\text { en Bedrijfsgeneeskunde }\end{array}$ & Netherlands Society of Occupational Medicine \\
\hline 13 & $\begin{array}{l}\text { NVK - Nederlandse Vereniging voor } \\
\text { Kindergeneeskunde }\end{array}$ & Dutch Paediatric Association \\
\hline 14 & TNO Kwaliteit van leven & $\begin{array}{l}\text { Research organisation (developing Preventive Child } \\
\text { Health Care guidelines) }\end{array}$ \\
\hline 15 & Trimbos Instituut & Netherlands Institute of Mental Health and Addiction \\
\hline 16 & V\&VN - Verpleging en Verzorgenden Nederland & Dutch Nurses Association \\
\hline 17 & $\begin{array}{l}\text { Zorginstituut Nederland (voorheen College voor } \\
\text { Zorgverzekeringen, CVZ) }\end{array}$ & $\begin{array}{l}\text { National Health Care Institute (previously Health Care } \\
\text { Insurance Board) }\end{array}$ \\
\hline $18^{*}$ & $\begin{array}{l}\text { IVM - Instituut voor Verantwoord } \\
\text { Medicijngebruik }\end{array}$ & Dutch Institute for Rational Use of Medicine \\
\hline 19 & Med-decs.org & Med-decs.org \\
\hline $20^{*}$ & NKP - Netwerk Klinische paden & Clinical Pathway Network \\
\hline 21 & $\begin{array}{l}\text { NTvG - Nederlands Tijdschrift voor } \\
\text { Geneeskunde }\end{array}$ & Dutch Journal of Medicine \\
\hline 22 & $\begin{array}{l}\text { NVVG - Nederlandse Vereniging voor } \\
\text { Verzekeringsgeneeskunde }\end{array}$ & Dutch Association of Insurance Medicine \\
\hline 23 & Regieraad Kwaliteit van Zorg & Dutch Council for Quality of Health Care \\
\hline 24 & $\begin{array}{l}\text { RVS - Raad voor Volksgezondheid en } \\
\text { Samenleving }\end{array}$ & Council for Health and Society \\
\hline 25 & $\begin{array}{l}\text { VSOP/VSN - Vereniging Samenwerkende } \\
\text { Ouder- en Patiëntenorganisaties Betrokken } \\
\text { Bij Erfelijkheidsvraagstukken / Vereniging } \\
\text { Spierziekten Nederland }\end{array}$ & $\begin{array}{l}\text { Association of Cooperating Parent and Patient } \\
\text { Organisations on hereditary diseases/Neuromuscular } \\
\text { Diseases Association }\end{array}$ \\
\hline 26 & $\begin{array}{l}\text { VWS - Ministerie van Volksgezondheid, Welzijn } \\
\text { en Sport }\end{array}$ & Ministry of Health, Welfare and Sport \\
\hline $27^{*}$ & SGB - Stichting Geneesmiddelenbulletin & $\begin{array}{l}\text { Geneesmiddelenbulletin Foundation (Dutch drug } \\
\text { bulletin) }\end{array}$ \\
\hline
\end{tabular}

* Websites 18 - 27 (in italics) were found via snowballing and searched as well; only the results of the three websites marked with an asterisk $\left(^{*}\right)$ were included, as these were the only ones that met the selection criteria of the originally selected organisations. 


\section{Appendix B - Search terms}

\section{SEARCH TERMS (DUTCH)}

\section{Kennis}

Kennisinstrument

Kennisbevordering

Kennisontwikkeling

Kennisoverdracht

Kennistransfer

Kennisverwerving

Kennisdeling *

Kennisverbetering ${ }^{*}$

Beslissing

Beslissing(s)ondersteuning

Besluitvorming

Keuzehulp

Keuzewijzer

Beslisboom

Besliskunde

Decision support

Decision aid

Keuze

Shared decision (-) making

Informatie (-) uitwisseling

Informatiebehoefte

Informatiefolder

Informatie (-) overdracht

Informatieverstrekking

Informatieverwerving

Informatiemateriaal

\section{Richtlijn}

Protocol

Zorgstandaard

Standaard

Kwaliteit(s)standaard

Professionele standaard

Norm

Zorgmodule/module

Leidraad

Klinisch/zorgpad (patient care way)

Aanbevelingen

Clinical evidence samenvattingen

Samenvatting(skaart)

Evidence tabel

Patiëntenversie

Patiëntenmateriaal

Patiëntenbrief

Patiëntenparticipatie

Patiëntenperspectief

Preferenties/preferences

PROM's

Brochure

Patiënt/cliënt/burger/zorgvrager/

zorgconsument*

Kwaliteitsinstrument/interventie*

Taxonomie $^{*}$

Definitie(s)*
SEARCH TERMS (ENGLISH)

Knowledge

Knowledge tool

Knowledge advancement

Knowledge development

Knowledge transfer

Knowledge transfer

Knowledge acquisition

Knowledge sharing

Knowledge enhancement

Decision

Decision support

Decision (-) making

Decision aid

Decision pointer

Decision tree/flow chart

Decision theory

Decision support

Decision aid

Choice

Shared decision (-) making

Information exchange

Information need

Information brochure

Information transfer

Information provision

Information acquisition

Information material

Guideline

Protocol

Care standard

Standard

Quality standard

Professional standard

Norm

Care module/module

Guiding principle

Clinical /care pathway

Recommendations

Clinical evidence summaries

Summary (sheet)

Evidence table

Patient version

Patient material

Patient letter

Patient participation

Patient perspective

Preferences

PROMs

Brochure

Patient / client / civilian / care recipient /

care consumer

Quality tool / intervention

Taxonomy

Definition(s)

* These search terms were added during the search as they surfaced repeatedly. 
Chapter $2 \mid 43$ 


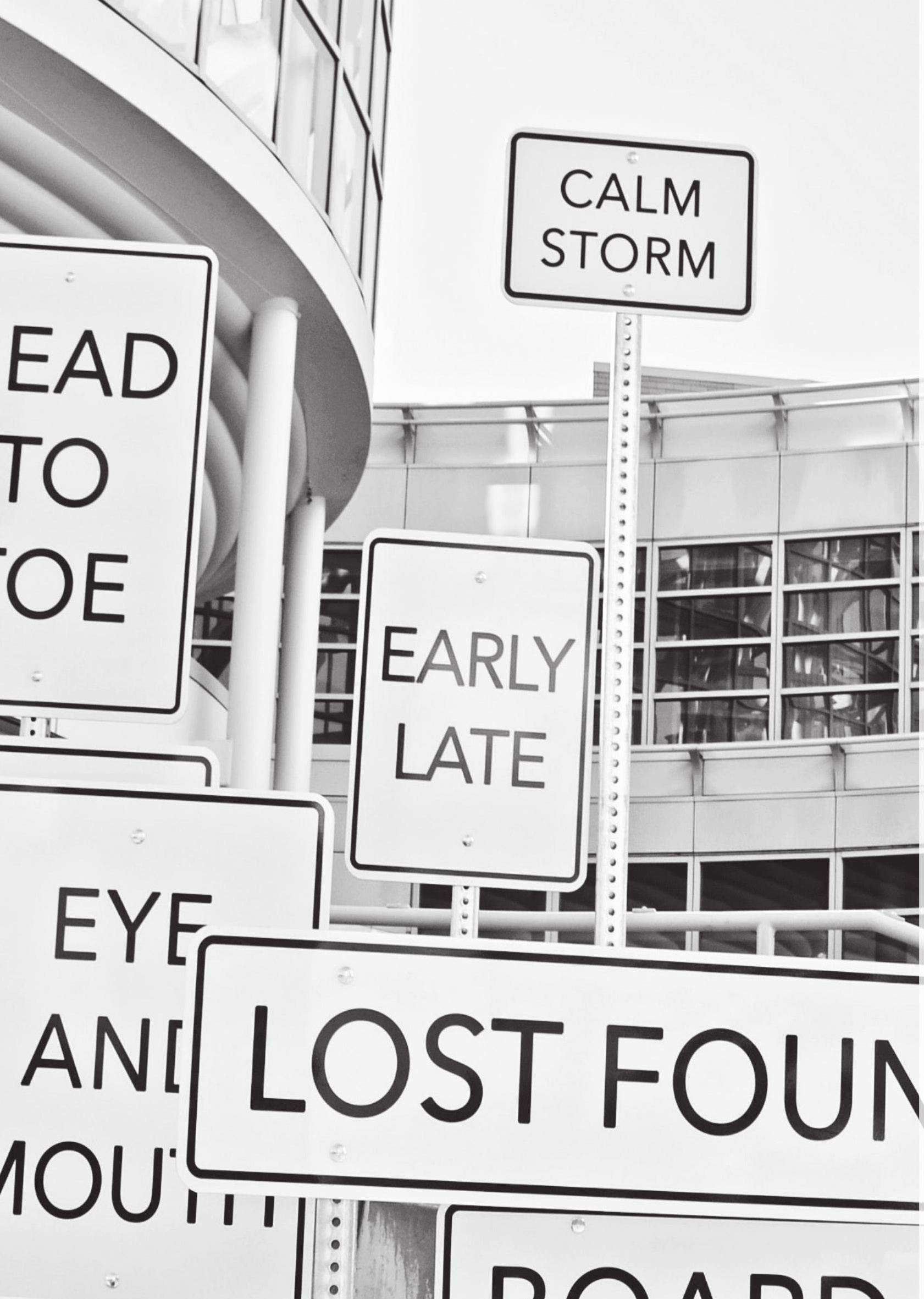


Chapter 3

Lost in definitions:

reducing duplication and

clarifying definitions of know-

ledge and decision support

tools. A RAND-modified Delphi

consensus study

Dunja Dreesens

Leontien Kremer

Jako Burgers

Trudy van der Weijden 


\section{Abstract}

\section{Background}

A review of tools for knowledge translation and decision support yielded an abundance of tool types and confusion over the definitions of these knowledge tools. The aim of this study was to limit the number of tool types, reach consensus on their definitions and clarify their intended use.

\section{Methods}

We used the RAND-modified Delphi approach to select a core set of knowledge tools and to reach agreement on the tools' definitions. The knowledge tool types were scored using a Likert scale in two Delphi rounds on importance; the provided definitions were also scored and commented on by the experts.

\section{Results}

Over 20 experts from parties involved with development of knowledge and decision support tools reduced the number of tool types from 34 to 13. The Delphi participants reached consensus on nine tools as being important for knowledge translation and supporting (shared) decision-making. Furthermore, they reached consensus on the definition of five of the 13 tools.

\section{Conclusions/discussion}

A large group of experts, representatives of Dutch knowledge tool developers, managed to reach consensus on a core set of 13 knowledge tool types for the Netherlands. Implementing the use of this set and limiting the expansion with other tool types remains challenging.

\section{Keywords}

Knowledge (translation) tools; Decision support; Definitions; Delphi procedure; Qualitative research; Netherlands 


\section{Introduction}

The amount of knowledge in health care is vast and accumulates fast (14). Clinical practice guidelines (CPG) and patient decision aids (PDA) are common tools being developed to support healthcare professionals and patients in knowledge translation and (shared) decision making (95). These tools can help in staying abreast of the available knowledge and contribute to the improvement of quality health care. Beyond CPGs and PDAs, a scoping review yielded an abundance of types of knowledge tools available to professionals and patients in the Netherlands to support quality improvement. It also became clear that contrasting or incomplete definitions were used to describe these tool types (143). Moreover, these tools are not often used in practice for instance due to unfamiliarity, limited usability, or non-acceptance $(42,43,141,144-147)$. It might be argued whether the sheer number of tool types is helpful or complicates the process of knowledge translation (KT) (148), and quality improvement in health care.

Organisations such as Agency for Healthcare Research and Quality (AHRQ), Canadian Institutes of Health Research (CIHR), the Cochrane Collaboration and World Health Organization (WHO) have glossaries or A-to-Z's on their websites, but these mostly explain health terms and do not describe the knowledge tools in detail $(122,123,129,130,132)$. Existing overviews of tools include similar tool types with different names and without a clear definition or description $(70,88,149)$. No attempts seem to have been made to limit the number of tool types and achieve consensus on the definitions on a national level. A comprehensive, commonly accepted set of knowledge tool types and their definitions seems to be lacking in the Netherlands, as we expect is the case elsewhere.

Although we focused on the Netherlands in this study, we aimed to link English terms and tool types to the Dutch ones and to contact international research communities active within knowledge translation (120), and connected to the Guideline International Network (G-I-N) and International Shared Decision Making (ISDM) (88). The research and preliminary results were discussed with experts and at two conferences of G-I-N and ISDM $(138,139)$. We learned that others encountered the same issue in other countries. This led to an invitational meeting with international experts to develop a framework for (patient-directed) knowledge tool types (142).

The objectives of this study are: first, to agree at a national level on a core set of knowledge tool types that supports clinicians and patients in knowledge translation, (shared) decision-making and quality improvement; and, second, to agree on the definitions of these tool types. Our ultimate aim is to promote a mutual understanding and use of a limited set of tool types. The Dutch National Health Care Institute, responsible for quality of care against acceptable costs in the Netherlands supported and participated in the study. 


\section{Methods}

\section{General design}

This study, conducted in 2015/2016, combined a survey with the RAND-modified Delphi method (also known as RAND/UCLA Appropriateness Method) (150) to identify a core set of knowledge tools and to reach agreement on the definitions of these tool types. The survey was added ahead of the Delphi to limit the number of tool types to be assessed during the Delphi, as the experts were expected to answer three questions per tool type. The project group thought this would be too time consuming and might jeopardize their participation. A knowledge tool can be defined as a tool to assess and synthesise the highest-quality knowledge and research, aimed at healthcare professionals and/or patients, serving to translate knowledge and support (shared) decision-making (95). The definition of a knowledge tool consists of three parts: a description of the tool, its goal and its target user(s) (151).

\section{Participants and project group}

The participants were purposively sampled for this study. Eligible candidates were identified by the project group using the following characteristics: professional activity in health care, palliative care or long-term care; expertise, either academically or in practice, in developing, implementing or evaluating knowledge tools for professionals, patients, or both; expertise in (shared) decision-making, linguistics or terminology; active in the public, academic or private domain of health care in the Netherlands; and with understanding of the Dutch language. In addition, we aimed for diversity in affiliation, gender and age among the participants. The group of experts was complemented with members of a working group advising the National Health Care Institute on tool development and use. As these members were representatives of the main (health)care organisations in the Netherlands which develop and disseminate knowledge tools, their involvement and contribution was considered essential. The anonymity of participants was ensured at all levels. First, the experts did not know who participated. Furthermore, their responses in the Delphi rounds were submitted under code aliases. The list with code aliases was only known to the administrator of the Delphi platform. By agreeing to participate in the survey and Delphi process, the experts also gave consent to use their comments for publication. The participants were contacted via email by the first author explaining the nature and goal of the study and the consecutive steps of the study. The participants were informed of the outcomes after each round. None of the participants received any remuneration.

The project group consisted of the authors and the secretary of the working group of the National Health Care Institute.

\section{Identification and selection of tools}

Starting point was a longlist of knowledge tool types $(n=67)$ yielded by a scoping review of knowledge and decision support tool types (143), separately executed before this study. The scoping review looked at tool types - developed by national, non-commercial, organisations - that support knowledge translation and (shared) decision making and their definitions. The 
project group merged overlapping tool types and excluded tool types that are only developed by one organisation. In addition to excluding tools, the project group decided to split two tool types into two as the project group could not agree whether these tools were actually one or two tool types combined. The National Health Care Institute identified another five tool types to be added to the list. Some of these were excluded in the scoping review, but as these tool types were part of the institute's monitoring responsibility they were added again (indicated with ${ }^{\mathrm{c}}$ in table 2 (and table 3)) (152). A few members of the project group considered that some of the tool types in the category 'umbrella tools' could be regarded as actual tools. Because we could not reach agreement on this, we decided to let the study participants decide. Finally, the project group added one emerging tool type (indicated with ${ }^{\mathrm{d}}$ in table 2), resulting in a list of 34 tool types.

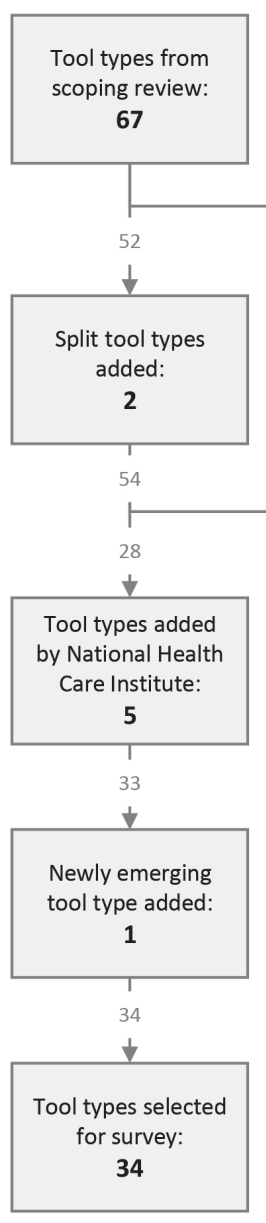

Figure 1: Selection of tools for survey
The definitions originating from the review were combined with those developed by the institute into an overview to compare the definitions of the tool types included by the survey. If the tool type definitions in the review differed from those developed by the Institute, were unavailable, or lacked any of the three required parts of a definition (a description of the tool, its goal and its target user(s)), such information was completed by the project group, preferably using glossaries and internationally available definitions (9).

\section{Survey and Delphi set-up}

The project group decided that assessing 34 tool types in a Delphi process by answering three questions per tool type would be too time consuming for the experts and might jeopardize their participation. Therefore, a survey was held ahead of the Delphi to decrease the number of tools to be assessed in the first Delphi round. The participants were only asked to indicate for each tool whether to keep or eliminate it; no criteria were provided

by the project group. Definitions of the tools were not provided at this stage as we did not want to influence them during the in-/exclusion process. At the end of the survey, the participants were given the possibility to add tool types, preferably with a definition. Added tool types suggested by at least three participants were added to the list for the Delphi. Tools receiving a positive score ('keep') from more than $50 \%$ of the participants remained on the list. 


\section{0 | Chapter 3}

The survey was followed by an online RAND-modified Delphi. This consensus method was chosen with the aim to reach agreement with regard to different opinions, fluctuations in use and number of tools over time, and political involvement as the Dutch Ministry of Health, Welfare, and Sports was involved (via the National Health Care institute) in the development and monitoring of knowledge tools. The ministry wanted to have some influence regarding the quality of the tools developed, monitor efforts by the parties involved and see to an improved synchronized effort in developing these tools. Defining these tools therefore became of interest to the ministry as well. By using consensus methods, one can determine to which extent the participants agree with the issue posed and to which extent participants agree with each other. Choosing the RAND-modified Delphi also prevented more vocal people to dominate (153).

The Delphi process consisted of two rounds. In both rounds, the participants were asked to score the tool types on a Likert scale according to the importance of the tool type (0-8; not important at all - very important) and their agreement with the definition provided (0-8; very much disagree - very much agree). In addition, they had the possibility to suggest amendments to the definitions provided for each tool and to add tools, preferably including a description. In the first round, the participants scored without seeing any scores of the other participants. In the second round, the scores and comments were visible to all participants, who were also able to discuss these with each other.

The sequence of the tools was randomly determined for the first Delphi round. The different tool types were printed on paper and a colleague, who was not involved in the study, blindly selected the papers from a non-transparent bag. In the second round, we reversed the sequence of the tools and provided adapted definitions based on the first-round comments.

The scoring and comments were analysed by the first author and checked by the project group before these were shared with the participants.

\section{Data analysis}

Consensus on relevance/importance of the tool type and agreement with the definition was defined as: the median of the scores $\geq 6$ AND $70 \%$ of the participants' scores were in the Likert score cluster 6-8. Consensus on irrelevance/unimportance of the tool type and disagreement with its definition was defined as the median of the scores $\leq 2$ AND $70 \%$ of the participants' responses are in the Likert score cluster 0-2. Tool types were discussed if: $30 \%$ of the responses were in group 0-2 AND 30\% of the responses were in group 6-8. All other scores indicated ambiguity, and results scored by fewer than nine participants were considered invalid (see Appendix A).

Concerning the suggestions for the definitions made by the participants, the first author compiled the suggestions, determined whether to adapt the definition, and discussed the findings with the project group. The same approach was followed for added tool types suggested by the participants.

To conclude the study, a linguist aided the first author in editing and finalising the definitions of the tools for which the experts had assessed the definitions. 


\section{Results}

We describe briefly the main results of the survey and Delphi-process before we present the process and the results in more detail. The survey and Delphi achieved a reduction of the number of tool types: from 34 to 13 tool types. For five of these 13 tool types consensus was reached on the definitions, and for nine of the 13 selected tool types there was consensus on the importance of these tools concerning knowledge translation and supporting (shared) decision-making (Table 4).

\section{Survey and participants}

Fifty-seven experts participated in our study (Table 1), 13 (19\%) declined or did not respond to the invitation. From the 57 participants, $82 \%(n=47)$ responded to the survey, of which $44(77 \%)$ completed the entire survey.

Table 1: Background of survey participants BACKGROUND* OF PARTICIPANT (more than one option could apply) NUMBER OF PARTICIPANTS

$\begin{array}{lr}\text { Employed by research/knowledge institute (not being a university) } & 21 \\ \text { Tool developer and/or implementer } & 12 \\ \text { Healthcare professional } & 10 \\ \text { Employed by healthcare professional association/society } & 10 \\ \text { Professor/lecturer at (applied sciences) university } & 10 \\ \text { Policy advisor } & 9 \\ \text { Patient (representative) } & 6 \\ \text { Employed by industry / commercial party } & 2 \\ \text { Otherb } & 4\end{array}$

\section{Legend table 1}

* The participants could choose to indicate more than one background, so the total of the background exceeds the number of participants

a Healthcare professionals could choose from: long term care, curative care, public health, primary and secondary care

b Others were: experienced clinical practice guideline developer, tool user/patient coach, methodologist and retired healthcare professional in secondary care

The results of the survey are presented in table 2 and figure 2 . 


\section{2 | Chapter 3}

Table 2: Tool types (34) assessed by experts in survey

TOOL TYPES

SELECTED \& ADDED

IN SURVEY

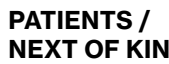

PATIENTS / NEXT OF KIN

Information folder

Patient decision aid

Patient leaflet

Patient version (of CPG)

Patient translation (of CPG)

$\checkmark$

$\checkmark$

$x$

$\checkmark$

$\checkmark$

Option Grid ${ }^{\mathrm{TM}}$

HEALTHCARE PROFESSIONALS
Pharmaco-therapeutic guideline

Information standard ${ }^{c}$

Clinical guideline

Multidisciplinary guideline

Network guideline

Norm ${ }^{\mathrm{c}}$

Practice guideline

Clinical practice guideline (CPG)

Clinical practice guideline module ${ }^{d}$

Standard

Care module

Care standard

Occupational health benefit insurance protocol

\section{Protocol}

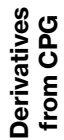

Decision tree

Flow chart

Quick reference guide

Summary (of CPG)

Care pathway

Indicator

Clinical pathway

Guiding principle

Viewpoint

\begin{tabular}{|c|c|}
\hline \multirow{4}{*}{ స్ } & Care pathway \\
\hline & Indicator ${ }^{c}$ \\
\hline & Clinical pathway \\
\hline & Guiding principle \\
\hline & Viewpoint \\
\hline
\end{tabular}

\section{X}

$\checkmark$

$x$

$x$

$x$

$\checkmark$

$x$

$\checkmark$

$\checkmark$

$x$

$\checkmark$

$\checkmark$

X

$\checkmark$
$v$
$x$
$d$

$\checkmark$

$\checkmark$
$\checkmark$
$x$
$\checkmark$

'Helping hand' (guidance)

UMBRELLA

TERMS

\section{Quality framework ${ }^{c}$}

Quality standard

Professional standard

Quality assessment framework ${ }^{c}$

Field norm

$x$
$\checkmark$
$x$
$\checkmark$
$x$




\section{Legend table 2}

$\checkmark$ Selected in survey

$X \quad$ Not selected in survey

c Tool types added by National Health Care Institute

d Tool type added by project group

TM Option Grid: decision aids are brief, easy-to-read tools that help patients and providers compare healthcare options, focusing on the questions patients most frequently ask when they need to make preference-sensitive decisions (154).

Two additional tools were mentioned by more than three participants: 'Option Grid" ${ }^{\mathrm{TM}}$ ' and 'guidance'. After discussing the results, the project group decided to merge the tools 'pharmaco-therapeutic guideline', 'multidisciplinary guideline' and 'clinical practice guideline' into a single tool 'clinical practice guideline'. Furthermore, the project group decided to keep four tool types on the list even though less than $50 \%$ of the participants considered them important.

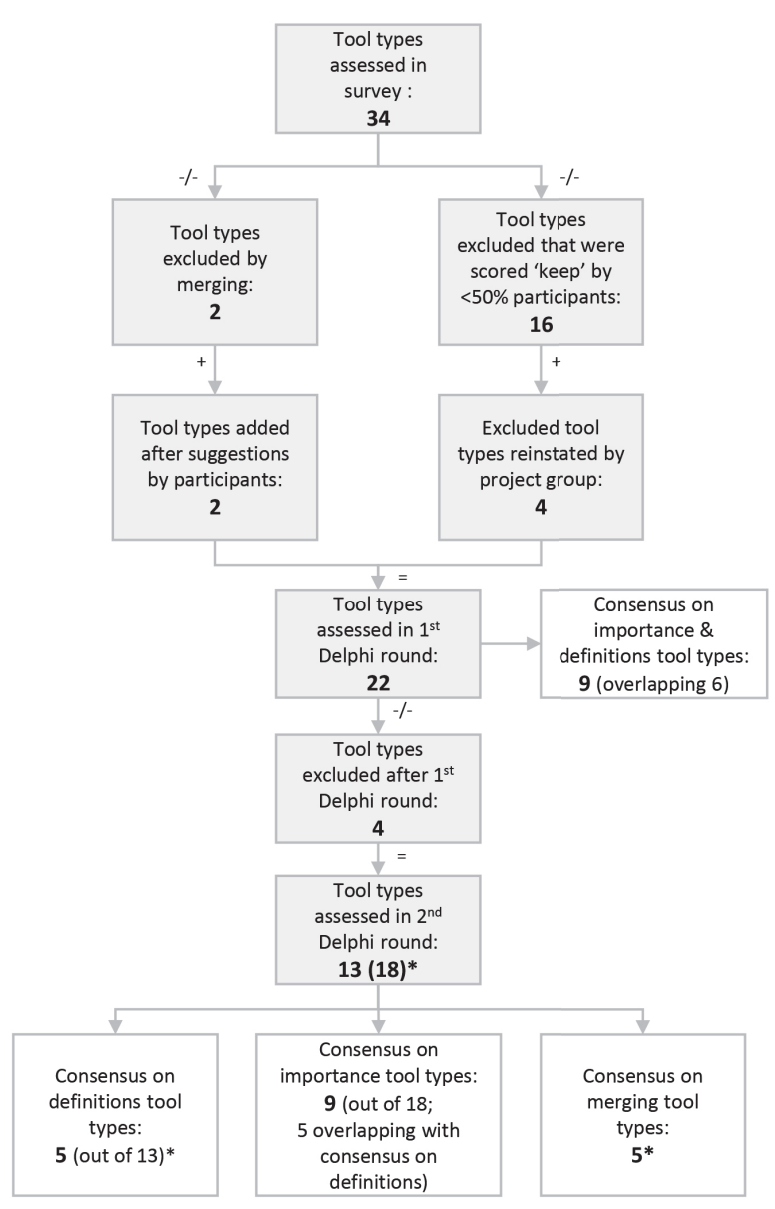

We considered two of these kept-on tool types - 'information standard' and 'guideline module' - to be too new and therefore probably too unknown to the participants to be assessed without a definition. Regarding the third kept-on tool type 'clinical pathway', we decided that this tool name was better established than 'care pathway' and the project group argued whether the experts would be able to distinguish between these tool types, and if so, how they would distinguish between them. Finally, we considered the fourth kept-on tool type 'viewpoint' of added value to and different from 'clinical practice guideline', and wanted to know whether the experts shared our opinion. The participants of the survey were informed of the results and decisions by the project group. The list after the survey finally included 22 tool types to be assessed in the Delphi (Figure 2 and table 4).

Figure 2: Assessment and number of tools in survey and Delphi process

* From the 18 tool types in the $2^{\text {nd }}$ Delphi round it was suggested that five should be merged. The definitions of the to be merged tool types were not assessed again, leaving 13 tool definitions. 


\section{4 | Chapter 3}

\section{Experts participating in Delphi}

In the first Delphi round, 31 experts participated (54\% response rate of the 57 participants of the survey), of whom 21 (36\%) completed all the questions in this round. In the second Delphi round, 20 (35\%) experts participated, of whom 17 (30\%) completed all questions. Table 3 describes the backgrounds of the experts.

Table 3: Background of Delphi experts*

BACKGROUND* OF EXPERT (more than one could apply)

NUMBER OF EXPERTS

\begin{tabular}{|c|c|}
\hline Tool developer and/or implementer & 13 \\
\hline Employed by research/knowledge institute (not being a university) & 11 \\
\hline Healthcare professionala ${ }^{\mathrm{a} b}$ & 9 \\
\hline Patient (representative) & 6 \\
\hline Professor/lecturer at (applied sciences) university & 6 \\
\hline Policy advisor ${ }^{c}$ & 5 \\
\hline Employed by industry / commercial party & 3 \\
\hline Otherd & 4 \\
\hline
\end{tabular}

\section{Legend table 3}

* The experts could choose to indicate more than one background, so the total of the backgrounds exceeds the number of experts

a Healthcare professionals worked in long term care, curative care, mental healthcare and public health

b Healthcare professionals were either medical specialist, general practitioner, nurse or paramedic

c Policy advisors were from the Department of Health, Health Inspectorate or National Health Care Institute

d Others were: linguists, IT expert or hospital employee

\section{Delphi-process}

Each question was scored by at least nine participants, making the results valid (153). Six additional tools were suggested, but each by one participant only. There was consensus on the importance of nine tools, and on the definition of nine tools; of which six tools overlapped. For one tool - 'quality assessment framework' - the scores differed on its importance. The remaining tools were scored ambiguously, with the divergent Likert scores indicating a lack of consensus on either agreement or disagreement of their importance. Notably, the newly emerging tool 'Option Grid ${ }^{\mathrm{TM}}$ ' was the tool most often scored as 'no opinion': eight times for importance and six times for definition. Most comments of the participants could be categorised into the following issues: can we limit the number of tools; can we merge similar tools; and can we visualise how the tools relate to each other?

Looking at the scores and comments, the project group decided to eliminate four tool types, even though there was no consensus on the unimportance of these tools: 'indicator', 'information standard', 'quality assessment framework' and 'information folder' (indicated with

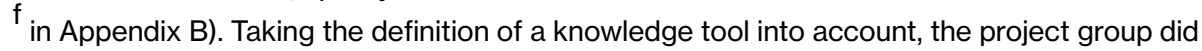
not consider the first three tools as knowledge tools. 'Information folder' was judged too broad by the experts, as it could cover information of any kind. Moreover, it was felt that there was 
overlap with the tools 'patient leaflet' and 'patient information'.

Concerning the definitions, some participants felt it important that the definition also stated which organisation(s) developed or owned (i.e. is responsible for, of maintaining) the tool, which would increase the trustworthiness of the tool. Another frequent comment was to change the wording in such a way that the definition not only covered curative care but also long-term care.

Because of the participants' suggestions regarding the similarity of some tools, the second round we asked them whether they agreed or disagreed on merging some of these tool types (marked with an asterisk in Appendix B). In the second round, the scoring option 'no opinion' was removed, as the project group felt that the Likert scores 3-5 (neutral) should cover this option.

In the second Delphi round, every question was scored by at least nine participants, making the results valid. Again, there was consensus on the importance of nine tools (see table 4), of which eight were identical to the ones in the first round. More than $85 \%$ agreement on importance was reached on five tool types (see table 4): 'summary', 'flowchart', 'clinical practice guideline', 'patient information' and 'patient decision aid'. A notable score was the $100 \%$ consensus on the importance of the tool 'clinical practice guideline' (see Appendix B). In this round, there was consensus on the definitions of five tools (bold in Appendix $B$ and $C$ ). The overlap with the first round amounted to four tools, while the overlap regarding the consensus on importance and definitions comprised five tools. There was overall consensus on the merging of the five suggested tools (70-94\% agreement (Likert score 6-8) with a median score of 8 for all the tool types).

Recently introduced tool types had low levels of consensus on importance (and definition), which could be due to lack of familiarity or that other tool types were considered more important.

As was reflected in the consensus scores regarding the definitions, the experts in round one reached agreement on more definitions than they did on the adjusted definitions in round two. The experts were aware of this discrepancy and commented on it in the discussion phase of the Delphi. Except for minor differences in wording, they indicated they preferred the definitions of round one. Furthermore, the main suggestion in the second round was to broaden the scope from health care to include the whole spectrum of care, notably public health. The project group concluded that not all adjustments to the definitions were perceived as improvements, or perhaps participants were being more forward in the second round. 


\section{6 | Chapter 3}

Table 4: Tool types (22) assessed in Delphi, clustered per target group

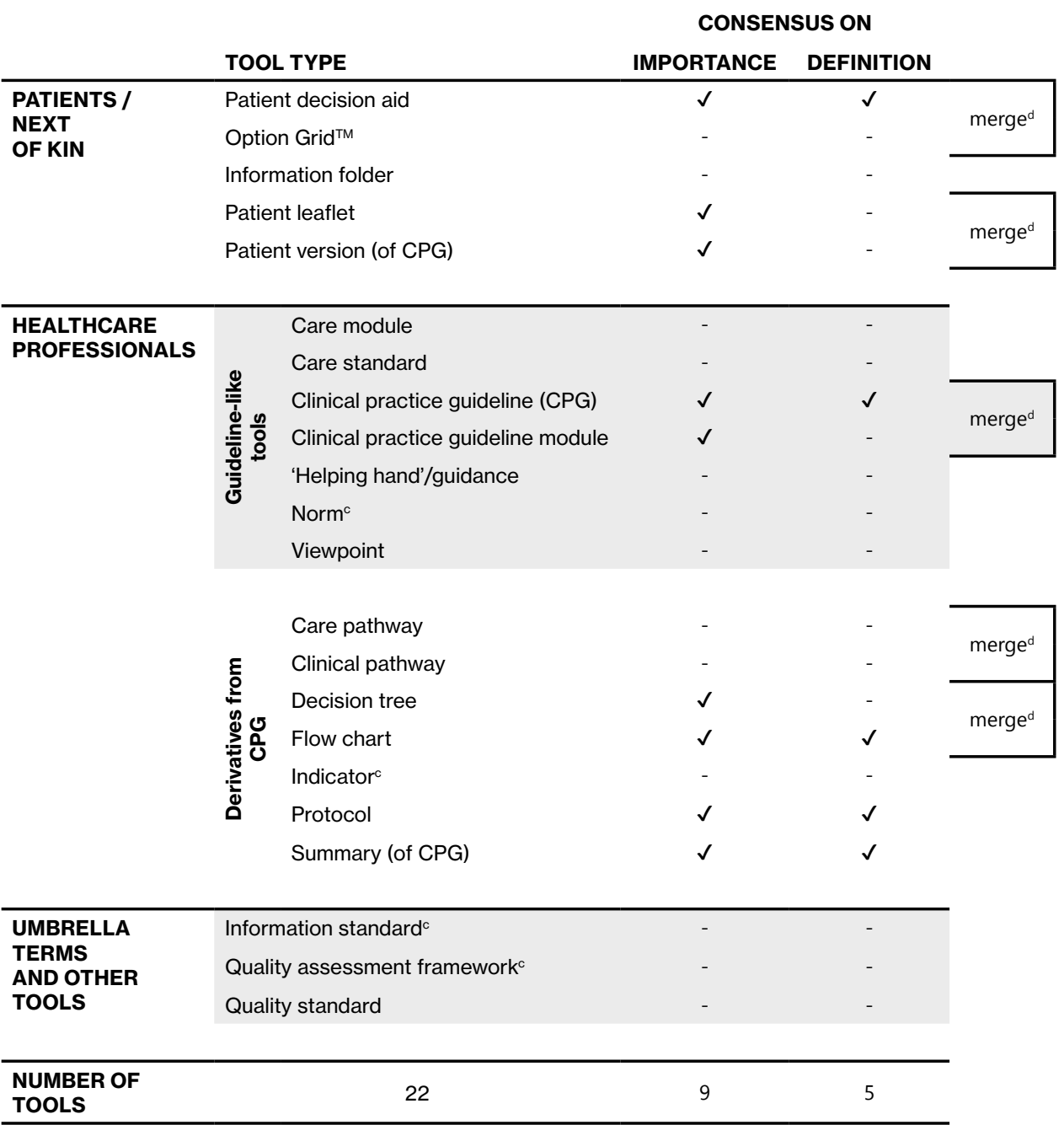

\section{Legend table 4}

$\checkmark$ Consensus in Delphi on importance or definition

- No consensus nor dissensus on importance or definition

c Tool types added by National Health Care Institute

d Tools that were merged in Delphi round 2

e This merged tool type was renamed: Patient information 


\section{Discussion}

Our study aimed to agree at a national level on a core set of knowledge tool types supporting clinicians and patients in knowledge translation and (shared) decision-making and other stakeholders in healthcare quality improvement and policy. We succeeded in reducing the number of tool types from 34 to 13. Furthermore, the experts reached consensus on the importance of nine tool types as being important to for knowledge translation and supporting (shared) decision-making. Additionally, for five tool types, the experts agreed on their definition. We also created awareness among the organisations and experts involved, encouraging them to follow-up actions. More collaboration between organisations and experts is necessary for mutual understanding and sustainability of the set of tool types agreed.

\section{Strengths and limitations of the study}

The Delphi consensus method has a number of limitations. Some issues include: the accuracy of experts' answers; time constraints; the level of detail of the input by experts; and the possible effect of the presented order of the tool types on the scoring. We think that the accuracy of the answers did not affect the outcomes too much because of the number of participants and their diverse backgrounds. The same applies to the level of detail; some experts gave more input than others, but because of the size of the group we feel that the input overall was balanced. The time to respond in the Delphi rounds was limited. As 17 experts of the original 21 also completed the second Delphi round, the effect of the time constraint might be considered as limited. To reduce the effect of the tool order, the order was reversed in the second Delphi round. Although none of the invited insurers participated in the study (they indicated that this exercise should be left to the experts), most health care domains with varying expertise were represented. We think that selection bias is limited, because the number of experts participating in the Delphi was above the required minimum of nine. There were some discrepancies between the narrative comments on tool types, which were described as unimportant but which still scored four (neutral) on the Likert scale. This issue was addressed by the project group during the analysis.

Our study is the first study that systematically evaluated the tool types available to support knowledge translation. Other studies focus on defining or assessing the quality of clinical practice guidelines (155-157), developing or validating tools (158-160), or prioritising research agendas $(161,162)$. Some organisations use A-to-Z's and glossaries but without detailed analysis and comparisons. There are also studies listing the divergent names and terms being used in health care, concluding that this hinders knowledge translation $(120,163)$. For example, Elwyn et al discern between decision and behaviour support interventions to describe the characteristics of these two categories; however, they do not address the individual tools within these categories (91).

\section{Follow-up of the study}

The Delphi has already had impact in Dutch healthcare policy and management. In June 2015, the National Health Care Institute presented the Delphi results in a meeting of the 


\section{8 | Chapter 3}

aforementioned working group, to attempt to reach consensus on the remaining tools. The group reconvened in June 2016, again discussing the tools and their interrelations. In 2018, the Federation of Medical Specialists, an umbrella organisation of 32 medical specialist societies acknowledged the importance of having a limited set of tool types and agreed on a list with five tool types and their definitions [29]. Furthermore, organisations and agencies in the mental healthcare and nursing have tried to elaborate on our work by aiming to reach agreement on care terminology used by both parties. Finally, the Dutch Federation of Patient Organisations, an umbrella organisation of more than 200 patient organisations, has endorsed the core set and started using its definitions.

\section{Conclusions and implications for practice}

For successful implementation, it is necessary that the parties involved use and stick to the core set of tool types. It requires discipline and resisting the temptation to design new tools, regardless trends in health policy (108). Imbedding clearly defined tools in knowledge translation strategies, combining them with other $\mathrm{KT}$ interventions or integrating them in the KT-cycle, might contribute to their implementation as well $(147,164,165)$. So far, organisations have made steps in using the core set and reducing the number of tool types to be funded and developed but collaboration could be improved. This is of increasing relevance as healthcare services are becoming more multidisciplinary and patients are getting more involved in policy making. A shared taxonomy at a national level and a clear governance structure with defined tasks and roles of different stakeholders within the healthcare system will help reducing confusion and duplication of efforts. In addition, formal and informal networks nationally and internationally can contribute to raise awareness and understanding. Repeating the Delphi in an international context, for instance within the Guidelines International Network, including more than 100 organisational members in 30 countries across the world, or the International Society for Evidence Based Health Care (EBHC), might be a worthwhile exercise.

As language is dynamic, and meanings and use of the tool types might change over time, the tool types and their definitions need to be reviewed periodically. The challenge is to balance between the need to keep definitions over time and to keep up-to-date with new knowledge and research findings.

\section{Acknowledgements}

- All the experts who participated in the survey and the Delphi rounds.

- Synmind, especially Fred Balhuizen and Caroline de Roos, for providing the web-based platform for the Delphi study, as well as their support and expertise.

- Arnoud van den Eerenbeemt for editing the definitions of the tools so that they were written in proper Dutch.

- Jannes van Everdingen from the NVDV Dutch Society of Dermatology and Venerology and the National Health Care Institute for his expertise and participation in the project group. 


\section{Appendix A - Scoring analysis of RAND-modified Delphi}

\begin{tabular}{|c|c|c|c|}
\hline & \multicolumn{3}{|c|}{ LIKERT SCALE SCORE } \\
\hline & $0-2$ & $3-5$ & 6-8 \\
\hline $\begin{array}{r}\text { IMPORTANCE OF } \\
\text { TOOL }\end{array}$ & unimportant & neutral & important \\
\hline \multirow[t]{3}{*}{$\begin{array}{c}\text { AGREEMENT } \\
\text { DEFINITION }\end{array}$} & disagree & neutral & agree \\
\hline & \multicolumn{3}{|c|}{$\begin{array}{c}\text { Consensus (important tool a/o agreement with definition) if: } \\
\text { median } \geq 6 \text { AND } 70 \% \text { of scores in Likert score group } 6-8 \\
\text { Consensus (unimportant tool a/o disagreement with definition) if: } \\
\text { median } \leq 2 \text { AND } 70 \% \text { of responses in Likert-score group } 0-2 \\
\text { Discussion if: } 30 \% \text { of responses in group } 0-2 \\
\text { AND } 30 \% \text { of responses in group } 6-8\end{array}$} \\
\hline & \multicolumn{3}{|c|}{ Scoring result is valid if: responses $\geq 9$ per question } \\
\hline
\end{tabular}

In the first round, the participants indicated for each tool:

- $\quad$ whether they were familiar with the tool, and, if yes, how so. If the participants were unsure, they could skip to the next tool;

- the (level of) importance of the tool in knowledge translation and/or supporting decision-making (Likert scale: 0 - not important at all; 8 - very important). If the participants scored the tool 0-2, they could skip to the next tool;

- the (level of) agreement with the definition provided for the tool (Likert scale: 0 - total disagreement; 8 total agreement).

In the second round, the first question on familiarity was omitted. 
Appendix B - Delphi scores round 2

DELPHI SCORES - ROUND 2

\begin{tabular}{|c|c|c|c|c|}
\hline \multicolumn{3}{|c|}{$\begin{array}{c}\text { Likert scores } \\
\text { Importance of tool (\%) }\end{array}$} & \multirow{2}{*}{$\frac{\frac{c}{\pi}}{\frac{\mathbb{O}}{d}}$} & \multirow{2}{*}{ 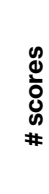 } \\
\hline $\begin{array}{c}0-2 \\
\text { unimp. }\end{array}$ & $\begin{array}{c}\text { 3-5 } \\
\text { netural }\end{array}$ & $\begin{array}{c}\text { 6-8 } \\
\text { import. }\end{array}$ & & \\
\hline 11 & 56 & 33 & 5 & 18 \\
\hline 18 & 35 & 47 & 3 & 17 \\
\hline 12 & 23 & 65 & 6 & 17 \\
\hline 22 & 50 & 28 & 5 & 18 \\
\hline 0 & 15 & 85 & 8 & 20 \\
\hline 10 & 11 & 79 & 7 & 19 \\
\hline 0 & 11 & 89 & 7 & 18 \\
\hline 0 & 0 & 100 & 8 & 19 \\
\hline 22 & 6 & 72 & 8 & 18 \\
\hline 24 & 41 & 35 & 4 & 17 \\
\hline N/A & N/A & N/A & N/A & $\mathrm{N} / \mathrm{A}$ \\
\hline $\mathrm{N} / \mathrm{A}$ & N/A & $\mathrm{N} / \mathrm{A}$ & N/A & $\mathrm{N} / \mathrm{A}$ \\
\hline N/A & N/A & N/A & N/A & $\mathrm{N} / \mathrm{A}$ \\
\hline 44 & 28 & 28 & 2 & 18 \\
\hline 22 & 28 & 50 & 5 & 18 \\
\hline 0 & 25 & 75 & 8 & 20 \\
\hline N/A & N/A & N/A & N/A & $\mathrm{N} / \mathrm{A}$ \\
\hline 0 & 6 & 94 & 8 & 18 \\
\hline 5 & 17 & 78 & 8 & 18 \\
\hline N/A & N/A & N/A & N/A & N/A \\
\hline 21 & 26 & 53 & 8 & 19 \\
\hline 0 & 11 & 89 & 8 & 19 \\
\hline 6 & 41 & 53 & 7 & 17 \\
\hline
\end{tabular}


(Continued) Appendix B - Delphi scores round 2

\begin{tabular}{|c|c|c|c|c|}
\hline \multicolumn{3}{|c|}{ Likert scores } & \multirow{2}{*}{$\begin{array}{l}\frac{5}{\pi} \\
\frac{\sqrt{\delta}}{d} \\
\text { है }\end{array}$} & \multirow{2}{*}{ 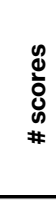 } \\
\hline $\begin{array}{c}0-2 \\
\text { disagree }\end{array}$ & $\begin{array}{c}\text { 3-5 } \\
\text { neutral }\end{array}$ & $\begin{array}{c}6-8 \\
\text { agree }\end{array}$ & & \\
\hline 5 & 58 & 37 & 4 & 19 \\
\hline 17 & 61 & 22 & 5 & 18 \\
\hline 29 & 30 & 41 & 6 & 17 \\
\hline N/A & N/A & N/A & N/A & $\mathrm{N} / \mathrm{A}$ \\
\hline 0 & 14 & 86 & 8 & 20 \\
\hline N/A & N/A & $\mathrm{N} / \mathrm{A}$ & N/A & $\mathrm{N} / \mathrm{A}$ \\
\hline 11 & 17 & 72 & 7 & 18 \\
\hline 0 & 25 & 75 & 7 & 20 \\
\hline N/A & N/A & $\mathrm{N} / \mathrm{A}$ & N/A & $\mathrm{N} / \mathrm{A}$ \\
\hline 24 & 41 & 35 & 4 & 17 \\
\hline NA & N/A & N/A & N/A & NA \\
\hline N/A & N/A & $\mathrm{N} / \mathrm{A}$ & N/A & $\mathrm{N} / \mathrm{A}$ \\
\hline N/A & N/A & N/A & N/A & $\mathrm{N} / \mathrm{A}$ \\
\hline 5 & 39 & 56 & 6 & 18 \\
\hline N/A & $\mathrm{N} / \mathrm{A}$ & $\mathrm{N} / \mathrm{A}$ & $\mathrm{N} / \mathrm{A}$ & $\mathrm{N} / \mathrm{A}$ \\
\hline N/A & N/A & N/A & N/A & $\mathrm{N} / \mathrm{A}$ \\
\hline $\mathrm{N} / \mathrm{A}$ & $\mathrm{N} / \mathrm{A}$ & N/A & $\mathrm{N} / \mathrm{A}$ & $\mathrm{N} / \mathrm{A}$ \\
\hline 16 & 42 & 42 & 7 & 19 \\
\hline 5 & 17 & 78 & 8 & 18 \\
\hline $\mathrm{N} / \mathrm{A}$ & $\mathrm{N} / \mathrm{A}$ & $\mathrm{N} / \mathrm{A}$ & N/A & $\mathrm{N} / \mathrm{A}$ \\
\hline 15 & 50 & 35 & 4 & 20 \\
\hline 0 & 26 & 74 & 8 & 19 \\
\hline 17 & 39 & 44 & 7 & 18 \\
\hline
\end{tabular}

\section{Legend Appendix B - Delphi scores round 2}

unimp. unimportant

import. important

N/A not applicable

CPG clinical practice guideline

* Tool types suggested to merge

** New name for tool type which resulted from merging two tools: patient folder and patient version

$f \quad$ Tool types eliminated after first Delphi round

bold Tool types on which there was consensus on the definition after the second Delphi round 


\section{Appendix C - Tool types for which there was consensus on the definition}

\section{TOOL TYPE}

Clinical practice guideline (merged with clinical practice guideline module)

Flow chart

(merged with decision tree)

Patient decision aid (patient support tool)

Summary

(of guideline / quality standard)

Protocol

\section{DEFINITION}

Recommendations for a specific (health)care issue based on 1) a systematic summary of scientific research, 2) considerations of the advantages and disadvantages of various care options and 3) the knowledge and experiences of patients and providers; supports decision-making in the care process and is aimed at safeguarding and improving the quality of life and care

Logically structured visualisation of possibilities in a (health)care issue with associated outcomes, opportunities, risks and decision points; offers care providers and patients insight into the relevant care policies and supports decision making

Supporting information and answers to frequently asked questions for patients when choosing, with their care providers, from different options - including the option to forgo care - in areas such as diagnostics, treatment, screening, counselling and aftercare; discusses the possible outcomes and effects of each option - desirable or otherwise - their likelihood to occur; helps patients weigh up their options based on their own values, standards and personal circumstances

Instruction derived from a guideline, indicating how care providers should act in daily practice, within the restraints of specific local circumstances

Concise overview of the guideline providing main conclusions and recommendations in clear and simple language; can be applied in practice independently from the guideline; intended for both care providers and patients

Dutch definitions (NB these were not included in the article)

\section{TYPE KENNISINSTRUMENT}

Beslisboom

Kwaliteitsstandaard

Patiënten/cliënteninformatie

Keuzehulp(middel)

\section{DEFINITIE}

schematische weergave van mogelijkheden bij een zorgvraag/-taak en daarmee samenhangende uitkomsten, kansen, risico's en beslissingen, het geheel logisch geordend; biedt zorgverleners en zorggebruikers inzicht in het probleemgerelateerde zorgbeleid en helpt hen hierbij keuzes te maken

ondersteunende informatie voor zorggebruikers bij het kiezen, samen met zorgverleners, uit verschillende opties (inclusief afzien van zorg) voor onder meer diagnostiek, behandeling, screening, begeleiding en nazorg; behandelt bij elke optie het mogelijke resultaat en (on)gewenste effecten en de waarschijnlijkheid hiervan; helpt zorggebruikers een afweging te maken op basis van eigen waarden en normen en voorts de mogelijkheden en veelgestelde vragen

beschrijving van goede zorg voor een specifiek gezondheidsgerelateerd thema volgens de criteria van het toetsingskader; verbetert en waarborgt de kwaliteit van zorg en van leven; is bestemd voor zorgverleners en/of zorggebruikers

uitleg over een specifieke aandoening of zorgvraag/-taak op basis van een kwaliteitsstandaard; wordt beschikbaar gesteld aan zorggebruikers en hun naasten; biedt informatie over beschikbare zorgkeuzes en over wat zorggebruikers van het zorgproces kunnen verwachten

van een kwaliteitsstandaard afgeleide instructie die zorgverleners aangeeft hoe in de dagelijkse praktijk te handelen met inachtneming van de plaatselijke mogelijkheden en beperkingen 
Richtlijn

Samenvatting

Standpunt

Zorgmodule

Zorgpad

Zorgstandaard aanbevelingen voor een specifieke zorgvraag/-taak die is gebaseerd op 1) een systematische samenvatting van wetenschappelijk onderzoek, 2) afwegingen van voor- en nadelen van de verschillende zorgopties en 3) (vak)kennis en ervaringen van zorgverleners en zorggebruikers; is opgebouwd uit modules, die afzonderlijk in verscheidene richtlijnen kunnen worden ingepast; ondersteunt de besluitvorming in het zorgproces en is gericht op het veiligstellen en verbeteren van de kwaliteit van zorg en leven

beknopt overzicht van de kwaliteitsstandaard in de vorm van de belangrijkste conclusies en aanbevelingen in begrijpelijke taal; is onafhankelijk van de kwaliteitsstandaard in de praktijk toe te passen; bestemd voor zorgverleners en tevens zorggebruikers

omgangsregels voor een actuele en/of delicate zorgvraag/-taak; is ad hoc en versneld opgesteld door een beroepsvereniging of wetenschappelijke vereniging in samenwerking met zorggebruikers; geeft richting aan zorgverleners en zorggebruikers wanneer een richtlijn nog ontbreekt

beschrijving van een onderdeel van zorg dat relevant is voor meerdere zorgproblemen; kan onderdeel vormen van meerdere zorgstandaarden; uniformeert ziekteoverstijgende zorg in relevante zorgstandaarden

op een kwaliteitsstandaard gebaseerde beschrijving van de gemeenschappelijke besluitvorming over de zorg die een zorggebruiker met een specifieke zorgvraag/-behoefte doorloopt; bestemd voor zorgverleners; beoogt optimale zorg, afgestemd op de noden van de specifieke zorggebruiker

beschrijving van de organisatie van (multidisciplinaire) zorg, inclusief preventie, bij een specifieke zorgvraag/-taak; is gebaseerd op wetenschappelijk onderbouwde actuele inzichten; is zo mogelijk functioneel en opgesteld vanuit perspectief van de zorggebruiker; behandelt in het bijzonder ondersteuning bij zelfmanagement; kan prestatie-indicatoren omvatten

\section{Kennisinstrumenten wel voorgelegd maar bij prioritering $2^{\mathrm{e}}$ ronde afgevallen omdat het geen kennisinstrumenten zijn (dan wel de zorgverlener e/o zorggebruiker ondersteunen bij de zorginhoudelijke besluitvorming)}

Indicator

Informatiestandaard

Norm meetbare factor van zorgverlening, veelal uitgedrukt in een teller (waarde) en een noemer (eenheid); heeft signalerende rol bij geleverde zorg, het zorgproces en/of de uitkomsten hiervan; maakt kwaliteit van zorg meetbaar en inzichtelijk; sets van indicatoren bieden keuzeinformatie aan patiënten/cliënten en bieden voorts aan zorgverleners terugkoppeling (feedback) over verleende zorg

deel van de kwaliteitsstandaard dat beschrijft welke brongegevens bij uitvoering van zorg worden vastgelegd en uitgewisseld tussen welke zorgverleners op basis van geaccepteerde codestelsels; dient voor overdracht van eenduidige en betrouwbare informatie tussen zorgverleners en patiënten/cliënten en verbetert de samenwerking in het zorgproces

overeengekomen voorwaarde waaraan zorg moet voldoen voor behoud en/of bevordering van zorgkwaliteit, eenduidigheid van zorg en inzichtelijkheid (transparantie) van zorgkwaliteit 


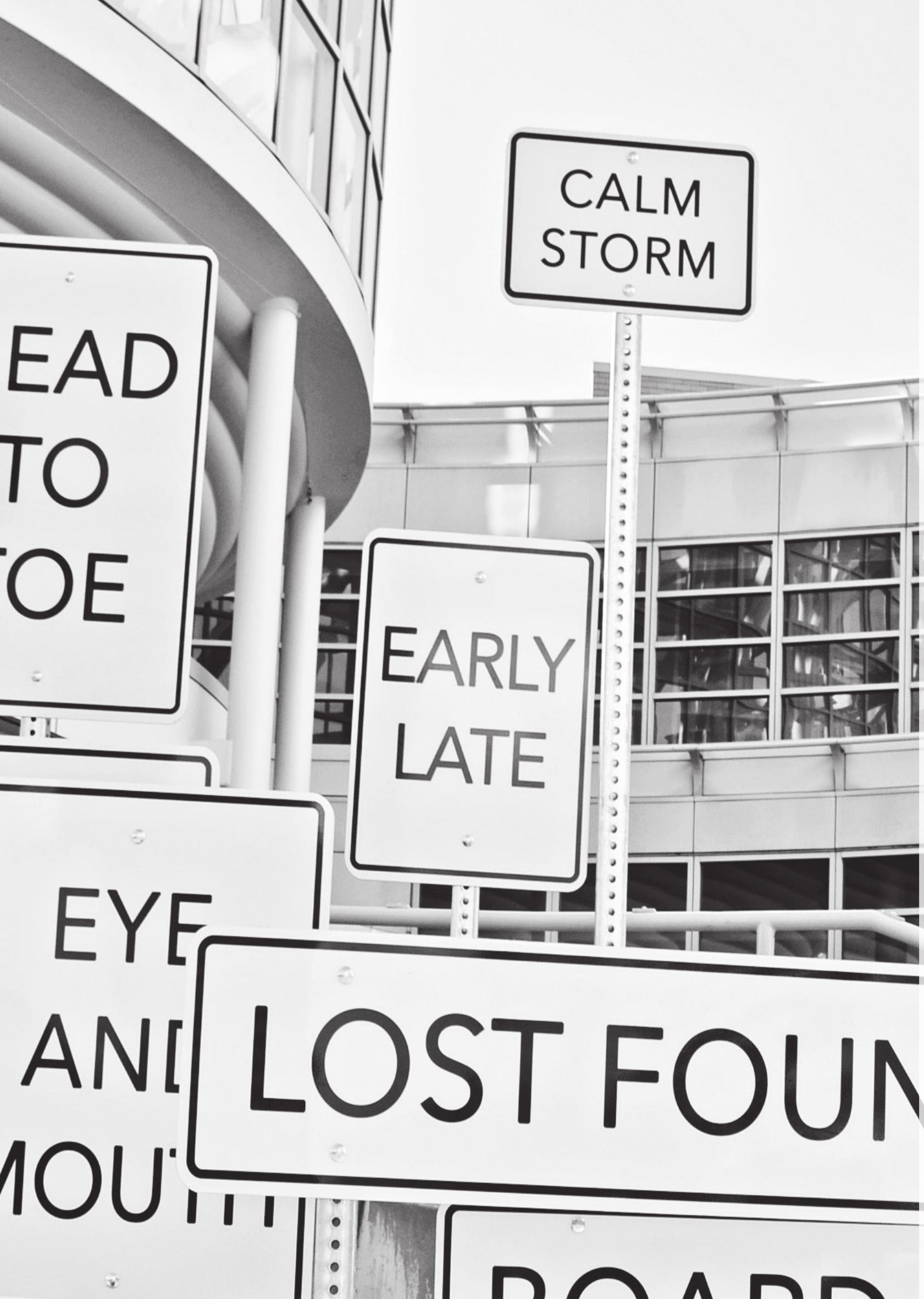




\section{Chapter 4}

\section{A conceptual framework for patient-directed knowledge tools to support patient- centred care: results from an}

evidence-informed consensus meeting

Dunja Dreesens, Anne Stiggelbout, Thomas Agoritsas, Glyn Elwyn, Signe Flottorp, Jeremy Grimshaw, Leontien Kremer, Nancy Santesso, Dawn Stacey, Shaun Treweek, Melissa Armstrong, Anna Gagliardi, Sophie Hill, France Légaré, Rebecca Ryan,

Per Vandvik, Trudy van der Weijden 


\section{6 | Chapter 4}

\section{Abstract}

\section{Objective}

Patient-directed knowledge tools are designed to engage patients in dialogue or deliberation, to support patient decision-making or self-care of chronic conditions. However, an abundance of these exists. The tools themselves and their purposes are not always clearly defined; creating challenges for developers and users (professionals, patients). The study's aim was to develop a conceptual framework of patient-directed knowledge tool types.

\section{Methods}

A face-to-face evidence-informed consensus meeting with 15 international experts. After the meeting, the framework went through two rounds of feedback before informal consensus was reached.

\section{Results}

A conceptual framework containing five patient-directed knowledge tool types was developed. The first part of the framework describes the tools' purposes and the second focuses on the tools' core elements.

\section{Conclusion}

The framework provides clarity on which types of patient-directed tool types exist, the purposes they serve, and which core elements they prototypically include. It is a working framework and will require further refinement as the area develops, alongside validation with a broader group of stakeholders.

\section{Practice implications}

The framework assists developers and users to know which type a tool belongs, its purpose and core elements, helping them to develop and use the right tool for the right job.

\section{Keywords}

Framework; knowledge; tools; (shared) decision-making; patient education; communication 


\section{Introduction}

In 1996, Sackett et al described evidence-based medicine as integrating "the best external evidence with individual clinical expertise and patients' choice", and Charles et al tried in 1997 to define shared (treatment) decision-making $(26,166)$. Both heralded the more formal recognition of patient engagement. The WHO defines patient engagement as the capacity of patients, families, carers, as well as healthcare providers, to facilitate and support the active involvement of patients in their own care, in order to enhance safety, quality and people-centredness of healthcare service delivery (167).

In the past, patient engagement might have been primarily a moral-ethical imperative (168), but this engagement is also associated with numerous beneficial outcomes such as improved knowledge, satisfaction and self-management and reduced decisional conflict (169-173). Moreover, involving the patient is important because physicians may recommend treatments that they would not have chosen themselves (174), and physicians are mostly not adept at predicting what their patients want $(32,63)$. These and other reasons to engage patients in decisions about care have led to the development of a range of knowledge tools $(175,176)$.

Overall, there exists an abundance of tool types to engage patients in decision-making and contribute to patient-centred care. Examples of knowledge tools are clinical practice guidelines (CPG), protocols, patient decision aids (PDAs) and patient education materials (143, 177179). Knowledge tools distil and synthesize the highest quality knowledge and research (95). Patient-directed knowledge tools are aimed directly at the patient (family members and carers), with the goal to engage patients in dialogue or deliberation during a clinical encounter, or to support and/or improve patient decision-making which may or may not take place during a clinical encounter (175). The ultimate goal is to contribute to safer and higher quality healthcare. However, these types of tools are frequently ill defined $(70,88,143,178)$. Moreover, lack of clarity on development, content, and purpose has likely contributed to poor uptake $(8,47,145$, 180).

Several streams of work have contributed to the development of this area. These include development of specific quality criteria for certain tools (such as PDAs, leading to IPDAS, the International Patient Decision Aid Standards) (181-184) as well as frameworks and taxonomies on patient involvement. The purpose of IPDAS is to enhance the quality and effectiveness of PDAs by establishing a shared evidence-informed framework $(59,60,185)$. IPDAS does not consider other patient-directed knowledge tools. Several frameworks related to decision support tools have been developed (186). O'Connor et al developed a decision support framework to develop a specific PDA, concentrating on determinants of decisions leading to the Ottawa Decision Support Framework $(187,188)$. Another example is a taxonomy of outcomes developed by the Cochrane Consumers \& Communication Group (CCCG) which can be used by researchers and others to conceptually map the range of outcomes, at different levels of health care, that might be relevant when assessing different forms of communication (such as shared decision making) (189). 


\section{8 | Chapter 4}

Existing frameworks tend to focus on PDAs, and the CCCG taxonomy has a far broader scope than just patient-directed knowledge tools. The aim of our study was therefore, building on existing work, to develop a conceptual framework of patient-directed knowledge tools (190). Our objective was to create a framework that would identify existing patient-directed tool types, allow organisation of these types of tools by their purpose(s) and describe their core elements. The framework is intended primarily for tool developers, and possibly also for those who commission the development of tools, healthcare professionals and policy makers. It should help developers to identify where there is a gap or need for a tool to be developed, and how such a tool may best make information, knowledge and decision support available to patients (144).

\section{Methods}

We used a two-day consensus meeting with international experts. We are not aware of standards for reporting a consensus-based meeting. Instead, we followed the Standards for Reporting Qualitative Research (SRQR) as closely as possible, when writing the manuscript (191).

To arrive at a conceptual framework of patient-directed knowledge tool types to engage patients and support patient decision-making within a short time frame, the initiators (TVDW, DD) and chair (JG) decided that a two-day, face-to-face meeting with experts was the most optimal design. We followed a consensus-based process based on a written meeting protocol (see annex A) (192-194). The meeting was audio-recorded, DD took minutes. JG and TVDW made field notes. The meeting took place in February 2016, in Leiden, the Netherlands.

The participants were purposefully sampled from the Guideline International Network (GIN), International Shared Decision Making network (ISDM) and the professional networks of the initiators. The participants worked in different domains of knowledge (transfer), implementation and decision support, e.g. as tool developers, implementers or implementation researchers, decision-making researchers, or practitioners. The aim was to have representation from a range of countries, individuals with various professional backgrounds, and patients (see Annex B). There were two groups of participants; those who participated face-to-face in the group meeting and those who joined remotely for the conference call with the large group, or via e-mail.

During the preparatory phase the participants received a list with relevant literature (see Annex C). This list included participants' key articles - suggested by TVDW - and its aim was to achieve a common ground between the participants. They also received a list with possible knowledge tool types to be discussed (see annex D). The list was the result of a scoping review undertaken by initiator $D D$. The meeting protocol was also shared with the participants in this phase (see Annex A) (195). The experts were asked to add missing literature, review the proposed tools and comment on the protocol. If the experts had queries on the provided tools, DD and TVDW provided information to clarify these issues, copying all participants. The meeting consisted of nine steps (see Table 1). In step 1, the face-to-face participant 
group discussed and came to agreement on the scope of the meeting, and the intended final product(s). In step 2, they discussed the list with tool types (Annex D) to ensure that all participants present in the face-to-face meeting were familiar with the tools and their definitions, and, if not, described the tool, and verified that the list was complete. After agreeing on the scope and the tool list, the participants broke up into two groups to sort the tools: which ones to be included in the framework and which ones not, using the definition of the patient-directed knowledge tool (step 3). The two groups presented and discussed each other's findings, and agreed on a list of preliminary tools to be included. Based on this list, the two groups independently identified purposes of the tools, taking the discussed and agreed upon definitions from step 2 into account (step 4). The outcomes of both groups were presented and discussed. This resulted in a first draft of the framework stating the preliminary included tools and their purposes. In step 5, the participants were split up in the two same groups, and were asked using their research and practice knowledge - to identify core elements of the included tools. Once more, the findings of both groups were presented, discussed, and categorised leading to the second draft of the framework stating tool types, purposes and core elements.

Dividing the participants into two groups facilitated involving all participants, and avoiding any individual dominating the group. When there was disagreement the participants discussed the issue until consensus was reached.

The next step involved compiling the discussions and findings during a longer break and sent via email - together with the second draft of the framework - to participants taking part via a telephone conference at the end of day 1 . The first day's discussions and findings were presented by DD to the participants calling in, and the other participants in the room. The former participants were given the opportunity to ask clarifying questions, and propose/suggest additional tools, purposes, and core elements (step 6). The draft framework was adapted with the input of the remote participants. A summary of the discussions and findings, together with the latest draft framework, were sent via email to participants SH and RR in Australia who could not participate in the teleconference. They would add their knowledge and input during the night (step 7), so that it could be discussed during day 2 of the meeting.

Day 2 was dedicated to fine-tuning the draft framework. Therefore, in step 8 the chair (JG) reviewed the possible tools and purposes with the participants to ensure that these were correct and complete, and if all agreed, confirming the purpose(s) for each tool. This exercise was repeated for the core elements (step 9). These steps resulted in the final draft of the framework as developed during the meeting. 


\section{0 | Chapter 4}

Table 1: Step-by-step process during two-day consensus meeting

\begin{tabular}{|c|c|c|}
\hline STEP & WHAT & WHO \\
\hline 1 & Discussed and agreed on the scope. & Participants in face-to-face meeting \\
\hline 2 & $\begin{array}{l}\text { Discussed the list with tool types to familiarize with the tools } \\
\text { and their definitions, and if the list was complete. }\end{array}$ & Participants in face-to-face meeting \\
\hline 3 & $\begin{array}{l}\text { Including and excluding tools for the framework in subgroups; } \\
\text { outcomes presented and discussed with whole group. }\end{array}$ & Participants in face-to-face meeting \\
\hline 4 & $\begin{array}{l}\text { Identified purposes of the tools in subgroups; discussed } \\
\text { outcomes presented and discussed with whole group. }\end{array}$ & Participants in face-to-face meeting \\
\hline 5 & Identified core elements of the included tools. & Participants in face-to-face meeting \\
\hline \multicolumn{3}{|c|}{ - FIRST DRAFT OF CONCEPTUAL FRAMEWORK READY } \\
\hline 6 & $\begin{array}{l}\text { Presented and discussed draft framework; additional tools, } \\
\text { purposes, and core elements suggested. }\end{array}$ & Teleconference participants \\
\hline \multicolumn{3}{|c|}{ - SECOND DRAFT OF CONCEPTUAL FRAMEWORK READY } \\
\hline 7 & Received input on draft framework via email. & Australian participants \\
\hline 8 & $\begin{array}{l}\text { Fine-tuning: reviewed \& confirmed the possible tool types and } \\
\text { purposes to ensure that these were correct and complete. }\end{array}$ & Participants in face-to-face meeting \\
\hline 9 & $\begin{array}{l}\text { Fine-tuning: reviewed \& confirmed the core elements to } \\
\text { ensure that these were correct and complete. }\end{array}$ & Participants in face-to-face meeting \\
\hline \multicolumn{3}{|c|}{ - FINAL DRAFT OF THE FRAMEWORK AS DEVELOPED DURING THE MEETING } \\
\hline
\end{tabular}

TVDW and DD finalized the draft framework based on the minutes, field notes and recorded data. This also entailed comparing the draft framework with existing frameworks and taxonomies. The comparison was done for two reasons: first, to compare language and terminology used, and second, to establish where the frameworks differed or were alike.

The draft framework was distributed in the form of a scientific manuscript to the participants for final feedback. It took one face-to-face session between DD and JG and two rounds by email with all co-authors before consensus was reached on the draft framework.

All participants completed a declaration of interests. The initiators and chair proposed how to deal with the declared interests. This was discussed and decided upon at the start of the meeting. The plenary parts of the meeting were audio-recorded and DD took minutes during both days. Furthermore, DD and TVDW compared the minutes and field notes, and adjusted the former if needed. The adjusted minutes - checked against the recorded data - were shared afterwards with the participants for comments.

\section{Results}

The actual meeting was not as linear as described in the meeting protocol and methods section. It turned out to be an iterative process where discussions on tools and purposes lead to core elements and vice versa, but also prompting new or dismissed tool types to be (re-) included.

Meeting participants included the moderator (TVDW), secretary (DD), and 15 experts; nine participants attended in person (JG (chair), TA, GE, SF, LK, NS, DS, AS, ST), and four (MA, AG, $\mathrm{FL}, \mathrm{PV})$ additionally took part in the teleconference. Two participants $(\mathrm{SH}, \mathrm{RR})$ took part via 
email (see annex B). All participants took part in the iterative discussions by email afterwards to finalise the manuscript with the draft framework.

Step 1 was to select the tool types to be used when building the framework. Inclusion criteria were:

- Main target group are patients (family, care givers);

- Content driven instead of process oriented;

- Tool type globally known and used;

- Fits within the definition of the patient-directed knowledge tool.

Based on the outcomes of the subgroups and decisions on these with all participants, we excluded seven tool types (not aimed directly at the patient) from the original list of 11 and added one tool perceived to be aimed at the patient directly but not on the list provided (see Table 2). While discussing the selection with the whole group, we decided to split PDAs into an encounter patient decision aid (ePDA) and an 'independent' PDA, leading to six tools. This distinction is important because the patients will use the former while talking with a healthcare professional and the latter independently, pre- or post-encounter. Tools such as action plans and decision guides were excluded because they concentrate on 'how' (process), and less on 'what' (knowledge). Decision coaching tools were deemed out of scope as well because these are aimed at the patient's coach, rather than primarily at the patient. During the telephone conference two tool types - question prompt list and decision box - were added because they support involving the patient in the care process, leading to a total of eight tools (see Table 2 and Annexes $F$ and $D$ ).

Table 2: overview of preliminary included and excluded tool types during face-to-face meeting and teleconference

\begin{tabular}{lll}
$\#$ & TOOL TYPE & INCLUDED, EXCLUDED AND REMARKS \\
\hline 1 & Decision tree & Preliminary included from list during face-to-face meeting \\
2 & Summary of clinical practice guideline & Preliminary included from list during face-to-face meeting \\
& Patient decision aid (PDA), split into: & Preliminary included from list during face-to-face meeting \\
3 & - Encounter patient decision aid (ePDA) & \\
4 & - Independent patient decision aid (PDA) & \\
5 & Patient information & Preliminary included during face-to-face meeting \\
6 & Care map & Added during face-to-face meeting and preliminary included \\
7 & Decision box & Added during teleconference and preliminary included \\
8 & Question prompt list & Added during teleconference and preliminary included \\
& Action plan & Added during face-to-face meeting, excluded \\
& Decision guide & Added during face-to-face meeting, excluded \\
Care pathway & Excluded from list \\
Quality standard & Excluded from list \\
Care standard & Excluded from list \\
Care module & Excluded from list \\
& & Excluded from list
\end{tabular}


From the preliminarily included tools, we deduced and described the possible purpose(s) of the tools. The purpose to inform patients was combined with 'to educate patients', because the emphasis was to make patients knowledgeable. Another reason to extend the purpose was that informing and educating are often used interchangeably. We made a distinction between the purpose supporting decision-making, and that of engaging in shared decision-making. Even though tools can support decision-making by patient and professional, this does not necessarily mean that the tool also promotes shared decision-making. In the end, the listed possible purposes were aggregated into four purposes (see Table 3):

- Inform or educate;

- Provide recommendation(s);

- Support decision-making;

- Engage in shared decision-making.

When discussing possible purposes, alleviating fear(s), and decreasing decisional conflict were mentioned as well. The participants concluded they were outcomes, and were therefore not listed as a purpose. Communication was not included as a purpose as well. To engage patients, or exchange knowledge/information with a patient, as a healthcare professional, you need to communicate (verbally and non-verbally) with the patient. It is an overarching means, not a purpose in itself.

The next step was to identify core elements of the included patient-directed knowledge tool types. The participants compared the tool types, identified recurring elements within tool types and between tools. Furthermore, based on existing frameworks and taxonomies they determined which elements should be included in a tool type (prototypical), even though existing examples of those tool types may not include these elements. Mentioned elements were for example, (link to) evidence, background on condition, care or treatment options/ alternatives, burden (and evidence thereof), relative importance of outcomes as different patients may weigh importance of outcomes differently (196). Also, possible effects of the tools, such as improving the knowledge of the patient, improving patient's expectations of the treatment, impact on their health and quality of life, improving patient-provider communication, and changes in decision-making behaviour) were discussed as possible purposes. Whilst discussing the elements, explicit mentioning of harms and benefits of treatment/care in the tools was stressed by the participants. Harms were especially emphasised as these are often not mentioned or mentioned less often than benefits $(69,197,198)$. At the end, the core elements were put into preliminary categories.

When discussing the framework, the purposes, and core elements of the tool types, several issues surfaced. First, at the beginning of the meeting, one participant stated that the patient-directed knowledge tools are preferably based on trustworthy clinical practice guidelines. However, there appears to be a pivotal point between PDAs and CPGs: the element 'recommendation'. A CPG centres on recommendations, meaning that the healthcare 
professional needs to 'translate' it together with the patient to the patient characteristics and preferences (199), whereas decision aids aim to acquaint patients with information about choices and available options, including watchful monitoring. Of late, clinical practice guidelines (recommendations) are created or re-written to include these elements as well, but it is not a common practice yet $(180,200,201)$.

As one of the participants involved in the meeting noted: "Looking through a future lens and decision making view: [there will be] a set of guidelines that don't [provide room for contemplation], and 'innovator' guidelines that do list options." [quote on reconciling clinical practical guidelines and shared decision-making] (202)

Furthermore, some participants argued using other sources than CPGs as a basis for patientdirected knowledge tools, such as evidence summaries or systematic reviews, and questioned how to include qualitative data in the evidence base (203).

We also discussed whether the framework should be discretionary or prototypical. Discretionary meaning that the core elements mentioned in the framework are optional; and prototypical indicating that we should aim to include the core elements listed in the framework in patient-directed knowledge tools. For example, current tools mostly disregard core elements such as harms and the need to elicit patient's values (204). Often only one option is stated, instead of giving a complete overview of options, including watchful waiting when relevant (69). We decided that it would be a descriptive and prototypical framework. This decision resulted in one participant to say: "We are wasting time on patient education material without options; we need to be bold." [quote on importance of a prototypical framework]

Finalizing the draft framework entailed checking and rewriting the wording used in the framework, and reorganizing the core element categories $(171,205-207)$. The category 'outcomes', which refers to the effect(s) of the tools, was not included in the framework. Possible effects proposed and discussed during the meeting were: improved knowledge acquisition by the patient, more realistic or informed expectations, decreased decision burden/ stress or less regret. As most of these outcomes have not been confirmed by research (yet), we felt it premature to include this category in the framework (208).

The draft framework at the end of the meeting contained eight tools (see table 2), of which two - 'care map' and 'decision box' - were conditionally included as we were not entirely sure if they were patient-directed knowledge tools. The framework in the article contains five tool types, because when looking further into the tools 'question prompt list' and 'decision box', we decided that these tools belong to the tool type 'encounter PDAs, and they were therefore removed from the framework as separate tool types. The tool type 'care map' was left out as well, as they are also called 'care pathways' $(70,143,178)$, and we excluded the latter at the beginning of the meeting. It was also suggested in the feedback rounds via email to leave out the tool 'decision tree'. Due to renewed attention to this tool type - e.g. digitalising CPGs into decision trees to enhance use by healthcare professionals and patients $(107,209,210)$, and because the tool was not included conditionally, it is still part of the draft framework.

The final draft of the framework contains five patient-directed tool types, and consists of two 


\section{4 | Chapter 4}

parts: one stating the four purposes of the tools (see Table 3) and the other the core elements (see Table 3).

Table 3: Draft framework part 1: purposes of patient directed knowledge tools

\begin{tabular}{|c|c|c|c|c|c|c|}
\hline & \multicolumn{5}{|c|}{$\begin{array}{c}\text { PATIENT-DIRECTED } \\
\text { KNOWLEDGE TOOL TYPES }\end{array}$} \\
\hline & & 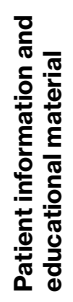 & 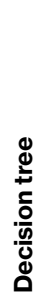 & 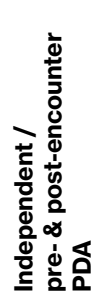 & 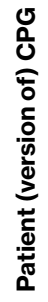 & 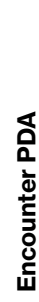 \\
\hline \multirow[t]{4}{*}{$\begin{array}{l}\text { 山ू } \\
\text { О } \\
\frac{0}{\alpha} \\
\frac{\alpha}{\alpha}\end{array}$} & $\begin{array}{l}\text { To inform or to educate } \\
\text { provide information on the disease/complaint; what its } \\
\text { treatment/care options are; how it can affect the patient's } \\
\text { life; what the patient can do herself/himself to cope/deal } \\
\text { with the disease/complaint and what are the expected } \\
\text { harms and benefits of treatment. }\end{array}$ & + & & + & + & + \\
\hline & $\begin{array}{l}\text { To provide recommendation(s) } \\
\text { summarize evidence \& provides recommendation(s) - e.g. } \\
\text { stemming from guidelines - regarding care option(s). }\end{array}$ & & + & & + & \\
\hline & $\begin{array}{l}\text { To support decision-making } \\
\text { (and not decision making together with a healthcare } \\
\text { professional): provide information on option(s) (including } \\
\text { doing nothing, watchful waiting); harms and benefits, risks } \\
\text { thereof; elicit values, preferences and contemplation so } \\
\text { that patients can choose the treatment/care or option that } \\
\text { suits best. Possibly indicate which \% of patients in a similar } \\
\text { situation chose which option. }\end{array}$ & & + & + & + & + \\
\hline & $\begin{array}{l}\text { To engage in SDM } \\
\text { invite, stimulate or instruct the patient to } \\
\text { decide together with healthcare provider on } \\
\text { treatment/care. }\end{array}$ & & & & & + \\
\hline
\end{tabular}

\section{Legend of table 3:}

$+\quad$ knowledge tool serves purpose

$\checkmark$ necessary

+ - possibly

O Not typical

P Present

? Not known (yet)

$1 \mathrm{P}$ (in Netherlands only)

$2 \mathrm{P}$ (in USA only)
Abbreviations:

CPG clinical practice guideline

PDA patient decision aid

DM decision making

SDM shared decision making

GRADE grading of recommendations assessment, development and evaluation 
(Continued) Table 3: Draft framework part 1: purposes of patient directed knowledge tools

\section{CONTENT ELEMENTS}

Information on disease, illness

Eligibility information (describing the target group of the tool)

Treatment \& care options identified (including wait and see)

Features of each option (e.g. practical issues, process, burden, cost, harms and benefits of these options)

Possible benefits harms of these options

Explicit decision(s) identified

Personalizing features

Values implicitly clarified

Values explicitly clarified

Explicit recommendations

DM process guidance
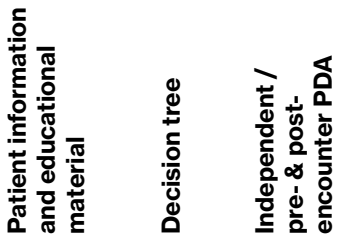

$\begin{array}{lllll}+/- & ? & \checkmark & +/- & \checkmark \checkmark\end{array}$

$\begin{array}{llllll}+/- & ? & \checkmark & +/- & \checkmark\end{array}$

$\begin{array}{llllll}0 & \checkmark & \checkmark & + & & \end{array}$

$\begin{array}{lllll}0 & \checkmark & + & 0 & +\end{array}$

$+/-\quad+/-\quad \mathrm{N} \quad+/$

$\begin{array}{lllll}\mathrm{O} & \mathrm{O}+/- & & +\end{array}$

$\begin{array}{lllll}0 & \checkmark & 0 & \checkmark & 0\end{array}$

$\begin{array}{lllll} & & \checkmark & + & \end{array}$

\section{QUALITY ELEMENTS}

Link to evidence explicit

Grading of evidence described, e.g. GRADE

Date stamp

Certification process / trustworthy source

Stating developers' conflicts of interests (or where to find these)

Available in clearing house, register

$\begin{array}{ccccc}+/- & +/-1 & \checkmark & \checkmark & \checkmark \\ 0 & 0 & +/- & +/- & +/- \\ \checkmark & \checkmark & \checkmark & \checkmark & \checkmark \\ 0 & 0 & \mathrm{P}^{2} & 0 & \mathrm{P}^{1} \\ \checkmark & \checkmark & \checkmark & \checkmark & \checkmark \\ 0 & 0 & \checkmark & +/- & \checkmark\end{array}$

USE / TIMING OF TOOL

\begin{tabular}{|c|c|c|c|c|c|}
\hline Independent of consult & $+/-$ & $\mathrm{O}$ & $+/-$ & $+/-$ & $\mathrm{O}$ \\
\hline Pre-consult & $\checkmark$ & $+/-$ & $\checkmark$ & $\checkmark$ & $+/-$ \\
\hline During consult & $\mathrm{O}$ & $+/-$ & $+/-$ & $\mathrm{O}$ & $\checkmark$ \\
\hline Post-consult & $+/-$ & $\mathrm{O}$ & $+/-$ & $+/-$ & $+/-$ \\
\hline
\end{tabular}




\section{6 | Chapter 4}

\section{Discussion}

We developed a working (or draft) framework containing five patient-directed knowledge tool types describing the purposes and (prototypical) core elements of these tools. There already exist other related frameworks; however, these tend to focus on patient decision aids. At the other end of the spectrum, the CCCG taxonomy takes a far broader view, incorporating all interventions for communication without a specific focus on knowledge tools, and without delineating the core elements of the interventions $(59,60,205,211)$.

\section{Conclusions}

As there exists an abundance of different patient-directed knowledge tools, with different names and mostly unclear definitions, our working framework can help tool developers, people who commission the development of these tools, policy makers, patients and healthcare professionals to discern between the different tools, and to identify to which tool type it belongs, which purposes it serves and which core elements it should contain. Possibly, when there is more clarity on development, content and purpose of the tool, it may lead to a better understanding of the roles of, and uptake of, the tool. We feel that the field of tools development and implementation might profit from initiatives such as this one; it might provide the sought for direction.

Regarding the discussion whether to use only CPGs as basis for patient-directed knowledge tools, such as ePDAs, the group discussed the benefits of harmonizing evidence summaries across these tools, also within the context of updating content. Such CPGs and accompanying PDAs have been developed, for example within the MAGIC-project, providing proof of concept for this approach $(144,165,201)$.

New (types of) tools will emerge. We can use these to test our working framework by assessing if the new tool fits within the current types, whether it requires adding a new tool type, additional purposes or core elements to the framework, or if it is a different type of tool not belonging within the framework.

Next steps are to review the framework thoroughly with a broader group of stakeholders, including patients and other users. Working with the framework will demonstrate if it is helpful and complete regarding tool types, purposes, and core elements. For example, it may be helpful to discuss whether or not merging the last two purposes ('support SDM' and 'engage in shared decision-making') which would be a useful revision to the framework. A first cautious check of the framework took place at the International Shared Decision Making (ISDM) Conference, Lyon, in 2017 (212), meeting general agreement and receiving no major comments with respect to content. The framework, a work in progress, could be further enhanced by identifying which effect outcomes of the tools are supported by evidence, and describing the core elements in more detail. Additionally, it is important to consider the implementation and use of these tools, for instance by exploring what skills or support patients need to be able to use them (213). 
A potential weakness was the extent to which the participants are involved in this subject. We tried to counteract this by having a group consisting of participants with different expertise and from various backgrounds, and by providing descriptions of the discussed tools before the meeting. Also, the group was limited in its size. Therefore, the framework was not presented as finished but as a draft framework. Another risk of the group composition and size could be that it obscured tools as not being within scope. There were no patient representatives present during the face-to-face meeting; however, two participants (SH and RR) with extensive experience in health consumer participation and patient-centred care commented and added to the work of the group at the end of day 1. Having (most of) the participants together for a prolonged time in one room, contributed to enhanced participation, open discussions and the liberty to ask each other questions, making it possible to respond to non-verbal communication, and leading to a first draft of the conceptual framework.

\section{Implications for practice}

Our working framework on different types of patient-directed knowledge tools is aimed at developers, and possibly at those who commission the development of tools, healthcare professionals and policy makers, and hopefully adds to clarity on the different knowledge tools by stating the purpose(s) they serve and which core elements they should include. The ambition is that tool types are no longer developed without a clear definition and use. This framework will make it easier for developers to identify when to develop which patient-directed knowledge tool and what core elements to include, and to help patients and professionals to understand when to use which tool type. 
Annex A-Meeting protocol

POW(W) - PURPOSE, OUTCOME, WHY - OF MEETING

\begin{tabular}{|c|c|c|}
\hline Purpose & $\begin{array}{l}\text { Statement of meeting } \\
\text { objective(s) }\end{array}$ & $\begin{array}{l}\text { To develop a framework that makes it possible to position } \\
\text { knowledge and decision support tool types along } 3 \text { or } 4 \text { axes/ } \\
\text { dimensions, next to clarifying their mutual relations. By doing so, } \\
\text { this framework would help tool developers which tool needs to be } \\
\text { developed in which case. }\end{array}$ \\
\hline Outcome & $\begin{array}{l}\text { More specific; it is what } \\
\text { you have when you } \\
\text { walk out of the door } \\
\text { of the meeting, the } \\
\text { desired result }\end{array}$ & $\begin{array}{l}\text { A framework to be presented to the knowledge and decision } \\
\text { support tools community of developers, and, implementers, } \\
\text { possibly even users, to test whether it is usable and suitable. } \\
\text { A framework that can be adjusted to the national situation. } \\
\text { A plan how to ensure that stakeholders worldwide are informed } \\
\text { about the framework. }\end{array}$ \\
\hline Why & $\begin{array}{l}\text { The rationale for } \\
\text { achieving the meeting } \\
\text { objective(s) and each } \\
\text { individual's "what's in it } \\
\text { for me" }\end{array}$ & $\begin{array}{l}\text { To meet a heart-felt need by developers, implementers and } \\
\text { users of knowledge and decision support tools to clarify the } \\
\text { different types of tools and how they are mutually related, so that } \\
\text { developers can develop the right tool for the right job. } \\
\text { To contribute to the different domains of research of the } \\
\text { participants, and unifying terminology in and across domains. }\end{array}$ \\
\hline
\end{tabular}

\section{MEETING PROGRAMME}

DAY 1 (Feb 23 ${ }^{\text {rd }}$ )

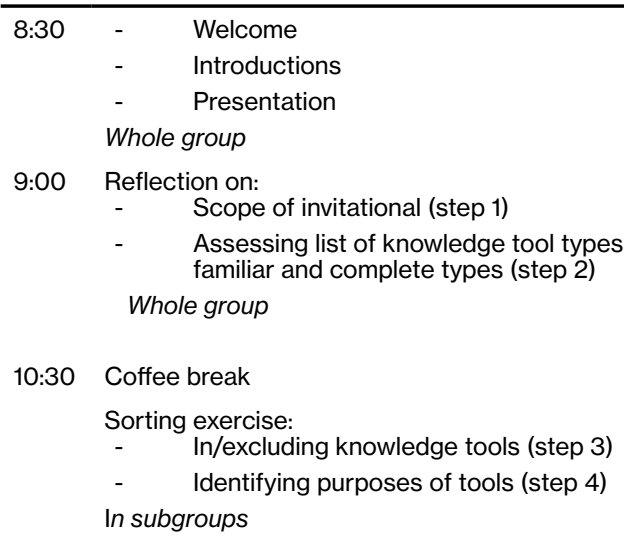

12:30 Lunch break

Identifying core ingredients (step 5) In subgroups

15:00 Break - preparing material for teleconference Whole group

16:30 Video- and/or teleconference Presenting \& discussing results of invitational so far (step 6)Knowledge tools

- $\quad$ List of purposes \& core ingredients

- Visual representation of draft framework

Chair and TC participants (60min.), followed by discussion (30 min., all)

18:00 Line-up \& end of day one Material to be send via email to SH \& RR (step 7)
DAY 2 (Feb 24 ${ }^{\text {th }}$ )

$\begin{array}{ll}\text { 9:00 } & \begin{array}{l}\text { Reflection \& summarizing day } 1 \\ \text { Whole group }\end{array}\end{array}$
Whole group

Fine tuning and finalizing (1): (step 8)

- $\quad$ Purposes of tools (part 1)

- $\quad$ Checking/ticking boxes of part 1 of framework

Presentation subgroup results \& whole group

10:30 Coffee break

Fine tuning and finalizing (2): (step 9)

- $\quad$ Core ingredients of tools (part 1)

- $\quad$ Checking/ticking boxes of part 2 of framework

Presentation subgroup results \& whole group

12:30 Follow-up and next steps

13:00 Barometer \& end of day two 


\section{Annex B-Participants consensus meeting}

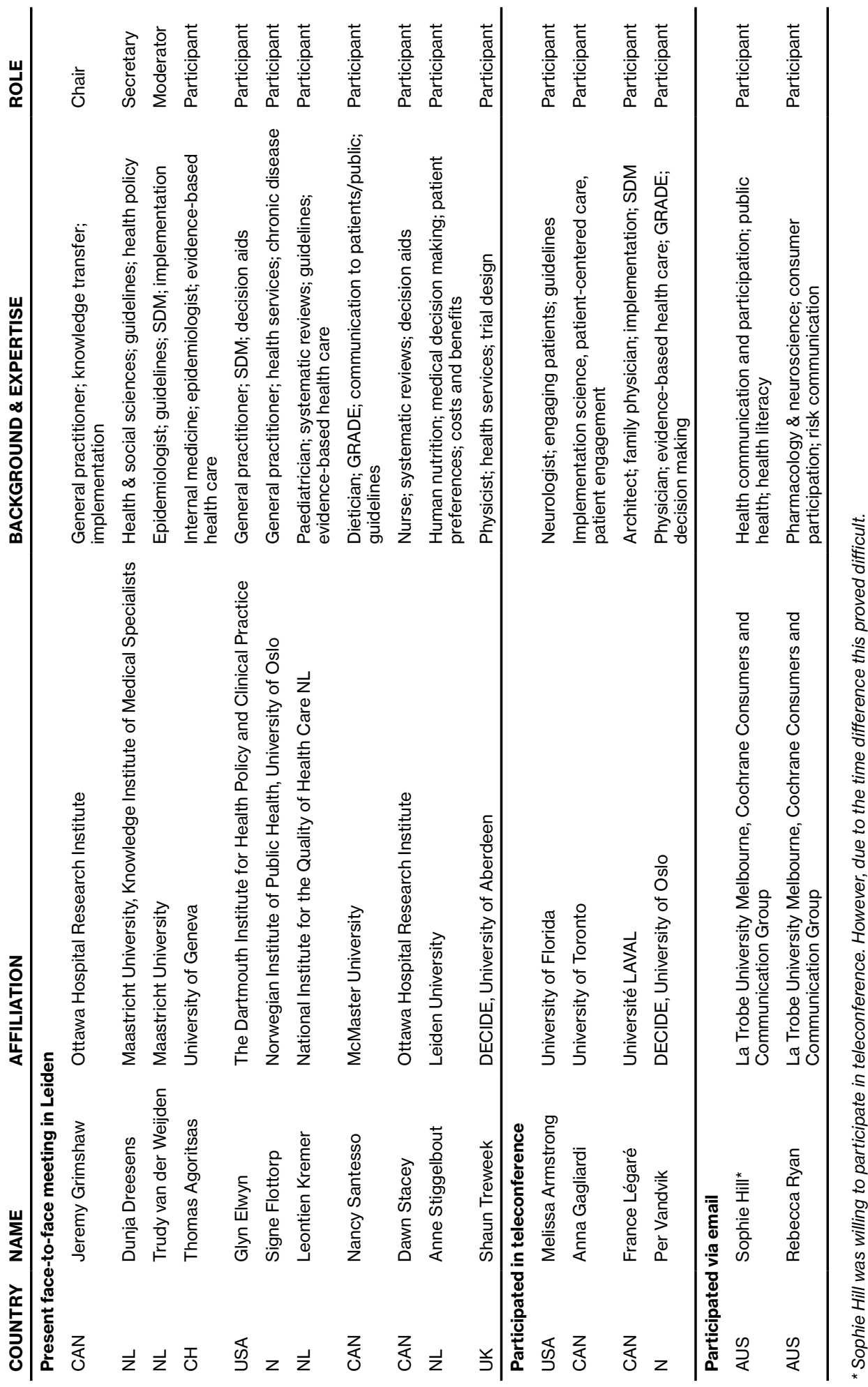




\section{Annex C - List with references provided to participants before the invitational meeting}

1. Michie S, Richardson M, Johnston M, Abraham C, Francis J, Hardeman W, et al. The behavior change technique taxonomy (v1) of 93 hierarchically clustered techniques: building an international consensus for the reporting of behavior change interventions. Annals of behavioral medicine : a publication of the Society of Behavioral Medicine. 2013 Aug;46(1):81-95. PubMed PMID: 23512568.

2. Grande SW, Faber MJ, Durand MA, Thompson R, Elwyn G. A classification model of patient engagement methods and assessment of their feasibility in real-world settings. Patient Educ Couns. 2014 May;95(2):281-7. PubMed PMID: 24582473.

3. Elwyn G, Lloyd A, May C, van der Weijden T, Stiggelbout A, Edwards A, et al. Collaborative deliberation: a model for patient care. Patient Educ Couns. 2014 Nov;97(2):158-64. PubMed PMID: 25175366.

4. Willis N, Hill S, Kaufman J, Lewin S, Kis-Rigo J, De Castro Freire SB, et al. "Communicate to vaccinate": the development of a taxonomy of communication interventions to improve routine childhood vaccination. BMC international health and human rights. 2013;13:23. PubMed PMID: 23663327. Pubmed Central PMCID: 3655915.

5. Vandvik PO, Brandt L, Alonso-Coello P, Treweek S, AkI EA, Kristiansen A, et al. Creating Clinical Practice Guidelines We Can Trust, Use, and Share: A New Era Is Imminent. Chest. 2013;144(2):381-9.

6. Schoemaker C, Van Everdingen J, Van Loon J. De toekomst van richtlijnen; een verkenning aan de hand van vier perspectieven van de VTV-2014. Ned Tijdschr Geneeskd. 2015;159(A8347):1-5 (?).

7. Agoritsas T, Heen AF, Brandt L, Alonso-Coello P, Kristiansen A, AkI EA, et al. Decision aids that really promote shared decision making: the pace quickens. Bmj. 2015;350:g7624. PubMed PMID: 25670178. Pubmed Central PMCID: 4707568.

8. Leeman J, Baernholdt M, Sandelowski M. Developing a theory-based taxonomy of methods for implementing change in practice. Journal of advanced nursing. 2007 Apr;58(2):191-200. PubMed PMID: 17445022.

9. Lowe D, Ryan R, Santesso N, Hill S. Development of a taxonomy of interventions to organise the evidence on consumers' medicines use. Patient Educ Couns. 2011 Nov;85(2):e101-7. PubMed PMID: 21036505.

10. Charnock D, Shepperd S, Needham G, Gann R. DISCERN: an instrument for judging the quality of written consumer health information on treatment choices. Journal of epidemiology and community health. 1999 Feb;53(2):105-11. PubMed PMID: 10396471. Pubmed Central PMCID: 1756830.

11. Coulter A, Ellins J. Effectiveness of strategies for informing, educating, and involving patients. Bmj. 2007 Jul 7;335(7609):24-7. PubMed PMID: 17615222. Pubmed Central PMCID: 1910640.

12. Gillies K, Entwistle V, Treweek SP, Fraser C, Williamson PR, Campbell MK. Evaluation of interventions for informed consent for randomised controlled trials (ELICIT): protocol for a systematic review of the literature and identification of a core outcome set using a Delphi survey. Trials. 2015;16:484. PubMed PMID: 26507504. Pubmed Central PMCID: 4624669. 
13. Giguere AM, Labrecque M, Haynes RB, Grad R, Pluye P, Legare F, et al. Evidence summaries (decision boxes) to prepare clinicians for shared decision-making with patients: a mixed methods implementation study. Implement Sci. 2014;9:144. PubMed PMID: 25280742. Pubmed Central PMCID: 4201673.

14. Akl EA, Oxman AD, Herrin J, Vist GE, Terrenato I, Sperati F, et al. Framing of health information messages. The Cochrane database of systematic reviews. 2011 (12):CD006777. PubMed PMID: 22161408.

15. Group GIW, Group GPW. Guidance for Developing Patient-Oriented Guideline Implementation Tools. Guidelines International Network, 2015 in progress. Report No.

16. van der Weijden T, Pieterse AH, Koelewijn-van Loon MS, Knaapen L, Legare F, Boivin A, et al. How can clinical practice guidelines be adapted to facilitate shared decision making? A qualitative key-informant study. BMJ quality \& safety. 2013 Oct;22(10):855-63. PubMed PMID: 23748154.

17. Gagliardi AR, Brouwers MC, Palda VA, Lemieux-Charles L, Grimshaw JM. How can we improve guideline use? A conceptual framework of implementability. Implement Sci. 2011;6:26. PubMed PMID: 21426574. Pubmed Central PMCID: 3072935.

18. van der Weijden T, Legare F, Boivin A, Burgers JS, van Veenendaal H, Stiggelbout AM, et al. How to integrate individual patient values and preferences in clinical practice guidelines? A research protocol. Implement Sci. 2010;5:10. PubMed PMID: 20205815. Pubmed Central PMCID: 2824684.

19. Legare F, Stacey D, Turcotte S, Cossi MJ, Kryworuchko J, Graham ID, et al. Interventions for improving the adoption of shared decision making by healthcare professionals. The Cochrane database of systematic reviews. 2014;9:CD006732. PubMed PMID: 25222632.

20. Blencowe NS, Brown JM, Cook JA, Metcalfe C, Morton DG, Nicholl J, et al. Interventions in randomised controlled trials in surgery: issues to consider during trial design. Trials. 2015;16:392. PubMed PMID: 26337522. Pubmed Central PMCID: 4558964.

21. Ryan R, Santesso N, Lowe D, Hill S, Grimshaw J, Prictor M, et al. Interventions to improve safe and effective medicines use by consumers: an overview of systematic reviews. 2014.

22. Elwyn G, Frosch D, Volandes AE, Edwards A, Montori VM. Investing in deliberation: a definition and classification of decision support interventions for people facing difficult health decisions. Med Decis Making. 2010 Nov-Dec;30(6):701-11. PubMed PMID: 21088131.

23. Stacey D, Hill S. The Knowledge to Action Cycle. Selecting KT interventions: Patient-direct and Patient-mediated KT Interventions. ?: ?; 2013.

24. Carman KL, Dardess P, Maurer M, Sofaer S, Adams K, Bechtel C, et al. Patient and family engagement: a framework for understanding the elements and developing interventions and policies. Health affairs. 2013 Feb;32(2):223-31. PubMed PMID: 23381514.

25. Liira H, Saarelma O, Callaghan M, Harbour R, Jousimaa J, Kunnamo I, et al. Patients, health information, and guidelines: A focus-group study. Scandinavian journal of primary health care. 2015;33(3):212-9. PubMed PMID: 26205344.

26. Taylor SJC, Pinnock H, Epiphaniou E, Pearce G, Parke HL, Schwappach A, et al. A rapid synthesis of the evidence on interventions supporting self-management. A rapid synthesis of the evidence on interventions supporting self-management for people with long-term conditions: PRISMS - Practical systematic Review of Self-Management Support for longterm conditions. Health Services and Delivery Research. Southampton (UK)2014. 


\section{2 | Chapter 4}

27. Colquhoun H, Leeman J, Michie S, Lokker C, Bragge P, Hempel S, et al. Towards a common terminology: a simplified framework of interventions to promote and integrate evidence into health practices, systems, and policies. Implement Sci. 2014;9:51. PubMed PMID: 24885553. Pubmed Central PMCID: 4021969.

28. Elwyn G, Quinlan C, Mulley A, Agoritsas T, Vandvik PO, Guyatt G. Trustworthy guidelines excellent; customized care tools - even better. BMC medicine. 2015;13:199. PubMed PMID: 26324120. Pubmed Central PMCID: 4556022.

29. Cox CE, White DB, Abernethy AP. A universal decision support system. Addressing the decision-making needs of patients, families, and clinicians in the setting of critical illness. American journal of respiratory and critical care medicine. 2014 Aug 15;190(4):366-73. PubMed PMID: 25019639. Pubmed Central PMCID: 4214132.

30. Rhodes CA. User involvement in health and social care education: a concept analysis. Nurse education today. 2012 Feb;32(2):185-9. PubMed PMID: 22153057.

31. Zuiderent-Jerak T, Jerak-Zuiderent S, van de Bovenkamp HM, Swan TS, Hakkaart-van Roijen L, Brouwer W, et al. Variatie in richtlijnen; wat is het probleem? The Hague, The Netherlands: Regieraad Kwaliteit van Zorg, 2011 April 2011. Report No.

32. Boivin A, Green J, van der Meulen J, Legare F, Nolte E. Why consider patients' preferences? A discourse analysis of clinical practice guideline developers. Medical care. 2009 Aug;47(8):908-15. PubMed PMID: 19543120.

The Dutch Chaos Case: a scoping review of knowledge transfer and decision support tools in the Netherlands, Dunja Dreesens - submitted 


\section{Annex D - Tool types and definitions used at the start of the meeting}

In a Delphi study in the Netherlands an expert panel reached consensus on the selection and definitions of a core set of knowledge and decision support tools primarily used in the care process by patient and / or professional (in or outside consultation).

In the grey rows the tool types that were included during the invitational.

$\begin{array}{lll}\text { TOOL DEFINITION } & \text { IN/ } \\ \text { TYPE } & & \text { EXC }\end{array}$

IN/

Clinical Recommendations for a specific (health) care issue based on 1) a systematic practice summary of scientific research, 2) considerations of the advantages guideline and disadvantages of various care options and 3) the knowledge and Included (as patient version experiences of patients and providers; supports decision-making in the care process and is aimed at safeguarding and improving the quality of life and care

Decision Logically structured visualization of possibilities in a (health) care issue with

Included (2) tree/flow associated outcomes, opportunities, risks and decision points; offers care chart providers and patients insight into the relevant care policies and supports decision making

$\begin{array}{ll}\begin{array}{l}\text { Summary } \\ \text { (of }\end{array} & \begin{array}{l}\text { Concise overview of the guideline providing main conclusions and } \\ \text { recommendations in clear and simple language; can be applied in practice } \\ \text { guideline) }\end{array} \\ \begin{array}{l}\text { independently from the guideline; intended for both care providers and } \\ \text { patients }\end{array}\end{array}$
of guideline)

Protocol Instruction derived from a guideline, indicating how care providers should act in daily practice, within the restraints of specific local circumstances

\section{Patient decision aid (PDA) /support tool}

Supporting information and answers to frequently asked questions for patients when choosing, with their care providers, from different options including the option to forgo care - in areas such as diagnostics, treatment, screening, counselling and aftercare; discusses the possible outcomes and effects of each option - desirable or otherwise - their likelihood to occur; helps patients weigh up their options based on their own values, standards and personal circumstances

Patient / client Explanation of a specific condition or (health) care issue based on a information guideline; made available to patients and their next of kin; provides information on available care choices and the care they can expect from the care process

Viewpoint Rules of conduct for a topical and/or delicate (health) care issue; drawn up on a fast-track, ad hoc basis by a professional or scientific association in collaboration with patients; provides guidance for care providers and patients when a guideline is not yet available

Care Guideline-based description of the shared decision-making in the care pathway setting regarding the (health) care provided to a patient with a specific care
need; intended for care providers; aimed at delivering optimal care, tailored to the needs of the specific patient
Quality standard*
Description of good care for a specific health-related theme in accordance with the Dutch National Health Care Institute's assessment framework; helps to improve and ensure quality of life and care; intended for guideline developers

Care standard*

Description of the organization of multidisciplinary care - including prevention - for a particular care issue; based on scientifically substantiated topical insights; may indicate tasks and be drafted from the perspective of the patient; covers in particular support for self-management; may include performance indicators
Care Description of an item of care relevant to several care issues; can be part of module* multiple care standards; brings into line non-disease-specific care in relevant care standards

\section{Excluded}

\section{Excluded}

Included - and split into two: encounter PDA (3) and independent PDA (4)

Included (5)

Excluded

Excluded

Excluded

Excluded

Excluded 


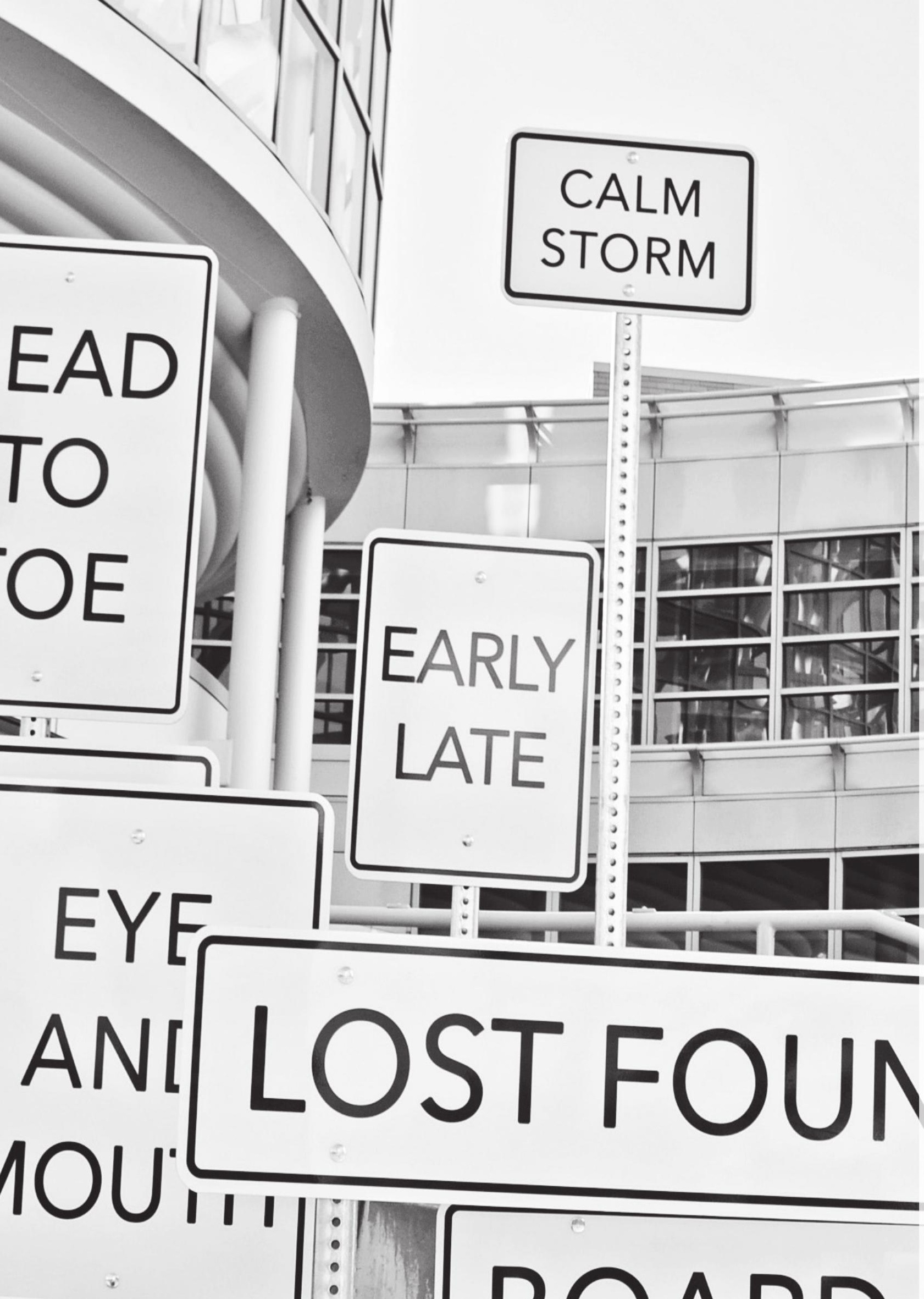




\section{Chapter 5}

\section{Different knowledge, different styles of reasoning: a challenge for guideline development}

Sietse Wieringa, Dunja Dreesens, Frode Forland, Carel Hulshof, Sue Lukersmith, Fergus Macbeth, Beth Shaw, Arlène van Vliet, Teun Zuiderent-Jerak on behalf of the AID Knowledge Working Group of the Guidelines International Network 
86 | Chapter 5 


\section{Introduction}

\section{The challenge of knowledge inclusion in guidelines}

Evidence-based guidelines whether national, regional or developed by specialty groups, must search for, and explicitly consider, evidence from sources other than conventional clinical trials and their quantitative data. This need for appraising and including knowledge from a wide variety of sources in guideline development is well recognised $(47,214,215)$. Although evidence on statistical association - usually from randomised controlled trials (RCTs) - is commonly thought to be the dominant type of knowledge appraised and included, guideline developers frequently use a range of other types of knowledge including the views and experiences of those using and providing health services, understanding of how interventions work (e.g. from logic models or realist evaluations), and other information, such as aetiology and the context of care (see Text box 1).

\section{Text box 1: Types of knowledge}

\section{TYPES OF KNOWLEDGE}

Defining knowledge is challenging as many ideas and theories about what knowledge entails exist. In this paper, we regard other types of knowledge as any knowledge that would not be considered a systematic review or RCT. This would include, but not be limited to, a broad range of explicit understandings of knowledge such as knowledge from outbreak investigations, laboratory research, mathematical modelling, qualitative research, quality improvement processes and clinical audits but also tacit knowledge, practical knowledge and heuristics.

These different types of knowledge are used and needed in many situations, for example, when evidence from RCTs is not available, impossible to obtain, contradictory or inappropriate. They can also be used in conjunction with knowledge from RCTs to provide context, to assess relevance and to understand bias. Furthermore, explicit (written or spoken) knowledge and the more intricate forms of knowledge like experiential and contextual knowledge can help guideline makers to take an approach consistent with the intentions of early evidence-based medicine (EBM) proponents: namely, that best evidence is not restricted to evidence from RCTs and meta-analyses alone (26).

However, how to properly appraise (judge) and include (integrate) different kinds of knowledge remains unclear. Agreed methods are not yet available or are in the early stages of development and the need for and use of different kinds of knowledge is not always explicitly acknowledged, which affects the use of guidelines in practice $(8,216-218)$. International and cultural differences in guideline production practices may further impede developments in appraising and including a broader range of types of knowledge (see Text box 2 ). 


\section{8 | Chapter 5}

Text box 2: International and cultural differences in guideline production

\section{INTERNATIONAL AND CULTURAL DIFFERENCES IN GUIDELINE PRODUCTION}

Guideline development methods have been developed by international networks and presented as universally applicable. But there may be differences in what methods are most appropriate for different contexts. In the workshops and conference sessions organised by the AID Knowledge Working Group, guideline developers from Europe, Latin America and Australia have generally welcomed efforts to include a wider range of types of knowledge in guidelines. USAbased guideline developers have been more critical, especially voicing the idea that any guidance not based on the highest level of evidence derived from RCTs should not be called a guideline. Such different assessments of what knowledge can/should be included in guidelines may have to do with the context in which guidelines are developed, including factors such as how the healthcare system is organised, who develops a guideline, litigation, what additional risks for conflict of interest this implies, and therefore whether guideline methods are more rigid. Approaches towards guideline appraisal and inclusion need to suit the context in which they are used.

In this paper, we discuss four specific aspects of guideline development to highlight the main challenges identified by the GIN AID Knowledge Working Group through discussions and workshops with guideline developers and users (see Text box 3):

- The purpose of guideline development;

- The problem of induction;

- The dominance of frequency based reasoning;

- The challenge of integrating different sources of knowledge.

In order to do this, we refer to some philosophical concepts around knowledge creation.

Text box 3: About GIN AID and the development of this paper

\section{ABOUT GIN AID AND THE DEVELOPMENT OF THIS PAPER}

GIN AID is a working group of the Guidelines International Network (GIN). The AID Knowledge Working Group tries to contribute to bridging the gap in methods for Appraising and Including Different (AID) Knowledge. To support this ongoing challenge, the GIN AID Knowledge Working Group aims to:

- Identify methods and promising initiatives for appraising and including a range of knowledge sources in guidelines;

- Facilitate sharing experiences with such methods and their application in practice through workshops at GIN conferences and elsewhere; - Identify areas / questions for methodological development; 
- Work towards reporting standards for knowledge appraisal and inclusion; and

- Develop a guide for appraising and including different knowledge.

For this paper, members of the GIN AID Knowledge Working Group met several times to discuss the issues of using different knowledge and reasoning in guideline development, based on examples from their own experience and from published literature. After several rounds of revision, the work was presented in a workshop at GIN 2016 Conference in Philadelphia. Input of workshop attendees was compiled, reviewed and included in the final draft of this position paper.

For more information please visit: http://www.g-i-n.net/workinggroups/aid-knowledge

\section{The purpose of guideline development}

The efforts of the pioneers of the EBM movement were primarily in response to the discovery of the variation problem in population studies. Reducing variation of the care provided at a population level was considered to be an important way to achieve improved quality for individual patients (217). Hence, epidemiology, the science of studying populations, gained prominence in guidelines, the aims of which are to support decisions for individual patients. Classic epidemiology became clinical epidemiology when introduced to the bedside and the dominance of RCTs as the gold standard for intervention studies to assess causal relation between interventions and effect followed in this construct of epidemiology as used in EBM. The underlying - yet little explored - assumption is that guidelines based on population studies provide the best advice to inform clinical decisions for individual patients or situations. However, reducing variation is not the only reason for developing guidelines; they are developed for several reasons, of which the most important one is to improve the quality of care. In order to meet the range of needs, guidelines may need different approaches, such as summarising large quantities of knowledge for practising healthcare professionals, serving as an intermediate product for other tools or applications (such as clinical decision support software) or providing implementation guidance. Although not primarily developed for this purpose, guidelines can also serve as tools to legally shield both patients and professionals, to help governments and health insurers allocate scarce resources and to act as governance frameworks for practitioners and governments.

There is also the role of guideline development as a discipline in itself; along with its associated practices and institutions, it provides employment and intellectual interest for many. There has been surprisingly little research into the purposes of guideline development. One mixed-method study found the purposes of guidelines were: defining norms, summarising evidence, formalising current consensus and/or describing current practices in a handbook-type format (8).

Making the purposes of guidelines more explicit may help determine how different types of knowledge could and should be used. For instance, if the aim is to describe current good 


\section{0 | Chapter 5}

practice (e.g. how services are organised to deliver care), this may be better achieved by drawing on qualitative or mixed-method evaluative research rather than RCTs. If the aim is to assess the effectiveness of a specific treatment or approach, evidence from RCTs or high-quality prospective cohort studies would usually be the primary source of knowledge, with qualitative or mixed-method studies serving to help understand the local context of implementation. It is important to note, however, that for most guideline developers, the primary purpose remains that of supporting decision making in the clinical encounter. This leads us to the next fundamental aspect of guideline development.

\section{The problem of induction}

How do different types of knowledge in guidelines development help to make clinical decisions? Some basic concepts from the philosophy of science may help to understand the problem.

\section{Inference, the problem of induction and evasions}

In logic, to infer means to conclude from evidence using reasoning (218)..In everyday healthcare practice, care professionals and patients reason to reach conclusions about what has happened, to make predictions about what will happen and to decide what to do next. Because of uncertainty in medicine, we usually deal with a specific type of inference, called induction, where the conclusions of our reasoning are not always right even when based on true premises. In philosophy, there is a concern whether this is actually possible, called the problem of induction (218), as introduced by Hume in 1739 (219)._At its simplest, this means we cannot predict the future with certainty. Although this seems reasonable, we are in fact able to predict the future quite accurately on many occasions in clinical practice. How is this possible? Philosopher of science lan Hacking (218) argues that we never solve the problem of induction, but only evade it by applying different kinds of reasoning to reduce uncertainty and increase our chance of reaching the best possible outcome.

\section{The dominance of frequency-based reasoning}

The evasion most dominantly used in guideline development is frequency-type reasoning in the form of systematic reviews, RCTs and observational studies (8)._This evades the problem of induction by recognising that 'although we can't predict the future for the individual case, we can be "usually" right (e.g. $95 \%$ of the time)' (218) as long as events or cases are frequent enough.

Frequency-based reasoning relies on basic assumptions that have some drawbacks. First, this line of reasoning assumes that reality is dice like and that we - e.g. scientists, guideline developers and healthcare professionals - are rolling the same dice (see Text box 4). Frequency-type reasoning presupposes adequate framing and defining of what is similar and what is not, which is always based on judgement and choice. 
Text box 4: Frequency based induction: rolling dice (paraphrased from Hacking 2001)

\section{FREQUENCY BASED INDUCTION: ROLLING DICE}

The central reasoning in RCTs can be summarised simply as assuming that everything in the world (such as people, relations) behave like dice. That is, if dice roll perfectly, they are fair. If they are unfair - where one side is heavier than the others - they are biased. We're aware of many types of bias a priori in real life situations: for example, known causes, confounders and differences between groups. An RCT of patients with therapy $A$ versus patients with therapy $B$ is like trying to make two similar dice as fair as possible, rolling them many times, and comparing the results of the rolls to show their tendency. The assumption is that by rolling two fair dice, one would expect to see similar results in the end. If this does not happen then the reverse must be true; one of the dice is unfair or biased; one of the faces is heavier than the other. In that case, one of the therapies was better at causing the outcome. We don't know why (rolling dice doesn't give us an explanatory mechanism), but we conclude that it just did, because we found an a priori 'unknown' bias.

It is important to note that frequency-type reasoning doesn't work for single case scenarios. A patient can get a first hip replacement only once, not a hundred times. It goes well or it goes wrong. There is no frequency about it. It's like throwing a dice once: you're never sure what will happen. You either throw a six or you don't.

Second, frequency-based reasoning aims to find simple causal correlations, independent of context. The question is whether these simple correlations hold true in real life. Different understandings of causality exist that could help us address this drawback (220).For instance, a network of complex causal relationships may be more realistic. This drawback is described as the efficacy paradox, where the different interference from non-specific effects (different from those controlled for between groups in a trial), measurement artefacts (that mimicked therapeutic effects in the trial) and regression patterns (such as the self-limiting nature of a disease) in real life can outweigh the specific effect found in a trial. This paradox may become especially apparent when inferring in the context of multimorbidity (221). Finally, and most importantly, although frequency-based reasoning works well for frequent events (large groups, many data points and long periods of time), such reasoning faces fundamental limitations when inferring in the single-case scenario: a single patient, a rare disease, a system intervention and a one-off event. This can be particularly challenging when recommendations based on frequency-type evidence alone are deployed to help decision making for individual patients or unique situations, such as a public health response to a disease outbreak (47). Given these drawbacks, it is worth noting that other types of reasoning to evade the epistemological problem of induction exist. In table 1 , several alternative ways of reasoning are listed. They are mainly used in areas where frequency-based reasoning is particularly problematic, for instance in guidelines focusing on complex interventions, public and occupational health, rehabilitation, and social care and 


\section{2 | Chapter 5}

welfare (221-223). These different types of reasoning try to help make valid inferences for the single-case scenario, when there is no frequency of events. Many of these are already recognised and stated by Bradford-Hill (224) in his criteria for causation, but some are newer, such as Annemarie Mol's logic of care (225), where a practitioner will try something, wait and see and let unfolding events guide the next step. Using this type of reasoning, the problem of induction is solved through 'tinkering', making incremental changes to improve a situation.

Guidelines can and do support these kinds of evasions by including different types of knowledge. For instance, providing laboratory information about aetiology helps to make an inference based on mechanistic reasoning (226). A description of cases of harm can offer an inference based on the precautionary principle (227). Rethinking how inferences are made in practice may shift the dominance of frequency-based reasoning and its reliance on a restrictive type of knowledge to a broader spectrum of knowledge being used to support different reasoning approaches. The need for using different type of knowledge is shown by a large Dutch analysis showing that knowledge from RCTs far outweighed other knowledge types used, irrespective of the question at hand, thus ignoring important and relevant knowledge from other sources $(8,216)$.

\section{The challenge of integration}

Making a recommendation for a specific healthcare problem in a specific healthcare system requires the assessment of knowledge not just on its own merits, but importantly its integration with other knowledge. Indeed, EBM is defined as integrating the best evidence with clinical expertise and patient preference (26). However, in the context of medicine, and even more so in that of guideline production, integration of different types of knowledge remains underexplored and undertheorized. Some areas of evidence synthesis have addressed integration. For example, statistical techniques such as meta-analysis can be used to combine data from different studies, and another range of techniques can be used to synthesise qualitative data.

In guideline development, most of the activities and tools to support high-quality evidence synthesis such as risk of bias assessment and quality assessment (such as GRADE) tend to focus primarily on frequency-based reasoning and knowledge. For the assessment of quality of qualitative evidence, there are limited but relevant initiatives for guideline development in progress, for example, the recently published Grading of Recommendations Assessment, Development, and Evaluation - Confidence in the Evidence from Reviews of Qualitative research (GRADE-CERQual) (228) guidance. However, many of these efforts try to achieve integration by synthesizing studies that share the same questions and design (e.g. a set of qualitative or, more narrowly, ethnographic studies) (229),_at times appraising (228)_all such knowledge again in frequentist terms, like with some qualitative evidence synthesis methods (230)_that "emphasize frequencies of the qualitative data they present ... undermin[ing] the uniqueness of the qualitative knowledge they proclaim by focusing on frequency and the general patterns" (231).

The main issue is that these tools, activities and initiatives aim to integrate similar knowledge, such as data from the same study designs, the same populations or the same outcomes. How different kinds of knowledge are valued, appraised and weighed in relation 
to each other, for example, regarding effectiveness, efficiency or ethical concerns, is not clearly articulated.

Nonetheless, guideline developers do recognise that other types of knowledge are often used and somehow integrated in practice, particularly when discussing the evidence and formulating recommendations, often called 'judgement' or 'considered judgement' (232, 233). This is the traditionally less clearly described or analysed black box part of the process that new initiatives try to shed a light on, such as NICE's structured tables linking evidence to recommendations and the GRADE Evidence to Decision frameworks (232).

Table 1: Alternative types of reasoning to evade the problem of induction

\section{TYPE OF REASONING* (WITH EXAMPLES OF KEY SCHOLARS)}

Bayesian evasion
(Bayes, Hacking)

Abduction
(Peirce)

\begin{tabular}{|c|c|}
\hline Mechanistic/deterministic & $\begin{array}{l}\text { How things } \\
\text { appear to work }\end{array}$ \\
\hline $\begin{array}{l}\text { Falsification } \\
\text { (Popper) }\end{array}$ & Trial and error \\
\hline
\end{tabular}

\section{SHORTHAND DESCRIPTION}

Learning from experience

Reasoning to the best explanation
(Popper)

Precautionary principle
In case of uncertainty about the future prevent harm

\section{EXPLANATION}

This type of inductive inference agrees with Hume that we cannot predict the future perfectly, but that we can learn from our experiences reasonably well. This allows us to do more and better predictions. This type of reasoning can update current beliefs with information from frequent events (informing prior probabilities and likelihood ratios). However, because we can learn from a single event too, this approach is suited for the individual case scenario (218).

Abduction makes inferences by updating beliefs leading to the best explanation (234)._Where Bayesian evasion takes prior probabilities as a given (at least as some argue), which may not be the case, abduction does not. It introduces the consideration of theory and mechanism in the act of inferring (235).

This type of reasoning makes an inference based on a mechanism. Illari et al (226) define a reasoning mechanism as consisting 'of entities and activities organised in such a way that they are responsible for the phenomenon'.

Popper (236) $)^{30}$ agreed with Hume: we cannot say anything about the future, there are only theories that cannot even be proven. At best, we can only prove that they are wrong (falsifiable). This 'anti-inductivist' reasoning suggests to continue using a certain theory or practice and adjust if they fail.

The precautionary principle, often used in environmental decision making and occupational health, favours to take preventive action in the face of uncertainty when making an inference. It puts 'the burden of proof to the proponents of an activity; exploring a wide range of alternatives to possibly harmful actions; and increasing public participation in decision making' $(227,237)$. 


\begin{tabular}{|c|c|c|}
\hline Means-to-ends reasoning & $\begin{array}{l}\text { Find ways to } \\
\text { reach a goal }\end{array}$ & $\begin{array}{l}\text { This type of reasoning asks the question what ways are } \\
\text { there to reach a certain wanted outcome and which of } \\
\text { those ways would be the more efficient? Often used } \\
\text { in clinical consultations to make sure that something } \\
\text { happens whatever the circumstances. The inference } \\
\text { remains uncertain but less so by using multiple means } \\
\text { that will lead to the same outcome (238). }\end{array}$ \\
\hline $\begin{array}{l}\text { Logic of care } \\
\text { (Mol) }\end{array}$ & $\begin{array}{l}\text { Taking care while } \\
\text { the uncertain } \\
\text { future unfolds }\end{array}$ & $\begin{array}{l}\text { In The Logic of Care, Annemarie Mol (225) suggests } \\
\text { that healthcare is more like a 'practice' than it is about } \\
\text { making choices. This approach puts emphasis on the } \\
\text { importance of taking good care for the patient and the } \\
\text { prevention of neglect. Inferring is a process that unfolds } \\
\text { over time, while addressing many factors on the way. }\end{array}$ \\
\hline $\begin{array}{l}\text { Non-analytical reasoning } \\
\text { (Gigerenzer, Stolper) }\end{array}$ & Using intuition & $\begin{array}{l}\text { Non-analytical reasoning such as heuristics and gut } \\
\text { feelings (combination of heuristics and emotions } \\
(239) \text { ) used to make inferences. These types of } \\
\text { reasoning are considered fast, } \\
\text { intuitive and automatic thought processes. Gigerenzer } \\
\text { showed that non-analytical reasoning can in certain } \\
\text { environments outperform analytical reasoning in } \\
\text { psychological, biological, sociological and economic } \\
\text { inference tasks (240). }\end{array}$ \\
\hline
\end{tabular}

* Types of reasoning are not exclusive and may overlap.

They appear promising yet challenges remain. First, findings from ethnography question whether structured frameworks really influence or reflect guideline development processes $(241,242)$. In an ethnographic study of guideline development meetings, Moreira showed that guideline developers formulate guidance by combining different "repertoires of evaluation, organised around four different epistemic criteria: robustness, usability, acceptability and adequacy" (241). Importantly, such criteria are deployed at each stage of evidence appraisal: usability, acceptability and adequacy are integral to evidence assessment, rather than being easily categorised as either 'judgements' or 'additional considerations' as current evidence to decision frameworks suggest (232).

Acknowledging the importance of these epistemic skills in evidence appraisal become much more important when it is understood that recommendations nearly always draw on different types of knowledge. Second, bringing knowledge together is not just a process of integrating, triangulation and finding a single answer. Knowledge from many sources is often conflicting, and indeed the exploration of opposing ideas is often very important. In social sciences, methods for evidence synthesis of other kinds of data have been developed and assessed in research (243) and in practice guideline development (223),_but these have not yet been adopted routinely in healthcare guideline development. A process of integration is not just a technical, simple mechanistic process. Guideline development is a human, social process involving relevant stakeholders in discussion, debate and judgement. Therefore, the guideline development processes also rely on a balanced and representative guideline committee that functions well (244). Finally, integrating many types of knowledge is not a process in which anything goes. Some integration processes are likely to be better than others. Guideline development needs to be transparent and consistent so that reality, be it physical or social, can limit the inferences and recommendations made. We need a range of integration approaches depending on our understanding of what is true and 
real. For example, integration of different knowledge could be based on combinations of coherence (what fits best in a network of other theories), on consensus (what people agree on) and/or on correspondence (what links best to what is believed to be real).

Given the current state of evidence to decision frameworks, there is still little guidance on how to robustly and consistently combine knowledge of different types without using the frequentist understanding of knowledge. A broader discussion within the guideline community is needed about the frameworks used to integrate and include different kinds of knowledge. Considering theories from epistemology and findings from ethnography (see Text box 5) could be instrumental to deepen our understanding of how other types of knowledge can be synthesised and integrated in guideline production.

Text box 5: Theoretic and empirical concepts of integrating knowledge

\section{THEORETIC AND EMPIRICAL CONCEPTS} OF INTEGRATING KNOWLEDGE

William James was a philosopher of science who developed the idea of pragmatism, where many kinds of evidence can serve to support and continuously update beliefs about reality and truth within communities of people [1]. Another philosopher of science, the physicist Thomas Kuhn described how researchers within a research tradition develop and nourish theories which are overthrown, leading to the emergence of new paradigms [2]. Based on an ethnographic research on knowledge translation Gabbay and Le May coined the term "mindlines" to denote the continuously evolving, socially shared and mostly tacit knowledge that informs clinical practice [3]. Explicit knowledge from guidelines is incorporated into mindlines - where it is made sense of, challenged and integrated (or not) with practitioners' existing knowledge-in-practice-in-context.

1. James W. Pragmatism and The Meaning of Truth. Rough Draft Printing 2011.

2. Kuhn TS. The Structure of Scientific Revolutions. The University of Chicago Press 1970.

3. Gabbay J, Le May A. Evidence based guidelines or collectively constructed'mindlines?' Ethnographic study of knowledge management in primary care. BMJ Br Med J 2004;329:1013. doi:10.1136/bmj.329.7473.1013 


\section{6 | Chapter 5}

\section{Conclusion}

The development of guideline recommendations is an interactive human process that requires a range of knowledge and experience including, but not exclusively, knowledge from frequency-based research, such as clinical trials. As in the clinical encounter, appraising and including different types of knowledge in guideline development should be used to make better inferences to guide decisions, but in practice, arguments are used to exclude some kinds of knowledge for a range of reasons, including concerns about introducing bias in frequentist reasoning.

In this paper, we present important epistemological reasons to appraise and include a (wide) variety of different types of knowledge to highlight important aspects of guideline development that await further exploration and practical suggestions.

We acknowledge that appraising and including knowledge from a different variety of sources is likely to be complex and ongoing. Discussions about purpose, reasoning and integration in guideline development will continue. A simple set of tools or methodological quick fixes are unlikely to suffice, and developing criteria for appraising and integrating different knowledge will remain a challenge. However, we believe that much can be done to help guideline developers improve this - now often implicit (8) practice that is central to their work. Capacity-building workshops that confront implicit forms of reasoning are one example. AID Knowledge runs such workshops annually at GIN conferences. They help to strengthen ties between guideline developers who are concerned about the increasingly rigid methodological constraints on guideline methods at the expense of fostering epistemic sensibilities. It is important for guideline developers to feel they are part of a community of practice that encourages epistemic skill development, rather than a hierarchical community where superior guideline methods are defined by a small group of experts. This will help to keep guideline development innovative and diverse.

Acknowledging that dominant frequentist methods are excellent for some questions but do not fit all knowledge needs is the first step to implementing different kind of reasoning in guide- line development. How to address the diversity in methods for different kinds of questions should be among the top guideline research priorities.

\section{Glossary}

Inference

To reach a conclusion from premises (points, reasons, evidence, etc.)

Induction

A kind of inference that is risky. Even when the premises are correct, the conclusion may not be. This in contrast to deductive reasoning where the conclusion is necessarily correct.

The problem of induction A concern in philosophy whether inductive inference is justifiable.

Evasion A certain way of reasoning to deal with the problem of induction. 
Chapter 5 | 97 


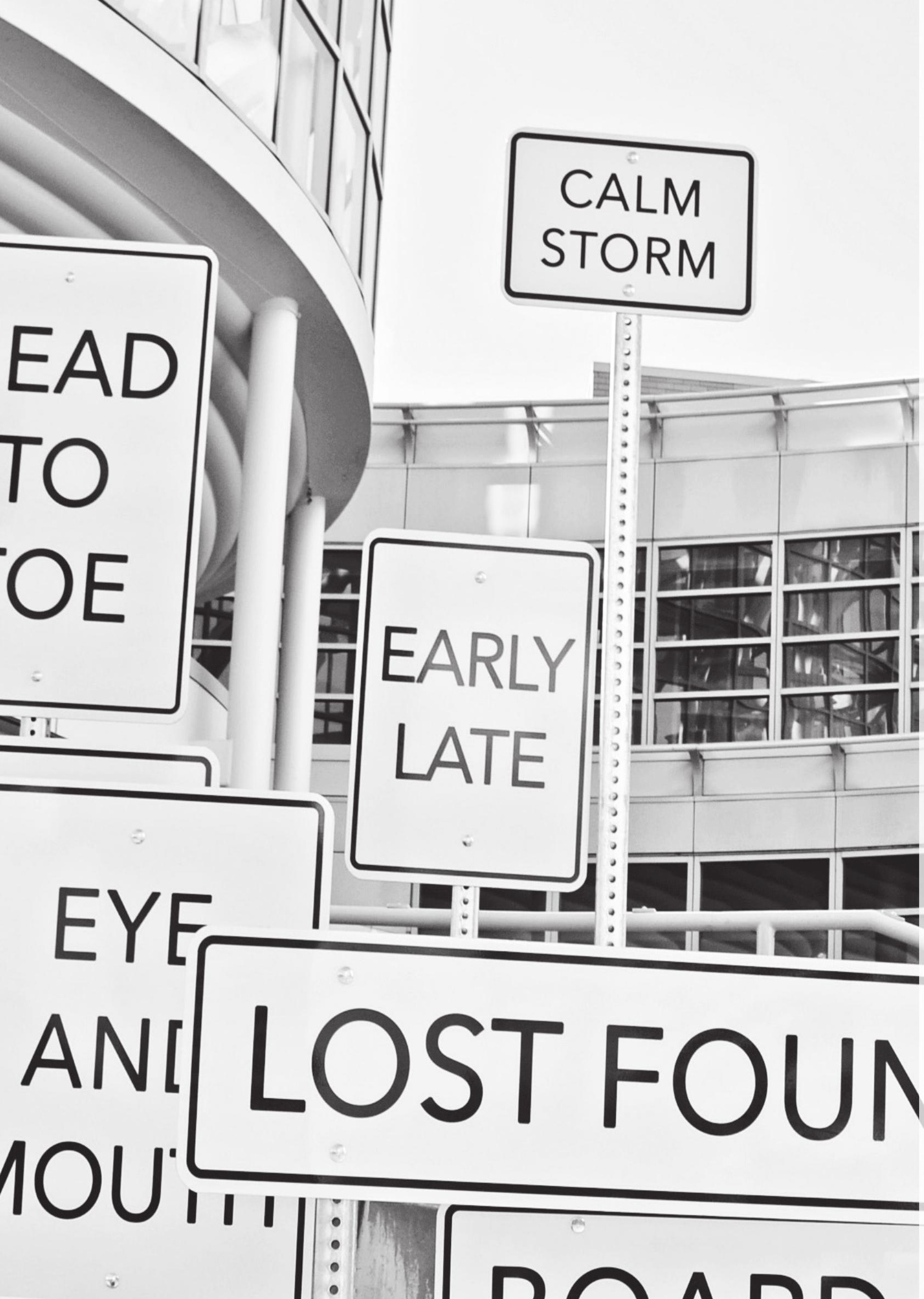


Chapter 6

The clinical practice guideline Palliative care for children and other strategies to enhance shared decision-making in pediatric palliative care: pediatricians' critical reflections

Dunja Dreesens, Lotte Veul, Jonne Westermann,

Nicole Wijnands, Leontien Kremer,

Trudy van der Weijden, Eduard Verhagen 


\section{Abstract}

\section{Background}

Because of practice variation and new developments in palliative pediatric care, the Dutch Association of Pediatrics decided to develop the clinical practice guideline (CPG) palliative care for children. With this guideline, the association also wanted to precipitate an attitude shift towards shared decision-making (SDM) and therefore integrated SDM in the CPG Palliative care for children. The aim was to gain insight if integrating SDM in CPGs can potentially encourage pediatricians to practice SDM. Its objectives were to explore pediatricians' attitudes and thoughts regarding (1) recommendations on SDM in CPGs in general and the guideline Palliative care for children specifically; (2) other SDM enhancing strategies or tools linked to CPGs.

\section{Methods}

Semi-structured face-to-face interviews. Pediatricians (15) were recruited through purposive sampling in three university-based pediatric centers in the Netherlands. The interviews were audio-recorded and transcribed verbatim, coded by at least two authors and analyzed with NVivo.

\section{Results}

Some pediatricians considered SDM a skill or attitude that cannot be addressed by clinical practice guidelines. According to others, however, clinical practice guidelines could enhance SDM. In case of the guideline Palliative care for children, the recommendations needed to focus more on how to practice SDM, and offer more detailed recommendations, preferring recommendations stating multiple options. Most interviewed pediatricians felt that patient decisions aids were beneficial to patients, and could ensure that all topics relevant to the patient are covered, even topics the pediatrician might not consider him or herself, or deems less important. Regardless of the perceived benefit, some pediatricians preferred providing the information themselves instead of using a patient decision aid.

\section{Conclusions}

For clinical practice guidelines to potentially enhance SDM, guideline developers should avoid blanket recommendations in the case of preference sensitive choices, and SDM should not be limited to recommendations on non-treatment decisions. Furthermore, preference sensitive recommendations are preferably linked with patient decision aids.

\section{Keywords}

Clinical practice guideline; shared decision-making; palliative care; children; interviews; qualitative 


\section{Background}

It is estimated that 750-1,000 children with a life-threatening illness die each year in the Netherlands and 5,000 children are diagnosed with a life-threatening illness (245). Of the 1,200 Dutch pediatricians, 60 pediatricians (being part of pediatric palliative teams in university medical centers) regularly encounter children with a life-threatening disease. Most Dutch pediatricians - and other healthcare professionals - infrequently encounter children who are in need of palliative care, making them less sure how to proceed in these cases. Moreover, a lifethreatening illness has an enormous impact on both the parents and the child. The pediatrician can help in coping, and counseling on treatment related issues as well psycho-social aspects should start as early as possible. Furthermore, new developments in pediatric palliative care and limited knowledge thereof among pediatricians led to unwarranted practice variation $(245,246)$. The Dutch Association of Pediatricians therefore deemed it necessary to develop the clinical practice guideline (CPG) Palliative care for children to improve the quality of care for these children. The objective of this guideline is to provide pediatricians support and guidance when caring for children with a life-threatening disease. The guideline was published in the summer of 2013 (247).

The introduction of the CPG Palliative care for children stresses the importance of knowing and discussing the needs of the patient and his or her parents. In addition to palliative intervention recommendations, the guideline consequently also contains recommendations on communication and shared decision-making (SDM) (see Box 1) (247). The underlying assumption of SDM models is that the doctor-patient relationship is based on mutual respect and on a joint interest to achieve the most beneficial outcomes for the patient, with partners sharing decisions. In this process it is important to understand the patients' preferences and values, and to acknowledge the doctor's expertise (248). However, it is still unclear if and how SDM can be incorporated in CPGs (199, 249-252). Van der Weijden et al described how guidelines can be adapted to facilitate SDM, e.g. by incorporating patient-centered questions, flagging recommendations for which considering patient preferences is particularly important, or by embedding relevant patient support tools (249). The Institute of Medicine recommends including patients in the guideline panels to address heterogeneity in patient preferences and include trade-offs in recommendations (157). Prior to 2013, only a few guidelines tried to do this (253-255).

Sharing decisions in pediatric care is triadic in nature as parents or other care givers may be as much or even more involved as the child (256). Furthermore, in the Netherlands children have a right to be involved in deciding about their care from the age of 12 years (257). A majority of both parents and children prefer to participate in treatment decision-making and consider it an essential component of quality of care, together with relationship building, demonstration of effort and information exchange $(258,259)$. 
Box 1: Quick overview of the CPG Palliative care for children

CLINICAL PRACTICE GUIDELINE PALLIATIVE CARE FOR CHILDREN (NVK, 2013)

The guideline consists of three chapters, each providing recommendations on the topic at hand.

\section{Symptoms}

Recommendations on recognition and treatment of symptoms, such as anxiety, nausea, pain,spasticity and fatigue.

\section{Communication \& decision-making}

Recommendations on decision-making, such as:

- Take into account the values and preferences of the child and/or parents;

- Be conscious of the fact that decision-making is a continuous process;

- Ask the child and/or parents at various moments which decision-making role they would like to have;

- Cary out the conversations in a quiet, private and comfortable space;

- Clarify mutual goals;

- Confer with the child and the parents, [...], use nonprofessional language, and repeat what has been discussed;

- Record the view of the parents in the patient file.

\section{Organisation of palliative care}

Recommendations on the organisation of care, such as coordination \& responsibilities, patient record, educating healthcare professionals and financing palliative care for children.

Despite the large number of publications in support of children's (ethical) right - and desire - to participate in their own health care and decisions, pediatricians usually do not involve them in the decision-making. One reason being the clinicians' underestimation of children's capabilities, because of the children's age, pediatricians think they cannot or do not want to be involved in the decision making $(260,261)$. A national survey (2011) among Dutch pediatricians showed that $21 \%$ perceived a need to share the final responsibility for an end-of-life decision with the parents. Half of the respondents would inform parents and ask for their permission to discontinue treatment, and a quarter would merely inform parents (262). Reasons for not sharing the decision were: complexity/uncertainty of the decision at hand, and/or protecting the parents. Another important aim of the guideline Palliative care for children was therefore to trigger an attitude shift towards SDM in palliative pediatric care.

The aim was to gain insight if integrating SDM in CPGs can potentially encourage pediatricians to practice SDM. Its objectives were to explore pediatricians' attitudes and thoughts regarding (1) recommendations on SDM in CPGs in general and the guideline Palliative care for children specifically; (2) other SDM enhancing strategies or tools linked to CPGs. 


\section{Methods}

We applied the Standards for reporting qualitative research (SRQR) and Consolidated criteria for reporting qualitative studies (COREQ) for this article $(191,263)$.

\section{Study design}

We conducted semi-structured, face-to-face interviews to gather 'deep' information and perceptions of the participating pediatricians using a phenomenological approach $(264,265)$. This qualitative research method emphasizes the importance of personal perspective and interpretation. It is a suitable method for gaining insight into participants' motivations and actions and understanding subjective experience.

\section{Researchers' characteristics}

The second author (LV) conducted the face-to-face interviews, with the assistance of JW and NW. LV, NW and JW were sixth year medicine students carrying out a science research internship at Maastricht University. There were no prior relationships between the participants and any of the authors. We informed the participants of the researchers' background and their roles in the PhD-research of the first author (DD), (1) at the time of recruitment, and (2) at the start of the interview. The interviewer (LV) had no previous experience with interviewing. She was trained on the job by TVDW and DD and closely supervised by the research team through regular meetings and feedback on audio-recorded interviews.

\section{Participants}

We purposively sampled pediatricians with experience in providing palliative pediatric care. The respondents were also purposeful sampled regarding tenure (professor, specialist, fellow); age; and gender. We recruited pediatricians from five subspecialty divisions: oncology, metabolic diseases, neurology, intensive care and neonatology at three university based pediatric centers in the Netherlands. These centers were UMCG, MUMC+ and Amsterdam UMC location AMC. We tailored the approach to each pediatric center to ensure timely recruitment of participants. Participants were approached via personal mailings sent by the author linked to the specific pediatric center or via personal invitations by one of the authors (LK, EV). The interviews took place at an office in the hospital in the second quarter of 2014. During the interview, only the participant and interviewer were present.

\section{Data collection}

Based on the relevant literature and the guideline Palliative care for children (PCFC), an interview guide was developed (266). Box 1 contains an overview of the (recommendations of the) guideline. The research team discussed the interview guide within the research team and the guide was piloted in two interviews. We followed an iterative approach; meaning that the interview guide was adjusted - if needed - in response to the preceding interviews (see Appendix 2). 


\section{4 | Chapter 6}

During the pilot interviews, it became clear that not all participants might have an in-depth knowledge of the guideline PCFC. Consequently, it was decided that if the pediatrician was not familiar in detail with the guideline that the researcher would walk the pediatrician through the guideline and the SDM-recommendations at the start of the interview.

In addition to the PCFC guideline, all participants were presented with two other SDMapproaches (249). First, participants were shown two patient decision aids (PDA) for children: one on anticoagulants and another on bone infection $(267,268)$. Second, we showed them the PCFC guideline recommendation on pain relief (Appendix 1) that we had rewritten so that it offered several options for pain relief and could stimulate discussion with the patient and/ or parents. Approval for the study protocol was granted by the Medical Ethical Committee of the University Medical Center Groningen, reference number M14.150.681/METc 2014.057 (10 February 2014).

Verbal informed consent was gained from all participants, which included consent for use of anonymized quotes in publications. No follow-up interviews took place. The interviews were audio-recorded and transcribed verbatim by LV, JW and NW, with at least one author carrying out a reliability check on each transcript correcting any transcribing errors. The participants received the transcripts for comments, correction and approval (member check). Furthermore, LV made field notes before and after the interviews, and these were discussed with DD.

\section{Data analysis}

Data analysis was performed by using the constant comparative method (264). Three authors (LV, NW and DD) read and reread all transcripts independently. Text fragments related to the research questions were selected and coded. The research team did not identify themes or codes in advance.

The codes were developed inductively, while reading the transcripts and making notes about selected fragments in the transcripts. After the first five transcripts, the researchers (LV, DD) compared their observations and developed preliminary coding categories. After analyzing individual interviews, we added and altered codes and categories in an iterative process. LV and DD discussed disagreement about the coding until consensus was reached. When all the interviews were analyzed and coded, we collected the codes in a preliminary coding scheme. Through axial analysis, we constructed (sub-) categories. LV and DD discussed and compared all the codes and categories resulting in the final coding scheme (see Appendix 3). Data analysis was supported by NVivo-software. The research team met to discuss and complete the study report and manuscript. We did not invite participants to provide feedback on the findings. 


\section{Results}

\section{Sample}

In total 22 pediatricians were approached to be interviewed and 15 agreed to participate (Table

1). Three were moderately interested and preferred to decline, three did not respond and one pediatrician was not interested in the subject and declined. The participants consisted of two professors, 12 medical specialists, and one fellow. Nine of them had 15 years of experience or more.

\section{Data collection}

The 15 interviews lasted between 20 and 75 minutes (average 48 minutes). Data saturation occurred after eight interviews; no new codes emerged from the data.

Table 1: Characteristics of the interviewed participants

\begin{tabular}{|c|c|c|c|}
\hline $\begin{array}{c}\text { INTERVIEW \# } \\
\text { PER SPECIALISM }\end{array}$ & GENDER & HOSPITAL CODE & $\begin{array}{l}\text { DURATION OF INTERVIEW } \\
\text { (MINUTES) }\end{array}$ \\
\hline \multicolumn{4}{|l|}{ Oncology } \\
\hline 1 & M & 1 & 58 \\
\hline 10 & $\mathrm{~F}$ & 3 & 75 \\
\hline 11 & M & 2 & 43 \\
\hline 15 & M & 3 & 34 \\
\hline \multicolumn{4}{|l|}{ Intensive care } \\
\hline 8 & $\mathrm{~F}$ & 1 & 30 \\
\hline 9 & $M$ & 2 & 60 \\
\hline \multicolumn{4}{|l|}{ Metabolic disease } \\
\hline 3 & M & 1 & 54 \\
\hline 6 & M & 1 & 47 \\
\hline 12 & M & 3 & 39 \\
\hline 14 & $\mathrm{~F}$ & 3 & 20 \\
\hline \multicolumn{4}{|l|}{ Neonatology } \\
\hline 2 & $\mathrm{~F}$ & 1 & 65 \\
\hline 5 & M & 1 & 46 \\
\hline 13 & M & 2 & 48 \\
\hline \multicolumn{4}{|l|}{ Neurology } \\
\hline 4 & $\mathrm{~F}$ & 1 & 45 \\
\hline 7 & M & 1 & 57 \\
\hline
\end{tabular}

\section{Abbreviations table 1}

F Female

M Male 


\section{6 | Chapter 6}

\section{Main findings}

Three main findings became apparent when analysing the interviews:

- Possibility (or desirability) of CPGs enhancing the practice of SDM;

- Added value of integrating SDM in CPGs in general and the PCFC guideline specifically;

- Usefulness of a PDA accompanying a guideline.

Before describing the main findings, it is important to note that interviewees interpreted the term SDM differently. When asked to describe SDM, half of the participants referred to it as reaching a decision together with other clinicians, e.g. during a (multidisciplinary) team meeting without involving the patient. After providing participants with a commonly used definition of SDM, and briefly discussing the concept, several participants were of the opinion that if there was a clear superior treatment option, the decision should lie with the clinician and there was no need for patient involvement. Almost half of the participants found that patients and/or parents needed to be included only when there was not an obvious best choice ("grey area"), or when decisions were not treatment related, e.g. decisions about where to die or how to say their goodbyes. Furthermore, there seemed to be confusion between sharing decisions and who has the final responsibility for the decisions made. Some participants did not want to burden the patient/parents with the responsibility of deciding on their child's (end-of-life) care, stating: "The parents have to live with that decision." (Participant 3).

\section{Possibility (or desirability) of CPGs enhancing the practice of SDM}

When asked if CPGs could potentially enhance SDM, the responses were mixed. About half of the participants mentioned that it could be helpful when there is disagreement; to make sure you cover all the relevant topics, including topics you yourself might consider less important, but are valuable to patients; and to ensure completeness of information provided.

Some pediatricians commented that CPGs and SDM do not go together as they regarded CPGs paternalistic in principle and are therefore irreconcilable with SDM. Others thought it could be a good combination (Table 2).

Another reason why some participants said that CPGs and SDM do not go together was because they regarded SDM an attitude or skill. A pediatrician is either willing or capable to share decisions with a patient or not, and adding SDM as a recommendation to a guideline will not change that attitude. "It is the difference between 'the art of medicine' and 'medicine' ", according to two participants (2 and 12). Several participants commented that to support SDM as a skill, the recommendations in the CPG needed to be more practical. For example: one of the guideline recommendations is to clarify and collaboratively set goals; but no practical guidance is offered on how to do this in clinical practice. Some participants, however, thought that incorporating recommendations on SDM in a CPG, might make it easier to practice it because e.g. it makes it less scary (see Table 2). 
Table 2: Illustrative quotes on possibility (or desirability) of CPGs enhancing the practice of SDM

\section{THEME THE PRACTICE OF SDM ILLUSTRATIVE QUOTE}

\section{Useful/helpful}

"Perhaps it could help a clinician who is SDM-minded, but doesn't dare. I mean, if you

aren't experienced in palliative care yet, it can be quite, um, scary."

"Sure, especially when it comes down to points of disagreement, it can be helpful to choose a certain direction. In other guidelines, it is mentioned explicitly that you need to check with other specialists before you proceed. And with the patient and parents, of course."

"For some aspects, it could be the case that you yourself don't consider them, or that you are partial to certain things. But by mentioning all the aspects in a structured way in the guideline and discussing these with the patients, all topics that matter are covered."

"If you go through a list the patient probably thinks that you are a meticulous doctor who makes sure to tick all the boxes. However, it can also appear as being callous because it is not a conversation, you just go through the list."

"It must be useful when your peers have thought about it and decided to add recommendations on SDM, to support you or make it easier for you to do it yourself."

"It means you can adhere to the guideline more often without you having to explain time and again why you didn't adhere."

\section{Guidelines are paternalistic}

"A guideline will not immediately contribute to SDM. SDM depends on communication. And a guideline can obstruct that, as it says 'do this' and some people will claim that they are legally required to follow the guideline."

"Often guidelines say do A, B or C. They don't say consider A, B or C because there's the same amount of evidence. And if it would say consider $A, B$ or $C$ then you can discuss it with the parents."

\section{SDM is an attitude/skill}

"You don't need a guideline on how to have a conversation."

"If doctors don't do SDM, a guideline will not make them do SDM."

"I think that the way you involve the parents is 'the art of medicine' and not medicine. So, I think it comes down to the competencies of the doctor. You can't capture those in a guideline."

\section{SDM irrespective of guideline subject}

"I don't think it will help to integrate SDM in the guideline. A guideline helps when there's no common sense. This is common sense."

"Maybe we need a guideline on SDM; namely involve the parents and the patient with every choice concerning their care. These two lines, easy as that." 


\section{SDM integrated in guidelines}

Several options exist to address SDM in a guideline. The PCFC guideline opted to add recommendations on (shared) decision-making in the guideline as a separate chapter (see Box 1). The participants were asked how they felt about the innovative section on decision-making in the guideline. A participant noted that the recommendations on (shared) decision-making could help prepare the discussions with the patient/parents, and could help to put the patient in a social context. Several of the participants thought that most of the SDM-recommendations stated the obvious and that experienced pediatricians already practiced this. However, others said the recommendations might be useful for pediatricians who are less experienced or a bit hesitant. One participant indicated that the SDM-recommendations are valid for pediatrics in general and therefore need not be in this guideline. He suggested developing a separate guideline solely on SDM in pediatrics (see Table 3).

\section{Modifying a recommendation into an SDM-recommendation}

When showing the participants, the original single-option recommendation on pain relief and the modified multiple-option recommendation from the symptoms' section of the PCFC guideline (see Appendix 1), most participants preferred the modified recommendation. The modified recommendation was viewed as beneficial to engage patients/parents in the decision-making by showing considerations that are important to the patient/parents (Table 3). According to one participant the usefulness of the short, single-option recommendation versus the longer, multiple-option recommendation depends on the context, e.g. in acute or neonatal intensive care, the original - shorter - recommendation would be more useful. Views expressed by the participants working in neonatal intensive care reflected this notion.

Table 3: Illustrative quotes on added value of SDM integrated in CPGs
THEME ADDED VALUE OF SDM INTEGRATED IN THE GUIDELINE PCFC AND INTERVIEW \# GUIDELINES IN GENERAL ILLUSTRATIVE QUOTE

SDM-recommendations in guideline PCFC
"I feel that a disadvantage of this guideline is that, even though it is
corroborated by evidence, that the recommendations state the obvious."
"If you write it down in such detail, I would like to know the added
value for myself. What's in it for me when I have to deal with a high
complex situation? However, do I think everyone applies these SDM-
recommendations all the time in practice? No."
"If you are inexperienced, you can read these SDM-recommendations. I
think it's nice, but they are not really practical."

Modified multi-option(SDM) recommendation

"It's more agreeable. Also, because it contains the lines of reasoning."

"It provides more information, more possibilities to consider."

"This does represent the actual situation you're dealing with in practice. Do you as a doctor take the lead, or do you provide more options? So that the parents are in a position to choose as well."

"For the more complex decisions, of which there many in palliative care, it is beneficial to indicate the whole spectrum of care." 
"Nothing is black and white. And then it is nice that the guideline also provides alternatives that meet a certain standard; it prompts you to more discussion on what to do."

"The SDM-recommendation requires more deliberation and demands more of your communication skills."

"I would like to know the evidence base of each item mentioned. If it's part of the guideline, I would question if it was properly assessed."

"And, there is of course a balance in what makes a guideline practical. You cannot include all the literature, because then it would no longer be a practical guideline."

"If you want you can put everything in a guideline. I don't believe that's the way to go."

"Especially for the doctors who are being trained, nurses and physician assistants who are less experienced, have less knowledge, they will need a very clear guideline."

\section{Usefulness of a PDA accompanying a guideline}

Another option to address SDM in guidelines is paring a specific conditional recommendation with a PDA. A conditional recommendation is used when the underlying evidence is scarce or conflicting, or when more than one relevant treatment options is available. For conditional recommendations, it is known that an individual patient values the uncertainties and trade-offs differently compared to other patients (202). Although most participants perceived the PDA to be beneficial for the patient/parents, but to a lesser degree for themselves. Most of the participants preferred to convey the information mentioned in the PDA in person, out of fear of losing rapport with the patient when looking at a piece of paper or tablet during a consultation. Others believed patients/parents would not want to use PDAs. Some interviewed pediatricians expressed that the PDAs contained useful topics they would normally not address during consultation, and suggested it could be used as a checklist to ensure important topics were covered. Two participants mentioned that patients/parents often do not remember everything mentioned during a consultation and that PDAs are ideal for patients as a reference document to take home, re-read and reflect on what was discussed (see Table 4).

Table 4: Illustrative quotes on usefulness of a PDA accompanying the CPG

THEME USEFULNESS OF A PDA ACCOMPANYING THE CPG

INTERVIEW \# ILLUSTRATIVE QUOTE

\section{Usefulness of PDAs to patient/parents}

"If the effects [of the interventions] are the same, then of course the parents can make the decision. And it's quite neat to have all the pros and cons on paper."

"I must honestly say, based on what I'm seeing right now, it would be nice to hand them [patient/parents] something. If they want to think about it, they can weigh the pros and cons."

"It can indeed be handy to make a decision, because sometimes the practicalities of a treatment decision elude you [as a doctor], but those can be very important to the parents."

"It is easy to have something like that, listing all the points. It won't make it easier, but it will make it more transparent. We don't have a lot of those yet, do we?"

"You can discuss it and read it again later. And it's way better than my illegible handwriting." 
"The patients remember only $20 \%$ of what's being discussed. And, because you can give it to take home, it means that people don't need to make on the spot decisions during consultation."

"I'm not sure if these make it much clearer. It could also complicate matters for patients, these kind of choices."

"I think it's a lot of text. I don't think patients will read it."

"It's more of a checklist for myself, not something you go through together."

\section{Usefulness of PDAs to pediatricians}

"When I look at it, I immediately notice that it covers a dilemma we deal with a lot. And it is actually a nice format, so I definitely think it's of use to us. Can you email it to me?"

"I think so. It shows you the experience of others in these instances, what they did. And it also gives you an idea of what to ask in cases you yourself are a bit hesitant about."

"Sometimes when talking to parents, you notice they get confused, and you need to tell more. If you can show it with visuals like this, is even better."

"Yes, I think it's really practical: not a lot of text and it looks appealing. Most of it, is in your head, but this makes the considerations really explicit. And translates it directly to aspects patients care about."

"It doesn't need to be part of a guideline, I can do it myself."

"I'd prefer to explain it myself. It is part of being a doctor. You'll notice a response, a hesitation. And as a doctor, you prefer some medicines yourself, because you're more familiar with them and you'll advise those."

"No, I can do that myself. I'm more inclined, on the basis of my experience and taking the patient into account, to take the lead and say: "I think this is the best medicine."

"I think I can explain it easily in 5 minutes. The question is whether that is true. Okay, you're making me reconsider my answer."

"I don't think I would use it. I feel a bigger urge to look the patient in the eyes and tell them what's it about."

"I don't think it's right. I suppose additional explanations are needed? But, I think they're risky, because it will affect the verbal communication negatively."

\section{Discussion}

Several participants acknowledged the added value of SDM being included in the guideline PCFC, and more participants were of the opinion that guidelines in general potentially could enhance SDM. Regarding the specific SDM-recommendations in the PCFC guideline, several participants judged these as stating the obvious and lacking detail and practical guidance. Some even said they were offended by these recommendations, perceiving it as an attack on their professionalism because they already do this. Clinical observations, however, have shown that SDM during patient contacts is not standard practice yet. Clinicians think or say that they practice SDM, but when their interactions with patients are analysed, it appears that the level of SDM leaves room for improvement $(67,68,252,269,270)$. The felt attack could perhaps be unjust because of optimistic bias. Furthermore, research suggests that there seems to be a tendency with clinicians to share non-treatment related decisions with patients, and to share the treatment related decisions to a lesser degree $(271,272)$. When it concerns children, this could be expected as parents and health professionals might take a protective stance towards the child. However, the child might prefer to be protected in some situations and wants to share decision-making in other situations. In addition, some children prefer to leave the more 'serious' decisions to their parents and healthcare professionals, whereas other children prefer to share the decision $(261,273)$. The 
views expressed by the participants seemed to confirm that mainly the non-treatment related decisions where shared, or the less 'serious' ones. Combined with the situation that the clinician 'decides' which information to share with a patient, the stage for SDM is not ideal $(69,270,274)$.

The intention of the Dutch Pediatric Association was to potentially enhance the practice of SDM in pediatric palliative care and to do so by integrating SDM in the guideline PCFC. Therefore, recommendations on SDM were included in the guideline and the necessity of SDM was explained in a separate chapter. However, these SDM-recommendations have not been integrated in the treatment related recommendations. The integration of SDM could be done e.g. by re-phrasing these recommendations to increase option awareness and/or to include patient preferences. Other possibilities are to structure the deliberation process and describe it more explicit in the guideline, and/or providing patient support tools (275). These tools could be linked to a specific recommendation or to the guideline as a whole (249). In the current format, the guideline might not encourage the interviewed pediatricians to involve patients/parents when talking about treatment choices which might inadvertently contribute to SDM only being used for non-treatment related decisions in children's palliative care.

Participants were open to recommendations related to an SDM-approach to treatment decisions (i.e. structuring the options in a recommendation to increase option awareness), as was shown when we discussed the modified recommendation on pain relief. More than half preferred the 'SDM'-recommendation because it can help open the discussion, it shows underlying arguments for different treatments, such as pros and cons, and it enables patients and/or parents to choose. Recommendations such as these are preferable according to the Institute of Medicine (IoM). In its report 'Clinical practice guidelines we can trust', loM suggests refraining from so-called blanket recommendations: a recommendation for all patients to choose one particular treatment, irrespective of the patient's characteristics, preferences and values. loM recommends to describe the options and trade-offs in a recommendation encouraging SDM, as its respects the individual choice. In this way guidelines, according to loM, become tools for patient engagement and activation (157). The last couple of years more CPGs are being developed in which recommendations address trade-offs and mention more than one option (199, 209, 276-278).

Another strategy to adapt guidelines so that they could enhance SDM is imbedding patient support tools - such as PDAs - in CPGs. The majority of participants thought that a guideline (recommendation) accompanied by a PDA would be beneficial to engaging patients and sharing the decision-making. Systematic reviews have shown that the use of PDAs supports patients to engage in deciding about their care (279). Our interviews suggest that the use of PDAs could also help pediatricians to check if they have covered all the topics (PDA as a checklist) and address issues they would normally forget or not consider important. Another benefit of PDAs mentioned by pediatricians was that patients can take the PDA home and reread it. Patients often do not remember everything when talking with the clinician, and by taking it home they can weigh the pros and cons in a more comfortable and less time-pressured setting. PDAs can also help patients to ask questions, as patients not always dare to ask their pediatrician everything $(280,281)$. The pediatricians who were not convinced of the benefit of a PDA 


\section{2 | Chapter 6}

claimed that patients did not want to use them (251). Research has shown that patients do want to be involved in (deciding about) their care, and need to be involved $(166,269,282)$, including children and adolescents (and their parents) (283-288). Another reason why some pediatricians were not inclined to use a PDA was that they felt they know best what to advise based on their expertise, experience with the treatments and the patient sitting in front of them. This attitude is risky for three reasons; firstly, well-informed patients who actively participate in their care are more satisfied with their decisions (289). Secondly, without using a PDA, the clinician will likely not be complete when providing information to the patient $(69,274)$. And thirdly, it has also been shown that clinicians are not always correct in predicting what the patient wants (32, 63). Moreover, the preferences of a clinician, from the perspective of being a patient herself or himself, often do not match with what they would recommend the patient (174). Instead of projecting their own opinion on their patients, clinicians should ask what the patient prefers; not only when it concerns treatment decisions but also when it comes to being involved and deciding about their care.

Another important finding is that participants were worried about burdening parents with the responsibility of deciding on their child's end-of-life care if they engaged them in SDM. However, instead of assuming that parents do not want to be burdened with this responsibility, discussing this with the parents, and/or child, acknowledging their autonomy in the decision-making process, seems to be justified and fitting with SDM. Some research has shown that parents want to be the ultimate decision maker for their child (290), and children value autonomous decision-making, without excluding their parents $(286,291)$. In the interviews the pediatricians used the words responsibility and sharing the decision-making interchangeably. It appears that the pediatricians are not aware that even when the decision-making is shared with the child and/or parents, they have the final responsibility for the decision. This unclarity might make pediatricians wary of SDM when it comes to sharing decisions.

Regarding the comments made by the pediatricians that SDM is a skill, and that the recommendations in the PCFC guideline mainly addressed the what and not the how of SDM, the guideline could be enriched with examples of SDM in the pediatric palliative care context. For example, Van der Weijden et al suggest using a vignette describing how a patient and a healthcare provider discuss the options to reach a shared decision, or could provide scripts modelling SDM-language. However, enhancement of the practice of shared decision-making requires more than an isolated guideline which integrates SDM, especially when it comes to skills and attitude. It needs to be imbedded in an overall SDM contextualized effort for SDM to become common practice. Healthcare professionals could be trained, receive feedback on SDM-performance, be facilitated in an SDM-approach, work in organizations which advocate SDM and where there is senior-level buy-in of engaging patients in their care and sharing the decision-making with them $(252,270)$.

\section{Limitations and strengths}

Limitations of this study are that the findings are limited to the 15 participants and the university medical centers (3) they work at. Even though the participating centers were considered forerunners of SDM, it does not mean that other pediatricians in other medical centers have the 
same opinions. However, data saturation occurred after the eight interviews. Another limitation was the timing of the interviews; in hindsight, the interviews might have taken place too early as the guideline PCFC had not been fully implemented yet. Which meant that most of the participants had not used the guideline yet, and some had only heard of it. This was countered by showing the participants the guideline and by walking through the recommendations on SDM. Key strengths were that we conducted the research with the developers of the PCFC guideline themselves (EV, LK) and that participants were very forthcoming and open during the interviews as they were being interviewed by a doctor to be. We also carried out a member check on the interview transcripts.

\section{Conclusions}

The interviews showed that most of the participants thought that CPGs in general potentially could enhance SDM. However, integrating SDM into a guideline seems not to be an easy feat, and guideline developers have to walk a tightrope on how to formulate recommendations on SDM. They have to avoid stating the obvious because it might offend and alienate the pediatrician. At the same time, they have to provide more detail on how to practice SDM. Furthermore, developers could consider formulating more 'open' recommendations. Especially in case of preference sensitive choices, the recommendation should describe (treatment) tradeoffs and (treatment) alternatives and provide more detailed guidance. Another consideration is to provide tools amalgamated with specific guideline recommendations that enhance SDM, such as PDAs.

\section{Acknowledgements}

We would like to thank all interviewed pediatricians for their input, openness and time. Especially, we would also like to express our thanks to Wim Tissing, MD (UMC Groningen, the Netherlands) and Astrid Heijnen (UMC Groningen) for their support in organizing the interviews. No conflicts of interest to report. 


\section{Appendix 1- Modified guideline recommendation on pain relief}

\section{ORIGINAL RECOMMENDATION PALLIATIVE CARE FOR CHILDREN}

The first choice in pain relief in the palliative phase is product $X$ with dose A.

\section{MODIFIED MULTI-OPTION GUIDELINE RECOMMENDATION}

The first choice in pain relief in the palliative phase is product $X$ with dosage A. After deliberation with the child/parents, you can decide on a lower dosage $\mathrm{B}$ or $\mathrm{C}$.

Considerations:

- Most of the children/parents want to be informed on the sideeffects, especially the side-effect drowsiness. (ref. $x x x x$ )

- For some children/parents the benefits of pain relief do not outweigh the side-effects (drowsiness of the child). (ref. xxyz)

Heterogeneity exists in the preferences of children/parents: $30 \%$ choses dose A; $50 \%$ choses dose B; and $20 \%$ choses dose $\mathrm{C}$. (ref. $x y z x)$

\section{Appendix 2 - Interview guide (translated into English)}

\section{QUESTIONS}

\section{$1 \quad$ Guideline ( $<5$ minutes)}

1.1 Can you briefly explain what you consider a clinical practice guideline?

1.2 Do you apply them? When/how do you apply them?

1.3 Do you find the guidelines beneficial to patient contacts? Why/why not and how?

\section{$2 \quad$ Decision-making}

2.1 Are you familiar with the practice of shared decision-making (SDM)?

- If yes: according to you what does SDM stand for?

- If no: read the definition out loud and ask for a reaction.

2.2 What is your opinion of SDM?

2.3 Having discussed this, do you believe guidelines offer possibilities for improving SDM among doctors and between doctors and patients? What I mean by this is that a doctor who uses guidelines during consults anyway feels more stimulated, supported or assisted to actively use guidelines.

\section{PRIMERS, EXAMPLES AND REMINDERS} FOR INTERVIEWER

a.k.a. national guidelines, local guidelines, protocols, other? Does the answer clearly reveal the interviewee's opinion?

\begin{abstract}
... remain quiet, leave room for explanations, if only yes or no then ... If the interviewee gives his/her opinion straight away, follow up by asking what they mean

... If the interviewee gives another description, let them read the working definition used in the study and ask for the interviewee's reaction (Can I summarize your answer as ..., for this study we used this definition - what is your reaction?)
\end{abstract}

If yes: how and why? 


\section{(Continued) Appendix 2 - Interview guide (translated into English)}

$3 \quad$ Guideline Palliative care for children

3.1 The national guideline Palliative care for children was introduced in the summer of 2013.

Are you familiar with this guideline?

How?

- (If yes: can you summarize your opinion of this guideline in two sentences?

- What did you find most striking about the guideline?

- Do you ever use the guideline?

o If yes: which part of the guideline do you use and/or in which situation/ when?

$\S$ When did you last use the guideline?

o If not: why not?

3.2 An innovation introduced by this guideline is a set of recommendations for the decision-making and organisation process.

(Are you familiar with these? (familiar with these elements, which were not mentioned under 3.1))

- If yes: do you use them? Why or why not?

- What is your opinion of the inclusion of this type of recommendations in guidelines?

We have a number of other examples of how SDM can be improved:

- Two decision aids: (1) anticoagulant comparison and (2) step-by-step plan for bone infection

- What is your opinion?

We have also made reformulated an SDMrecommendation.

- What is your opinion?

3.4 Do you have a preference? And why?

Casting a quick glance over a printout of the guideline, what is your first reaction?

(3.5) Form, usefulness, size, colours, number of recommendations, volume, availability in digital format

Earlier in the interview, we discussed whether guidelines could contribute to shared decisionmaking. Your answer at the time:... Did you find this guideline (if known to the interviewee) supportive?

If yes: in what way?

Can you think of other aids that would have been helpful in this respect?

3.6 Which aids do you feel could help patients and their parents become more involved in the healthcare process?

The final question l'd like to ask you about the guideline Palliative care for children is: has special attention been paid to this guideline on your ward?

- If yes: how was the guideline implemented on your ward?

o By whom?

o How?

o When? (> 1x)

o What was your opinion?

- If no: do you know why not?

$\begin{array}{ll}- & \text { Seen? } \\ -\quad & \text { Read? } \\ -\quad \text { Developed? } \\ \text { - Implemented? }\end{array}$

Summary, recommendations, decision chart, brochure for parents, indicators... Situations/moments: prior to, during or after the discussion/multidisciplinary meeting/ consultation, uncertainty, multiple options, no consensus...

Tools/training:

- Summary chart, flow chart, app, clinical path, decision aid, EPR link

- Words such as discuss, consult, ask the opinion of the parents/child, acknowledge their viewpoint

- Training, focus group, video (training), trial implementation, peer review 


\section{6 | Chapter 6}

\section{(Continued) Appendix 2 - Interview guide (translated into English)}

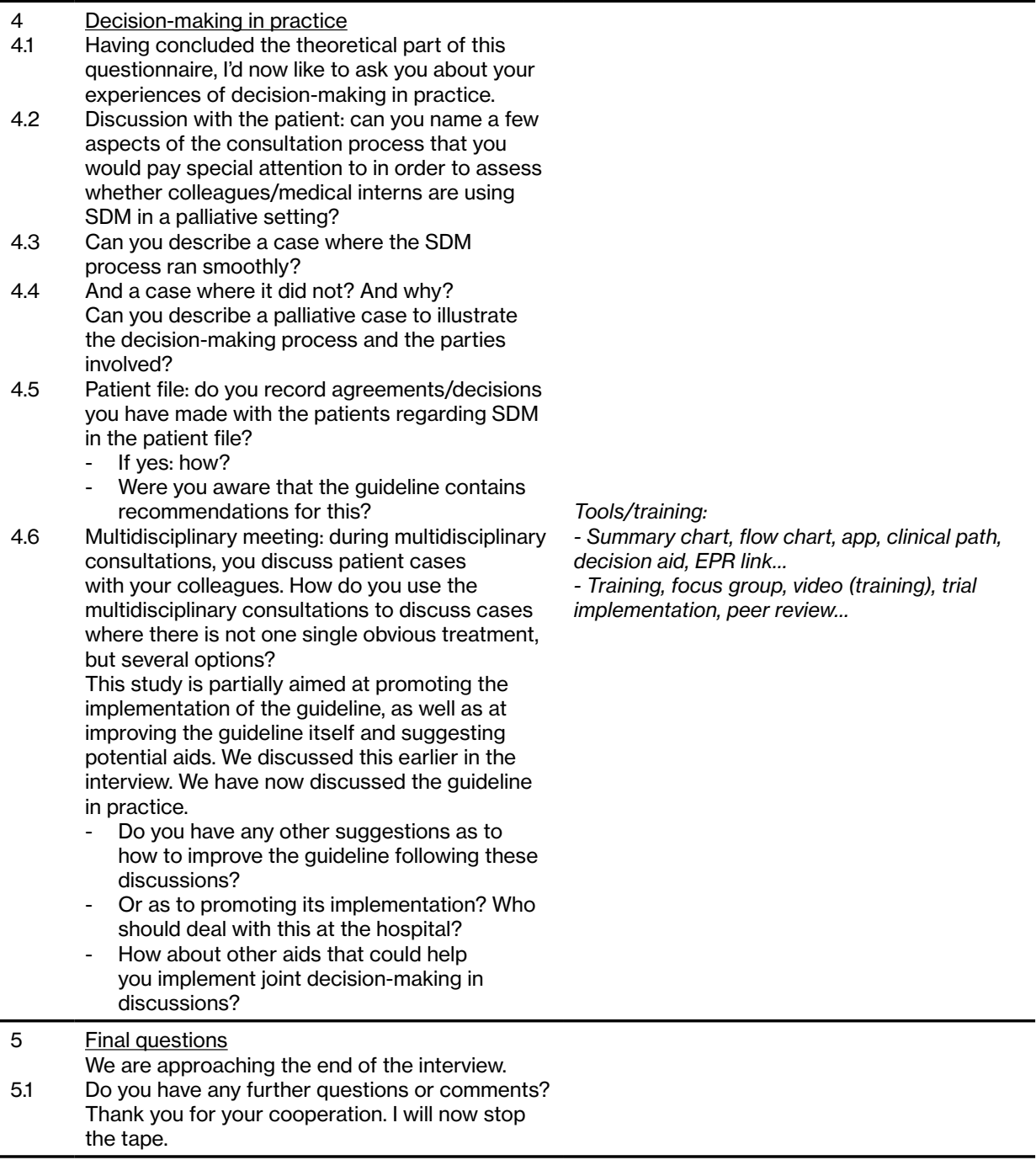

Evaluation after the tape has been stopped: what went well and what could have gone better during the interview? 
Appendix C - Code book final - English

\section{Clinical practice guideline (CPG)}

CPG: description

- CPG definition

- Scope of CPG concept (= broad concept)

- Multidisciplinary CPG

- CPG synonym/related term (reference point, reference work)

- Difference between protocol/CPG

CPG: qualification

- CPG qualification: evidence-based

- CPG qualification: legibility (illegible)

- CPG qualification: size (too big)

- CPG qualification: everyday practice

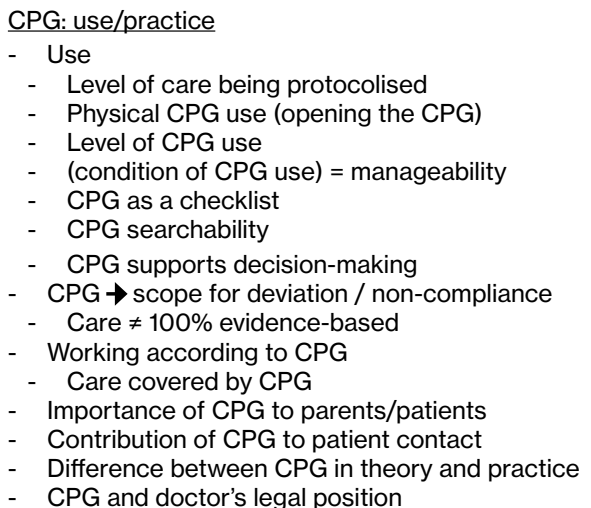

CPG: knowledge

- CPG internationalization (knowledge)

- Limited knowledge of professionals (e.g. due to specialization)

- CPG makes knowledge accessible

- $\quad C P G$ if knowledge area is not part of daily routine

- CPG as counterweight to 'random' information

- Knowledge-sharing in a profession not practiced by a lot

- $\quad$ Guideline = knowledge instrument

CPG: uniformization

- Importance of uniformization

- Uniformization (due to working with protocols/ guidelines) $=$

- Inter...variation (professional, center, ...)

CPG: development and implementation

- CPG development process

- Purpose of international cooperation (e.g. in CPG development)

- CPG and local implementation

- Difference between CPG and local practice

\section{Shared decision making (SDM)}

SDM: description

SDM definition

SDM definition unknown

- $\quad$ SDM = modern healthcare

- $\mathrm{SDM} \neq$ paternalism

- $\quad$ SDM = Multidisciplinary meeting (MDM)

- $\mathrm{SDM}=$ freedom of choice

- $\quad$ Care = SDM

SDM: information

- SDM = inform patient/parents

SDM: option

SDM = options incl. pros and cons

- $\quad$ SDM = optional talk after MDM (with parents)

- $\quad \mathrm{SDM}=$ point out consequences of preferences

- $\quad$ SDM = explain possibilities

- $\mathrm{SDM}=$ steer towards a decision

- $\quad \mathrm{SDM} \neq$ steer towards a decision

SDM: decision

SDM $=$ shared decision-making (patient + doctor)

SDM = share the decision-making

- $\mathrm{SDM}=$ together

- $\quad$ SDM = parents $/$ patient decide

- $\quad$ SDM = parents agree with chosen policy

- $\quad \mathrm{SDM}=$ involving the child in the decision-making

- $\mathrm{SDM}=$ doctor decides in case of superior option

- $\mathrm{SDM}=$ parents decide in case of grey area

- $\quad$ SDM = discuss consequences of decision

- $\quad \mathrm{SDM}=$ make agreements

- $\quad$ SDM = seek consensus

- $\quad$ SDM = second opinion

- $\quad$ SDM = agreements in MDM

- $\mathrm{SDM}=$ live with decision

- $\quad \mathrm{SDM}=$ patient/parents take no medical decisions

- $\quad \mathrm{SDM}=$ shared decision-making not compulsory

SDM and consult/talk

SDM = importance of interaction

SDM $=$ conversation technique

- $\mathrm{SDM}=$ room for acceptance

- $\mathrm{SDM}=$ transparency

- SDM = gather support

- $\quad$ SDM = keep in touch/show (and maintain) interest

- $\quad \mathrm{SDM}=$ room for discussion

- $\quad$ SDM = share precautions

- $\quad$ SDM = check that info/discussed topic has been understood

- $\quad \mathrm{SDM}=$ give room if parents disagree with policy

- $\mathrm{SDM}=$ create openness in first discussion

- Conversation techniques contribute to SDM

- $\mathrm{SDM}=$ importance of non-verbal communication

- Medical interns conduct no palliative care (PC) discussions

- Trap: think on behalf of parents/patient

- Trap: fall back on knowledge (instead of feeling)

- SDM = room for emotions

- Doctor knows what patient/parents want 


\section{8 | Chapter 6}

\section{(Continued) Appendix C - Code book final - English}

SDM: role of doctor

- SDM = doctor advises

- $\quad$ SDM = doctor knows best

- $\quad$ SDM = responsibility lies with doctor

- $\mathrm{SDM}=$ attitude/competence

- $\quad$ SDM = gauge opinion of parents/ patient

- $\quad$ SDM = ask parents for their perception

SDM: role of patient/parents

- SDM = initiative with parents

- Role of patient/parents in SDM

- SDM contributes to patient's autonomy

- Should parents know everything (about CPG)

- $\quad S D M=$ stress of choice for patient/parents

\section{SDM and MDC}

- SDM = include parents' viewpoint in MDM

$\underline{\text { SDM and practice }}$

- SDM in practice

- $\mathrm{SDM}=$ not easy in practice

- SDM differs per phase

- Differences in palliative care paths

- When to apply SDM

- How to apply SDM

- Limited choice in child oncology/IC/Neonatal care

- $\quad$ SDM = not every detail

- $\quad$ SDM = always involve parents/patient

- $\quad$ SDM = importance of parental involvement

- $\quad$ SDM = dependent on parents' capability

- SDM depends on equality of knowledge

- $\quad$ SDM = dependent on type of parents

- SDM should be included in training (explanation: in order to equip doctors to implement/practice SDM, it should become part of their training)

SDM: assessment

- Importance of SDM

- $\quad$ SDM = must/always (ethical/principle)

- $\mathrm{SDM}=$ common sense

- Usefulness/purpose of SDM (compliance, mastery)

SDM: limitation

- SDM obstacles

- SDM and time

- SDM time as limitation

- Complexity of SDM practice (surrogate parents)

SDM: quideline

- Need of CPG on SDM or an SDM CPG

SDM in CPG positive

- CPG can improve SDM $\underline{\text { SDM in CPG negative }}$

- CPG hampers SDM

- Little room for SDM in CPGs

- Doubts regarding effectiveness of SDM in CPG on SDM in practice

- SDM in CPG does not contribute to SDM attitude

\section{SDM: choice of words in CPG}

SDM case

- SDM case description positive

- SDM case description negative

SDM recommendation

- Preference for SDM recommendation

- Preference for short recommendation

- SDM recommendation leads to SDM

- Relation between SDM recommendation and CPG size

- Disadvantage of SDM recommendation

- Preference for type of recommendation depends on situation

\section{CPG Palliative care for children (PCFC)}

CPG PCFC: use

- Familiar with CPG PCFC

- Familiar with "entire" CPG PCFC

- Familiar with parts of CPG PCFC

- Familiar with existence of CPG PCFC (e.g. through cooperation)

- Not familiar with CPG content

- CPG PCFC use

- CPG PCFC not used

- CPG PCFC not read

- Intention to use CPG PCFC

- CPG PCFC as knowledge instrument

- Relation between CPG use/introduction and release date

- CPG PCFC as reference work

- Importance of acting in practice $\neq \mathrm{CPG}$

- Amount of clinician's expertise in regard to need of using CPG

- Match between CPG PCFC and daily practice

CPG PCFC: assessment

- Positive existence of CPG PCFC

- CPG PCFC description

- CPG PCFC usefulness

- CPG PCFC usefulness negative

- CPG PCFC size

- $\quad$ CPG PCFC = illegible

- CPG PCFC not applicable to subspecialty

- CPG PCFC not usable

- CPG PCFC in digital format only is not useful

- Ease of CPG access/location

- CPG disadvantage: recommendation "states the obvious"

- CPG PCfC searchability

- Importance of CPG summary (usefulness/ applicability thanks to summary)

- CPG PCFC invites reflection 
- $\quad$ CPG PCFC provides support

- SDM language use in CPG PCFC

- CPG PCFC includes social context

- $\quad$ CPG PCFC is problem-oriented

- CPG PCFC color use is useful

- CPG PCFC in digital format only is fine

- Set of recommendations = summary

- Relation between topic size and CPG size

- Relation between CPG comprehensiveness and CPG size

GPG PCFC: Evidence-based medicine (EBM)

$$
\text { - } \text { CPG PCFC = EBM }
$$

\section{CPG PCFC: Palliative Care (PC)}

CPG PCFC: decision-making and organization

- Positive about CPG PCFC layout

- Negative about CPG PCFC layout

- Decision-making (belongs) in CPG

- Reach agreements regarding decision making (= CPG PCFC recommendation)

- Organization of care (belongs) in CPG

CPG PCfC implementation:

- App improves CPG PCFC implementation

\section{Patient Decision Aid (PDA)}

- Preference for oral advice rather than PDA

- PDA incomplete

- PDA useful to patient/parents

- PDA not useful to patient/parents

- PDA is handy = useful to doctor?

- Comprehensiveness of PDA information / checklist

- PDA n/a or not required

\section{Implementation}

Local implementation

- No implementation on ward

- Implementation by ambassador/ward

Promotion of implementation

- Implementation thanks to publicity

- Implementation thanks to CPG PCFC evaluation

- CPG PCFC dissemination

- Usefulness of CPG summary for implementation

- Implementation thanks to peer review (= added value according to $C P G$ )

- CPG must influence user action (= added value according to CPG)

- Implementation thanks to feedback of CPG compliance (= added value according to CPG)

Obstacles to implementation

- CPG delivery $\neq$ implementation

- Necessity of CPG implementation prior to application

- No active reminder to implement CPG PCFC

\section{File/notes}

Record keeping

- (Limited) record in file

- Record keeping by letter

- File: summary of discussion with parents

- Record keeping equals policy note keeping

- Parental opinion/decision in file

- Notes in file for transfer purposes

- Note in file regarding personal experience of patient/parents

\section{CPG PCfC file recommendation}

- CPG file recommendation (unknown)

\section{Multidisciplinary meeting (MDM)}

- No parents in MDM

- MDM options to be proposed to parents 


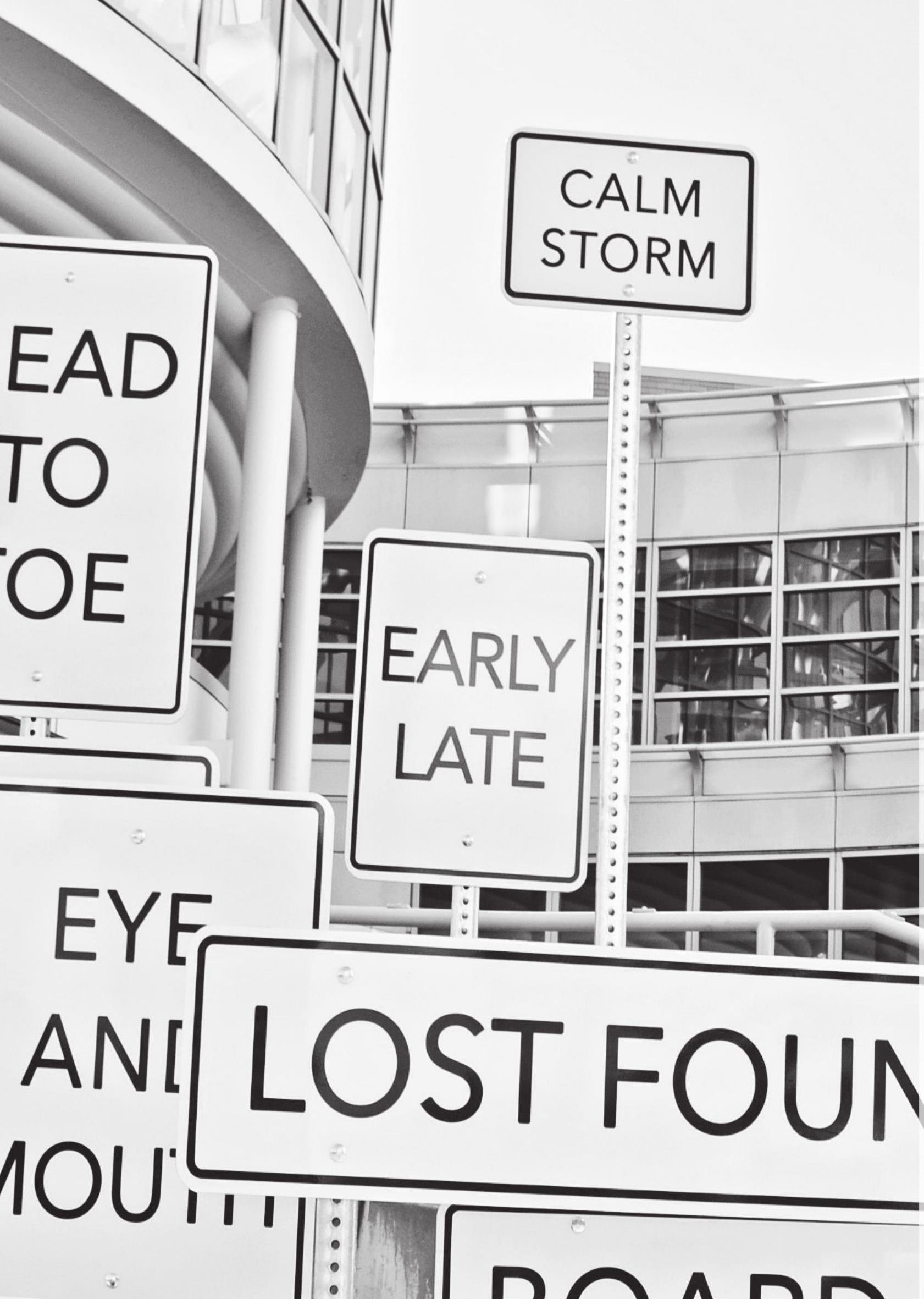


Chapter 7

\section{General discussion}

PREVENT CURE 
122 | Chapter 7 


\section{General discussion}

The general discussion first restates the aims and research questions of this thesis. Second, it provides an overview of the study results in the main findings. The strengths and limitations of this thesis are described next. After that, I will return to the concerns as described in the (worlds of the) introduction while reflecting on the main findings and compare these findings to other research. Finally, I present the conclusions on tools and knowledge, the needs of healthcare professionals, and recommendations for practice, research and policy.

\section{Aim \& research questions}

Knowledge in health care is vast and accumulating fast. Next to knowledge from scientific research, data and knowledge from clinical practice and on patient preferences, experiences and outcome are becoming more readily available. To make all this knowledge available to healthcare professionals and patients in a timely matter and in such a way that it is easy to digest and apply, tools are developed. These tools support knowledge translation and (shared) decision-making. Knowledge translation is "the synthesis, dissemination, exchange, and ethically sound application of knowledge to improve health, provide more effective health services and products, and strengthen the healthcare system" (292). Shared decision-making (SDM) is defined as "an approach where clinicians and patients share the best available evidence when faced with the task of making decisions, and where patients are supported to consider options, to achieve informed preferences" (293).

The aim of this thesis was fourfold. Firstly, in the domains of health care (curative, palliative care, long term care and public health) tool types are no longer developed without a clear definition and use (chapters 2 and 3). Secondly, there exists a common terminology when referring to tool types (chapters 3 and 4). Thirdly, to make better use of the different knowledge sources available (chapter 5), and finally provide healthcare professionals and patients, and possibly other users such as policy advisors and insurers, with a set of pragmatic tools that cover their needs in knowledge translation and decision support (chapters 3 and 6).

The following research questions were formulated:

1. What tool types to translate knowledge and support (shared) decision-making are available to healthcare professionals (and patients) in the Netherlands? (Chapter 2)

2. How are these tool types defined and does consensus exist on the definitions across the healthcare domains in the Netherlands? (Chapters 2 and 3 )

3. Which criteria do these tool types need to meet and which purposes do they serve so that healthcare professionals and patients consider them trustworthy and useful? (Chapter 4)

4. Do we consider all knowledge sources when developing tools, and what does that mean for tool development? (Chapter 5)

5. What are healthcare professionals' needs using tools for knowledge translation and shared decision-making? (Chapter 6) 


\section{Main findings}

The first research question, and part of the second research question, was addressed by carrying out a scoping review (chapter two). A scoping review examines the extent and nature of research activity; it does not depict research findings in any detail but maps fields of study where it is difficult to visualize the range of material that could be available (93). The review looked at 20 national organisations that develop and disseminate knowledge tools. A knowledge tool is defined as a tool that distils, synthesizes and interprets the highest quality knowledge and research to serve knowledge translation and support (shared) decision-making. A tool type refers to a category, a kind of tool such as clinical practice guidelines (CPG) and patient decision aids (PDA). The clinical practice guideline Palliative care for children is considered a tool, not a tool type. When referring to a tool type such as clinical practice guidelines, it is in general and not to a specific guideline on a certain subject. The scoping review revealed numerous tool types. Even though only a limited set of national organisations that develop tools within the curative and palliative domain were included in the review, and thus disregarding locally, commercially and internationally developed tools, 126 tool types were found. Sixty-four of those were included in the review. Most of the tool types were ill defined or no definition was provided at all. The majority of these tool types were aimed primarily at healthcare professionals, a few at patients, and almost none (primarily) at policy advisors. A shared common terminology and mutual understanding of tool types in an ever increasing multidisciplinary and multi-level stakeholders' involvement is deemed necessary for the development and use of these tool types.

Preferably the definition of a tool type contained a description of the tool, its goal and its target user(s). This was one of the results of the RAND-modified Delphi-procedure (chapter three). The aim of the Delphi-procedure was first to reach nationwide consensus on the definitions of knowledge tool types. And two, to limit the number of tool types in the Netherlands. Thus, answering thesis research question two. The participants of the Delphi procedure were from various domains in health care such as curative and long term care, tool developers, scientists, practitioners, and government. These participants reached agreement on a set of nine tool types, which they considered important for knowledge translation and (shared) decisionmaking. Furthermore, they reached consensus on the definitions of five tool types within that set of nine tool types. These five tools were: clinical practice guideline, summary, flow chart, patient decision aid and protocol (of clinical practice guideline).

As the Netherlands were not the only country dealing with an abundance of ill-defined knowledge tool types, the third research question was dealt with on an international level. Therefore, a group of international experts with different backgrounds developed - during an evidence-informed consensus meeting - a framework for patient-directed knowledge tool types (chapter four). The experts decided to start with patient-directed knowledge tool types instead of a broader set of tool types, as developing a framework for just patient-directed knowledge tool types would be difficult enough. Expanding to other tool types could be a next step. Patient-directed knowledge tools are directly aimed at patients and their next of kin, not at their 
representatives such as patient coaches or patient organisations. The developed framework stated the purposes of these tool types and their core elements. The aim of this framework was to create clarity not only on what kind of patient-directed knowledge tool types exist but also which elements they prototypically should contain and to support tool developers and commissioners of tool development to decide when to develop which tool. The framework can also help healthcare professionals, patients and possibly policy advisors when to use which tool type. The framework needs further testing and probing by a larger group of stakeholders, which is why it was presented as a working framework.

As was mentioned before, a knowledge tool distils, synthesizes and interprets the highest quality knowledge and research to serve knowledge translation and support (shared) decisionmaking. But do these tools consider and use all the knowledge sources available? Even though efforts are being made that clinical practice guidelines use different knowledge sources, there still seems to be a preference for scientific evidence. Furthermore, the hierarchy within scientific evidence seems to be very persistent; systematic reviews (SR) and randomized clinical trials $(\mathrm{RCT})$ are often the preferred knowledge source. However, RCTs may be unavailable or not provide the most suitable knowledge. Therefore, the GIN Working Group Appraising and Including Different (AID) Knowledge attempted first to draw (more) attention to the different existing knowledge sources, the exclusion of some of these sources, or using them implicitly without acknowledging them. And second, the Working Group attempted to indicate how to use these different knowledge sources, and showing possible flaws when mainly SRs and RCTs are used when developing tools such as clinical practice guidelines. The working group did this during several consecutive workshops at the annual conferences of the Guidelines International Network (GIN). It resulted in presenting important epistemological ${ }^{1}$ reasons to appraise and include a (wider) variety of different types of knowledge when developing guidelines. Appraising and integrating different knowledge will remain a challenge. However, the G-I-N Working Group AID Knowledge believes that much can be done to help guideline developers improve this. By appraising and including different types of knowledge in guideline development, guidelines will contribute to better inferences guiding decisions (chapter 5 ).

To find out what the needs of healthcare professionals are regarding knowledge tools, paediatricians were asked to reflect on tool types and strategies that integrated clinical knowledge and shared decision-making (chapter 6). Paediatricians reviewed and assessed the Dutch clinical practice guideline Palliative Care for Children (2013), that has a separate chapter on shared decision-making including communication recommendations. Other tools and strategies were patient decision aids and altered recommendations on pain relief of the Palliative care for children guideline. The altered recommendations included patient preferences regarding pain relief. Most of the interviewed paediatricians indicated that clinical practice guidelines could enhance the practice of shared decision-making; and did not think that guidelines and shared decision-making were mutually exclusive. They also thought integrating shared decision-making in a guideline was of added value for guidelines in general. Although

1 Epistemology is the branch of philosophy concerned with the theory of knowledge (source https://en.wikipedia. org/wiki/Epistemology). The theory of knowledge and understanding, especially regarding its methods, validity, and scope, and the distinction between justified belief and opinion; (as a count noun) a particular theory of knowledge and understanding (source: Oxford English Dictionary). Date: $1^{\text {st }}$ August 2019. 
for the clinical practice guideline Palliative Care for Children it would have been more helpful if the guideline would have made clear how to practice shared decision-making instead of just recommending it. Modified guideline recommendations, in such a way that they prompted asking for or clarified patient preferences were in majority regarded as useful strategies to enhance shared decision-making. Which was also the case for providing patient decisions aids together with the guideline. SDM does not concern just non-treatment related decisions but also treatment related decisions.

\section{Strengths \& limitations}

For the research in this thesis, I have chosen a predominant qualitative research approach. This was done for several reasons. First of all, the research is of an exploratory nature and a better, detailed understanding of a complex issue, requiring inductive and deductive reasoning was needed. Moreover, quantitative methods and statistical analyses seemed not to fit the research questions (264). On the one hand, I was after improved understanding of perspectives, experiences, opinions, attitudes concerning the use and translation of knowledge, knowledge tool types, and comprehension of the needs of healthcare professionals when using these tool types. On the other hand, I tried to reach consensus on (developing) criteria and purposes of these tool types. First, I will reflect on the different studies described in this thesis, the various methods and settings used suitable for a policy oriented thesis that also looks at the primary process in the end. However, related to qualitative research certain strengths and limitations should be mentioned. These will be addressed when reflecting respectively on credibility, transferability and dependability of the research per chapter and overall for the thesis.

Credibility refers to the believability and trustworthiness of the findings. In qualitative research, the richness of data is important and that participants feel the findings are credible and accurate. Transferability is about the generalizability of the data. Dependability concerns the consistency with which the findings can be repeated and will result in similar findings. It is also interlinked with the chosen research method (294). The terms 'credibility', 'transferability' and 'dependability' are also known respectively as 'internal validity', 'external validity' and 'reliability' and these terms can be loosely matched respectively with the terms 'validity', 'generalizability', 'reliability' and 'replication' which are more common in quantitative research (295).

We tried to accomplish the credibility, transferability and dependability via several approaches.

\section{Credibility}

To achieve credibility a number of approaches were used. Regarding the scoping review (chapter 2; Dutch chaos case) a broad range of different organisations were included to ensure a good overview of the Dutch situation concerning the availability of knowledge tools. Furthermore, an iterative approach was used to reveal possible additional new sources to be considered. The findings were spot-checked twice independently by the co-authors. A scoping review is not as thorough as a systematic review, combined with the restriction to curative and palliative care, this could mean that some tool types were missed. The aim however was to prove the hypothesis that there existed numerous knowledge tool types in the Netherlands and not to achieve an exhaustive overview of these tools. 
To ensure the credibility of the Delphi-study (chapter 3 ) the results of each round were shared with all participants, quantitative as well as qualitative, including the decisions the project group made based on the results. They also had the opportunity to ask questions anonymously, regarding the process, method and the outcomes. Moreover, the chosen Delphi-method was copied from the RAND cooperation, which has a lot of experience with this method. Shortcomings were that although we invited participants from all domains in health care, some domains were limited or not represented, for example health insurers; their perspective was missed in the Delphi. As the number of participants was well above the required minimum we felt that we mitigated this limitation. Another limitation could have been the accuracy of the experts' answers. That is why we chose a broad selection of participants with different backgrounds and expertise, instead of a small panel of experts, and shared all the participants' responses during and at the end of the Delphi procedure.

The experts participating in developing the framework of patient-directed tool types (chapter 4) were involved almost during the whole process. They developed the framework during the meeting and discussed it when finalising it via e-mail. Before publication they gave their approval. The elements of the framework were cross-checked with existing literature. A potential weakness was the extent to which the participants were involved in the subject. This was counteracted by establishing a group consisting of participants with different expertise and from various backgrounds, and by providing information beforehand so we started with a common ground.

The GIN Working group AID Knowledge (chapter 5) held open invitation workshops in which they presented the issue at hand. The participants, delegates of GIN conferences from all over the world, were asked for their input and feedback. The minutes were shared and participants were invited to comment. One could say that because of the highbrow character of the subject, interest in the subject is limited and participants do not represent the average group of people involved. We counteracted that with a group that has representatives with theoretical, practice and policy backgrounds. Additionally, literature and earlier research was also used as a basis and for comparison.

Credibility measures within chapter six (interviews with paediatricians) were member checking and independent coding by three 3 authors. Also, field notes were taken and discussed to reveal possible biases. Credibility could have been improved further by giving the participants the opportunity to comment on the analysis findings. Due to time constraints with the research team and the participants themselves this was deemed unfeasible.

\section{Transferability}

Transferability of the data is a slightly more complicated matter and is regarded limited. Partially because the research was mainly executed with tool types used in the Netherlands and a Dutch clinical practice guideline (respectively chapters two, three and six). Also, transferability is limited because part of the research was meant as a starting point to be followed through. However, moving from the scoping review to the Delphi-study more healthcare domains were included. The former covered curative and palliative care and the latter included long term care and public health as well. The newly added domains did not suggest many new tool types to be included in the Delphi. Which could suggest that the scoping review data sufficiently covered tool types used in long term care and public health for a large part as well. Outcomes 
of the review and Delphi were compared with other studies. Although glossaries existed of healthcare terms and some tools, and reviews of one specific tool type, similar exercises as carried out in the Netherlands were not found. The approach of the review and the Delphi could be repeated in other countries and/or in an international setting to see if it renders comparable results. Though this might be more a criterion for dependability. The data of the scoping review and Delphi-study were transferred to an international setting when developing the framework of patient-directed knowledge tools (chapter four). Again, the international experts did not add many new tool types when developing the framework. They, however, constricted themselves to patient-directed tool types. Possibly the framework could be transferred to other populations, such as healthcare providers or policy advisors, and the set up with purposes and core elements could be maintained. It is doubtful if the purposes and core elements would be (exactly) the same content wise, as the target group(s) of the tool types differ.

The findings of the study concerning different kinds of knowledge and different kinds of reasoning (chapter five) might be transferable to other domains. Not just health care tries to be as much evidence-based as possible to decide what is 'the best' way to go forward and to change practice and policy. Evidence-based working is becoming more eminent in other domains such as policy decision-making and the practice of law as well (296), even though they might have different knowledge sources and have not progressed as far with the evidencebased approach yet, they have to deal with some of the same issues and pitfalls as health care has.

The findings of the interviews regarding integrating knowledge translation tools with shared decision making (chapter six) could be transferred to guidelines on other subjects and guidelines for other healthcare professionals than paediatricians. Guideline developments groups are increasingly looking into how they can incorporate patient perspective and preferences in the clinical practice guidelines.

\section{Dependability}

Qualitative research is characterised by fluid structures, which change because of incoming and available data. Therefore, for each study the approach and/or method chosen and the changes therein, if any, were exhaustively described. Furthermore, proven methods such as the RAND-modified Delphi were used. Another limitation of qualitative data (but also of quantitative research) is that non-reported data can disappear. By being transparent about the found and used data, making them available with the publication of each article or on request, this limitation is hopefully addressed.

That does not mean that findings will be similar if the studies were to be repeated. Reasons why findings might be different could be due to firstly different participants in the Delphi-study, interviews and invitational meeting, or original participants might have gained more knowledge on the subject and changed their mind. Secondly there might have been developments since the studies were executed which could affect settings and the findings; for example, the uptake of a core set of tool types and the definitions of these tool types and a revised clinical practice guideline Palliative care for children. Thirdly, different researchers with another mind-set might infer different conclusions, as qualitative research is more subjective in nature and is influenced by the researcher. That is why, the research was executed under supervision and within a team, so that not one perspective could get the upper hand. Field notes were taken and discussed to 
discern and mitigate possible biases. To prevent that the perspective of the researchers was not clear to outsiders, the research was put into context (also called 'confirmability'). By being aware of this and acknowledging these experiences and beliefs, we tried to be as open minded as possible, and not to dismiss any data of face value.

Another means to increase dependability, the so-called SRQR and/or COREQ checklists were applied for all the studies in this thesis, except chapter five. SRQR stands for 'Standards for reporting qualitative research' and consists of 21 items. The aim of the checklist is to improve the transparency of all aspects of qualitative research. COREQ is the abbreviation of 'Consolidated criteria for reporting qualitative research' and focuses on interviews and focus groups. It aims for explicit and comprehensive reporting of qualitative studies by providing a 32-item checklist helping researchers to report on aspects such as the research team, study methods, context of the study, findings, analysis and interpretations $(191,263)$.

\section{Planned versus realised}

Related to dependability is the chosen research method. The method was chosen after formulating the aim and the research question(s). However, when I started my thesis, the research plan consisted of two parts: a theoretical part and an empirical one. The empirical part was to test some of the findings yielded by the theoretical research, in clinical practice. The findings of the theoretical part could have been corroborated, refined or disproven. It would have made the results more robust and additionally, it would have put the results more into context. Due to personal health circumstances, I had to put aside much of the work done by Lotte Veul, Nicole Wijnands (systematic review) and Jonne Westermann (patient file audit). This was unfortunate for me but even more for them. Despite this, I think the remaining empirical chapter (chapter six; interviews) - to which all three contributed - shows the value of letting practitioners reflect on what the clinical practice guideline Palliative care for children wanted to achieve and how it was received.

\section{Breadth versus depth}

Lastly, this thesis does not always delve as deep as other theses do. This could be considered a weakness. However, I would prefer to regard the thesis approach as a strength, as it tries to present a integral, complex picture, building bridges between (perceived as) separate worlds, and it searches for links and connections between and draws from different scientific fields. By having worked in different areas of health care, but also outside health care enables me not only to discern the gaps between the different areas more clearly but also enables me to see where the different areas overlap, both inside and outside health care. Which is a reflection of my background, having been and still being embedded in policy, research and partly in healthcare practice.

\section{Funding}

Funding (in kind) and means were provided by Maastricht University/CAPHRI, ZonMw, Zorginstituut Nederland and Kennisinstituut van Medisch Specialisten. Synmind provided their expertise in kind (chapter three). The researcher received no funds from commercial organisations. 


\section{Tools and knowledge}

The following section provides a somewhat deeper reflection on the main issues encountered, as well as comparisons with the current literature while returning to the concerns as described in the (worlds of the) introduction of this thesis. As there are many issues relevant to the uptake of knowledge and the use of tools, I focus on four overarching issues.

\section{Be more precise and stick to it}

One way of coping with the vast and expanding knowledge body (in 200711 new systematic reviews each day, nowadays 82 systematic reviews according to KSR Evidence) in health care is to develop tools. Tools that assist knowledge translation and support evidence-informed (shared) decision making, in short knowledge tools. These tools synthesize and interpret knowledge and in this way help to get research from 'bench to bedside' (73), or as it is called in the domain of knowledge translation (KT) in health care: 'moving knowledge to use' (292). And while we are very conscious and deliberate regarding the 'defining and interpretation' of evidence, for example when developing clinical practice guidelines $(297,298)$, we seem to be more careless when it comes to defining and explaining knowledge tools. A multitude of tool types is available to clinicians and patients, and they are mostly ill defined. There is no common shared terminology, which is key for development, implementation and use of these tools, which in turn might impede knowledge translation in health care. Not a lot of similar research has been found on defining tool types at a (inter)national level and limiting the number of tool types, but there have been several appeals to reduce the number of tool types with the aim to increase clarity and use, and so improve quality of health care and to be more vigilant about defining tools $(70,112)$. Stiggelbout $(88)$ did so in 2010 when reviewing the definition and classification of patient decision aids and Blume did so in 2016 when looking at external demands, among which knowledge tools hospitals have to comply with in order to deliver high quality and safe care (80, 299).

Already in 1992, Norma Lange made an acute observation when explaining the trouble if we cannot define things; if we cannot define it, we cannot control it, practice it, teach it, finance it, or put in into practice (112). Stakeholders reaching consensus on a national level on a core set of tool types and their definitions in the Netherlands was a promising first step. Several Dutch tool developers even decided to use or adopt the core set and to assign funding only to developing tool types belonging to this core set. However, real life practice proved (as expected) to be more wilful. For example, one of the stakeholders involved in the consensus procedure felt it necessary to re-do the exercise of defining the tool types for the benefit of their own organisation's rank and file acceptance $(300,301)$.

Furthermore, it seems that with an expanding knowledge base, the tool box keeps expanding as well. New tool types are still emerging, or they appear to be. The National Health Care Institute is for example working on a tool type called 'care tree' (107), which in essence is a digital decision tree. Another example is the 'quality standard'. In the Delphi study it was considered an umbrella term for tool types such as clinical practice guidelines and care standards, and it 
still is described as such in the document 'Toetsingskader' (Quality assessment framework) (302), however in recent years the term has been used for a tool type in its own right (303305). This begs the question if these new tool types, are actually new tools or similar tool types with new names. This was illustrated by a study by De Bleser et al carried out in 2006 regarding the tool type 'clinical pathway'; they found 84 different definitions (70). These findings are reminiscent of Walshe's characterization of developments in the quality improvement (QI) domain. He described how a similar set of quality improvement ideas and methods are presented repeatedly under different names and terminologies, and called it pseudo innovation. He 'blamed' the human tendency to be allured by the new and improved. And healthcare is not immune to it either. When embracing new ideas (or tool types in this case) we should ask ourselves are they really new and are they really an improvement. Constantly introducing 'new' tool types is in contradiction with Deming's first principle of quality management: the need for constancy of purpose (108).

The uptake and use of tools in health care is usually poor $(42,148)$. Although the amount of tool types has not been the (main) focus of tool implementation research, it could be a factor just as it is suspected in QI. And perhaps the "serial 'pumping and dumping' of" a myriad of tools during the last decades has - instead of sustained and continuing improvement - led to some waste of effort and resources as it did in the quality improvement domain (108).

If we want to help healthcare professionals and patients with making sense of all the knowledge available to them, we should not inundate them with tools. And we need to be more vigilant about their definitions and implementation. More discipline by and collaboration between stakeholders is necessary for sustainability of the core set. The Netherlands do not have an organisation such as NICE (The National Institute for Health and Care Excellence) that could take the lead in orchestrating this. Tool developers in the Netherlands are organised per healthcare domain, serving their own rank and file (e.g. The Dutch College of General Practitioners (NHG) for general practitioners, the Knowledge Institute of Medical Specialists, Akwa for mental health care, TNO for youth health care, and Vilans for long term care). Moreover, they are considered peers amongst one another. One organisation taking the lead to bind them more together regarding the (maintenance of and adherence to the) tool set, would be considered presumptuous. The National Health Care Institute could be considered, as it is an independent body, and taking its goals on quality and affordability of health care (system) into account (306). So far, the institute has been regarded with some suspicion and considered a 'bogeyman' by some parties because of unwanted interference when it comes to who is responsible for the quality of health care.

The funding of these tool developing and quality improvement organisations however is being centralised at ZonMw, the Netherlands Organisation for Health Research and Development. For the time being separate funding programmes are still in place, but in time ZonMw - in collaboration with the parties involved - might bring them closer together in developing and maintaining tools (i.e. following the agreed rules for tools), including sticking to the established core set of tool types (307). 


\section{Use the best of both worlds}

Another overarching issue is that the different approaches in health care share elements. To achieve quality health care or optimal care, patient engagement is essential. Both evidencebased medicine (EBM) and shared decision-making heralded from their beginnings the formal recognition of patient engagement $(26,166,168)$. Both struggle with getting evidence and patient preferences into daily practice of health care $(68,308,309)$. Despite the partially equal footing and aim, EBM and SDM have been separate worlds for a long time (310-312). At the same time, because of the partially equal footing and aim, it has been argued that EBM and SDM should be brought closer together.

Barratt, even though not agreeing on patient engagement as being part of EBM, made suggestions how research evidence as well as patient preferences could be combined and put into practice better. Next to funding trials that answer patients' questions better, and including patients in working groups and committees in health care, she suggested to develop tools that provide healthcare professionals and patients with answers to evidence-based questions and help them elicit and integrate patient preferences. Barratt however did not combine the tools yet, distinguishing between tool types for answering evidence based questions and other tool types to find out about patient preferences and to integrate them into the decision-making (310). However, more voices to connect and combine the approaches and their tools were speaking up. Van der Weijden et al proposed strategies to adapt clinical practice guideline - the epitome of EBM - to facilitate shared decision-making (249). Acknowledging that EBM and SDM have different origins - SDM emerging from law practice (313) and communication for example, and EBM from clinical epidemiology - Hoffmann et al propose to connect the two approaches as well, claiming that 'authentic EBM' as they call it, cannot occur without SDM (see figure 1).

\section{Optimal patient care}

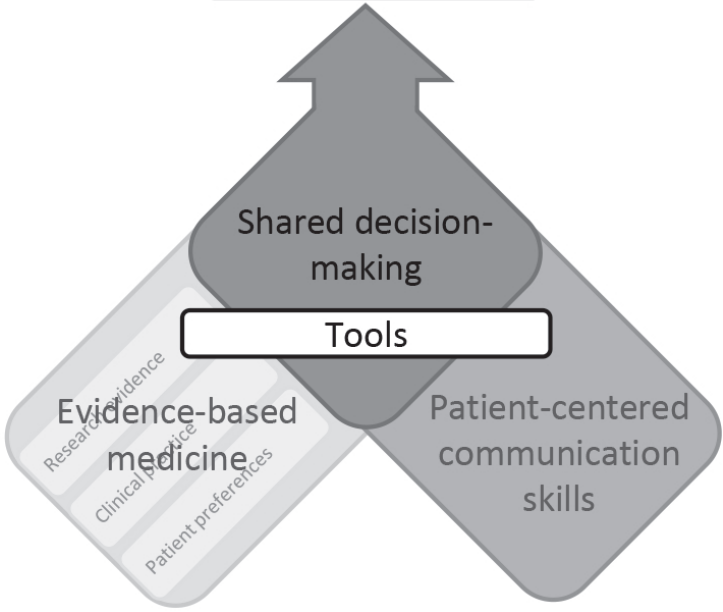

A strategy they suggested is to bring SDM and EBM together in clinical practice guideline development and implementation, as most CPGs still do not consider patient preferences and/or do not offer how to discuss these preferences, and talk about evidence in such a way that a patient understands it. The teaching of clinicians and students needs to be addressed as well as it focusses on critical appraisal and clinicians are not taught in depth how to integrate and apply evidence in daily practice when dealing with individual patients. They recommended combining EBM training with SDM and communications skill training (311).

Figure 1: The interdependence of EBM and SDM, and 'their' tools (adapted from Hoffmann et al, 2014) 
Hoffman et al are joined in their plea by Ubel, and Elwyn et al. The former deems that next to patient decision aids, clinical practice guidelines should be preference-sensitive so that viable choices are not taken away from patients (314). The latter expressed their appreciation for trustworthy guidelines, but preferred so called 'customized care tools', translate existing evidence into tools to help patients and clinicians work together to decide next steps (144). Not everybody is convinced though; Wennberg for example prefers patient decision aids (not derived from guidelines) to CPGs when it comes to patient informed choice as CPGs (used to) over-rely on expert judgement $(35,315)$.

Two initiatives that can contribute to making clinical practice guidelines, in the Netherlands often called evidence-based guidelines, more patient-centred and preference-sensitive are GIN and the GRADE Working Group. The Guideline International Network (GIN) "facilitates networking, promotes excellence and helps our members create high quality clinical practice guidelines that foster safe and effective patient care." (316). One way to make guidelines more patient-minded is to include patients in guideline development. The Working Group GIN Public has developed a toolbox which addresses issues such as how to include (qualitative) research on patient views in CPGs and how to recruit and support patients in guideline development (317). GRADE stands for Grading of Recommendations Assessment, Development and Evaluation and the GRADE Working Group approaches the issue from a slightly different angle. Starting in the early 2000's, the Working Group's aim was and is addressing the shortcomings of grading systems in health care. Therefore, the Working Group has developed a transparent approach of grading quality (or certainty) of evidence and strength of recommendations. In short, when the graded evidence is of high quality (or certainty) for the main outcomes to be achieved this would lead to a so-called strong guideline recommendation. If the graded evidence is less relevant, certain, contradictory or unavailable, this would lead to a weak (or conditional) recommendation (298). Besides being transparent, the GRADE approach is also quite complex.

The grading of evidence is not an easy feat, a lot of criteria must be factored in. The grading is therefore often done by guideline development methodology specialists, who are not most of the time healthcare professionals or patients (or their representatives). The approach consists of two main steps: 1 / rating the quality of evidence; 2 / determining the strength of recommendations. In step one the level of confidence is established, working with a hierarchy of evidence; randomized trials start at the top of the grading and observational studies at the bottom. The level can be downgraded or upgraded depending on certain criteria, such as: risk of bias or large effect. There is no mention of patient preferences, outcomes preferred by patients in step one. Nor clinical practice for that matter. In step two, the quality level of evidence is combined with other factors: benefits and harms, resources and cost, and patients' values and preferences. For an innocent bystander, it could seem that the other factors are not considered evidence. A bit more informed bystander could conclude that the other factors (benefits and harms; resources and costs; and patients' preferences and values could be part of the evidence but as these factors often cannot be or are not studied with RCTs their starting position in the GRADE approach could be regarded as less favourable (17). 
In 2016, the working group introduced the Evidence to Decision framework which would support making well informed healthcare choices and formulate guideline recommendations. The article starts with "Clinicians regularly face situations with two or more alternative actions. Each alternative often has different advantages and disadvantages, including differences in effectiveness, adverse effects, costs and other factors (criteria). To make these choices, clinicians rely on recommendations from clinical practice guidelines, other recommendations (such as from colleagues or experts) or implicit rules for decision making, such as based on their personal experience or what others do." (318). First, I find it is striking that patients are not mentioned; they are faced with these choices as well. Moreover, the Working Group seems to limit evidence mainly to research evidence. The presented framework is however not devoid of patient input. For example, when there is uncertainty about how much the patients value the outcomes or unpredictability in how patients value the main outcomes (meaning that patients with different values might make other decisions), they recommend formulating a weak recommendation $(196,318)$. However, in daily practice this often means that the language used in the recommendation is less firm, using words like 'consider'. It is not a preferencesensitive recommendation if options and patient preferences are not specified in the guideline recommendation. From that perspective, I would prefer the term 'conditional recommendation' as it indicates that the decision(s) to be made are subject to certain conditions, may that be uncertainty of the outcome or patient preferences. Another reason why I prefer the term 'conditional' to 'weak' is that to me there is a (un)conscious devaluation of the recommendation by calling it weak, when perhaps it might lead to more optimal care by being more preferencesensitive or conducive to shared decision-making.

Including patient preferences or making CPGs more preference-sensitive is not easy, as was shown by Utens et al. For example, research on patient preferences is done by various domains, which is not always considered when searching for evidence and there exists a great variety in the terms and definitions that are used for preferences, which complicates searching and synthesizing evidence. Furthermore, it is unclear how to integrate such evidence, and what weight patient preferences should have in relation to other decision criteria (319-321). Montori et al made a similar observation. When suggesting together with Hoffmann to connect EBM and SDM, in another article he and others were cautious regarding clinical practice guidelines and incorporating patient preferences. One reason being that access to generalizable preferences of patients is difficult and complex. Furthermore, lack of means and expertise might hinder integrating patient preferences or lead to so-called "tokenist patient involvement" in guideline development. They therefore advise that guideline working groups should recognize that guideline recommendations should seldom accept uniform patient preferences and contexts in favour of a specific course of action and should embrace ambiguity more (322).

Even though it might not be common practice yet, there is an increase in clinical practice guidelines that include patient preferences and/or SDM $(199,209,278,323)$. Other initiatives point in that direction as well; e.g. the DECIDE/MAGIC project that combines EBM and SDM (tools) $(324,325)$, as well as the Dutch 'consultkaarten' (326) in concordance with quality criteria for patient-directed tools related to CPGs (275). These examples, initiatives and the joint organisation of a conference by the International Society for Evidence-Based Health Care 
(ISEHC) and International Shared Decision-making (ISDM) (327) can be considered as signs that EBM and SDM, and their tools are connecting.

\section{Be inclusive, not exclusive}

It has been said several times already, knowledge in health care keeps accumulating and it is almost impossible to keep abreast of the research evidence in health care. Tools are being developed to help cope with the vast amount of knowledge, but these tools do not consider all knowledge sources. And as the previous section pointed out, it is not always that easy to include other sources of knowledge (patient preferences) as means are scarce and 'how to' remains elusive. The development of clinical practice guidelines has profited immensely from evidence-based medicine, but as was described in the introduction and by the GIN working group AID Knowledge the focus in EBM has been skewed towards research evidence (26, 308,328 ) and within this body of knowledge, randomised clinical trials are the dominant type of knowledge. Attention to this imbalance has been called by others as well. Not just because relying on one knowledge source, is short-selling the other knowledge sources, but also because they are some flaws within that particular knowledge source $(28,74)$.

\begin{tabular}{|c|c|c|c|c|}
\hline $\begin{array}{l}\text { 1. Questions relevant } \\
\text { to users of research? }\end{array}$ & $\begin{array}{l}\text { 2. Appropriate } \\
\text { research, design, } \\
\text { conduct and analysis? }\end{array}$ & $\begin{array}{l}\text { 3. Efficient research } \\
\text { regulation and } \\
\text { management? }\end{array}$ & $\begin{array}{l}\text { 4. Accessible, full } \\
\text { research reports? }\end{array}$ & $\begin{array}{l}\text { 5. Unbiased and } \\
\text { usable reports? }\end{array}$ \\
\hline $\begin{array}{l}\text { Clinicians and patients } \\
\text { not involved in } \\
\text { research agenda: low } \\
\text { priority research } \\
\text { questions addressed. } \\
\text { Important outcomes } \\
\text { are not assessed } \\
\text { Over } 50 \% \text { of studies } \\
\text { are designed without } \\
\text { reference to } \\
\text { systematic reviews of } \\
\text { existing evidence }\end{array}$ & $\begin{array}{l}\text { Over } 50 \% \text { of studies } \\
\text { do not take adequate } \\
\text { steps to reduce biases } \\
\begin{array}{c}\text { Inadequate statistical } \\
\text { power }\end{array} \\
\begin{array}{c}\text { Inadequate replication } \\
\text { of initial observations }\end{array}\end{array}$ & $\begin{array}{l}\text { Hyper-regulation of } \\
\text { research } \\
\text { Inefficient delivery of } \\
\text { research } \\
\text { Poor reuse of data } \\
\text { Do not promote } \\
\text { evaluative research as } \\
\text { an integral element of } \\
\text { good clinical practice }\end{array}$ & $\begin{array}{l}\text { More than } 50 \% \text { of } \\
\text { studies are never } \\
\text { published in full } \\
\text { Biased under- } \\
\text { reporting of studies } \\
\text { with disappointing } \\
\text { results } \\
\text { Biased reporting of } \\
\text { data within studies }\end{array}$ & $\begin{array}{l}\text { Over } 30 \% \text { of trial } \\
\text { interventions are not } \\
\text { sufficiently well } \\
\text { described } \\
\text { More than } 50 \% \text { of } \\
\text { planned study } \\
\text { outcomes are not } \\
\text { reported } \\
\text { Most new research } \\
\text { not interpreted in the } \\
\text { context of systematic } \\
\text { assessment of other } \\
\text { relevant evidence }\end{array}$ \\
\hline \multicolumn{5}{|c|}{ 'Evidence-biased medicine' } \\
\hline \multicolumn{5}{|c|}{ Research waste } \\
\hline
\end{tabular}

Figure 2: Research waste and 'evidence-biased' medicine (adapted from Chalmers et al, 2009; Moher et al, 2016; Burgers, 2016)

Describing those flaws in 2009, Chalmers et al made it clear that there is a 'chain of knowledge' and each link has its flaws, leading them to conclude that there is research waste and that by relying too much on flawed knowledge leads to 'evidence-biased' medicine (see figure 2). 


\section{6 | Chapter 7}

In 2014, a follow-up of the review was carried out to see how the research waste could be reduced. The subsequent recommendations to reduce waste were not just aimed at researchers but also at funders, regulators, journals and academic institutions (329-333). In 2016, Moher et al tried to establish if the recommendations from 2009 and 2014 were followed through (see figure 2). They noticed some "gratifying traction" but concluded more effort was still needed, repeating that stakeholders should interact more (334). Greenhalgh et al (328) and two Dutch governmental advisory boards reached similar conclusions $(335,336)$ and made a plea to return to 'real evidence based medicine'. They were referring to the three pillars of EBM as defined by Sackett et al (26); restating that more attention needs to be paid to patient experience, the real life clinical encounter and context.

Attempts are carried out to include different sources of knowledge while developing clinical practice guidelines $(247,337)$. And with effect; several NICE guidelines have been refocussed due to patient input (328). When Lukersmith et al tried to use different sources of knowledge developing a guideline, they experienced the difficulty in current guideline methodology to consider context and information from different sources of knowledge besides quantitative research. They therefore used the ICF (International Classification of Functioning, Disability and Health framework (WHO, 2001) to manage the complexity of using different sources of knowledge (312).

To achieve optimal patient care, provide more effective healthcare services and strengthen the healthcare system, the use of all knowledge sources is necessary. Not using all sources is a kind of research waste as well. I concur with Askheim et al when they said: we need to "remodel EBM in a broader, more pluralistic, more democratic and less authoritarian manner' (338). This means making tool developers (and other stakeholders) more aware of the availability of different knowledge sources, the possible flaws within the knowledge base and that it is pertinent to continue working on methods how to appraise and include different knowledge sources. We might take our cue from other disciplines, such as environmental sciences. To make their research findings more robust and trustworthy the IPCC (Intergovernmental Panel on Climate Change) involved other sciences and worked cross-disciplinary when developing their report on climate change and food shortages $(339,340)$.

\section{A case of consilience}

If one thing has become clear to me at the end of this thesis, is that a lot of domains, disciplines, expertise, parties and professionals are involved when it comes to knowledge translation and the tools developed to support knowledge translation and (shared) decision-making. However, most of these domains, disciplines, parties and professionals currently work in their own silos of the knowledge cycle. This knowledge cycle consists of: knowledge production; knowledge synthesis; tool development; dissemination and implementation of knowledge (tools) into practice; knowledge use; and evaluation of knowledge use and impact on healthcare and patient outcomes $(292,341)$. In order to achieve optimal (health) care, the different parts of the knowledge cycle and their 'inhabitants' need to be well connected, so that knowledge moves more fluently into practice. It also means that all knowledge sources should be considered, and we should not restrict ourselves to knowledge sources within medicine. You could say it is a case of consilience (342). The term was coined by William Whewell in the $19^{\text {th }}$ century. In his 
book Philosophy of the Inductive Sciences, he used it to discuss the unification of knowledge between the different branches of learning (343). I think the concept can be applied not just to knowledge but to knowledge translation and knowledge tools as well. With the unification of all the domains, disciplines, parties and professionals involved in knowledge translation and tool development, we might create a more sound and solid knowledge base, develop better tools for knowledge translation and (shared) decision-making, and improve the use of knowledge in healthcare practice.

\section{Conclusions}

I set out to achieve that tools are no longer developed without a clear definition, that there exists a common terminology when referring to tool types, to make better use of the different knowledge sources available, and finally provide healthcare professionals and patients, and possibly other users such as policy advisors and insurers, with a set of pragmatic tools that cover their needs in knowledge translation and decision support. It has become clear that healthcare professionals and patients are inundated with tools, but a first step to limit the number of tools and to agree on their definitions has been achieved in the Netherlands. More robust adherence is the next step and to maintain a certain level of consistency of available tool types, pseudo innovation of tool types needs to be avoided. Clarifying which purposes patient-directed knowledge tools serve and which core elements they should contain can further help tool developers, people who commission the development of these tools, patients and healthcare professionals to discern between the different tools available. It became clear that not all knowledge sources are used when developing knowledge tools, particularly clinical practical guidelines. But the disregard of knowledge sources such as more patient-driven empirical data on the patient perspective (e.g. qualitative data on patients' experiences with side-effects of treatment, with quality of care, or on patient preferences) and the main use of 'classical' doctor-driven research evidence (i.e. clinical epidemiological, quantitative research evidence) has been one of the main critiques of evidence-based medicine lately. Not just because patient preferences, clinical practice and context are still relatively underexposed, but also because the dominant knowledge source used has some flaws. Awareness of this is growing and efforts such as GRADE-CERQual (Confidence in the Evidence from Reviews of Qualitative research) are underway to include and appraise other knowledge sources and to address the flagged flaws in certain knowledge sources.

Another way to bring the best scientific evidence and patient preferences more closely together could be achieved by connecting the evidence-based medicine approach with the approach of shared decision-making. Several strategies to achieve this have been proposed and tentative steps have been taken. One strategy concerns the training and education of healthcare professionals integrating EBM and SDM. Other strategies suggest integrating tools used in EBM and SDM or to use these tools more in concordance. Although not a straightforward method on how to integrate SDM in guidelines is available yet, more guidelines contain 'open' recommendations describing (treatment) trade-offs and (treatment) alternatives and provide more detailed guidance on how to decide with the patient on the patient's care. Another consideration is to provide tools amalgamated with specific guideline recommendations that enhance SDM, such as patient decision aids. 


\section{Recommendations and implications}

The results of this thesis may contribute to a better insight into tool development and the use of knowledge while connecting different approaches in health care which aim to improve quality of care. The recommendations and implications will be described separately for practice, research and policy. One recommendation however relates to all three: in favour of improved knowledge use the cycle of development, implementation and evaluation of knowledge tool types should be followed through. Meaning that once a tool type is developed, implementation strategies should be in place to see to the use of these tools, and after a while the implementation and use of the tools should be measured and evaluated. Then it can be decided if the tool needs changing (or dispensed with), or that the implementation strategies need adjustment, before deciding new tools should be introduced, however fancy they sound or look. Adherence to the PDCAcycle (plan do check act), quality cycle, knowledge circle or whatever its name, is paramount to avoid wasting resources in tool development and limiting the effect of the tools in knowledge translation.

\section{Recommendations \& implications for practice}

- To achieve a common tool terminology and avoid 'new' tool types from emerging, the core set of tool types needs to be disseminated further by the stakeholders to their rank and file. Also, the involved stakeholders should agree on next steps on how to stick to the agreed core set of tool types, implement it and evaluate and maintain it. Tool types such as clinical practice guidelines and patient decision aids have an 'expiration date'. This should also be the case with the established core set of tool types, because definitions can change as well as the needs for tools.

- Furthermore, the framework of patient-directed knowledge tools should be put to the test to see whether it does help tool developers choose the right tool and helps clarify the different kinds of patient-directed tools for commissioners of tools and users.

- Guideline working groups together with tool developers should be more brave and experiment with formulating recommendations that include patient preferences and/or viable treatment/care options available, to show the ambiguity of the available evidence and admit that the perception of optimal patient care is in the eye of the beholder and therefore a subjective matter. Perhaps they should invite other disciplines to the table as well, such as implementation experts, behavioural scientists, and ethicists. The Dutch College of General Practitioners is one of the few tool developers in the Netherlands to employ implementation experts and involve them when developing clinical practice guidelines.

- Evidence-based medicine training should be integrated with shared decision-making and communication skills training, as the Dutch Federation of Medical Specialists is trying to do for example. However, not just for the new generation of healthcare professionals but also the older generations should receive this training. In this way, healthcare professionals are trained to use the available knowledge to their advantage whilst translating it to the patient's unique characteristics and preferences. And enabling them to discuss the patient preferences with that patient. 


\section{Recommendations \& implications for research}

- It needs to be acknowledged that randomized clinical trials (RCT) and other dominant frequentist methods might be excellent for answering some questions in health care (in part), such a diagnostics and therapeutic interventions, and when developing guidelines but they do not fit all knowledge needs in health care, such as complex interventions, multimorbidity, organisation of care, the gender data gap, patient preferences, public health issues (e.g. pandemics), and healthcare policy and coverage decisions; other research methods need to be considered more and the different methods need to be combined.

- To enhance the further use of knowledge, and the use of all knowledge sources more effort is needed in finding out how to include and appraise other knowledge sources and how to put these methodologies to use. This might mean that evidence-based medicine needs to look at other disciplines and domains, such as psychology, (youth) social care, behavioural sciences, communication and language sciences, IT and industrial design. Not just for knowledge creation, distribution and use, but also to learn how some of these domains include and appraise different kinds of knowledge.

- The importance of and need for a common terminology was shared by international experts. To get more traction on the core set of tool types, the consensus procedure could be repeated on an international level. Also, to prevent 'new' tool types entering the Netherlands

\section{Recommendations \& implications for policy}

- Funding organisations such as ZonMw should reconsider their funding policies. They should be more open to other kinds of research methods than RCTs, stimulate research into other areas such as patient preferences, patient experiences, organisation of care, implementation studies and evaluative research and stimulate cross-disciplinary research efforts.

- To make health care really patient-centred, you have to start at the beginning by saving a proper seat for patients at the table that sets the research agenda. The Dutch Research Agenda (Nationale Wetenschapsagenda) was a promising first step. Though, I am curious how (well) it plays out for the questions submitted by patients and the general public. Increased funding of patient participation in knowledge translation and tool development, or broader to enable actual patient emancipation and become an equal partner, could be considered. Perhaps healthcare insurers could assume some kind of responsibility in putting patients more centre stage.

- It is becoming increasingly clear that (medical) decision-making is not merely an objective and rational process, nor free from intrusion of emotions and behavioural and cognitive biases, whether it concerns patients, healthcare professionals or other stakeholders. We need to acknowledge that and deal with it (better). The Dutch government should follow up on the reports of the Netherlands Scientific Council for Government Policy (Wetenschappelijke Raad voor de Regering) on the psychology of deciding, choice and behaviour explaining the complex and sometimes erratic dynamics of human choice behaviour; for example in healthcare covering subjects such as limited rationality, unstable preferences, habits, and influences by the social and physical environment $(344,345)$, and see to it that it permeates to healthcare practice and research. 


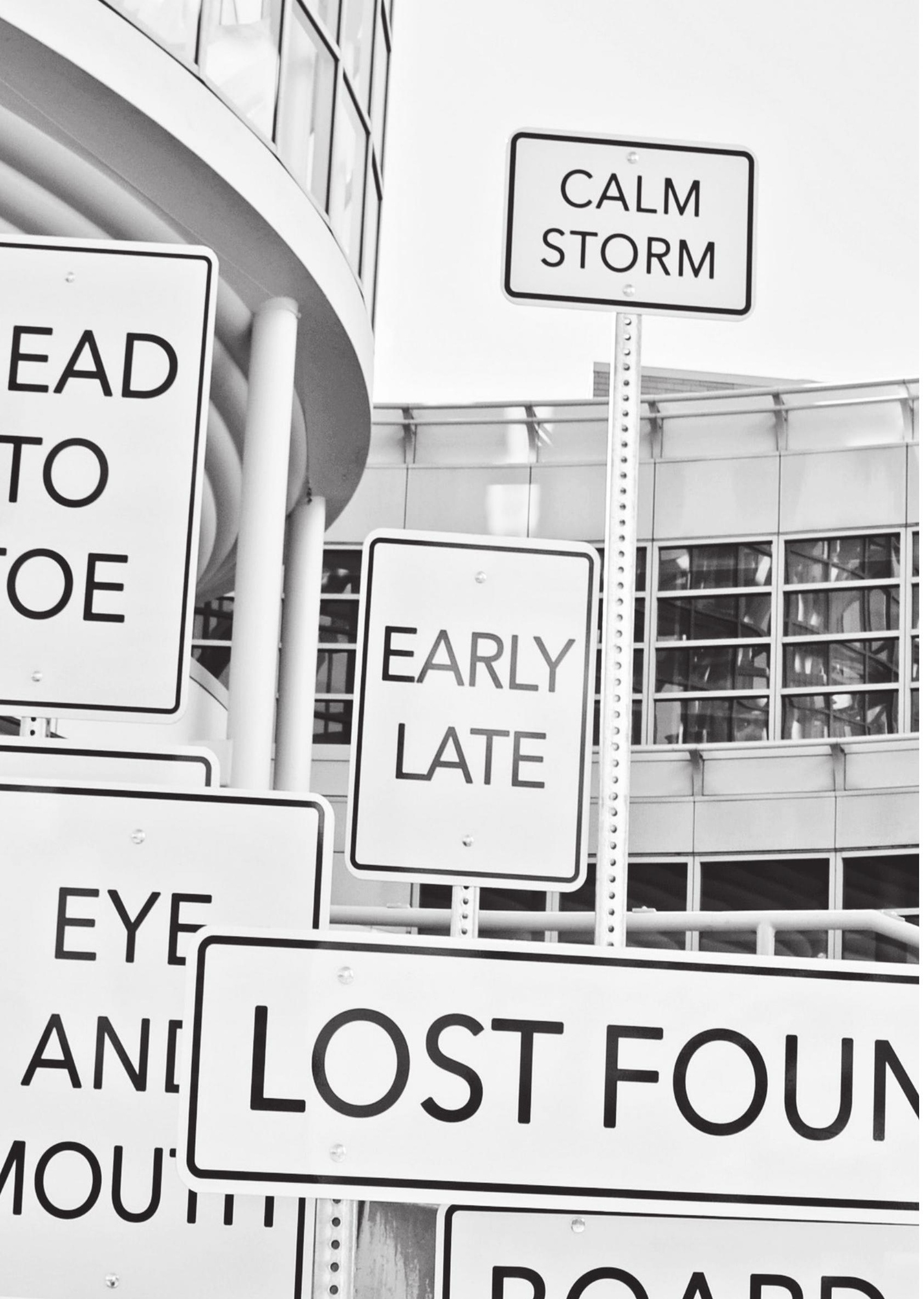




\section{List of references}

1. Kennisbeleid Kwaliteit Curatieve Zorg (KKCZ) The Hague: ZonMw; 2006 [Available from: https://www.zonmw.nl/nl/onderzoek-resultaten/kwaliteit-van-zorg/programmas/ programma-detail/kennisbeleid-kwaliteit-curatieve-zorg/.

2. International classification of functioning, disability and health : ICF. Geneva: WHO; 2001.

3. Beoordelen, behandelen, begeleiden. Medisch handelen bij ziekteverzuim en arbeidsongeschiktheid The Hague: Gezondheidsraad 2005 [Available from: https:// www.gezondheidsraad.nl/documenten/adviezen/2005/07/22/beoordelen-behandelenbegeleiden.-medisch-handelen-bij-ziekteverzuim-en-arbeidsongeschiktheid.

4. Instellingsbesluit Regieraad Kwaliteit van Zorg (Establishment order Council for the Quality of Care), MC-U-2927498 (2009).

5. Burgers JS, van Everdingen JJE. Evidence-based richtlijnontwikkeling in Nederland: het EBRO-platform. Ned Tijdschr Geneeskd. 2004(42):2057-9.

6. Richtlijn voor richtlijnen (Guideline for clinical practice guidelines). The Hague: Council for the Quality of Care; 2012.

7. van Everdingen JJE, Burgers JS, Assendelft WJJ, Swinkels JA, van Barneveld TA, van de Klundert JLM. Evidence-based richtlijnontwikkeling: een leidraad voor de praktijk (Evidence-based clinical practice guideline development; a manual). Houten: Bohn Staflue Van Loghum; 2004.

8. Zuiderent-Jerak T, Jerak-Zuiderent S, van de Bovenkamp HM, Swan TS, Hakkaartvan Roijen L, Brouwer W, et al. Variatie in richtlijnen; wat is het probleem? [Variance in guidelines; what is the problem?]. The Hague, The Netherlands: Regieraad Kwaliteit van Zorg; 2011 April 2011.

9. Glossarium kwaliteit van zorg; kernbegrippen uit de zorg in duizend- en eenvoud samengebracht (Glossary of quality of care; core terminology assmbled in a 1,000 words). Houten: Bohn Stafleu van Loghum / Springer Media; 2011.

10. Kwaliteitscanon: 'Kwaliteit van zorg in honderd woorden' (Quality of care in 100 words). The Hague: De Woordenwinkel; 2009.

11. Maassen H. Glossarium Kwaliteit van zorg. Medisch Contact. 2011.

12. Kim DR, Joffe H. Use of antidepressants during perimenopause. Women's health. 2006;2(4):627-37.

13. Why research matters London: National Institute for Health Research; 2019 [Available from: https://www.nihr.ac.uk/patients-and-public/why-join-in/why-research-matters.htm.

14. Bastian $\mathrm{H}$, Glasziou $P$, Chalmers I. Seventy-five trials and eleven systematic reviews a day: how will we ever keep up? PLoS medicine. 2010;7(9):e1000326.

15. Fraser A, Dunstan F. On the impossibility of being expert. Bmj. 2010;341(Christmas Issue):c6815.

16. Smith R. Strategies for coping with information overload. Bmj. 2010;341:c7126.

17. Duckett S, Breadon P, Romanes D, Fennessy P, Nolan J. Questionable care: Avoiding ineffective treatment. Victoria, Australia; 2015.

18. Hall A, Walton $G$. Information overload within the health care system: a literature review. Health information and libraries journal. 2004;21(2):102-8.

19. Beasley JW, Wetterneck TB, Temte J, Lapin JA, Smith P, Rivera-Rodriguez AJ, et al. Information chaos in primary care: implications for physician performance and patient safety. J Am Board Fam Med. 2011;24(6):745-51.

20. De vries M. Personal conversation. The Hague2012.

21. Cochrane AL. 1931-1971: a critical review with particular reference to the medical profession. In: Medicines for the Year 2000. London, England: Office of Health Economics; 1979.

22. Morris ZS, Wooding S, Grant $\mathrm{J}$. The answer is 17 years, what is the question: 
understanding time lags in translational research. J R Soc Med. 2011;104(12):510-20.

23. Green LW, Ottoson JM, Garcia C, Hiatt RA. Diffusion theory and knowledge dissemination, utilization, and integration in public health. Annu Rev Public Health. 2009;30:151-74.

24. Glasziou P, Haynes B. The paths from research to improved health outcomes. Evidencebased nursing. 2005;8(2):36-8.

25. Balas EA, Boren SA. Managing clinical knowledge for health care improvement. Yearbook of Medical Informatics 2000: Patient-Centered Systems. Stuttgart, Germany: Schattauer; 2000. p. 65-70.

26. Sackett DL, Rosenberg WM, Gray JA, Haynes RB, Richardson WS. Evidence based medicine: what it is and what it isn't. Bmj. 1996;312(7023):71-2.

27. Boyd CM, Darer J, Boult C, Fried LP, Boult L, Wu AW. Clinical practice guidelines and quality of care for older patients with multiple comorbid diseases: implications for pay for performance. JAMA. 2005;294(6):716-24.

28. Ioannidis JP. Why most published research findings are false. PLoS medicine. 2005;2(8):e124.

29. Haynes RB. Some problems in applying evidence in clinical practice. Ann N Y Acad Sci. 1993;703:210-24; discussion 24-5.

30. Chalmers I, Glasziou P. Avoidable waste in the production and reporting of research evidence. Obstet Gynecol. 2009;114(6):1341-5.

31. Schunemann HJ, Ghersi D, Kreis J, Antes G, Bousquet J. Reporting of Research. In: Gigerenzer G, Muir Gray JA, editors. Better doctors, better patients, better decisions; envisioning health care 2020. Cambridge, Massachusets: The MIT Press; 2011. p. 83-101.

32. Stalmeier PF, van Tol-Geerdink JJ, van Lin EN, Schimmel E, Huizenga H, van Daal WA, et al. Doctors' and patients' preferences for participation and treatment in curative prostate cancer radiotherapy. Journal of clinical oncology : official journal of the American Society of Clinical Oncology. 2007;25(21):3096-100.

33. Washer P, Joffe H. The "hospital superbug": social representations of MRSA. Soc Sci Med. 2006;63(8):2141-52.

34. Een visie op richtlijnontwikkeling. Den Haag; 2010.

35. Wennberg JE. Tracking Medicine: A Researcher's Quest to Understand Health Care. New York: Oxford University Press; 2010.

36. Woolf SH. Practice guidelines: a new reality in medicine. I. Recent developments. Arch Intern Med. 1990;150(9):1811-8.

37. van Everdingen JJE, Dreesens D, Burgers JS, Swinkels JA, Barneveld TA, van der Weijden T. Handboek evidence-based richtlijnontwikkeling: een leidraad voor de praktijk (Manual for evidence-based clinical practice guideline development: guidance for practice). 2nd ed. Houten: Bohn Stafleu van Loghum; 2014.

38. Reese S. Will You Be Pressured to Perform 'Cookbook' Medicine? : Medscape; 2013.

39. Goudswaard L, In t Veld K, Dijkstra R. Van richtlijnen, de dingen die niet voorbijgaan (Clinical practice guidelines are here to stay). Huisarst \& Wetenschap. 2010;53(1):51-4.

40. Joffe S, Miller FG. Rethinking risk-benefit assessment for phase I cancer trials. Journal of clinical oncology : official journal of the American Society of Clinical Oncology. 2006;24(19):2987-90.

41. Woolf SH. Practice guidelines, a new reality in medicine. II. Methods of developing guidelines. Arch Intern Med. 1992;152(5):946-52.

42. Grimshaw JM, Thomas RE, MacLennan G, Fraser C, Ramsay CR, Vale L, et al. Effectiveness and efficiency of guideline dissemination and implementation strategies. Health technology assessment. 2004;8(6):iii-iv, 1-72.

43. Gabbay J, le May A. Evidence based guidelines or collectively constructed "mindlines?" Ethnographic study of knowledge management in primary care. Bmj. 2004;329(7473):1013. 
44. Woolf SH. Practice guidelines: a new reality in medicine. III. Impact on patient care. Arch Intern Med. 1993;153(23):2646-55.

45. Knaapen L. Evidence Based Medicine or Cookbook Medicine? Addressing Concerns over the Standardization of Care. Sociology Compass 2014;8(6):823-36.

46. Zuiderent-Jerak T, Jerak-Zuiderent S, van de Bovenkamp H, Swan Tan S, Hakkaartvan Roijen L, Brouwer W, et al. Variatie in Richtlijnen: wat is het probleem? (Variance in guidelines: what is the problem?). The Hague: iBMG - Erasmus University Rotterdam; 2011.

47. Zuiderent-Jerak T, Forland F, Macbeth F. Guidelines should reflect all knowledge, not just clinical trials. Bmj. 2012;345:e6702.

48. Working Groups / AID Knowledge Pitlochry: Guidelines International Network (G-I-N); 2012 [Available from: https://www.g-i-n.net/working-groups/aid-knowledge/about-aidknowledge.

49. G-I-N Public: Guidelines International Network; [Available from: https://www.g-i-n.net/ working-groups/gin-public.

50. Zorgstandaarden in Nederland: 'de balans opgemaakt'. Den Haag; 2012.

51. Netwerk Klinische Paden Leuven: KU Leuven; 2013 [Available from: https://nkp.be/ zorgpaden/definitie.

52. HPV-vaccinatie. Utrecht: NHG; 2009.

53. O'Connor AM, Bennett CL, Stacey D, Barry M, Col NF, Eden KB, et al. Decision aids for people facing health treatment or screening decisions. The Cochrane database of systematic reviews. 2009(3):CD001431.

54. Veatch RM. Models for ethical medicine in a revolutionary age. What physician-patient roles foster the most ethical realtionship? The Hastings Center report. 1972;2(3):5-7.

55. Brody DS. The patient's role in clinical decision-making. Ann Intern Med. 1980;93(5):71822.

56. Deber RB. Physicians in health care management: 7 . The patient-physician partnership: changing roles and the desire for information. CMAJ. 1994;151(2):171-6.

57. Charles C, Gafni A, Whelan T. Decision-making in the physician-patient encounter: revisiting the shared treatment decision-making model. Soc Sci Med. 1999;49(5):651-61.

58. Stacey D, Bennett CL, Barry MJ, Col NF, Eden KB, Holmes-Rovner M, et al. Decision aids for people facing health treatment or screening decisions. The Cochrane database of systematic reviews. 2011(10):CD001431.

59. Elwyn G, O'Connor A, Stacey D, Volk R, Edwards A, Coulter A, et al. Developing a quality criteria framework for patient decision aids: online international Delphi consensus process. Bmj. 2006;333(7565):417.

60. IPDAS. IPDAS 2005: Criteria for Judging the Quality of Patient Decision Aids. International Patient Decision Aid Standards Collaboration; 2005.

61. O'Connor AM, Wennberg JE, Legare F, Llewellyn-Thomas HA, Moulton BW, Sepucha KR, et al. Toward the 'tipping point': decision aids and informed patient choice. Health Aff (Millwood). 2007;26(3):716-25.

62. Quality Chasm 2001 Report brief. Washington: Institute of Medicine; 2001.

63. Mulley AG, Trimble C, Elwyn G. Stop the silent misdiagnosis: patients' preferences matter. Bmj. 2012;345:e6572.

64. Coulter A, Collins A. Making shared decision-making a reality: No decision about me, without me. London: The King's Fund; 2011.

65. Liberating the NHS: No decision about me, without me - Government response to the consultation. London; 2012.

66. Richards T, Montori VM, Godlee F, Lapsley P, Paul D. Let the patient revolution begin. Bmj. 2013;346:f2614.

67. Pieterse AH, Henselmans I, de Haes HC, Koning CC, Geijsen ED, Smets EM. Shared decision making: prostate cancer patients' appraisal of treatment alternatives and 
oncologists' eliciting and responding behavior, an explorative study. Patient Educ Couns. 2011;85(3):e251-9.

68. Couet N, Desroches S, Robitaille H, Vaillancourt H, Leblanc A, Turcotte S, et al. Assessments of the extent to which health-care providers involve patients in decision making: a systematic review of studies using the OPTION instrument. Health Expect. 2015;18(4):542-61.

69. Snijders HS, Kunneman M, Bonsing BA, de Vries AC, Tollenaar RA, Pieterse AH, et al. Preoperative risk information and patient involvement in surgical treatment for rectal and sigmoid cancer. Colorectal Dis. 2014;16(2):O43-9.

70. De Bleser L, Depreitere R, De Waele K, Vanhaecht K, Vlayen J, Sermeus W. Defining pathways. J Nurs Manag. 2006;14(7):553-63.

71. Qaseem A, Forland F, Macbeth F, Ollenschlager G, Phillips S, van der Wees P, et al. Guidelines International Network: toward international standards for clinical practice guidelines. Ann Intern Med. 2012;156(7):525-31.

72. bench-to-bedside Bethesda: National Institutes of Health; 2019 [Available from: https:// www.cancer.gov/publications/dictionaries/cancer-terms/def/bench-to-bedside.

73. Ripples to revolution; from bench to bedside. International Journal of Evidence-Based Healthcare. 2009.

74. Chalmers I, Glasziou P. Avoidable waste in the production and reporting of research evidence. Lancet. 2009;374(9683):86-9.

75. Sackett DL, Rosenberg WM. The need for evidence-based medicine. Journal of the Royal Society of Medicine. 1995;88(11):620-4.

76. Graham ID, Logan J, Harrison MB, Straus SE, Tetroe J, Caswell W, et al. Lost in knowledge translation: time for a map? The Journal of continuing education in the health professions. 2006;26(1):13-24.

77. Macdermid JC, Miller J, Gross AR. Knowledge Translation Tools are Emerging to Move Neck Pain Research into Practice. Open Orthop J. 2013;7:582-93.

78. OHRI. Patient Decision Aids \& Other KT Tools Ottowa: OHRI and University of Ottowa; 2014 [updated 2014-08-21. Available from: https://decisionaid.ohri.ca/index.html https://decisionaid.ohri.ca/kt tools.html.

79. Elwyn G, Lloyd A, Joseph-Williams N, Cording E, Thomson R, Durand MA, et al. Option Grids: shared decision making made easier. Patient education and counseling. 2013;90(2):207-12.

80. Blume L, Van weert N, Kerkkamp H. Ruim twaalfhonderd richtlijnen is te veel (Over 1200 guidelines is way too much). Medisch Contact. 2013.

81. Burgers JS, Grol R, Klazinga NS, Makela M, Zaat J, Collaboration A. Towards evidencebased clinical practice: an international survey of 18 clinical guideline programs. International journal for quality in health care : journal of the International Society for Quality in Health Care / ISQua. 2003;15(1):31-45.

82. O'Hara J. Standards and quality measures for services for people with intellectual disabilities. Current opinion in psychiatry. 2006;19(5):497-501.

83. Kris Vanhaecht MB, Kathy Bower et al. Prevalence and use of clinical pathways in 23 countries - an international survey by the European Pathway Association. International Journal of Care Coordination. 2006;10(1):28-34.

84. McCaffery KJ, Smith S, Shepherd HL, Sze M, Dhillon H, Jansen J, et al. Shared decision making in Australia in 2011. Zeitschrift fur Evidenz, Fortbildung und Qualitat im Gesundheitswesen. 2011;105(4):234-9.

85. Dimoska A, Martin H.N. Tattersall, Phyllis N. Butow, Heather Shepherd, Paul Kinnersley. Can a "prompt list" empower cancer patients to ask relevant questions?†. Cancer 2008;113(2):225-37.

86. Dhaliwal R, Madden SM, Cahill N, Jeejeebhoy K, Kutsogiannis J, Muscedere J, et al. 
Guidelines, guidelines, guidelines: what are we to do with all of these North American guidelines? JPEN J Parenter Enteral Nutr. 2010;34(6):625-43.

87. Savelberg W, van der Weijden T, Boersma L, Smidt M, Willekens C, Moser A. Developing a patient decision aid for the treatment of women with early stage breast cancer: the struggle between simplicity and complexity. BMC medical informatics and decision making. 2017;17(1):112.

88. Stiggelbout AM, Timmermans DR. Revisiting decision aids: about definitions and classifications. Med Decis Making. 2010;30(6):696-8.

89. Hummel H, van der Meer JY, de Vries J, Otter R. Integrale oncologische zorgpaden, opzet en toepassing (Integral oncological care pathways, format and implementation). Assen: Van Gorcum; 2009.

90. Renholm M, Leino-Kilpi H, Suominen T. Critical pathways. A systematic review. J Nurs Adm. 2002;32(4):196-202.

91. Elwyn G, Frosch D, Rollnick S. Dual equipoise shared decision making: definitions for decision and behaviour support interventions. Implement Sci. 2009;4:75.

92. Shekelle PG, Woolf SH, Eccles M, Grimshaw J. Clinical guidelines: developing guidelines. Bmj. 1999;318(7183):593-6.

93. Arksey H, O'Malley L. Scoping studies: towards a methodological framework. International Journal of Social Research Methodology. 2005;8(1):19-32.

94. Levac D, Colquhoun H, O'Brien KK. Scoping studies: advancing the methodology. Implement Sci. 2010;5:69.

95. Straus SE, Tetroe J, Graham I. Defining knowledge translation. CMAJ : Canadian Medical Association journal = journal de l'Association medicale canadienne. 2009;181(3-4):165-8.

96. Thesaurus zorg en welzijn (Thesaurus care and wellbeing): Stimulansz; 2013 [Available from: http://www.thesauruszorgenwelzijn.nl/.

97. Peleg M, Gutnik LA, Snow V, Patel VL. Interpreting procedures from descriptive guidelines. Journal of biomedical informatics. 2006;39(2):184-95.

98. van der Weijden T, Boivin A, Burgers J, Schunemann HJ, Elwyn G. Clinical practice guidelines and patient decision aids. An inevitable relationship. Journal of clinical epidemiology. 2012;65(6):584-9.

99. Venhorst K. Discussions on the use of the term Option Grid. In: Dreesens D, editor. Update meeting on decision aids ed. Utrecht2016.

100. Option grid: health decisions made easier: Trustees of Dartmouth College; [Available from: http://optiongrid.org/.

101. Richard Grol MW, Martin Eccles. Improving Patient Care: The Implementation of Change in Clinical Practice. London: Elsevier Limited; 2005.

102. Hunnink M, P. Glasziou et al. Decision making in health and medicine; Integrating evidence and values. 5th ed. Cambridge: Cambridge University Press; 2001 2006. 388 p.

103. MedicalApp Journal: Peer review for medical apps 2011-2012 [Available from: http:// medicalappjournal.com/.

104. IMS. Patient Apps for Improved Healthcare: From Novelty to Mainstream. Parsippany, USA: IMS Institute for Healthcare Informatics; 2013.

105. Vartabedian B. Doctors and the reality of information overload [Internet]: 33 charts. 2011. [cited 2014]. Available from: http://33charts.com/2011/08/doctors-information-overload. html

106. Kotler P. Marketing management: analysis, planning, implementation, and control. 7th revised ed: Prentice-Hall; 1991.

107. Verstijnen I, Nistelrooij LPJv, Enzing JJ, Timmermans NGL, Heer PD, Sent D. Plant a tree to stay tuned-in. Interactive flowcharts known as CareTrees ("Zorgbomen") help to keep guidelines up-to-date. Guidelines International Network 2015 Conference; Amsterdam2015. 
108. Walshe K. Pseudoinnovation: the development and spread of healthcare quality improvement methodologies. International journal for quality in health care : journal of the International Society for Quality in Health Care / ISQua. 2009;21(3):153-9.

109. Michie S, Lester K. Words matter: increasing the implementation of clinical guidelines. Qual Saf Health Care. 2005;14(5):367-70.

110. Francke AL, Smit MC, de Veer AJ, Mistiaen P. Factors influencing the implementation of clinical guidelines for health care professionals: a systematic meta-review. BMC medical informatics and decision making. 2008;8:38.

111. Gagliardi AR, Brouwers MC, Palda VA, Lemieux-Charles L, Grimshaw JM. How can we improve guideline use? A conceptual framework of implementability. Implement Sci. 2011;6:26.

112. "If we cannot name it, we cannot control it, ......". 29 July 2015 ed. Youtube: ICNInternational Council of Nurses; 1992.

113. Gabbay J, le May A. Mindlines: making sense of evidence in practice. The British journal of general practice : the journal of the Royal College of General Practitioners. 2016;66(649):402-3.

114. Dijkstra R. Stop misbruik van onze standaarden; zorgverzekeraars dwingen huisartsen om op basis van standaarden te registreren (Stop the abuse of our clinical practice guidelines; health insurers force GPs to register on the basis of their guidelines). Medisch Contact. 2015.

115. McDonald A. What doctors say and what patients hear. Bmj. 2016;354:4453.

116. Ubel P. Lost in translation. Critical decisions: How you and your doctor can make the right medical choices together. 1st ed. New York: HarperCollins; 2012. p. 87.

117. G-I-N. What we do. Pitlochry: Guidelines International Network; 2016 [Available from: http://www.g-i-n.net/.

118. ECS. Page Guidelines \& Education [website]. European Scoiety of Cardiology; 2016 [updated not mentioned. Available from: https://www.escardio.org/.

119. EU. CoCanCPG: European Union - ERA-Net; 2016 [updated not mentioned; cited 2016 August 3, 2016]. Available from: http://www.cocancpg.eu/.

120. Colquhoun H, Leeman J, Michie S, Lokker C, Bragge P, Hempel S, et al. Towards a common terminology: a simplified framework of interventions to promote and integrate evidence into health practices, systems, and policies. Implement Sci. 2014;9:51.

121. Conn J. Two competing clinical code groups team up. ModernHealthcare.com; 2013.

122. Health Topics A-Z: NIH; 2013 [Available from: http://health.nih.gov/topics/A.

123. AHRQ. Glossary of terms: AHRQ; 2013 [Available from: http://effectivehealthcare.ahrq. gov/index.cfm/glossary-of-terms/.

124. AlHW. Glossary: Australian Institute of Health and Welfare; 2013 [Available from: http:// www.aihw.gov.au/glossary/.

125. AlHW. SQHC-definitions: Australian Institute of Health and Welfare; 2013 [Available from: http://www.aihw.gov.au/sqhc-definitions/.

126. CIHR. Appendix 3 - Knowledge Translation Terminology: Canadian Institute of Health Research; 2013 [Available from: http://www.cihr-irsc.gc.ca/e/documents/III KT Framework FINAL_e.pdf.

127. ClHR. Introduction to Evidence-informed decision making - ClHR: Canadian Institute of Health Research; 2013 [Available from: http://www.cihr-irsc.gc.ca/e/45245.html - g1 http://www.cihr-irsc.gc.ca/e/41291.html - a6 http://www.cihr-irsc.gc.ca/e/34190.html - g.

128. Cochrane. Glossary: The Cochrane Collaboration; 2013 [Available from: http://www. cochrane.org/glossary/5 - letterg.

129. IMDF. Glossary of terms: Informed Medical Decisions Foundations; 2013 [Available from: http://informedmedicaldecisions.org/wp-content/uploads/2012/02/IMDFoundation 
Media Kit 2012.pdf.

130. NHS. Jargon buster: NHS; 2013 [Available from: http://www.nhs.uk/carersdirect/ carerslives/aboutcaring/pages/jargonbuster.aspx.

131. NICE. Glossary: National Institute for Health and Care Excellence; 2013 [Available from: http://www.nice.org.uk/website/glossary/glossary.jsp?alpha=C.

132. NICE. NICE Taxonomy: National Institute for Health and Care Excellence; 2013 [Available from: http://www.nice.org.uk/aboutnice/nicewebsitedevelopment/standards/metadata/ niceencodingschemes/nicetaxonomysubjectencodingscheme/nice taxonomy subject encoding scheme.jsp.

133. AHQR. Glossary: Agency for Healthcare Research and Quality; 2013 [Available from: http://guideline.gov/about/glossary.aspx.

134. ÄZQ. Glossar: Ärztliche Zentrum für Qualität in der Medizin; 2013 [Available from: http:// www.leitlinien.de/leitlinienmethodik/leitlinien-glossar/glossar.

135. WHO. Health Impact Assessment (HIA) - Glossary of terms used: World Health Organisation; 2013 [Available from: http://www.who.int/hia/about/glos/en/index.html.

136. EU. Index: Euopean Union; 2013 [Available from: http://ec.europe.eu/health-eu/ contentindex en.htm - A

http://ec.europe.eu/health-eu/care for_me/quality_assurance/index_en.htm http://www.cen.eu/boss/Pages/glossary.aspx

http://www.ond.vlaanderen.be/hogeronderwijs/bologna/documents/Standards-andGuidelines-for-QA.pdf.

137. AHRQ. 5.3 Quality standards: Agency for Healthcare Research and Quality; 2013 [Available from: http://www.ahrq.gov/legacy/qual/hcqgloss.pdf.

138. Dreesens D, Kremer L, Burgers J, van der Weijden T. Is it chaos? And can we unravel it? A RAND modified Delphi for knowledge instrument types. G-I-N 2015: Engaging all stakeholders; guidelines from a societal perspective; Amsterdam2015.

139. Dreesens D, Kremer L, Burgers J, Van der weijden T. Unraveling chaos: a modified RAND Delphi to limit the number of knowledge tools in the Netherlands and to define them at a national level. ISDM / ISEHC 2015: Bringing evidence-based medicine and shared decision-making together; Sydney2015.

140. DECIDE-collaboration.eu. DECIDE (2011 - 2015): Developing and Evaluating Communication Strategies to Support Informed Decisions and Practice Based on Evidence 2014 [updated 28th March 2016. Available from: http://www.decidecollaboration.eu/key-decide-tools.

141. Vandvik PO, Brandt L, Alonso-Coello P, Treweek S, AkI EA, Kristiansen A, et al. Creating Clinical Practice Guidelines We Can Trust, Use, and Share: A New Era Is Imminent. Chest. 2013;144(2):381-9.

142. Dreesens D, Stiggelbout A, Agoritsas T, Elwyn G, Flottorp S, Grimshaw J, et al. A conceptual framework for patient-directed knowledge tools to support patient-centred care: Results from an evidence-informed consensus meeting. Patient Educ Couns. 2019;102(10):1898-904.

143. Dreesens D, Kremer L, van der Weijden T. The Dutch chaos case: A scoping review of knowledge and decision support tools available to clinicians in the Netherlands. Health Policy. 2019;123(12):1288-97.

144. Elwyn G, Quinlan C, Mulley A, Agoritsas T, Vandvik PO, Guyatt G. Trustworthy guidelines excellent; customized care tools - even better. BMC Med. 2015;13:199.

145. Elwyn G, Scholl I, Tietbohl C, Mann M, Edwards AG, Clay C, et al. "Many miles to go ...": a systematic review of the implementation of patient decision support interventions into routine clinical practice. BMC medical informatics and decision making. 2013;13 Suppl 2:S14.

146. Burgers J. Valkuilen bij onderzoek naar richtlijnimplementatie (Pitfalls when researching 
clinical practice guideline implementation). Ned Tijdschr Geneeskd. 2016(160).

147. Scott SD, Albrecht L, O'Leary K, Ball GD, Hartling L, Hofmeyer A, et al. Systematic review of knowledge translation strategies in the allied health professions. Implement Sci. 2012;7:70.

148. Carthey J, Walker S, Deelchand V, Vincent C, Griffiths WH. Breaking the rules: understanding non-compliance with policies and guidelines. Bmj. 2011;343:d5283.

149. Stacey D, Légaré F, Col NF, Bennett CL, Barry MJ, Eden KB, et al. Decision aids to help people who are facing health treatment or screening decisions. 2014.

150. Fitch K, Bernstein SJ, Agullar MD, Burnand B, LaCalle JR, van het Loo M, et al. The RAND/ UCLA appropriateness method user's manual. Santa Monica: RAND; 2001.

151. van de Eerenbeemt $A$. What is the definition of a definition? (personal communication via e-mail). Utrecht2015.

152. AQUA. Leidraad voor Kwaliteitsstandaarden (Guidance for quality standards). DiemenZuid; 2015.

153. Jones J, Hunter D. Consensus methods for medical and health services research. Bmj. 1995;311(7001):376-80.

154. Option Grid TM decision aids; optimize shared decision making with patient-specific decision aids. Ipswich, Canada: EBSCO; 2019 [Available from: https://health.ebsco.com/ products/option-grid.

155. Venhorst K, Zelle SG, Tromp N, Lauer JA. Multi-criteria decision analysis of breast cancer control in low- and middle- income countries: development of a rating tool for policy makers. Cost Eff Resour Alloc. 2014;12:13.

156. Knops RR, Hulscher ME, Hermens RP, Hilbink-Smolders M, Loeffen JL, Kollen WJ, et al. High-quality care for all children with cancer. Ann Oncol. 2012;23(7):1906-11.

157. Clinical Practice Guidelines We Can Trust. Washington, DC: Inistitute of Medicine; 2011.

158. Unbeck M, Lindemalm S, Nydert P, Ygge BM, Nylen U, Berglund C, et al. Validation of triggers and development of a pediatric trigger tool to identify adverse events. BMC Health Serv Res. 2014;14:655.

159. Biondo PD, Nekolaichuk CL, Stiles C, Fainsinger R, Hagen NA. Applying the Delphi process to palliative care tool development: lessons learned. Support Care Cancer. 2008;16(8):935-42.

160. Moreno-Conde A, Austin T, Moreno-Conde J, Parra-Calderon CL, Kalra D. Evaluation of clinical information modeling tools. J Am Med Inform Assoc. 2016.

161. Hitzig SL, Hunter JP, Ballantyne EC, Katz J, Rapson L, Catharine Craven B, et al. Outcomes and reflections on a consensus-building workshop for developing a spinal cord injury-related chronic pain research agenda. J Spinal Cord Med. 2016:1-10.

162. Elfeddali I, van der Feltz-Cornelis CM, van Os J, Knappe S, Vieta E, Wittchen HU, et al. Horizon 2020 priorities in clinical mental health research: results of a consensus-based ROAMER expert survey. Int J Environ Res Public Health. 2014;11(10):10915-39.

163. McKenna HP, Keeney S, Currie L, Harvey G, West E, Richey RH. Quality of care: a comparison of perceptions of health professionals in clinical areas in the United Kingdom and the United States. J Nurs Care Qual. 2006;21(4):344-51.

164. LaRocca R, Yost J, Dobbins M, Ciliska D, Butt M. The effectiveness of knowledge translation strategies used in public health: a systematic review. BMC public health. 2012;12:751.

165. MAGIC; making GRADE the irresistible choice Oslo: MAGIC Association; 2013 [Available from: http://magicproject.org/.

166. Charles C, Gafni A, Whelan T. Shared decision-making in the medical encounter: what does it mean? (or it takes at least two to tango). Soc Sci Med. 1997;44(5):681-92.

167. Patient Engagement: Technical Series on Safer Primary Care. Geneva: World Health Organization; 2016. Contract No.: Licence: CC BY-NC-SA 3.0 IGO. 
168. Boivin A, Green J, van der Meulen J, Legare F, Nolte E. Why consider patients' preferences? A discourse analysis of clinical practice guideline developers. Medical care. 2009;47(8):908-15.

169. Doyle C, Lennox L, Bell D. A systematic review of evidence on the links between patient experience and clinical safety and effectiveness. BMJ Open. 2013;3(1).

170. Street RL, Jr., Krupat E, Bell RA, Kravitz RL, Haidet P. Beliefs about control in the physician-patient relationship: effect on communication in medical encounters. J Gen Intern Med. 2003;18(8):609-16.

171. Stacey D, Legare F, Col NF, Bennett CL, Barry MJ, Eden KB, et al. Decision aids for people facing health treatment or screening decisions. The Cochrane database of systematic reviews. 2014(1):CD001431.

172. Rathert C, Wyrwich MD, Boren SA. Patient-centered care and outcomes: a systematic review of the literature. Med Care Res Rev. 2013;70(4):351-79.

173. Shay LA, Lafata JE. Where is the evidence? A systematic review of shared decision making and patient outcomes. Med Decis Making. 2015;35(1):114-31.

174. Ubel PA, Angott AM, Zikmund-Fisher BJ. Physicians recommend different treatments for patients than they would choose for themselves. Arch Intern Med. 2011;171(7):630-4.

175. Stacey D, Hill S. Patient-direct and patient- mediated KT interventions In: Straus S, Tetroe J, Graham I, editors. Knowledge Translation in Health Care: Moving from Evidence to Practice. second ed. Hoboken: John Wiley \& Sons; 2013. p. 197-211.

176. Brouwers M, Stacey D, O'Connor A. Knowledge translation tools. In: Straus S, Tetroe J, Graham I, editors. Knowledge Translation in Health Care: Moving from Evidence to Practice. second ed. Hoboken: John Wiley \& Sons, Ltd.; 2013. p. 50-62.

177. Dreesens D, Kremer L, Burgers J, Van der Weijden T. Lost in definitions: reducing duplication and clarifying definitions of knowledge and decision support tools. A RANDmodified Delphi consensus study. Health Policy. 2020.

178. Dreesens D, Kremer L, van der Weijden T. The Dutch chaos case: a scoping review of knowledge and decision support tools available to clinicians in the Netherlands (in press). Health Policy. 2019.

179. Brouwers M, Stacey D, O'Connor A. Knowledge creation: synthesis, tools and products. CMAJ : Canadian Medical Association journal = journal de l'Association medicale canadienne. 2010;182(2):E68-72.

180. Charles C, Gafni A, Freeman E. Implementing shared treatment decision making and treatment decision aids: a cautionary tale Psicooncología. 2010;7(2-3):243-55.

181. Carman KL, Dardess P, Maurer M, Sofaer S, Adams K, Bechtel C, et al. Patient and family engagement: a framework for understanding the elements and developing interventions and policies. Health affairs. 2013;32(2):223-31.

182. Entwistle VA, Watt IS. Patient involvement in treatment decision-making: the case for a broader conceptual framework. Patient Educ Couns. 2006;63(3):268-78.

183. Wensing $\mathrm{M}$, Baker R. Patient involvement in general practice care: a pragmatic framework. Eur J Gen Pract. 2003;9(2):62-5.

184. Grande SW, Faber MJ, Durand MA, Thompson R, Elwyn G. A classification model of patient engagement methods and assessment of their feasibility in real-world settings. Patient Educ Couns. 2014;95(2):281-7.

185. IPDAS checklist. International Patient Decision Aid Standards Collaboration.

186. Durand MA, Stiel M, Boivin J, Elwyn G. Where is the theory? Evaluating the theoretical frameworks described in decision support technologies. Patient Educ Couns. 2008;71(1):125-35.

187. O'Connor AM, Tugwell P, Wells GA, Elmslie T, Jolly E, Hollingworth G, et al. A decision aid for women considering hormone therapy after menopause: decision support framework and evaluation. Patient Educ Couns. 1998;33(3):267-79. 
188. Patient Decision Aids: Ottawa Decision Support Framework (ODSF) Ottawa: Ottawa Hospital Research Institute; [Available from: https://decisionaid.ohri.ca/odsf.html.

189. Outcomes of Interest to the Cochrane Consumers \& Communication Review Group. CCCG Melbourne: La Trobe University; 2012 [Approved (Hill, S.)]. Available from: http:// cccrg.cochrane.org/author-resources.

190. Nilsen P. Making sense of implementation theories, models and frameworks. Implement Sci. 2015;10:53.

191. O'Brien BC, Harris IB, Beckman TJ, Reed DA, Cook DA. Standards for reporting qualitative research: a synthesis of recommendations. Academic medicine : journal of the Association of American Medical Colleges. 2014;89(9):1245-51.

192. Creatief Denken: brainstormtechnieken [Creative thinking; brainstorm techniques]: Creatief Denken; 2015 [Available from: https://www.creatiefdenken.com/nl/techniek/ brainstormtechnieken-overzicht.php.

193. Muller G. Meeting methods - pressure cooker. 2015.

194. Dirkse-Hulscher S, Talen A. Het grote werkvormenboek (The big book on interactive work methods). Amsterdam: Boom Ultgevers; 2007.

195. The Savvy Professional; Increasing Your Professional IQ. 2015.

196. Alonso-Coello P, Schunemann HJ, Moberg J, Brignardello-Petersen R, Akl EA, Davoli M, et al. GRADE Evidence to Decision (EtD) frameworks: a systematic and transparent approach to making well informed healthcare choices. 1: Introduction. Bmj. 2016;353:i2016.

197. Hoffmann TC, Del Mar C. Clinicians' Expectations of the Benefits and Harms of Treatments, Screening, and Tests: A Systematic Review. JAMA internal medicine. 2017;177(3):407-19.

198. Hoffmann TC, Del Mar C. Patients' expectations of the benefits and harms of treatments, screening, and tests: a systematic review. JAMA internal medicine. 2015;175(2):274-86.

199. Armstrong MJ, Gronseth GS. Approach to assessing and using clinical practice guidelines. Neurology Clinical practice. 2018;8(1):58-61.

200. O'Connor A, G Elwyn. IPDAS 2005: Criteria for Judging the Quality of Patient Decision Aids. In: -, editor. - -ed. -: IPDAS OHRI; 2005. p. 2-3.

201. Vandvik PO, Fog-Heen A, Agoritsas T. SHARE-IT: rapid production of online decision aids linked to guidelines for point-of-care shared-decision making. Cochrane Colloquium 2016; Seoul: The Cochrane Collaboration; 2016.

202. Guyatt GH, Oxman AD, Kunz R, Falck-Ytter $Y$, Vist GE, Liberati A, et al. Going from evidence to recommendations. Bmj. 2008;336(7652):1049-51.

203. Wieringa S, Dreesens D, Forland F, Hulshof C, Lukersmith S, Macbeth F, et al. Different knowledge, different styles of reasoning: a challenge for guideline development. BMJ Evid Based Med. 2018;23(3):87-91.

204. CONSORT. Harms - All important harms or unintended effects in each group Ottowa: CONSORT; 2010 [Available from: http://www.consort-statement.org/checklists/view/32-consort-2010/116-harms.

205. Kaufman J, Ryan R, Glenton C, Lewin S, Bosch-Capblanch X, Cartier Y, et al. Childhood vaccination communication outcomes unpacked and organized in a taxonomy to facilitate core outcome establishment. Journal of clinical epidemiology. 2017;84:173-84.

206. Willis N, Hill S, Kaufman J, Lewin S, Kis-Rigo J, De Castro Freire SB, et al. "Communicate to vaccinate": the development of a taxonomy of communication interventions to improve routine childhood vaccination. BMC international health and human rights. 2013;13:23.

207. Group CCCR. Taxonomy of relevant outcomes. Cochrane Consumers \& Communications Review Group; 2012.

208. Fonhus MS, Dalsbo TK, Johansen M, Fretheim A, Skirbekk H, Flottorp SA. Patientmediated interventions to improve professional practice. The Cochrane database of 
systematic reviews. 2018;9:CD012472.

209. Antimicrobial stewardship: systems and processes for effective antimicrobial medicine use London: NICE; 2015 [Available from: https://www.nice.org.uk/guidance/NG15.

210. De Vries AW, Klijn FAJ, Vernooij RW, Aben KH, De Reijke TM. Prostaatkankerrichtlijn: een routekaart in Oncoguide, beslisbomen en informatiestandaard (Prostate cancer guidelin: a route map in Oncology, decision trees and information standard). Tijdschr Urol [Internet]. 2019.

211. Kaufman J, Ames H, Bosch-Capblanch X, Cartier Y, Cliff J, Glenton C, et al. The comprehensive 'Communicate to Vaccinate' taxonomy of communication interventions for childhood vaccination in routine and campaign contexts. BMC public health. 2017;17(1):423.

212. Dreesens D, van der Weijden T, Grimshaw J. Supporting patient-centered care; making knowledge tools more accessible to patients, and professionals. ISDM 2017; 4th July; Lyon, France2017.

213. Hill S, Sofra TA. How could health information be improved? Recommended actions from the Victorian Consultation on Health Literacy. Aust Health Rev. 2017;42(2):134-9.

214. Burgers JS, van Everdingen JJ. Beyond the evidence in clinical guidelines. Lancet. 2004;364(9432):392-3.

215. Salvador-Carulla L, Lukersmith S, Sullivan W. From the EBM pyramid to the Greek temple: a new conceptual approach to Guidelines as implementation tools in mental health. Epidemiol Psychiatr Sci. 2017;26(2):105-14.

216. van de Bovenkamp HM, Zuiderent-Jerak T. An empirical study of patient participation in guideline development: exploring the potential for articulating patient knowledge in evidence-based epistemic settings. Health Expect. 2015;18(5):942-55.

217. Wennberg JE. Dealing with medical practice variations: a proposal for action. Health affairs. 1984;3(2):6-32.

218. Hacking I. An Introduction to Probability and Inductive Logic. Cambridge: Cambridge University Press; 2001.

219. Hume D. A treatise of human nature. London: Thomas and Joseph Allman; 1817.

220. Kerry R, Eriksen TE, Lie SA, Mumford SD, Anjum RL. Causation and evidence-based practice: an ontological review. J Eval Clin Pract. 2012;18(5):1006-12.

221. Walach H, Falkenberg T, Fonnebo V, Lewith G, Jonas WB. Circular instead of hierarchical: methodological principles for the evaluation of complex interventions. BMC Med Res Methodol. 2006;6:29.

222. Harder T, Abu Sin M, Bosch-Capblanch X, Bruno C, de Carvalho Gomes H, Duclos P, et al. Towards a framework for evaluating and grading evidence in public health. Health Policy. 2015;119(6):732-6.

223. Beauchamp S, Drapeau M, Dionne C. The Development of Practice Guidelines in the Social and Human Sciences. Can Psychol. 2015;56(4):357-67.

224. Bradford-Hill A. The environment and disease: association or causation? . Proceedings of the Royal Society of Medicine. 1965:295-300.

225. Mol A. The logic of care; health and the problem of patient choice: Routledge; 2008.

226. Illari PM, Williamson J. What is a mechanism? Thinking about mechanisms across the sciences. European Journal for Philosophy of Science. 2012;2:119-35.

227. van Dijk FJ, Verbeek JH, Hoving JL, Hulshof CT. A knowledge infrastructure for occupational safety and health. J Occup Environ Med. 2010;52(12):1262-8.

228. Lewin S, Glenton C, Munthe-Kaas H, Carlsen B, Colvin CJ, Gulmezoglu M, et al. Using qualitative evidence in decision making for health and social interventions: an approach to assess confidence in findings from qualitative evidence syntheses (GRADE-CERQual). PLoS medicine. 2015;12(10):e1001895.

229. Lewin S, Booth A, Glenton C, Munthe-Kaas H, Rashidian A, Wainwright M, et al. Applying 
GRADE-CERQual to qualitative evidence synthesis findings: introduction to the series. Implement Sci. 2018;13(Suppl 1):2.

230. Ring N, Ritchie K, Mandava L, al. e. A guide to synthesising qualitative research for researchers undertaking health technology assessments and systematic reviews. NHS Quality Improvement Scotland; 2011. Contract No.: 1-84404-917-5.

231. Juritzen TI, Soberg HL, Roe C, Saebu M, Engen G, Bliksvaer T, et al. The One or the Many: Quantified Subjectivity and Aggregated Uniqueness in Qualitative Rehabilitation Research. Qual Health Res. 2017;27(1):51-9.

232. Moberg J, Alonso-Coello P, Oxman A. GRADE Working group. GRADE Evidence to Decision (EtD) Frameworks Guidance. Version 1.1 GRADE Working group; 2015.

233. Verkerk K, Van Veenendaal H, Severens JL, Hendriks EJ, Burgers JS. Considered judgement in evidence-based guideline development. International journal for quality in health care : journal of the International Society for Quality in Health Care / ISQua. 2006;18(5):365-9.

234. Peirce C. Philosophical writings: Dover Publications Inc.; 1986.

235. Douven I. The Stanford Encyclopedia of Philosophy 2011 [Available from: https://plato. stanford.edu/archives/sum2017/entries/abduction/.

236. Popper KR. Objective knowledge; an evolutionary approach: Clarendon Press; 1979.

237. Kriebel D, Tickner J, Epstein P, Lemons J, Levins R, Loechler EL, et al. The precautionary principle in environmental science. Environ Health Perspect. 2001;109(9):871-6.

238. Pollock JL. The logical foundations of means-end reasoning. . Common sense, Reasoning, and Rationality. Oxford: Oxford University Press; 2002. p. 60-77.

239. Stolper E, Van de Wiel M, Van Royen P, Van Bokhoven M, Van der Weijden T, Dinant GJ. Gut feelings as a third track in general practitioners' diagnostic reasoning. J Gen Intern Med. 2011;26(2):197-203.

240. Gigerenzer G, Brighton H. Homo heuristicus: why biased minds make better inferences. Top Cogn Sci. 2009;1(1):107-43.

241. Moreira T. Diversity in clinical guidelines: the role of repertoires of evaluation. Soc Sci Med. 2005;60(9):1975-85.

242. Calderon C, Rotaeche R, Etxebarria A, Marzo M, Rico R, Barandiaran M. Gaining insight into the Clinical Practice Guideline development processes: qualitative study in a workshop to implement the GRADE proposal in Spain. BMC Health Serv Res. 2006;6:138.

243. Barnett-Page E, Thomas J. Methods for the synthesis of qualitative research: a critical review. BMC Med Res Methodol. 2009;9:59.

244. Lomas J. Words without action? The production, dissemination, and impact of consensus recommendations. Annu Rev Public Health. 1991;12:41-65.

245. StatLine [Internet]. Centraal Bureau voor de Statistiek. 2012 [cited 23 October 2012]. Available from: https://opendata.cbs.nl/statline/ - /CBS/nl/.

246. Molenkamp CM, Hamers JPH, Courtens AM. Palliatieve zorg voor kinderen: maatwerk vereist. Een exploratieve studie naar zorgbehoeften, aanbod, knelpunten en mogelijke oplossingen (Palliative care for children; taylor-made approach needed. An exploratory study into care needs, care options, bottle necks and possible solutions). Maastricht: Universiteit Maastricht, Cluster Zorgwetenschappen, Sectie Verplegingswetenschap.; 2005.

247. NVK. Palliatieve Zorg voor kinderen (richtlijn). Utrecht2013.

248. Karnieli-Miller O, Eisikovits Z. Physician as partner or salesman? Shared decision-making in real-time encounters. Soc Sci Med. 2009;69(1):1-8.

249. van der Weijden T, Pieterse AH, Koelewijn-van Loon MS, Knaapen L, Legare F, Boivin A, et al. How can clinical practice guidelines be adapted to facilitate shared decision making? A qualitative key-informant study. BMJ quality \& safety. 2013;22(10):855-63.

250. Gravel K, Legare F, Graham ID. Barriers and facilitators to implementing shared decision- 
making in clinical practice: a systematic review of health professionals' perceptions. Implement Sci. 2006;1:16.

251. Joseph-Williams N, Lloyd A, Edwards A, Stobbart L, Tomson D, Macphail S, et al. Implementing shared decision making in the NHS: lessons from the MAGIC programme. Bmj. 2017;357:j1744.

252. van der Weijden T, Post $H$, Brand PLP, van Veenendaal $H$, Drenthen $T$, van Mierlo LA, et al. Shared decision making, a buzz-word in the Netherlands, the pace quickens towards nationwide implementation. Z Evid Fortbild Qual Gesundhwes. 2017;123-124:69-74.

253. Galla JH. Clinical practice guideline on shared decision-making in the appropriate initiation of and withdrawal from dialysis. The Renal Physicians Association and the American Society of Nephrology. J Am Soc Nephrol. 2000;11(7):1340-2.

254. Moss AH. Shared decision-making in dialysis: the new RPA/ASN guideline on appropriate initiation and withdrawal of treatment. Am J Kidney Dis. 2001;37(5):1081-91.

255. Patel SS, Holley JL. Withholding and withdrawing dialysis in the intensive care unit: benefits derived from consulting the renal physicians association/american society of nephrology clinical practice guideline, shared decision-making in the appropriate initiation of and withdrawal from dialysis. Clin J Am Soc Nephrol. 2008;3(2):587-93.

256. Feudtner $\mathrm{C}$. Collaborative communication in pediatric palliative care: a foundation for problem-solving and decision-making. Pediatr Clin North Am. 2007;54(5):583-607, ix.

257. Wet op de geneeskundige behandelovereenkomst (Medical Treatment Contracts Act) WGBO(2006).

258. Hsiao JL, Evan EE, Zeltzer LK. Parent and child perspectives on physician communication in pediatric palliative care. Palliat Support Care. 2007;5(4):355-65.

259. Zwaanswijk M, Tates K, van Dulmen S, Hoogerbrugge PM, Kamps WA, Bensing JM. Young patients', parents', and survivors' communication preferences in paediatric oncology: results of online focus groups. BMC Pediatr. 2007;7:35.

260. Coyne I. Children's participation in consultations and decision-making at health service level: a review of the literature. International journal of nursing studies. 2008;45(11):1682-9.

261. Coyne I, Gallagher P. Participation in communication and decision-making: children and young people's experiences in a hospital setting. J Clin Nurs. 2011;20(15-16):2334-43.

262. de Vos MA, van der Heide A, Maurice-Stam H, Brouwer OF, Plotz FB, Schouten-van Meeteren $\mathrm{AY}$, et al. The process of end-of-life decision-making in pediatrics: a national survey in the Netherlands. Pediatrics. 2011;127(4):e1004-12.

263. Tong A, Sainsbury P, Craig J. Consolidated criteria for reporting qualitative research (COREQ): a 32-item checklist for interviews and focus groups. International journal for quality in health care : journal of the International Society for Quality in Health Care / ISQua. 2007;19(6):349-57.

264. Creswell JW. Qualitative inquiry and research design; choosing among five approaches. 3rd ed. London: Sage Publications, Inc.; 2013.

265. Lester S. An introduction to phenomenological research1999.

266. Evers J. Kwalitatief interviewen: kunst én kunde (Qualitative interviewing; art and practice). Den Haag: LEMMA; 2007.

267. Decision aid Bone infection Cincinnati: Cincinnati Children's Hospital Medical Center; 2012 [Available from: http://www.cincinnatichildrens.org/service/i/anderson-center/ evidence-based-care/decision-aids/.

268. Richtlijn voor richtlijnen: 20 criteria voor het ontwikkelen en implementeren van een klinische richtlijn. Den Haag; 2012 March 2012.

269. Coulter A. Shared decision making: everyone wants it, so why isn't it happening? World Psychiatry. 2017;16(2):117-8.

270. Facilitating shared decision-making with parents of chronically ill children Philadelphia: The Children's Hospital of Philadelphia, PolicyLab; 2014 [Available from: http://www. 
policylap.chop.edu/ (accessed 18th May 2014).

271. Wiering BM, Noordman J, Tates K, Zwaanswijk M, Elwyn G, De Bont ES, et al. Sharing decisions during diagnostic consultations; an observational study in pediatric oncology. Patient Educ Couns. 2016;99(1):61-7.

272. Brom L, De Snoo-Trimp JC, Onwuteaka-Philipsen BD, Widdershoven GA, Stiggelbout AM, Pasman HR. Challenges in shared decision making in advanced cancer care: a qualitative longitudinal observational and interview study. Health Expect. 2017;20(1):69-84.

273. Coyne I, Harder M. Children's participation in decision-making: balancing protection with shared decision-making using a situational perspective. J Child Health Care. 2011;15(4):312-9.

274. Dyer C. Doctors should not cherry pick what information to give patients, court rules. Bmj. 2015;350:h1414.

275. van der Weijden T, Dreesens D, Faber MJ, Bos N, Drenthen T, Maas I, et al. Developing quality criteria for patient-directed knowledge tools related to clinical practice guidelines. A development and consensus study. Health Expect. 2019;22(2):201-8.

276. Eckman MH, Wise RE, Naylor K, Arduser L, Lip GY, Kissela B, et al. Developing an Atrial Fibrillation Guideline Support Tool (AFGuST) for shared decision making. Curr Med Res Opin. 2015;31(4):603-14.

277. Lumbosacraal radiculair syndrom (lumbosacral syndrome) Utrecht: DCGP; 2015 [Available from: https://www.nhg.org/standaarden/volledig/nhg-standaard-lumbosacraal-radiculairsyndroom-Irs.

278. Stokes T. NICE Clinical Guidelines: involving patients, sharing decision-making, considering cost effectiveness. Huisarts \& Wetenschap. 2010;53(1):20-1.

279. Stacey D, Legare F, Lewis K, Barry MJ, Bennett CL, Eden KB, et al. Decision aids for people facing health treatment or screening decisions. Cochrane Database Syst Rev. 2017;4:CD001431.

280. Rodenbach RA, Brandes K, Fiscella K, Kravitz RL, Butow PN, Walczak A, et al. Promoting End-of-Life Discussions in Advanced Cancer: Effects of Patient Coaching and Question Prompt Lists. J Clin Oncol. 2017;35(8):842-51.

281. Sansoni J, Grootemaat P, Duncan C, Samsa P, Eagar K. A Systematic Literature Review on Question Prompt Lists in Health Care (Final Report). Wollongong: Centre for Health Service Development; 2014 June 2014.

282. Barry MJ, Edgman-Levitan S. Shared decision making--pinnacle of patient-centered care. N Engl J Med. 2012;366(9):780-1.

283. Hinds PS, Drew D, Oakes LL, Fouladi M, Spunt SL, Church C, et al. End-of-life care preferences of pediatric patients with cancer. J Clin Oncol. 2005;23(36):9146-54.

284. Lyon ME, McCabe MA, Patel KM, D'Angelo LJ. What do adolescents want? An exploratory study regarding end-of-life decision-making. J Adolesc Health. 2004;35(6):529 e1-6.

285. Mack JW, Feudtner C, Hinds PS. Communication and Decision Support for Children with Advanced Cancer and Their Families. American Society of Clinical Oncology educational book / ASCO American Society of Clinical Oncology Meeting. 2012;32:637-43.

286. Pousset G, Bilsen J, De Wilde J, Benoit Y, Verlooy J, Bomans A, et al. Attitudes of adolescent cancer survivors toward end-of-life decisions for minors. Pediatrics. 2009;124(6):e1142-8.

287. Sullivan J, Gillam L, Monagle P. Parents and end-of-life decision-making for their child: roles and responsibilities. BMJ Support Palliat Care. 2015;5(3):240-8.

288. Coyne I, Amory A, Kiernan G, Gibson F. Children's participation in shared decisionmaking: children, adolescents, parents and healthcare professionals' perspectives and experiences. Eur J Oncol Nurs. 2014;18(3):273-80.

289. Gochman DS, Bonham GS. Physicians and the hospice decision: awareness, discussion, reasons and satisfaction. Hosp J. 1988;4(1):25-53. 
290. Sullivan J, Monagle P, Gillam L. What parents want from doctors in end-of-life decisionmaking for children. Arch Dis Child. 2014;99(3):216-20.

291. Young B, Dixon-Woods M, Windridge KC, Heney D. Managing communication with young people who have a potentially life threatening chronic illness: qualitative study of patients and parents. BMJ. 2003;326(7384):305.

292. Knowledge translation in health care; moving from evidence to practice. 2nd ed. Chicester: John Wiley \& Sons, Ltd.; 2013.

293. Elwyn G, Frosch D, Thomson R, Joseph-Williams N, Lloyd A, Kinnersley P, et al. Shared Decision Making: A Model for Clinical Practice. Journal of General Internal Medicine. 2012.

294. Establishing Validity in Qualitative Research: Center for innovation in research and teaching; [Available from: https://cirt.gcu.edu/research/developmentresources/research ready/qualitative/validity.

295. Key Issues in Quantitative Research: Center for Innovation in Research and Teaching; [Available from: https://cirt.gcu.edu/research/developmentresources/research_ready/ quantresearch/keyissues.

296. Head BW. Reconsidering evidence-based policy: Key issues and challenges. Policy and Society 2010;29(2):77-94.

297. Cochrane; trusted evidence, informed decision, better health: The Cochrane Collaboration; [Available from: https://www.cochrane.org/.

298. GRADE: The GRADE working group; [Available from: https://www.gradeworkinggroup.org/.

299. Blume LH, van Weert NJ, Busari JO, Delnoij DM. Good intentions getting out of hand - is there a future for health care guidelines? Risk Manag Healthc Policy. 2017;10:81-5.

300. E-mail correspondence Van Everdingen - 2017.

301. Richtlijnachtige documenten - concept. Federatie Medisch Specialisten; 2017.

302. Toetsingskader kwaliteitsstandaarden, informatiestandaarden \& meetinstrumenten 2015. Diemen: Zorginstituut Nederland; 2018.

303. Kwaliteitsstandaard Organisatie van wondzorg in Nederland. V\&VN; 2018.

304. Kwaliteitsstandaard Psychosociale zorg bij somatische ziekte. Register Zorginstituut Nederland; 2019.

305. Kwaliteitsstandaard Transgenderzorg - Somatisch. Federatie Medisch Specialisten; 2019.

306. Zorginstituut Nederland (National Health Care Institute) Diemen: Zorginstituut Nederland; 2020 [Available from: https://www.zorginstituutnederland.nl/over-ons.

307. Programma Kwaliteitsgelden. Den Haag: ZonMw; 2019.

308. Schoemaker C vdWT. Patiëntvoorkeur versus evidencebased medicine; hadden de pioniers van EBM oog voor wat de patiënt wil?

[Patient preferences versus evidence-based medicine: did the pioneers of evidencebased medicine take the patient's preferences into account?] Ned Tijdschr Geneesk 2016;160(D24).

309. de Mik SML, Stubenrouch FE, Balm R, Ubbink DT. Systematic review of shared decisionmaking in surgery. The British journal of surgery. 2018;105(13):1721-30.

310. Barratt A. Evidence Based Medicine and Shared Decision Making: the challenge of getting both evidence and preferences into health care. Patient Educ Couns. 2008;73(3):407-12.

311. Hoffmann TC, Montori VM, Del Mar C. The connection between evidence-based medicine and shared decision making. JAMA : the journal of the American Medical Association. 2014;312(13):1295-6.

312. Lukersmith S, Hopman $\mathrm{K}$, Vine $\mathrm{K}$, Krahe L, McColl A. A new framing approach in guideline development to manage different sources of knowledge. J Eval Clin Pract. 2016.

313. Ubel P. Critical decisions; how you and your doctor can make the right medical choices together. 1st ed. New York: HarperOne; 2012.

314. Ubel P. Medical facts versus values judgments - towards preference-sensitive guidelines. The New England journal of medicine. 2015;372(26):2476-7. 
315. Wennberg JE. The road to guidelines. Health management quarterly : HMQ. 1991;13(2):2-7.

316. Guidelines International Network (G-I-N): G-I-N; 2016 [Available from: https://g-i-n.net/.

317. G-I-N Public: Guidelines International Network; 2016 [Available from: https://g-i-n.net/ working-groups/gin-public.

318. Alonso-Coello P, Oxman AD, Moberg J, Brignardello-Petersen R, AkI EA, Davoli M, et al. GRADE Evidence to Decision (EtD) frameworks: a systematic and transparent approach to making well informed healthcare choices. 2: Clinical practice guidelines. Bmj. 2016;353:i2089.

319. Dirksen CD, Utens CM, Joore MA, van Barneveld TA, Boer B, Dreesens DH, et al. Integrating evidence on patient preferences in healthcare policy decisions: protocol of the patient-VIP study. Implement Sci. 2013;8:64.

320. Utens CM, Dirksen CD, van der Weijden T, Joore MA. How to integrate research evidence on patient preferences in pharmaceutical coverage decisions and clinical practice guidelines: A qualitative study among Dutch stakeholders. Health Policy. 2016;120(1):1208.

321. Utens CM, Joore MA, van d W, Dirksen CD. Towards Integration of Research Evidence on Patient Preferences in Coverage Decisions and Clinical Practice Guidelines: A Proposal for A Taxonomy of Preference-Related Terms. Value in health : the journal of the International Society for Pharmacoeconomics and Outcomes Research. 2014;17(7):A5834.

322. Montori VM, Brito JP, Murad MH. The optimal practice of evidence-based medicine: incorporating patient preferences in practice guidelines. JAMA : the journal of the American Medical Association. 2013;310(23):2503-4.

323. Shared decision making bij ongeïnstrumenteerde wervelkolomchirurgie Utrecht: Federatie Medisch Specialisten; 2018 [Available from: https://richtlijnendatabase.nl/richtlijn/ ongeinstrumenteerde wervelkolomchirurgie/shared decision making bij hnp of stenose. $\underline{\mathrm{html}}$.

324. Evidence ecosystem Norway: MAGIC - Evidence ecosystem foundation; 2019 [Available from: http://magicproject.org/solutions/evidence-ecosystem/.

325. The Ecosystem of Evidence-Based Medicine: who is it and what does it do? : CEBM \& BMJ; 2019 [Available from: https://ebmlive.org/the-ecosystem-of-evidence-basedmedicine-who-is-it-and-what-does-it-do/.

326. Consultkaart; Utrecht: Patiëntenfederatie Nederland \& Federatie Medisch Specialisten; 2020 [Available from: https://consultkaart.nl/.

327. Less is more $+=-$ medicine [Internet]. Nanaimo: Less is more $+=-$ medicine. 2015. [cited 2019]. Available from: http://www.lessismoremedicine.com/blog/conferenceisdmisehc2015-bringing-evidence-based-practice-and-shared-decision-making-together.

328. Greenhalgh T, Howick J, Maskrey N, Evidence Based Medicine Renaissance G. Evidence based medicine: a movement in crisis? Bmj. 2014;348:93725.

329. Chalmers I, Bracken MB, Djulbegovic B, Garattini S, Grant J, Gulmezoglu AM, et al. How to increase value and reduce waste when research priorities are set. Lancet. 2014;383(9912):156-65.

330. Ioannidis JP, Greenland S, Hlatky MA, Khoury MJ, Macleod MR, Moher D, et al. Increasing value and reducing waste in research design, conduct, and analysis. Lancet. 2014;383(9912):166-75.

331. Al-Shahi Salman R, Beller E, Kagan J, Hemminki E, Phillips RS, Savulescu J, et al. Increasing value and reducing waste in biomedical research regulation and management. Lancet. 2014;383(9912):176-85.

332. Chan AW, Song F, Vickers A, Jefferson T, Dickersin K, Gotzsche PC, et al. Increasing value and reducing waste: addressing inaccessible research. Lancet. 2014;383(9913):257-66.

333. Glasziou P, Altman DG, Bossuyt P, Boutron I, Clarke M, Julious S, et al. Reducing waste 
from incomplete or unusable reports of biomedical research. Lancet. 2014;383(9913):26776.

334. Moher D, Glasziou P, Chalmers I, Nasser M, Bossuyt PM, Korevaar DA, et al. Increasing value and reducing waste in biomedical research: who's listening? Lancet. 2016;387(10027):1573-86.

335. Zonder context geen bewijs; over de illusie van evidence-based practice in de zorg (No evidence without context; about the illusion of evidence-based practice in healthcare). The Hague: Raad voor Volksgezondheid en Samenleving; 2017.

336. Passend bewijs. Ethische vragen bij het gebruik van evidence in het zorgbeleid. Den Haag: Raad voor de Volksgezondheid \& Zorg; 2007.

337. Richtlijn Vermoeden van ouderenmishandeling in het medisch-specialistische zorgdomein. Utrecht: Federatie van Medisch Specialisten; 2018.

338. Askheim C, Sandset T, Engebretsen E. Who cares? The lost legacy of Archie Cochrane. Med Humanit. 2017;43(1):41-6.

339. Land is a critical resource: IPCC; 2019 [Available from: https://www.ipcc.ch/2019/08/08/ land-is-a-critical-resource srccl/.

340. VN-klimaatrapport: voedseltekort dreigt vanaf 2050 door klimaatverandering Hilversum: NOS; 2019 [updated 8 August 2019. Available from: https://nos.nl/artikel/2296740-vnklimaatrapport-voedseltekort-dreigt-vanaf-2050-door-klimaatverandering.html.

341. Evidence Ecosystem Oslo: MAGIC Evidence Ecosystem Foundation; 2018 [Available from: https://magicproject.org/solutions/evidence-ecosystem/.

342. Consilience: Wikipedia; 2020 [Available from: https://en.wikipedia.org/wiki/Consilience.

343. William Whewell: Wikipedia; 2020 [Available from: https://en.wikipedia.org/wiki/William Whewell.

344. Tiemeijer WL, Thomas CA, Prast HMe. De menselijke beslisser: over de psychologie van keuze en gedrag. Den Haag: WRR (WETENSCHAPPELIJKE RAAD VOOR HET REGERINGSBELEID); 2009.

345. Tiemeier $\mathrm{H}$. Hoe mensen maken keuzes de psychologie van het beslissen. Amsterdam: WRR (Wetenschappelijke raad voor het regeringsbeleid); 2011. 


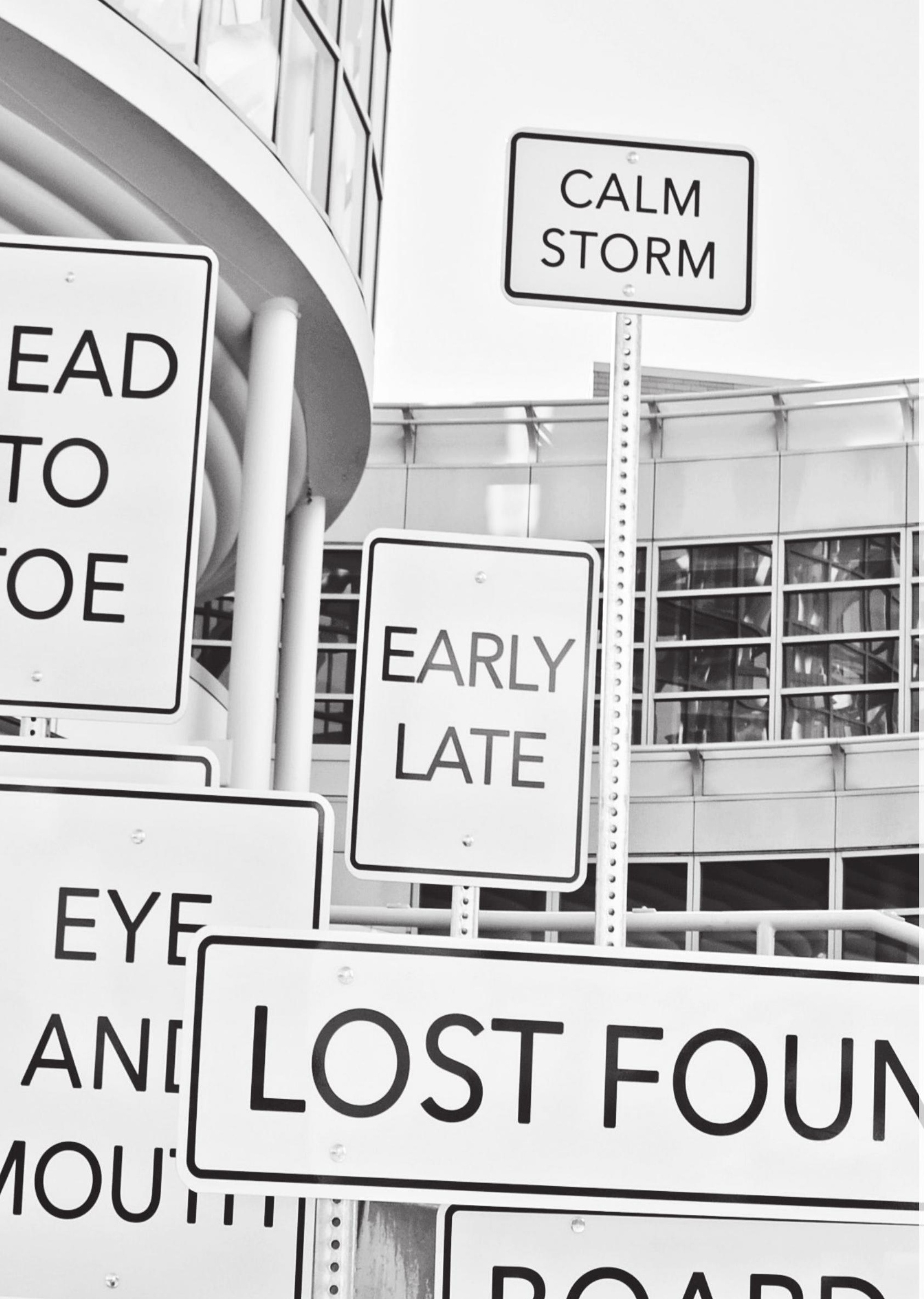




\section{Summary}

PREVENT CURE 
160 | Summary 


\section{Summary}

The body of knowledge in health care is vast and accumulating daily. To help healthcare professionals and patients handle and use this wealth of knowledge (something also dubbed 'information overload') when deciding about the patient's care, so-called knowledge tools are developed. The aims of this thesis were firstly, tool types are no longer developed without a clear definition and use. Secondly, there exists a common terminology when referring to tool types. Thirdly, to make better use of the different knowledge sources available, and finally provide healthcare professionals and patients, and possibly other users such as policy advisors and insurers, with a set of pragmatic tools that cover their needs in knowledge translation and decision support. This resulted in the following research questions:

- What tool types to translate knowledge and support (shared) decision-making are available to healthcare professionals (and patients) in the Netherlands? (Chapter 2)

- How are these tool types defined and does consensus exist on the definitions across the healthcare domains in the Netherlands? (Chapters 2 and 3)

- Which criteria do these tool types need to meet and which purposes do they serve so that healthcare professionals and patients consider them trustworthy and useful? (Chapter 4)

- Do we consider all knowledge sources when developing tools, and what does that mean for tool development? (Chapter 5)

- What are healthcare professionals' needs using tools for knowledge translation and shared decision-making? (Chapter 6)

\section{Available tool types}

There exist different kinds of tool types that support knowledge translation and/or (shared) decision making. A scoping review among national organisations that develop and implement tools yielded 67 different tool types in the Netherlands. Of these tool types, many were illdefined; meaning that there was no definition of the tool type (readily) available or the definition was (partially) incomplete: it contained no description of the tool type, its goal, and/nor who their intended target users were. In the pursuit of curtailing the information overload, we might have created an overload of tools and by ill defining them partially nullified the strived for use of knowledge and achieving optimal patient care.

\section{Defining tool types}

Therefore, a consensus procedure to limit the amount of tool types and to agree on the definition of the tool types was carried out at a national level in the Netherlands. Stakeholders from various domains in health care (curative care, long term care and public health) and with different expertise participated; patients, tool developers, healthcare professionals, policy advisors. In the end, consensus was reached on a core set of nine tool types and there was agreement on the definitions of five of these tools. These were: 'summary', 'flowchart', 'clinical practice guideline', 'protocol' and 'patient decision aid'. Despite the participation of the stakeholders and some organisations already adopting the core set, the reached consensus was just a first step. It remains a challenge to adhere to the core set. A more concerted effort by the parties involved is needed. But also, because new tool types or seemingly new tool types 
(pseudo innovation) keep emerging. Possibly illustrating that something new is more alluring and exciting than tinkering with and adhering to existing tool types. However, for change and implementation to take effect, a certain constancy of purpose and consistency is needed.

\section{Purposes and criteria of tool types}

Believing the issue of too many tool types available to healthcare professionals and patients, was not confined to the Netherlands, international experts were approached to participate in a two-day evidence-informed consensus meeting. The aim of this invitational meeting was to develop a conceptual framework categorizing the different tool types aimed directly at patients. The participants considered a framework including all tool types infeasible during a two-day meeting. The developed framework clarifies the purposes of the patient-directed tool types and indicates the core elements these tool types prototypically consist of. In this way, the framework can help tool developers, people who commission the development of these tools, patients and healthcare professionals to discern between the different tools, and to identify to which tool type it belongs, which purposes it serves and which core elements it should contain. As the framework was developed by a small group of experts, it is called a conceptual or working framework and it needs to be further tested and probed to check if it is usable and to make it more robust.

\section{Knowledge sources and tool types}

Besides having a closer look at the various tool types that convey knowledge, knowledge itself was looked at as well, as part of the work done by the G-I-N Working Group Appraising and Including Different (AID) Knowledge. Different knowledge sources exist but some seem to be favoured more than others. Evidence-based guidelines are supposed to search for, and explicitly consider, evidence from sources other than conventional clinical trials and their quantitative data. These different types of knowledge can be used and are needed in situations when for example evidence from RCTs is unavailable, impossible to obtain, contradictory or inappropriate. These sources can also be used in conjunction with RCTs to provide context, to assess relevance and to understand bias(es). Additionally, more complex forms of knowledge like experiential and contextual knowledge can help guideline developers to take an approach consistent with the intentions of early evidence-based medicine: the best evidence is not restricted to evidence from RCTs and meta-analyses. However, in the context of medicine and guideline production, integrating different types of knowledge continues to be underexplored and undertheorized.

\section{Paediatricians' reflections on tool types}

The worlds 'evidence-based medicine', 'shared decision-making' and 'tools' can come up with a lot of ideas, theories and concepts of how to move knowledge into use in daily practice but how do healthcare professionals feel about these endeavours. In interviews, 15 paediatricians reflected on several strategies to enhance shared decision-making (SDM) in paediatric palliative care. The first one being the clinical practice guideline Palliative care for children that contains recommendations on shared decision-making. The other strategies were a modified guideline recommendation on pain relief to reflect available options and patient preferences, and patient decision aids. Not all paediatricians felt that guidelines could enhance SDM as they regarded 
it a skill or attitude. Others, however, thought that guidelines in general could enhance shared decision-making in daily practice. In the case of the guideline Palliative care for children, however, they commented that the recommendations needed to focus more on how to practice SDM. When presented with a one option recommendation on pain relief and a multiple options recommendation on pain relief, most paediatricians preferred the latter, as it would open the discussion with the patient and/or its parents. Furthermore, most interviewed paediatricians felt that patient decisions aids were beneficial to patients, e.g. to ensure that all topics relevant to the patient are covered. For guidelines to enhance SDM, guideline developers could consider formulating more 'open' recommendations, especially in case of preference sensitive choices. Moreover, SDM should not be limited to non-treatment recommendations, should describe (treatment) trade-offs and (treatment) alternatives and provide more detailed guidance. Another consideration is to provide tools amalgamated with specific guideline recommendations to enhance shared decision-making, such as patient decision aids.

\section{A case of consilience}

Taking a step back and looking at the research findings some overarching issues could be discerned. If we want to help healthcare professionals and patients with making sense of all the knowledge and knowledge sources available to them, we should not inundate them with tools. And we need to be more vigilant about their definitions and implementation. More discipline by and collaboration between stakeholders is necessary for sustainability of the core set that was agreed on a national level.

Furthermore, we need to combine and connect the EBM and SDM approaches to integrate research evidence and patient preferences better. That means developing tools that provide healthcare professionals and patients with answers to evidence-based questions and help them elicit and integrate patient preferences. Next to patient decision aids, clinical practice guidelines should be more preference-sensitive so that viable choices are not taken away from patients.

To achieve optimal patient care, provide more effective healthcare services and strengthen the healthcare system, the use of all knowledge sources is necessary. Not using all sources is a waste of research as well. This means making tool developers (and other stakeholders) more aware of the availability of different knowledge sources, the possible flaws within the predominantly used knowledge base and that it is pertinent to continue working on methods how to appraise and include different knowledge sources.

To achieve all this an interdisciplinary and interprofessional approach is needed. The many domains, disciplines, expertise, parties and professionals involved in knowledge translation, (shared) decision-making and tool development should abandon their silos, combine their knowledge, compare methods. In addition, the different domains in health care such as cure, social care, occupational health, public health and long term care, could collaborate more frequently and learn from each other. And they might even look outside health care for other knowledge sources and how these other domains appraise and include the array of knowledge sources available. Getting knowledge used in daily practice is a case of consilience. The policy domain is a part of this as well and could contribute (more) by acknowledging that patients 
need to be better positioned, by having governmental agencies fund a more diverse palette of studies such as research on patient preferences and implementation, and by following up on governmental reports that looked into the psychology of deciding, choice and behaviour and how this affects the decision-making in healthcare practice.

\section{Strengths and limitations}

No thesis can go without a critical reflection on the used research methods. This thesis consists of predominant qualitative research as the research was exploratory in nature. First, it tried to achieve an improved understanding of perspectives, experiences, opinions, attitudes concerning translation of knowledge. Second, it looked into the use of knowledge tool types. Third, the comprehension of the needs of healthcare professionals was examined when using these tool types. And last, it tried to reach consensus on (developing) criteria and purposes of these tool types. Strengths and limitations of qualitative research relate to credibility, transferability and dependability. To increase credibility several approaches were used, such as involving participants as much as possible by sharing results and outcomes and by member checking and independent coding by three authors. Transferability is regarded as limited, mainly because the research was largely executed with tool types used in the Netherlands and a Dutch clinical practice guideline. However, methods and outcomes can be used in international settings and other guidelines as well. Qualitative research is characterised by fluid structures, which change because of incoming and available data. Therefore, to improve dependability, for each study the approach and/or method chosen and the changes therein, if any, were exhaustively described. Furthermore, the SRQR or COREQ checklists were applied for all the studies in this thesis, except chapter five.

\section{Conclusion}

It has become clear that healthcare professionals and patients are inundated with (loosely defined) tools. A first step to limit the number of tool types and agree on their definitions has been achieved in the Netherlands. The next step is more robust adherence to maintain a certain level of consistency of the available tool types. Pseudo innovation of tool types needs to be avoided.

Furthermore, the current knowledge tools do not always use all the knowledge sources that are available. Awareness of this is growing and efforts are underway to include and appraise these other knowledge sources. Different approaches in health care, such as SDM and EBM, exist to achieve optimal patient care. These approaches should combine their efforts more. Strategies to achieve this have been proposed and tentative steps have been taken. One strategy suggests integrating tools used in EBM and SDM or to use these tools more in concordance. Further recommendations for practice, policy and further research are described in detail at the end of the general discussion. 


\section{Samenvatting}

De hoeveelheid kennis in de medische wetenschap en (gezondheids)zorg is enorm en dijt dagelijks verder uit. Geen arts of patiënt overziet deze schat aan kennis (ook wel 'informationoverload' genoemd, zeg maar 'overdosis' aan informatie), laat staan dat ze in staat zijn er volledig gebruik van te maken in de dagelijkse praktijk. Daarvoor zijn hulpmiddelen nodig, en vooral op die momenten dat men beslissingen moet nemen. Deze kennishulpmiddelen heten in het Engels 'tools' en in het Nederlands 'instrumenten'. De doelstellingen van dit proefschrift vormen een drieluik. In de eerste plaats: eraan bijdragen dat men niet langer instrumenten ontwikkelt en inzet, zonder eenduidige definitie en handleiding voor gebruik. Ten tweede: bijdragen aan deze noodzakelijke gemeenschappelijke terminologie voor dit instrumentarium. Ten derde: beter gebruikmaken van de beschikbare kennisbronnen. Hoe? Door zorgprofessionals en patiënten, en mogelijk ook andere gebruikers, zoals beleidsadviseurs en verzekeraars, te voorzien van een kernset van pragmatische instrumenten, aansluitend bij hun behoefte aan kennisontsluiting en beslissingsondersteuning. Die doelstellingen resulteerden in de volgende onderzoeksvragen:

- Welke typen instrumenten om kennis te ontsluiten en (gezamenlijke) besluitvorming te ondersteunen, zijn beschikbaar voor zorgprofessionals (en patiënten) in Nederland? (Hoofdstuk 2)

- Hoe luiden de definities van de verschillende instrumenten en in hoeverre bestaat hierover consensus binnen de diverse zorgdomeinen in Nederland? (Hoofdstukken 2 en 3)

- Aan welke criteria moeten deze instrumenten voldoen en voor welke doeleinden dienen ze, opdat zorgverleners en patiënten ze betrouwbaar en bruikbaar achten? (Hoofdstuk 4)

- Nemen we alle kennisbronnen bij het ontwikkelen van instrumenten in overweging en, afhankelijk van het antwoord, wat betekent dat voor de ontwikkeling van deze instrumenten? (Hoofdstuk 5)

- Welke behoeften hebben zorgprofessionals wat betreft instrumenten voor kennisvertaling en samen beslissen? (Hoofdstuk 6)

\section{Beschikbare typen instrumenten (instrumentarium)}

Er bestaan uiteenlopende instrumenten die kennisontsluiting en/of (gezamenlijke) besluitvorming ondersteunen. Een scoping review bij Nederlandse organisaties deze instrumenten ontwikkelen en implementeren, resulteerde in 67 verschillende typen. Veel hiervan waren slecht gedefinieerd: de definitie bleek niet (eenvoudig) vindbaar of de definitie was - deels - onvolledig. Wat vaak ontbrak was een beschrijving van het instrument, het doel ervan en/of een heldere omschrijving van de beoogde doelgebruikers. Jongleren met definities valt af te raden. Als antwoord op de 'information-overload' ontstond mogelijk een overdaad aan instrumenten. Bovendien gebeurde dat slordig wat niet zonder gevolgen blijft; een slechte of onvoldoende heldere definitie doet het streven naar kennisgebruik mogelijk deels teniet, waardoor de uiteindelijke uitkomst - optimale patiëntenzorg - achter de horizon verdwijnt.

\section{Typen instrumenten gedefinieerd}

Een helder definitie is dus een basisvoorwaarde voor instrumenten. Via een 
consensusprocedure in Nederland is getracht om op landelijk niveau eensgezindheid te bereiken over de inperking van het instrumentarium en de definities van de type instrumenten. Belanghebbenden uit verschillende zorgdomeinen (curatieve zorg, langdurige zorg en volksgezondheid) en met verschillende expertise gingen ermee aan de slag: patiënten, toolontwikkelaars, zorgverleners, beleidsadviseurs. Het resultaat bestond uit een kernset van negen typen instrumenten. Over de definities van vijf instrumenten bestond overeenstemming. Dit waren: 'richtlijn', 'samenvatting', 'stroomdiagram', 'protocol' en 'patiëntenkeuzehulp'. Een mooie eerste stap. De daadwerkelijke uitdaging ligt echter daarin de belanghebbenden en sommige organisaties te overtuigen - of te verleiden - tot het zich committeren aan en beperken tot de instrumenten uit de kernset. Een meer gezamenlijke inspanning van de betrokken partijen is dan een vereiste, een inspanning die verder reikt dat de eigen perceptie van een instrument. Een andere verschijnsel onderstreept de noodzaak van die inspanning: het opduiken van alsmaar nieuwe instrumenten of schijnbaar nieuwe instrumenten (noem dat gerust pseudo-innovatie). Mogelijk illustreert dat fenomeen dat iets nieuws aantrekkelijker en spannender is dan sleutelen aan en vasthouden aan het bestaande instrumentarium. Het is een algemeen menselijk fenomeen, waarop bijvoorbeeld marketing berust. Met andere woorden: ook ontwikkelaars van instrumenten hebben menselijke trekjes... Een beter scenario: het vereist een zekere standvastigheid en consistentie - en misschien zelfs koppigheid - om instrumenten en de implementatie daarvan aan (zeggings)kracht te doen winnen.

\section{Instrumentarium: doeleinden en criteria}

Nederland is geen eiland, Nederlandse problemen zijn daarmee niet uniek (vooruit, enkele uitzonderingen daargelaten). Om het internationale perspectief zuiverder in beeld te krijgen, namen internationale experts deel aan een tweedaagse, empirisch onderbouwde consensusvergadering. Het doel: de ontwikkeling van een conceptueel kader inclusief een onderverdeling van de verschillende typen kennisinstrumenten, specifiek gericht op patiënten. Het bleek niet haalbaar een allesomvattend raamwerk te ontwikkelen met ruimte voor het hele instrumentarium.

Het ontwikkelde raamwerk verheldert de doelen van de patiëntgerichte instrumenten en maakt duidelijk welke kernelementen onderdeel uitmaken van deze typen instrumenten. Op deze manier kan het raamwerk behulpzaam zijn voor instrumentontwikkelaars, opdrachtverleners voor de ontwikkeling van deze instrumenten, patiënten en zorgverleners. Aangezien het raamwerk is ontwikkeld door een kleine groep experts, noemen wij dit een conceptueel of werkkader; meer onderzoek en tests zijn nodig om het werkkader te evalueren op bruikbaarheid en het kader robuuster te maken.

\section{Kennisbronnen en instrumenten}

Instrumenten dragen bij aan de kennisoverdracht naar de gebruiker. In die drietrapsraket van kennis via instrument naar gebruiker verdienen dus tevens de kennisbronnen nadere aandacht. Laten we inzoomen op dat punt. Er bestaan verschillende kennisbronnen, maar sommige lijken meer de voorkeur te genieten dan andere; al kan populariteit nimmer de doorslaggevende factor zijn. De ontwikkeling van evidence-based richtlijnen gaat uit van de volgende vooronderstelling: men houdt ook rekening met andere bronnen dan conventionele klinische studies en hun kwantitatieve gegevens. Deze aanvullende soorten kennis zijn namelijk 
nodig in situaties waarin bijvoorbeeld bewijsmateriaal van RCT's niet beschikbaar, onmogelijk te verkrijgen, tegenstrijdig of weinig passend is. Deze bronnen kan men ook combineren met RCT's om de context te schetsen, relevantie te beoordelen en mogelijke vertekening(en) te begrijpen. Bovendien helpen meer complexe vormen van kennis, zoals ervarings- en contextuele kennis, richtlijnontwikkelaars te ondersteunen in een aanpak overeenkomstig de klassieke intenties van evidence-based medicine (EBM): het beste bewijs beperkt zich niet tot bewijs van RCT's en meta-analyses. Helaas is deze integratie van verschillende soorten kennis binnen de context van farmacotherapie en richtlijnontwikkeling nog steeds onderbelicht en onderbestudeerd is.

\section{Instrumentarium: attituden en overwegingen van kinderartsen}

In theorie valt een ideale wereld te bedenken. Analoog hieraan is theorievorming over kennisoverdracht, samen beslissen en noodzakelijke hulpmiddelen beslist van waarde. Maar hoe denken gebruikers hierover? In interviews reflecteerden 15 kinderartsen op verschillende verbeterstrategieën om samen beslissen (shared decision-making in het Engels, ofwel SDM) in pediatrische palliatieve zorg. Dit gebeurde aan de hand van drie strategieën: de richtlijn Palliatieve zorg voor kinderen met daarin aanbevelingen over samen beslissen, de herziene aanbeveling over pijnverlichting en keuzehulpen voor de patiënt. Niet alle kinderartsen waren van mening dat richtlijnen samen beslissen zouden kunnen verbeteren omdat zij het samen beslissen veeleer als een uitgangshouding of als een vaardigheid beschouwen. Anderen waren echter van mening dat richtlijnen in het algemeen kunnen bijdragen aan samen beslissen in de dagelijkse praktijk. In het geval van de richtlijn Palliatieve zorg voor kinderen merkten ze echter op dat de aanbevelingen meer gericht zouden moeten zijn op de uitvoering van samen beslissen.

Overeenkomsten zijn de schaduwen van de verschillen. Ondanks dat idiomatisch geschipper leverden de interviews concreet resultaat op. Gesteld voor de keuze: een aanbeveling met één optie voor pijnverlichting of een aanbeveling met meerdere opties voor pijnverlichting, gaven de meeste kinderartsen de voorkeur aan de laatste variant. Als reden geven zij aan dat het weergeven van meer opties de discussie opent met de patiënt en/of ouders. Daarnaast waren de meeste kinderartsen van mening dat keuzehulpen nuttig en behulpzaam zijn voor patiënten, bijvoorbeeld om ervoor te zorgen dat alle, voor de patiënt relevante onderwerpen, aan bod komen.

Willen richtlijnen een grotere bijdrage leveren aan samen beslissen, zouden richtlijnontwikkelaars dus kunnen overwegen om aanbevelingen mee 'open' te formuleren. Zeker waar het voorkeursgevoelige keuzes betreft. Het lijkt een open deur dat samen beslissen in richtlijnen alle zorgaspecten betreft, maar de nadruk ligt nog vaak op procesmatige aspecten en communicatie, terwijl juist dilemma's over behandeling de kern vormen. Er is nadrukkelijk behoefte aan een nadere beschrijving van overwegingen en alternatieven plus het bieden van uitgewerkte specifieke begeleiding. Een andere overweging is het expliciet opnemen van handvatten in richtlijnen ter verbetering van samen beslissen; denk hierbij aan geïntegreerde keuzehulpen voor patiënten. 


\section{A case of consilience}

Laten we een blik werpen in de achteruitkijkspiegel van dit onderzoek om de onderzoeksresultaten te bezien. Enkele overkoepelende kwesties tekenen zich af. Als we zorgverleners en patiënten willen helpen met het begrijpen en gebruiken van alle kennisbronnen, mogen we hen niet overspoelen met instrumenten. En we moeten minder achteloos zijn inzake hun definities en implementatie. Zorgvuldigheid loont. Omzichtigheid evenzeer. Meer discipline door en samenwerking tussen stakeholders is nodig voor de bestendiging van de overeengekomen kernset op nationaal niveau.

Bovendien moeten we de EBM- en SDM-benaderingen combineren om onderzoeksbewijs en patiëntvoorkeuren beter te integreren. Dat betekent instrumenten ontwikkelen die zorgprofessionals en patiënten van evidence-based antwoorden voorzien en hen helpen bij het expliciteren en integreren van patiëntvoorkeuren. Naast de keuzehulpen voor patiënten, zouden richtlijnen meer voorkeurgevoelig moeten zijn, opdat patiënten geen relevante keuzes onthouden blijven.

Om optimale patiëntenzorg te realiseren, effectievere zorg te verlenen en het zorgstelsel te versterken, is benutting van alle kennisbronnen noodzakelijk. Niet alle bronnen gebruiken, is namelijk per definitie ook verspilling van onderzoek. Het rendeert om instrumentontwikkelaars (en andere belanghebbenden) bewuster te maken van de beschikbaarheid van verschillende kennisbronnen, te wijzen op mogelijke gebreken binnen de eigen, gebruikelijke kennisbronnen en het belang om te blijven werken aan methoden voor het beoordelen en opnemen van verschillende kennisbronnen te blijven benadrukken.

Dit alles vereist een interdisciplinaire en interprofessionele aanpak. De vele domeinen, disciplines, expertise, partijen en professionals die zich bezighouden met kennisvertaling, medische besluitvorming, samen beslissen en instrumentontwikkeling moeten hun stellingen verlaten, hun kennis combineren, methoden vergelijken. Hokjesgeest, verdediging van eigen belangen en kokerzicht verenigen niet, ze werken splijtend. Daarnaast zouden de verschillende domeinen in de zorg vaker kunnen samenwerken en van elkaar leren. En ze kunnen zelfs buiten de gezondheidszorg zoeken naar andere kennisbronnen, en hoe deze domeinen deze beoordelen en uiteindelijk gebruiken. Kennisontsluiting en kennis opdoen in de dagelijkse praktijk is 'a case of consilience': een kwestie van voortdurend heen en weer denken in een streven naar een reflectief evenwicht (dat voortdurend in 'beweging' is). In die zin pleit dit proefschrift voor invalshoeken die verder reiken dan het eigen domein, en is het tevens een pleidooi voor grensoverschrijdend denken en doen.

Het (overheids)beleidsdomein maakt hier eveneens deel vanuit en heeft een rol in de kennisontwikkeling en -ontsluiting. Het beleidsdomein kan (meer) bijdragen door de erkenning dat patiënten een sterke positionering toekomt, door overheidsinstanties een meer divers palet aan studies te laten financieren, zoals onderzoek naar patiëntvoorkeuren en implementatie, en door follow-up te geven aan overheidsrapporten via onderzoek naar de psychologie van besluitvorming, keuze en gedrag en hoe dit de besluitvorming in de gezondheidszorg beïnvloedt. 


\section{Sterke punten en beperkingen}

Geen proefschrift kan zonder kritische reflectie op de gebruikte onderzoeksmethoden. Dit proefschrift bestaat uit overwegend kwalitatief onderzoek, aangezien het onderzoek verkennend van aard was in het streven naar een dieper inzicht in perspectieven, ervaringen, meningen, attitudes met betrekking tot vertaling van kennis en het gebruik van hulpmiddelen hiervoor. Dit alles met inbegrip van de behoeften van zorgprofessionals bij het gebruik ervan deze instrumenten enerzijds, en anderzijds een poging tot consensus te komen over criteria en doelen van dit instrumentarium. De kracht en de beperkingen van kwalitatief onderzoek hebben betrekking op geloofwaardigheid, overdraagbaarheid en betrouwbaarheid. Om de geloofwaardigheid te vergroten, zijn verschillende benaderingen gebruikt, zoals het zoveel mogelijk betrekken van de deelnemers door resultaten met hen te delen en te laten controleren, plus een onafhankelijke codering van de interviews door drie auteurs. De overdraagbaarheid mag beperkt heten, omdat het onderzoek grotendeels is uitgevoerd met in Nederland gehanteerde instrumenten, een Nederlandse richtlijn, binnen een Nederlandse context. Methoden en resultaten zijn echter ook internationaal bruikbaar en voor andere richtlijnen. Kwalitatief onderzoek kenmerkt zich door fluïde structuren die voortdurend veranderen door de nimmer aflatende stroom van inkomende en beschikbare data. Ter verhoging van de betrouwbaarheid, is besloten een uitputtende beschrijving te geven van de gekozen aanpak en/of methode. Verder pasten wij de SRQR- of COREQ-checklists toe voor alle studies in dit proefschrift, behalve in hoofdstuk vijf.

\section{Conclusie}

Het is duidelijk dat zorgprofessionals en patiënten overspoeld worden met (losjes gedefinieerde) instrumenten. In Nederland is een eerste stap gezet om het aantal instrumenten te beperken en tot overeenstemming te komen over de definities. De volgende stap is krachtiger naleving om het consistentieniveau van het beschikbare instrumentarium te behouden; pseudoinnovatie van instrumenten verdient afkeuring.

Daarnaast benutten kennisinstrumenten niet altijd alle beschikbare kennisbronnen. Dit besef groeit en er wordt gewerkt aan het opnemen en beoordelen van andere kennisbronnen. Er bestaan verschillende benaderingen in de gezondheidszorg, zoals SDM en EBM, om optimale patiëntenzorg te realiseren. Deze benaderingen zouden hun inspanningen meer moeten bundelen. Er zijn strategieën voorgesteld om dit te bereiken en eerste stappen zijn gezet. Een strategie behelst de integratie van de instrumenten binnen EBM en SDM dan wel deze instrumenten beter op elkaar af te stemmen. Verdere aanbevelingen voor praktijk, beleid en verder onderzoek staan in detail uitgewerkt aan het einde van de algemene discussie. 


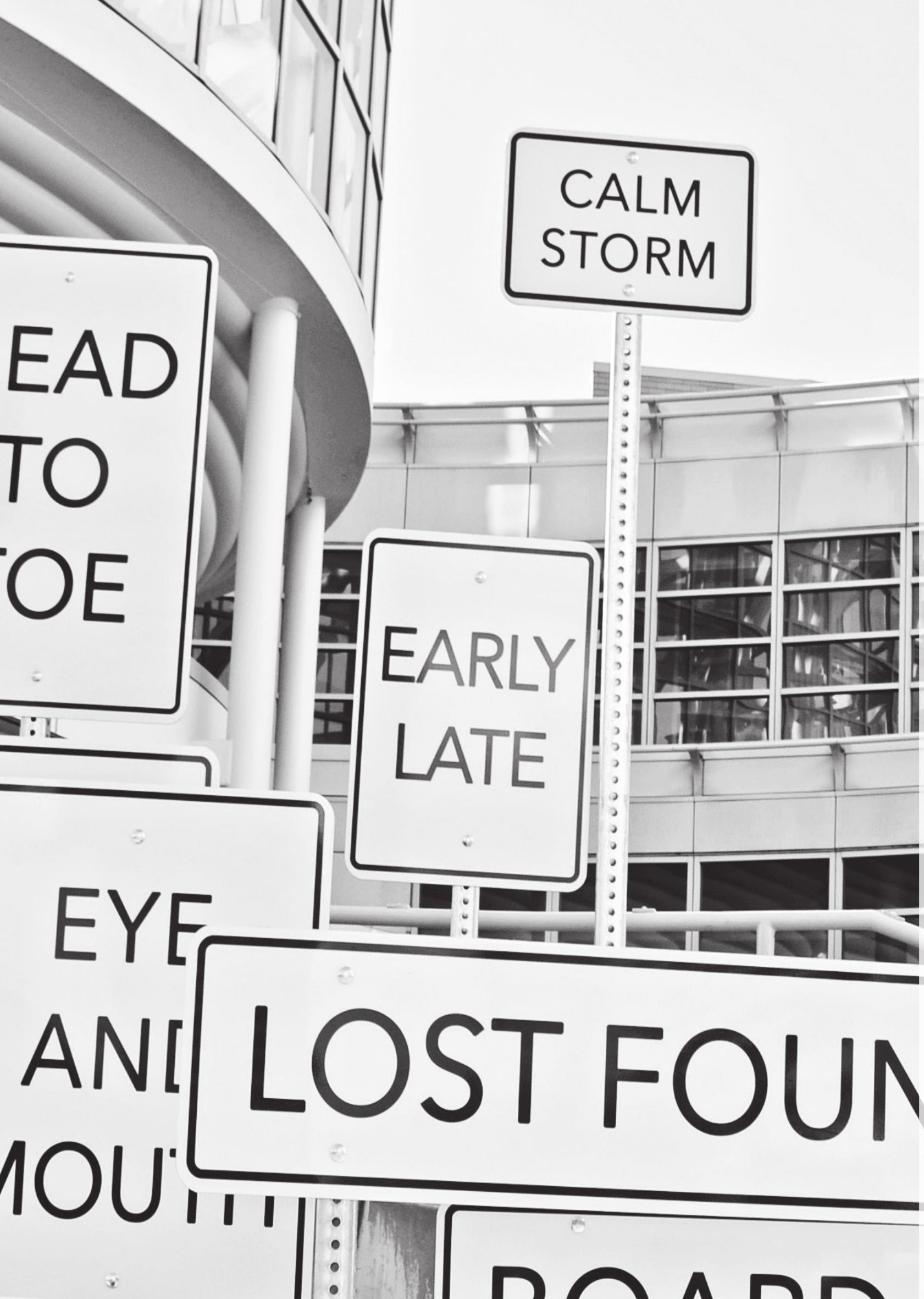




\section{Valorisation chapter}

\section{Developing quality criteria for patient-centred knowledge tools related to clinical practice guidelines. A development and consensus study}

Trudy van der Weijden, Dunja Dreesens, Marjan J. Faber, Nanne Bos, Ton Drenthen, Ingrid Maas, Sonja Kersten, Uriëll Malanda, Sander van der Scheur, Heleen Post, Anouk Knops
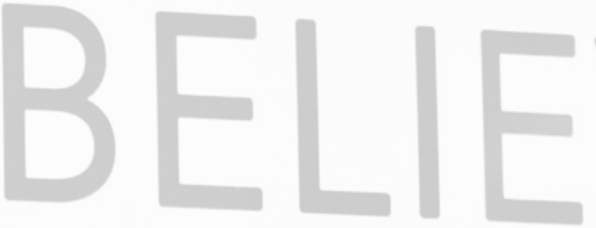


\section{Abstract}

\section{Background}

Patient-directed knowledge tools such as patient versions of guidelines and patient decision aids are increasingly developed to facilitate shared decision-making. In this paper, we report how consensus was reached within the Netherlands on quality criteria for development, content and governance of these tools

\section{Method}

A 12-month development and consensus study. The consortium worked on four work packages: $1 /$ reviewing existing criteria; 2 / drafting the quality criteria; 3 / safe-guarding the acceptability and feasibility of the draft criteria by participatory research in ongoing tool development projects; and 4/ gaining formal support from national stakeholders on the quality criteria.

\section{Results}

We reached consensus on an 8-step guidance; describing minimal quality criteria for $1 /$ the team composition, 2/ setting the scope, 3 / identifying needs, 4 / the content and format, $5 /$ testing the draft, $6 /$ finalising and approval, $7 /$ dissemination and application, and 8/ ownership and revision. The participants of the ongoing tool development projects were positive about the quality criteria in general, but divided as to the degree of detail. Whereas some expressed a clear desire for procedural standards, others felt that it would be sufficient to provide only general directions. Despite the different views as to the degree of detail, consensus was reached in three stakeholder meetings.

\section{Discussion}

We successfully collaborated with all stakeholders and achieved formal support from national stakeholders on a set of minimum criteria for the development process, content and governance of patient-directed knowledge tools.

\section{Keywords}

patient participation, patient involvement, shared decision-making, clinical practice guidelines, quality standards, patient decision aids, patient information, patient versions of guidelines 


\section{Introduction}

The knowledge in health care is expanding daily - so that keeping up with knowledge is a challenge 1 . The development of knowledge tools is intended to support clinicians to keep pace and to improve their decision-making. Many knowledge tools such as clinical practice guidelines, protocols, or clinical pathways have been developed over the years ${ }^{2}$. With the increasing call for a patient revolution ${ }^{3}$, further tool types have been added to the mix, including patient decision aids. A key source of information for patient-directed knowledge tools is clinical practice guidelines. Clinical practice guidelines summarize research evidence systematically and provide recommendations on a specific clinical topic ${ }^{4}$. Nowadays, the GRADE approach is used as a framework to rate the quality of the evidence, and to assess the strength of the recommendations taking into account the balance between benefits and harms, resource use, and feasibility considerations. The GRADE method also recognises the collective patient perspectives ${ }^{5}$; the strength of the recommendations is also affected by the patients' appreciation of advantages and level of acceptability of disadvantages of the intervention, such as side effects and treatment burden. Worldwide, patients and patient representatives increasingly take part in the development of guideline recommendations ${ }^{6}$.

Next to patient participation on a collective level, efforts are made to adapt or enrich guidelines so as to facilitate patient participation on an individual level, in clinical decision-making ${ }^{7}$. Patient participation is especially important in case of preference-sensitive decisions where multiple options exist, or where the benefits and harms of the intervention may be assigned a different weight by different patients ${ }^{8}$. Illustrative examples to facilitate patient participation in clinical decision-making are patient versions of a guideline such as a lay summary, or patient decision aids for specific preference-sensitive decisions attached to the guideline document. Some guidance for content of lay summaries of guidelines is provided by the Guidelines International Network $^{9}$. In 2006, standards were formulated for the content of patient decision aids by the International Patient Decision Aids Standards (IPDAS) group, a multi-stakeholder process that led to a self-assessment checklist ${ }^{10}$. Further work led to a measure IPDASi' ${ }^{11}$ and a set of criteria that should be met to achieve a 'minimum' acceptable standard ${ }^{12}$. Guideline developers are experimenting to derive the information for patient decision aids - evidence on benefits and harms of interventions and on patient considerations and patient preferences - directly from the guideline ${ }^{13}$.

Much is also happening with respect to the development of patient-centred knowledge tools such as patient versions of a guideline or patient decision aids in the Netherlands, on various sides of the care equation ${ }^{14}$. Patient organisations are gaining a more accurate picture of the information needs that these tools must satisfy. Professional and scientific associations feel a responsibility to ensure the accuracy and effectiveness of medical information supplied via such tools. Web and tool designers continue to introduce ever more user-interface friendly tools. For this study, we used the following definition: a patient-directed knowledge tool synthesizes and distils the highest quality knowledge and research, is aimed directly at the patient (and next of kin), with the goal to engage patients in dialogue or deliberation during a clinical encounter, 
or to support and/or improve patient decision making which may or may not take place during a clinical encounter ${ }^{15}$. Yet these patient-centred knowledge tools are subject to a multitude of varying definitions and criteria, especially regarding the patient versions of guidelines, and the development process ${ }^{16-22}$. As a result, it is difficult for parties to distinguish what is truly important from what is not, or what type of patient-directed knowledge tool is in fact the correct means to achieve the stated purpose. In addition to quality criteria, the need for national governance is also felt strongly, as many initiatives by patient organisations and professional bodies to develop patient-directed knowledge tools exist side by side. This situation has resulted in an uncoordinated, partly overlapping mixture of publicly and privately/commercially available patient decision aids ${ }^{23}$. Moreover, some of the patient decision aids do not seem to follow the rigid and multi-stakeholder methods to review the evidence base, as is common in clinical practice guidelines.

A guidance for the development of reliable patient versions of guidelines and patient decision aids can serve to integrate all existing knowledge and previously developed expertise, allowing the stakeholders to work together more effectively and more efficiently. The purpose of such a guidance is to promote the development of high-quality, reliable and publicly available patientdirected knowledge tools, which will contribute to achieving properly informed patients and shared decision-making.

Initiated by the National Health Care Institute of the Netherlands, a consortium of healthcare stakeholders started to develop such guidance, supported by academic researchers. Apart from validity, feasibility was important given the conflict between the aim of high-quality knowledge tools and the limited resources to develop such tools. The purpose of this article is twofold. First, we describe the methods used for arriving at the guidance as an illustrative example of how formal support from national stakeholders can be reached. Second, we present the list (guidance) of minimum quality criteria for the development, content and governance of patient information on guidelines and patient decision aids, as well as the way in which these tools can be connected to the clinical practice guidelines.

\section{Methods}

The National Health Care Institute of the Netherlands initiated and granted this 12-month development study, that was composed of a literature review, a feasibility check, and a consensus procedure. We took the position that we needed various types of input and processes to ensure a successful consensus process. To this end, we designed a consortium (see first four authors and last two authors) that worked together continuously in an iterative process using cross-fertilisation, without being hindered by hierarchy. A representative of the Dutch Federation of Patients' Organisations (last author) was co-leading the project with the first author.

In a 12-month project that started in October 2015, we worked on the basis of four work packages (WPs): WP1/ Radboud University (MF) reviewed existing criteria in the literature, synthesising evidence and best practices; WP2/ Maastricht University (TvdW, DD), the coordinating group, developed the drafts of the guidance; WP3/ NIVEL (NB) safeguarded 
the acceptability and feasibility of the draft criteria by gathering experiences with the draft guidance from knowledge tool developers; WP4/ the Dutch Federation of Patients' Organisations (AK) organised the consensus procedure aiming to support the guidance by national stakeholders.

\section{Work package 1}

We searched for formal criteria and methodologies in the scientific literature, in policy reports, and on websites by developers of guidelines and patient decision aids. The search strings that we used to explore PubMed are described in Table 1, as are the websites to search for the grey literature. This inventory supplied the basis for the first draft of the guidance. One of the researchers of WP1 made a first selection of the search based on title and abstract, and excluded references clearly not fulfilling the inclusion criteria. All full-text versions that resulted from this first selection were downloaded and assessed along the pre-set in- and exclusion criteria. In case of doubt a second researcher was consulted to reach consensus on in- or exclusion.

Inclusion criteria for literature on patient versions of guidelines:

- The paper describes the development process of a patient version or lay summary of a clinical practice guideline.

- Explicit description of the methods used (be it short or extensive) for development.

- English or Dutch language.

Exclusion criteria:

- Papers describing only the process of patient participation in development of a clinical practice guideline.

Inclusion criteria for literature on patient decision aids:

- The title reports the term 'development' or 'design'.

- The abstract reports the development of a patient decision aid as the aim of the paper.

- Description of development process of disease specific or generic decision aids.

- Explicit description of the methods used (be it short or extensive) for development.

- English or Dutch language.

Exclusion criteria:

- Papers describing development of tools that stretch further than patient decision aids (e.g. social support, self-management).

- Papers describing development of tools on other decisions than medical decisions. 
Table 1: Search strings used to explore Pubmed, and websites used to search for grey literature

\section{Search strings}

Patient information based on guidelines

- $\quad((($ method*[Title/Abstract] OR approach*[Title/Abstract] OR framework[Title/Abstract] OR develop*[Title/Abstract] OR creat*[Title/Abstract])) AND ("patient version*"[Title/Abstract] OR "information for the public"[Title/Abstract] OR "public information"[Title/Abstract] OR "patient booklet*"[Title/Abstract] OR booklet*[Title/Abstract])) AND ("clinical practice guideline*" OR "Practice Guidelines as Topic"[Mesh] OR "quality standard*")

- ("Practice Guidelines as Topic"[Mesh] OR "Practice Guideline" [Publication Type] OR guideline*) AND "patient version" AND develop*

- Patient decision aids

- "Decision Support Techniques"[Majr:NoExp] AND (method*[tiab] OR approach*[tiab] OR framework[tiab] OR develop*[tiab] OR creat*[tiab]) AND ("Patient Satisfaction"[Mesh] OR "Patient Participation"[Mesh] OR "Patient-Centered Care"[Mesh]))

\section{Websites}

- Dutch Knowledge Institute of Medical Specialists

- Netherlands Comprehensive Cancer Organisation

- Guidelines International Network, Patient and Public Involvement working group

- UK National Institute for Health and Care Excellence (NICE)

- German Ärztliches Zentrum für Qualität in der Medizin (ÄZQ)

- Finnish Duodecim

- Australian National Health and Medical Research Council (NHMRC)

- USA Oncoline Kaiser

- USA Agency for Healthcare Research and Quality (AHRQ)

- Canadian Task Force on Preventive Health Care (CTFPHC)

- IPDAS working Group www.ipdas.ohri.ca

- Patient Decision Aids Research Group https://decisionaid.ohri.ca

- The Preference Laboratory http://optiongrid.org/option-grids/about-the-grids

- Mayo Clinic for shared decision making http://shareddecisions.mayoclinic.org

- DECIDE research Group www.decide-collaboration.eu

- Joanna Briggs Institute University of Adelaide http://joannabriggs.org

\section{Work package 2}

The project was coordinated via monthly meetings with all WP leaders, complemented by numerous one-to-one contacts. We used definitions of the patient-directed knowledge tools that were recently formulated in another Dutch national consensus procedure; see Box ${ }^{24-25}$. The findings from the literature review were used to draft the first set of the minimal quality criteria for development, content and governance of patient-directed knowledge tools. The findings of the feasibility checks (WP3) and consensus meetings (WP4) were used to write the second and third draft of the guidance.

Box 1: The Dutch definitions of the patient-directed knowledge tools. ${ }^{24-25}$

Patient information based on a guideline ( $=$ patient version of a guideline): Explanation of a specific condition or (health) care issue based on a guideline; made available to patients and their next of kin; provides information on available care choices and the care that they can expect from the care process. 
Summary of guideline: Concise overview of the guideline, providing main conclusions and recommendations in clear and simple language; can be applied in practice independently from the guideline; intended for both care providers and patients.

Patient decision aid (PDA): Auxiliary information and answers to frequently asked questions for patients when choosing, with their care providers, from different options - including the option to forgo care - in a specific area such as diagnostics, treatment, screening, counselling or aftercare; discusses the possible outcomes and effects of each option - desirable or otherwise - and their likelihood of occurring; helps patients to weigh up their options based on their own values, standards and personal circumstances.

\section{Work package 3}

The first and second draft guidance was presented for a critical assessment of its feasibility to the project leaders of nine working groups tasked with the development of patient versions of guidelines or patient decision aids along clinical practice guidelines. These working groups were at that time in various phases of their development projects. Five projects focused on developing patient information based on guidelines, e.g. for patients with inflammatory bowel disease. Four projects focused on developing patient decision aids for specific recommendations, e.g. in the care for orthopaedic patients. For the third draft of the guidance we did not only seek for critical assessment by the project leader, but we also asked the project leader to actually apply (part of) the guidance steps in their working groups and to report about their experiences. Four of these nine ongoing projects were further analysed by means of outreach visits and participatory observations of working group meetings. Finally, the last draft and the experiences were fed back to each project leader in individual semi-structured qualitative interviews. The interviews were audiotaped, transcribed and analysed with thematic content analysis ${ }^{26}$.

\section{Work package 4}

The draft versions of the guidance were discussed in three invitational meetings. We purposefully sampled the participants for the first two meetings to guarantee continuity in the process by inviting a core group for both meetings. While we planned the input from academic experts in the first meeting, the profile of participants gradually shifted to stakeholders representing end-users only in the last meeting.

First, a two-hour expert meeting was held in March 2016 aimed at collecting the experts' suggestions, for which 43 stakeholders representing patients, care providers, researchers, web and tool designers and healthcare insurers were invited. Second, a two-hour meeting was held in June 2016, for which 29 stakeholders representing patients, care providers, knowledge institutions, healthcare insurers and the government were invited to question their support to the draft version of the guidance. Third and finally, a 90-minute consensus meeting was held in September 2016, for which only the formal representatives of patients, healthcare providers and healthcare insurers were invited in order to gain formal support. 


\section{Results}

\section{How did we arrive at the guidance?}

WP1 Inventory of existing methods and criteria in scientific and grey literature

We found 51 hits in PubMed, of which four studies were included that describe criteria for developing patient versions of guidelines. The grey literature revealed many websites publishing patient versions of guidelines, but information on how these knowledge tools were developed was scarce. Detailed descriptions were found, however, in the Guidelines International Network 'GIN Public toolkit on patient and public involvement in guidelines'. For developing patient decision aids, we found 385 hits in PubMed, of which 24 studies were included; 10 more relevant publications were added by the experts in the project group. In addition, the websites revealed rich data on what exactly patient decision aids are and how they should be developed.

The criteria for the content of patient decision aids were mostly based on empirical data ${ }^{26}$, while such data were more or less absent for the content of patient versions of guidelines. IPDAS criteria (ipdas.ohri.ca) enjoy broad support where criteria for the content of decision aids are concerned, due to their substantiation by means of systematic consensus methodology.

\section{WP3 Feasibility assessment in ongoing development projects}

While reactions to the ordering of the development steps in the draft guidance were unanimously positive, the project leaders were extremely divided as to the degree of detail when it came to the instructions within the steps of the guidance, such as how best to map the patient perspective in the scoping and needs assessment phase. Whereas some project leaders expressed a clear desire for procedural standards (it should be clear at all times who does what and when), others felt that it would be sufficient for the instructions in each step to provide only general direction. Concerning the other issues raised, we report those most frequently mentioned:

- Deviating from the linear ordering of the guidance should be possible. For example, the guideline working group may be no longer active, while the patient-directed tool is urgently needed.

- Language and jargon used in the guidance was often found to be too academic.

- The amount and complexity of the work to map the patients' perspective in the scoping and needs assessment phase, e.g. by organising a focus group or a questionnaire survey, was often underestimated. Due to limitations in resources and the high workload, work should not be done twice, in the guideline working group and in the patient tool development group. Moreover, the required minimum number of two patients in the team - as was prescribed in the earlier drafts - was a concern, as well as the mandatory inclusion of a representative of the guideline working group.

- Formal authorisation of the tool was not regarded necessary by all stakeholders, with the argument that the guideline was already approved.

- All project leaders plead for a central portal to host the patient directed knowledge tools, supported by a national party taking care of the governance of the tools. 


\section{WP4 The consensus meetings}

For the first meeting, 28 out of 43 invited experts were present. When asked to mark the most important sections of the guidance, experts prioritised the following issues: chose the right type of knowledge tool for the aim it pursues; use the guideline (recommendation) itself as the most important source of information for the knowledge tool; determine who will become the owner of the knowledge tool; make the knowledge tool easily accessible and free to use; organize authorization by the healthcare professional organization(s) as well as the patients' organization(s).

For the second meeting 21 out of 29 invited were present. All stakeholders were well represented. In general, they expressed a positive attitude towards the guidance although two critical remarks were made. Firstly, multiple stakeholders emphasized to widen the scope of the guidance so that patient-directed knowledge tools can also be developed on topics that are not covered by clinical practice guidelines; especially patient organizations claimed that the information needs of patients should determine the content of patient-directed knowledge tools, as opposed to only following the existing guideline recommendations. Secondly, the nursing organisation criticized the language of the guidance being too scientific and loaded with too much medical jargon.

The third meeting was attended by formal representatives of all parties except for the Dutch Association of Insurers, which formally declined while giving blind consent to the guidance as a token of trust in the representatives of the patients and providers. Therefore, the final meeting was attended by four participants, representing the Dutch Federation of Patients' Organisations (HP), the Dutch College of General Practitioners (TD), the Dutch Association of Medical Specialists (IM), and the Dutch Nurses' Association (SK). They expressed their positive intentions with regard to supporting the guidance, but only after the following issues were clarified: the minimum criteria should clearly be listed separate from the additional suggestions; developers of patient-directed knowledge tools should be encouraged to use the guidance according to the comply or explain principle; authorization of patient-related knowledge tools should be done on a process level and not on the level of authorizing the content of the tools, as content was already authorized in the final phase of the guideline development process.

In retrospect, it can be observed that the quest for clear and outspoken procedural standards that was verbalised by some project leaders in WP3 was strongly echoed in the first meeting but that it faded away in the second meeting, while only crude instructions for each step were regarded sufficient in the third and final meeting.

\section{The guidance}

WP1 provided rich data for formulating eight distinct development steps in the guidance (Table 2). The final guidance consists of three components: a) recommendations for which type of knowledge tool (such as a lay summary or decision aid) best fits the objectives of the development group; b) minimum criteria for the eight development steps, content and governance of each tool (Box 2); c) supplemental, detailed and concrete suggestions for each step in a second layer of information (14 pages in total, not presented, available on request). Developers deviating from these minimum criteria would have to provide a rationale for why a criterion does not apply ('comply or explain'). The steps need not always be followed in linear fashion, as the guidance establishes the criteria for an effective development process rather 
than laying out a strictly prescribed series of ordered steps. In the event that the development of the knowledge tool (patient information on a guideline or a patient decision aid based on a specific guideline recommendation) is part of a guideline project, the development team will ideally be commissioned by the guideline working group itself.

Table 2: The similarities and differences between the eight development steps for a) patient information on a guideline and b) a patient decision aid (PDA) connected to specific guideline recommendation(s)

\begin{tabular}{|c|c|c|}
\hline $\begin{array}{c}\text { Typical of patient information } \\
\text { on a guideline(s) }\end{array}$ & DEVELOPMENT STEPS & $\begin{array}{l}\text { Typical of PDA connected to } \\
\text { specific recommendation(s) }\end{array}$ \\
\hline \multicolumn{3}{|c|}{$\begin{array}{c}1 \text { TEAM } \\
\text { Chose members and define tasks }\end{array}$} \\
\hline $\begin{array}{l}\text { Provides an overview of the } \\
\text { entire guideline (module) }\end{array}$ & $\begin{array}{c}2 \text { SCOPE } \\
\text { Establish provisional scope } \\
\text { Create inventory of existing } \\
\text { versions }\end{array}$ & $\begin{array}{l}\text { Concerns one or several specific } \\
\text { recommendations. }\end{array}$ \\
\hline $\begin{array}{l}\text { Not a one-to-one application } \\
\text { of guideline. Information needs } \\
\text { may also differ from those } \\
\text { mentioned in the guideline. }\end{array}$ & $\begin{array}{l}3 \text { NEEDS } \\
\text { Identify information needs }\end{array}$ & $\begin{array}{l}\text { Establish attributes for } \\
\text { consideration in decision-making. } \\
\text { Needs of care providers as well. }\end{array}$ \\
\hline $\begin{array}{l}\text { Purposeful selection of } \\
\text { guideline recommendations. }\end{array}$ & $\begin{array}{l}4 \text { CONTENT } \\
\text { Content and form }\end{array}$ & $\begin{array}{l}\text { International criteria are in } \\
\text { place; IPDAS (Int. Pat. Dec. Aids } \\
\text { standards) }\end{array}$ \\
\hline \multicolumn{3}{|c|}{$\begin{array}{l}5 \text { TEST } \\
\text { Testing the concept }\end{array}$} \\
\hline \multicolumn{3}{|c|}{$\begin{array}{c}6 \text { FINALISING } \\
\text { Finalising and obtaining approval }\end{array}$} \\
\hline \multicolumn{3}{|c|}{$\begin{array}{c}7 \text { DISSEMINATION } \\
\text { Dissemination and application }\end{array}$} \\
\hline & $\begin{array}{c}8 \text { OWNERSHIP } \\
\text { Management and revision }\end{array}$ & \\
\hline
\end{tabular}

For patient versions of guidelines, the patients' information needs together with the subject of the guideline will form the basis for the content of the patient version; the guideline itself should be the most important source of information. Rather than assuming just one guideline as a starting point, this situation might mean that multiple guidelines will need to be integrated and translated into a single patient information document, as this process will more effectively address the desires and perceptions of the target group. Or, alternatively, it might mean that only a limited number of guideline modules will be applied in creating patient information documents. A need to develop one or more patient decision aids is especially indicated when one or more of the guideline's key recommendations are preference-sensitive in nature. 
Box 2: The guidance. A brief description of each step for the development of patient information on a guideline or a patient decision aid (PDA) connected to specific guideline recommendation(s).

1 TEAM The team composition is discussed with the relevant patients' and professional associations. The team has an independent chair and a process support member/secretary, along with at least one patient (-representative) with first-hand experience (acquired by the patients' organisation). Membership of the team is approved based on written Declarations of Interests. An editor with experience in writing copy for a non-expert audience will be involved in the team. If the development of the tool is part of a guideline project, the team will (ideally) be commissioned by the guideline working group itself, which has budgeted the developmental work.

2 SCOPE The team checks the availability of existing tools, and establishes the objective, the target group and the rough form of the tool.

Patient information: Determine where the guideline is failing to meet patients' information needs. After all, guidelines for practice are typically drawn up from the perspective of the care provider. Whenever possible, address the major underlying questions patients have about the guideline, as well as the key recommendations.

PDA: Select one or more recommendations from the guideline that have to do with the decision at hand, and that are preferencesensitive in nature.

3 NEEDS There are multiple ways to identify the needs of patients: a review of the literature, and/or additional qualitative or quantitative methodologies for collecting data, such as focus groups or questionnaires.

Patient information: Concerns any additional needs that have not yet been elaborated during the guideline development, e.g. with regard to multimorbidity, ethnic minorities, alternative interventions, selfmanagement.

PDA: Involves questions the patients and their proxies may have when faced with taking a specific decision. Which needs, preferences and attributes influence a given patient's decision-making? This might involve information needs and psychosocial needs, along with important strategies for self-management in connection with the illness or condition, and should also include the variations between patients. 
4 CONTENT For both type of tools describe:

- The target group and medical condition/symptom/healthcare topic.

- The guideline(s) serving as the basis (in part) for the creation of the information on evidence, etc.

- The source of funding, who has ownership, year of publication and expiry date (if applicable).

- The interests of each member of the development group (conflict of interest).

Patient information:

Describe the guideline recommendations on which patients would want to be informed in terms that a layperson can understand. Mention frequently-used examples of professional jargon so that patients can become familiar with them. The patient information will additionally indicate the following aspects:

- Point out where aspects have consciously been omitted and/or emphasis has intentionally shifted (if applicable), as compared to the guideline.

PDA:

Describe the situation/decision at hand and the relevant recommendation(s) from the guideline, in terms that a layperson would understand. The PDA will describe the following aspects (at minimum):

- An explanation that the patient has a choice; that he/she is facing a preference-sensitive decision.

- A description of the medical/care options, including the option to wait and see (if applicable) and an explanation of the procedure for each medical/care intervention.

- The desired and undesired outcomes (side effects) of the medical or care options, and the burden of treatment.

- The likelihood and risks of the outcomes, expressed as numeric data with equal denominator of population in natural frequencies and an identical length of time; preferably displayed in population diagrams; framed both positively and negatively (chances of both survival and fatality, for example); and in the case of risk reduction presented, at minimum, in terms of absolute (and potentially relative) risk reduction.

- An evidence table in which the medical/care options are summarised and compared in terms of a few key aspects.

- Ensure explicit mention of the attributes found in step 3 that are important for patients to keep in mind as they consider their options and elicit their values. These attributes must contribute to the key aspects described in the evidence table. 
5 TEST The development team will present the draft to the relevant professional, scientific and patients' associations for the purpose of obtaining feedback. The parties will assess whether the patient perspective is sufficiently reflected, ensure understanding of people with low literacy, and if the medical content is accurate. If the guideline working group is still active, the draft will be presented to that group for feedback as well.

6 FINALISING The development team establishes the final knowledge tool and presents it to the relevant professional, scientific and patients' associations for approval. This regards approval at the process level, i.e. concerning the creation of the knowledge tool. Ownership is determined and formally established.

7 DISSEMINATION The tool will ideally be submitted to the national Health Care Institute as a section of the relevant guideline(s). The knowledge tool becomes accessible to the public and is preferably made available at a central location, including points for attention to facilitate the actual application/implementation in healthcare practice.

8 OWNERSHIP The owner(s) of the knowledge tool will manage the tool and determine when the information is due to be revised: in any case when the expiry date has been reached. Ideally, the need for revision of the tool will be considered when the guideline as a whole is revised.

\section{Discussion}

We successfully collaborated as a consortium of researchers and end user representatives, with patient participation realised at the highest level of involvement, to achieve formal support from national stakeholders on a set of minimum criteria for the development process, content and governance of patient-directed knowledge tools related to clinical practice guidelines. What we provide is not a detailed 'recipe' for development but rather a series of recommendations based on the 'state of the art' and feasibility considerations.

A number of potential limitations should be mentioned. Our project was explicitly embedded in the guideline context, we did e.g. not include patient versions of systematic reviews. The guideline context may be a limiting context for developing patient-directed knowledge tools. As the starting point of a clinical practice guideline is predominantly the clinicians' perspective, important issues for patients may not be covered in the guideline. The assignment from the National Health Care Institute was aimed specifically at guidelines in the context of curative health care. While the literature is unclear in this regard, it is possible that the content of the guidance might have been different had representatives from public health, long-term and palliative healthcare been included. One strength of this project is the systematic approach 
and involvement of all national stakeholders, from patients to policymakers, with patient representatives in a co-leading role. We believe that the involvement of all stakeholders from the writing phase of the project proposal contributed to the successful collaboration. Another strength of the project is that the guidance was developed with prospective feasibility checks parallel to the nine ongoing development projects.

The relevance of patient-directed knowledge tools being publicly available has also been acknowledged in the UK, with one of the main institutions developing guidelines committed to develop patient decision aids based on clinical guidelines ${ }^{28}$. The relevance of this process was recently underpinned by empirical evidence in the Netherlands. The Dutch College of General Practitioners launched a non-commercial public website in March 2012 that provides easy access to patient versions of guidelines. Since its launch, the website has grown to become one of the most visited Dutch healthcare websites. Healthcare usage in primary care seems to have decreased by $12 \%$ after the launch of the website ${ }^{29}$.

We expect the criteria to evolve over time as they are further tested through developers using patient versions of guidelines and patient decision aids, as well as by adding new tools to the guidance. The next challenge will be the effective implementation of the guidance as a further step towards ensuring the development of high-quality, reliable and publicly available patientdirected knowledge tools with the support and acceptance of professional associations (and alliances), scientific associations and patients' organisations. The main stakeholders (the Dutch Federation of Patients' Organisations, the Dutch Association of Medical Specialists, the Dutch College of General Practitioners and the Dutch Nurses' Association) continued in working together to translate the guidance into a web-based practical version, and to arrive at consensus on a sustainable model for the development, publication, governance and financing of patient decision aids. An important follow-up step is to crosslink this guidance to the guidance for developers of clinical practice guidelines'.

Formal steps towards accreditation have not been taken yet, the question being whether this procedure is needed, and is warranted given the current level of evidence. In December 2016, the USA National Quality Forum released national standards for the certification of patient decision aids ${ }^{30}$. The certification criteria are meant to be used for 'complete' patient decision aids, which are standalone, independent tools for patients facing a clinical decision. Our guidance, although not formulated along the lines of certification criteria, is highly comparable with the USA criteria in terms of content. The only USA criterion that we do not cover is that the patient decision aid should report readability levels.

We believe that this study can be seen as an inspirational example for other countries that are facing the same challenges with regard to the development and governance of clinician- and patient-directed knowledge tools such as guidelines, guideline summaries, patient versions of guidelines and patient decision aids. 


\section{References}

\section{Literature references}

1. Bastian H, Glasziou P, Chalmers I. Seventy-five trials and eleven systematic reviews a day: how will we ever keep up? PLoS medicine. 2010;7(9):e1000326.

2. Brouwers M, Stacey D, O'Connor A. Knowledge creation: synthesis, tools and products. CMAJ 2010;182:E86-72.

3. Richards T, Montori VM, Godlee F, Lapsley P, Paul D. Let the patient revolution begin. BMJ 2013;346:f2614.

4. Qaseem A, Forland F, Macbeth F, et al. Guidelines International Network: toward international standards for clinical practice guidelines. Ann Intern Med. 2012;156:525-31.

5. Alonso-Coello P, Oxman AD, Moberg J, Brignardello-Petersen R, AkI EA, Davoli M, Treweek S, Mustafa RA, Vandvik PO, Meerpohl J, Guyatt GH, Schünemann HJ, the GRADE Working Group GRADE Evidence to Decision (EtD) frameworks: a systematic and transparent approach to making well informed healthcare choices. 2: Clinical practice guidelines BMJ 2016;353:i2089.

6. Boivin A, Currie K, Fervers B, Gracia J, James M, Marshall C, Sakala C, Strid J, Thomas V, van der Weijden T, Grol R, Burgers J, on behalf of GIN Public [the Guideline International Network Patient and Public Involvement Working Group]. Patient and public involvement in guidelines: international experiences and future perspectives. Qual Saf Health Care. 2010;19:e22.

7. van der Weijden T, Pieterse AH, Koelewijn-van Loon MS, Knaapen L, Légaré F, Boivin A, Burgers JS, Stiggelbout AM, Faber M, Elwyn G. How can clinical practice guidelines be adapted to facilitate shared decision making? A qualitative key-informant study. BMJ Qual Saf 2013;22:855-63.

8. van der Weijden T, Boivin A, Burgers J, Schünemann HJ, Elwyn G. Clinical practice guidelines and patient decision aids. An inevitable relationship. J Clin Epid 2012;65:584-9.

9. G-I-N Public Working Group. G-I-N Public Toolkit: Patient and Public Involvement in Guidelines. 2015.

10. Elwyn G, O'Connor A, Stacey D, Volk R, Edwards A, Coulter A, et al. Developing a quality criteria framework for patient decision aids: online international Delphi consensus process. BMJ 2006;333:417.

11. Elwyn G, O'Connor AM, Bennett C, Newcombe RG, Politi M, Durand MA, et al. Assessing the quality of decision support technologies using the International Patient Decision Aid Standards instrument (IPDASi). PLoS One 2009;4:e4705.

12. Joseph-Williams N, Newcombe R, Politi M, Durand M-A, Sivell S, Stacey D, et al. Toward minimum standards for certifying patient decision aids. Med Dec Mak 2014;34:699-710.

13. Agoritsas T, Fog Heen A, Brandt L, Alonso-Coello P, Kristiansen A, Akl EA, Neumann I, Tikkinen KAO, van der Weijden T, Elwyn G, Montori VM, Guyatt GH, Vandvik PO. Decision aids that really promote shared decision making: the pace quickens. BMJ 2015;350:g7624.

14. van der Weijden T, Post $H$, Brand PLP, van Veenendaal $H$, Drenthen T, van Mierlo LA, Stalmeier P, Damman OC, Stiggelbout A. Shared decision making, a buzz-word in the Netherlands, the pace quickens towards nationwide implementation.... Z Evid Fortbild Qual Gesundhwes 2017 May 18. pii: S1865-9217(17)30091-0. doi: 10.1016/j.zefq.2017.05.016.

15. Straus SE, Tetroe J, Graham I. Defining knowledge translation. CMAJ 2009;181(3-4):165-8.

16. Elwyn G, Kreuwel I, Durand MA, Sivell S, Joseph-Williams N, Evans R, et al. How to develop web-based decision support interventions for patients: a process map. Pat Educ Counsel 2011;82:260-5.

17. Coulter A, Stilwell D, Kryworuchko J, Mullen PD, $\mathrm{Ng} \mathrm{CJ}$, van der Weijden T. A systematic development process for patient decision aids. BMC Med Informatics Dec Making 2013;13(Suppl 2):S2.

18. Hoffman AS, Llewellyn-Thomas HA, Tosteson AN, O'Connor AM, Volk RJ, Tomek IM, et 
al. Launching a virtual decision lab: development and field-testing of a web-based patient decision support research platform. BMC Med Inform Dec Mak 2014;14:112.

19. Raats CJI, van Veenendaal H, Versluijs MM, Burgers JS. A generic tool for development of decision aids based on clinical practice guidelines. Pat Educ Counsel 2008;73:413-7.

20. The Patient Decision Aids Research Group. Ottawa decision support framework. Available from: https://decisionaid.ohri.ca/

21. Ng CJ, Mathers N, Bradley A, Colwell B. A 'combined framework' approach to developing a patient decision aid: the PANDAs model. BMC Health Serv Res 2014;14:503.

22. Option Grid Collaborative. How are Option Grids developed? Available from: http:// optiongrid.org/option-grids/about-the-grids.

23. Stiggelbout AM, van der Weijden T, de Wit MPT, Frosch D, Légaré F, Montori VM, Trevena $L$, Elwyn G. Shared decision making: really putting patients at the centre of health care. BMJ 2012;344:e256.

24. Dreesens D, Kremer L, van der Weijden T.. The Dutch chaos case: a scoping review of knowledge and decision support tools available to clinicians in the Netherlands. Submitted

25. Dreesens D, Kremer L, Burgers J, van der Weijden T.. Lost in definitions: reducing duplication of and clarifying knowledge tools using modified RAND Delphi method. Submitted

26. Berg B.L. Qualitative research methods for the social sciences (7th edition). US: Pearson Education Limited; 2008.

27. Stacey D, Légaré F, Lewis K, Barry MJ, Bennett CL, Eden KB, Holmes-Rovner M, LlewellynThomas H, Lyddiatt A, Thomson R, Trevena L. Decision aids for people facing health treatment or screening decisions. Cochrane Database of Systematic Reviews 2017, Issue 4. Art. No.: CD001431.

28. Leng G, Ingham Clark C, Brian K, Partridge G. National commitment to shared decision making. The only way to achieve truly person centred care. BMJ 2017;359:j4746 doi: 10.1136/bmj.j4746

29. Spoelman WA, Bonten TN, de Waal MWM, et al. Effect of an evidence based website on healthcare usage: an interrupted time-series study. BMJ Open 016;6:e013166. doi:10.1136/ bmjopen-2016-013166.

30. Elwyn G, Burstin H, Barry MJ, Corry MO, Durand MA, Lessler D, Saigal C. A proposal for the development of national certification standards for patient decision aids in the US Health Policy 2018 doi: 10.1016/j.healthpol.2018.04.010. [Epub ahead of print].

\section{References for Patient versions of guidelines}

1. de Wit MP, Smolen JS, Gossec L, van der Heijde DM. Treating rheumatoid arthritis to target: the patient version of the international recommendations. Ann Rheum Dis. 2011 Jun;70(6):891-5.

2. Stoffer MA, Smolen JS, Woolf A, et al. Development of patient-centred standards of care for osteoarthritis in Europe: the eumusc.net-project. Ann Rheum Dis. 2015 Jun;74(6):1145-9.

3. Williams NH, Amoakwa E, Burton K, et al. The Hip and Knee Book: developing an active management booklet for hip and knee osteoarthritis. Br J Gen Pract. 2010 Feb;60(571):6482.

4. Kiltz U, van der Heijde D, Mielants H, Feldtkeller E, Braun J; PARE/EULAR patient initiative group. ASAS/EULAR recommendations for the management of ankylosing spondylitis: the patient version. Ann Rheum Dis. 2009 Sep;68(9):1381-6.

\section{References for Patient Decision aids}

1. Hoffman AS, Llewellyn-Thomas HA, Tosteson AN, O'Connor AM, Volk RJ, Tomek IM, et al. Launching a virtual decision lab: development and field-testing of a web-based patient decision support research platform. BMC medical informatics and decision making. 2014;14:112. 
2. Carroll SL, McGillion M, Stacey D, Healey JS, Browne G, Arthur HM, et al. Development and feasibility testing of decision support for patients who are candidates for a prophylactic implantable defibrillator: a study protocol for a pilot randomized controlled trial. Trials. 2013;14:346.

3. Fleisher L, Ruggieri DG, Miller SM, Manne S, Albrecht T, Buzaglo J, et al. Application of best practice approaches for designing decision support tools: the preparatory education about clinical trials (PRE-ACT) study. Patient education and counseling. 2014;96(1):63-71.

4. Cranney A, O'Connor AM, Jacobsen MJ, Tugwell P, Adachi JD, Ooi DS, et al. Development and pilot testing of a decision aid for postmenopausal women with osteoporosis. Patient education and counseling. 2002;47(3):245-55.

5. Elwyn G, Kreuwel I, Durand MA, Sivell S, Joseph-Williams N, Evans R, et al. How to develop web-based decision support interventions for patients: a process map. Patient education and counseling. 2011;82(2):260-5.

6. Montori VM, Breslin M, Maleska M, Weymiller AJ. Creating a conversation: insights from the development of a decision aid. PLoS Med. 2007;4(8):e233.

7. Harwood R, Douglas C, Clark D. Decision aids for breast and nodal surgery in patients with early breast cancer: development and a pilot study. Asia-Pacific journal of clinical oncology. 2011;7(2):114-22.

8. Johnson SL, Kim YM, Church K. Towards client-centered counseling: development and testing of the WHO Decision-Making Tool. Patient education and counseling. 2010;81(3):355-61.

9. Raats CJI, van Veenendaal H, Versluijs MM, Burgers JS. A generic tool for development of decision aids based on clinical practice guidelines. Patient education and counseling. 2008;73(3):413-7.

10. Wong J, D’Alimonte L, Angus J, Paszat L, Metcalfe K, Whelan T, et al. Development of patients' decision aid for older women with stage I breast cancer considering radiotherapy after lumpectomy. International journal of radiation oncology, biology, physics. 2012;84(1):30-8.

11. LeBlanc A, Bodde AE, Branda ME, Yost KJ, Herrin J, Williams MD, et al. Translating comparative effectiveness of depression medications into practice by comparing the depression medication choice decision aid to usual care: study protocol for a randomized controlled trial. Trials. 2013;14:127.

12. Ng CJ, Mathers N, Bradley A, Colwell B. A 'combined framework' approach to developing a patient decision aid: the PANDAs model. BMC health services research. 2014;14:503.

13. Ozanne EM, Howe R, Omer Z, Esserman LJ. Development of a personalized decision aid for breast cancer risk reduction and management. BMC medical informatics and decision making. 2014;14:4.

14. Stacey D, O'Connor AM, DeGrasse C, Verma S. Development and evaluation of a breast cancer prevention decision aid for higher-risk women. Health expectations : an international journal of public participation in health care and health policy. 2003;6(1):3-18.

15. Schoorel EN, Vankan E, Scheepers HC, Augustijn BC, Dirksen CD, de Koning M, et al. Involving women in personalised decision-making on mode of delivery after caesarean section: the development and pilot testing of a patient decision aid. BJOG : an international journal of obstetrics and gynaecology. 2014;121(2):202-9.

16. Breslin M, Mullan RJ, Montori VM. The design of a decision aid about diabetes medications for use during the consultation with patients with type 2 diabetes. Patient education and counseling. 2008;73(3):465-72.

17. Fleisher L, Buzaglo J, Collins M, Millard J, Miller SM, Egleston BL, et al. Using health communication best practices to develop a web-based provider-patient communication aid: the CONNECT study. Patient education and counseling. 2008;71(3):378-87.

18. Lalonde L, O'Connor AM, Drake E, Duguay P, Lowensteyn I, Grover SA. Development and 
preliminary testing of a patient decision aid to assist pharmaceutical care in the prevention of cardiovascular disease. Pharmacotherapy. 2004;24(7):909-22.

19. Ameling JM, Auguste P, Ephraim PL, Lewis-Boyer L, DePasquale N, Greer RC, et al. Development of a decision aid to inform patients' and families' renal replacement therapy selection decisions. BMC medical informatics and decision making. 2012;12:140.

20. Schonberg MA, Hamel MB, Davis RB, Griggs MC, Wee CC, Fagerlin A, et al. Development and evaluation of a decision aid on mammography screening for women 75 years and older. JAMA internal medicine. 2014;174(3):417-24.

21. Bansback N, Li LC, Lynd L, Bryan S. Development and preliminary user testing of the DCIDA (Dynamic computer interactive decision application) for 'nudging' patients towards high quality decisions. BMC medical informatics and decision making. 2014;14:62.

22. Warner DO, LeBlanc A, Kadimpati S, Vickers KS, Shi Y, Montori VM. Decision Aid for Cigarette Smokers Scheduled for Elective Surgery. Anesthesiology. 2015;123(1):18-28.

23. Coulter A, Stilwell D, Kryworuchko J, Mullen PD, Ng CJ, van der Weijden T. A systematic development process for patient decision aids. BMC medical informatics and decision making. 2013;13 Suppl 2:S2.

24. Stacey D, Légaré F, Col NF, Bennett CL, Barry MJ, Eden KB, et al. Decision aids for people facing health treatment or screening decisions. Cochrane Database Syst Rev. 2014;CD001431.

25. Izquierdo F, Gracia J, Guerra M, Blasco JA, Andradas E. Health technology assessmentbased development of a Spanish breast cancer patient decision aid. International journal of technology assessment in health care. 2011;27(4):363-8.

26. Sherman KA, Harcourt DM, Lam TC, Shaw LK, Boyages J. BRECONDA: development and acceptability of an interactive decisional support tool for women considering breast reconstruction. Psycho-oncology. 2014;23(7):835-8.

27. Elwyn G, O'Connor A, Stacey D, Volk R, Edwards A, Coulter A, et al. Developing a quality criteria framework for patient decision aids: online international Delphi consensus process. Bmj. 2006;333(7565):417.

28. Holmes-Rovner M, Stableford S, Fagerlin A, Wei JT, Dunn RL, Ohene-Frempong J, et al. Evidence-based patient choice: a prostate cancer decision aid in plain language. BMC medical informatics and decision making. 2005;5:16.

29. Weyand SA, Frize M, Bariciak E, Dunn S. Development and usability testing of a parent decision support tool for the neonatal intensive care unit. Conference proceedings : Annual International Conference of the IEEE Engineering in Medicine and Biology Society IEEE Engineering in Medicine and Biology Society Annual Conference. 2011:6430-3.

30. Kelly-Blake K, Clark S, Dontje K, Olomu A, Henry RC, Rovner DR, et al. Refining a brief decision aid in stable CAD: cognitive interviews. BMC medical informatics and decision making. 2014;14:10.

31. Feldman-Stewart $D$, Brundage MD. Challenges for designing and implementing decision aids. Patient education and counseling. 2004;54(3):265-73.

32. Evans R, Elwyn G, Edwards A, Watson E, Austoker J, Grol R. Toward a model for fieldtesting patient decision-support technologies: a qualitative field-testing study. Journal of medical Internet research. 2007;9(3):e21.

33. Fraenkel L, Street RL, Jr., Fried TR. Development of a tool to improve the quality of decision making in atrial fibrillation. BMC medical informatics and decision making. 2011;11:59.

34. Milne J, Gafni A, Lu D, Wood S, Sauve R, Ross S. Developing and pre-testing a decision board to facilitate informed choice about delivery approach in uncomplicated pregnancy. BMC pregnancy and childbirth. 2009;9:50. 
Valorisation chapter | 189 


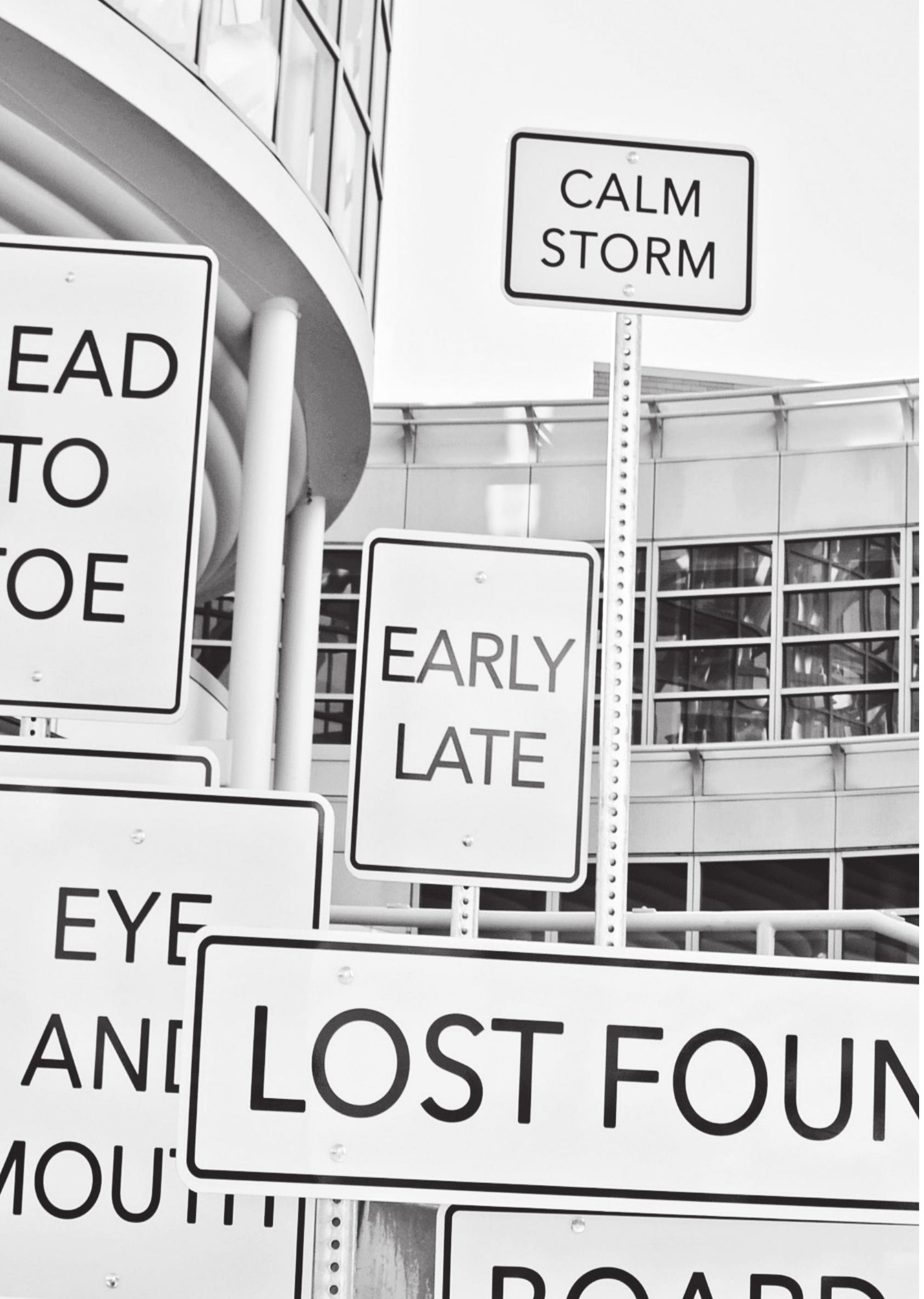




\section{Bibliography of author}

\section{Publications}

- Elias-Smale S, Meeder J, Kavousi M, Aribas E, Dreesens D, Keuken D. NVVC Leidraad Pijn op de borst zonder obstructief coronairlijden [Guidance Ischemia and No Obstructive Coronary Artery Disease (INOCA)], juni 2020, NVVC (Werkgroep Gender), Utrecht

- Dreesens D, Kremer L, Burgers J, van der Weijden T. Lost in definitions: Reducing duplication and clarifying definitions of knowledge and decision support tools. A RAND-modified Delphi consensus study. Health Policy. 2020; 124(5):531-9.

- Van Dalfsen M, Judith J, Dreesens D, Huisman M, Klok E, Kok L, Smits P, Volmeijer E, Wagner C. Rapport richtlijnanalyse diepe veneuze trombose en longembolie [Report analysis of DVT and pulmonary embolism clinical practice guidelines], januari 2020, Nivel, Utrecht

- Dreesens D, Kremer L, van der Weijden T. The Dutch chaos case: A scoping review of knowledge and decision support tools available to clinicians in the Netherlands. Health Policy. 2019;123(12):1288-97.

- Dreesens D, Veul L, Westermann J, Wijnands N, Kremer L, van der Weijden T, et al. The clinical practice guideline palliative care for children and other strategies to enhance shared decision-making in pediatric palliative care; pediatricians' critical reflections. BMC Pediatr. 2019;19(1):467.

- Dreesens D, Stiggelbout A, Agoritsas T, Elwyn G, Flottorp S, Grimshaw J, et al. A conceptual framework for patient-directed knowledge tools to support patient-centred care: Results from an evidence-informed consensus meeting. Patient Educ Couns. 2019;102(10):1898-904.

- Van der Weijden T, Dreesens D, Faber MJ, Bos N, Drenthen T, Maas I, et al. Developing quality criteria for patient-directed knowledge tools related to clinical practice guidelines. A development and consensus study. Health Expect. 2019;22(2):201-8.

- Zijlmans, M, Damink J, Dreesens, D. Kwaliteitsbeleid 2019-2025 - Nederlandse Vereniging voor Klinische Fysica, april 2019, NVKF, Utrecht

- Wieringa S, Dreesens D, Forland F, Hulshof C, Lukersmith S, Macbeth F, et al. Different knowledge, different styles of reasoning: a challenge for guideline development. BMJ Evid Based Med. 2018;23(3):87-91.

- Moesker MJ, Damen NL, Volmeijer EE, Dreesens D, de Loos EM, Vink R, et al. Guidelines' risk assessment recommendations for venous thromboembolism prophylaxis: A comparison and implementability appraisal. Thromb Res. 2018;168:5-13.

- Jaap van Dissel, Wiel Hoekstra, Dunja Dreesens, et al (red.). Antibioticaresistentie: wat als antibiotica niet meer werken? [Antibiotic resistance; what if when antibiotics are no longer effective], Cahier Biowetenschappen en maatschappij 2015, kwartaal 4. Stichting Biowetenschappen en Maatschappij, Den Haag

- Dunja Dreesens. Antibioticaresistentie staat weer op de agenda (hoofdstuk in: Antibioticaresistentie: wat als antibiotica niet meer werken?). Cahier Biowetenschappen en maatschappij 2015, kwartaal 4. Stichting Biowetenschappen en Maatschappij, Den Haag

- J.J.E. van Everdingen, D.H.H. Dreesens, J.S. Burgers, et al (red.). Handboek evidence-based richtlijnontwikkeling: Een leidraad voor de praktijk. 2014; 2e druk. Bohn Stafleu van Loghum, Houten

- D.H.H. Dreesens, J.J.E. van Everdingen, S.M.C. Kersten. Historisch perspectief van richtlijnontwikkeling in Nederland (hoofdstuk in: Handboek evidence-based richtlijnontwikkeling: Een leidraad voor de praktijk). 2014; 2e druk. Bohn Stafleu van Loghum, Houten

- T. van der Weijden, D.H.H. Dreesens, H. van de Bovenkamp. Gedeelde besluitvorming en richtlijnen (hoofdstuk in: Handboek evidence-based richtlijnontwikkeling: Een leidraad voor de praktijk). 2014; 2e druk. Bohn Stafleu van Loghum, Houten 
- Dirksen CD, Utens CM, Joore MA, van Barneveld TA, Boer B, Dreesens DH, et al. Integrating evidence on patient preferences in healthcare policy decisions: protocol of the patient-VIP study. Implement Sci. 2013;8:64.

- Van der Wouden H, Kortekaas M, Dreesens D, Keuken D, Dekker J. Alledaagse ziekten: wat heeft 10 jaar subsidie opgebracht [Every day diseases; what results did the funding programme deliver], Huisarts en Wetenschap. 2013;5:202-207

- Richtlijn voor richtlijnen [Guideline for Guidelines]. 2010, 2011 (1 herziening) en 2012 ( $2^{\mathrm{e}}$ herziening)), Regieraad Kwaliteit van Zorg, Den Haag

- Glossarium Kwaliteit van Zorg [Glossary Quality of Care] (red.). 2011, Regieraad Kwaliteit van Zorg, Den Haag

- Van Everdingen JJ, Dreesens DH, Tuut MK. Regie over richtlijnen [Advice on guidelines: planning for guideline development in the Netherlands]. Ned Tijdschr Geneeskd. 2010;154:A1599.

- Kwaliteitscanon Kwaliteit [Quality Top 100 in Health Care] (red.), 2010, Regieraad Kwaliteit van Zorg, Den Haag

\section{Conferences and abstracts}

- Key-note speaker KNGF scientific international conference (2018) Lost in translation, 4th ER-WCPT Conference on Clinical Guidelines 'Bringing evidence into practice', KNGF, Den Bosch, Netherlands

- Oral presentation, 1st Annual Implementation Science Research Conference, 2018, King's College, London, UK; Guideline implementation in real life; the gap between the developer, the medical association and the professional

- Key-note speaker, GuiaSalud \& Spanish Ministry of Health, 2017, Madrid, Spain:

- Jornada Científica - Shared decision making and clinical guidelines https://images.app. goo.gl/MyaV8PS4fpgtRpR39

- Oral presentation, ISDM 2017, Lyon, France:

- Supporting patient-centred care; making knowledge tools more accessible to patients, and professionals

- Oral presentation, G-I-N 2017, Cape Town, South Africa:

- Plotting instruments, implementation and evaluation on a quality cycle to improve care and cooperation

- Poster, G-I-N 2016, Philadelphia, United States of America:

- The right tool for the right job: a framework for patient direct knowledge tools

- G-I-N Working Group AID workshop

- Research forum NIVEL \& Zorginstituut Nederland, 2016, Utrecht, Netherlands

- Information and shared decision-making

- Oral presentations, G-I-N 2015, Amsterdam, Netherlands:

- Is it chaos? And can we unravel it? A RAND modified Delphi for knowledge instrument types;

- Integrating guidelines and SDM: Paediatricians reflecting on CPG Palliative Care for Children;

- Ariadne principles; multimorbidity and guidelines (Multimorbidity panel);

- Modular guidelines and multimorbidity;

- Workshop Patient participation in guideline development.

- Oral presentations, ISDM 2015, Sidney, Australia:

- Integrating a guideline and shared decision making: paediatricians reflecting on the clinical practice guideline Palliative Care for Children;

- Unravelling chaos: a modified RAND Delphi to limit the number of knowledge tools in the Netherlands and to define them at a national level 
- Poster ISDM 2013, Lima, Peru:

- The Dutch chaos case; a myriad of instruments to support patients' and physicians' decision making

- Oral presentations, G-I-N 2011, Seoul, South Korea:

- Guidelines and cost-effectiveness: a happy marriage?

- Safety (norms) in guidelines; handle with care?

- Post-conference, G-I-N 2010, Berlin, Germany:

- Appraising and Using Non-RCT Evidence in Clinical Guideline Production

- Workshop, G-I-N 2009, Lisbon, Portugal:

- Designing and testing a programme for multidisciplinary guideline development 


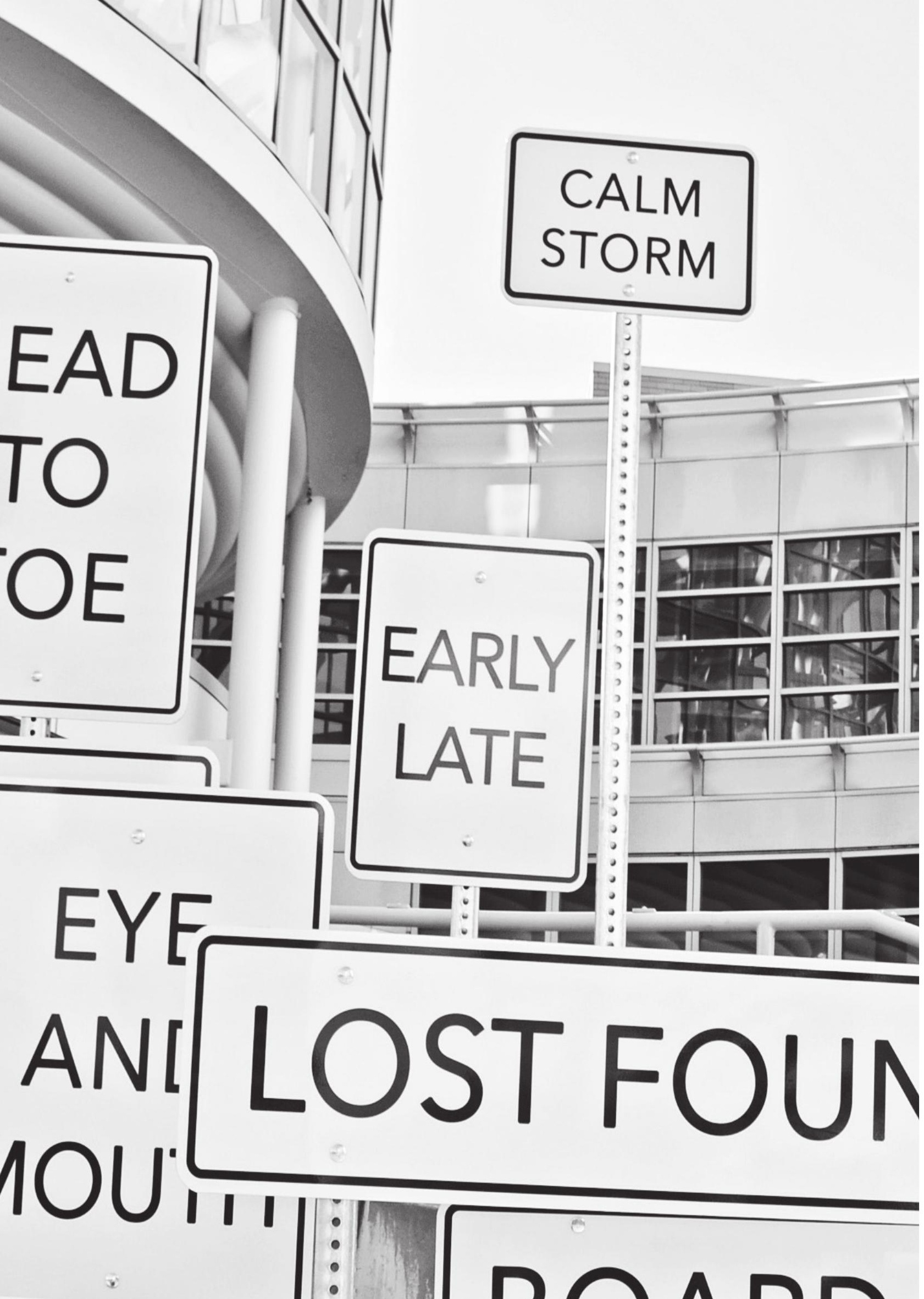




\section{Dankwoord}

Tijdens mijn leven ben ik zoveel lieve en aardige mensen tegengekomen. Alle contacten en vriendschappen hebben gemaakt tot wie ik nu ben. Hoe doe ik die recht in mijn dankwoord? Ik heb daarom even overwogen een ieder met naam en toenaam te noemen. De gedachte dat je uiteindelijk toch iemand over het hoofd hebt gezien, heeft me doen besluiten er van af te zien. Een poging tot die lijst staat echter wel in mijn laatste PhD-notitieboekje en die koester ik; deze brengt dierbare herinneringen te weeg aan wie ik allemaal ontmoet heb, ken en wat we allemaal hebben meegemaakt.

Een paar zal ik hier dan toch noemen ...

Allereerst mijn hartelijke dank aan Henk Smid, Diana Delnoij en Teus van Barneveld, respectievelijk van ZonMw, Zorginstituut Nederland en het Kennisinstituut van Medisch Specialisten. Deze drie personen hebben mede mogelijk gemaakt dat ik grotendeels tijdens werktijd mijn promotie-onderzoek kon uitvoeren.

Dank aan de leden van de ZonMw-programmacommissies KKCZ en PAZ van wie ik veel heb geleerd en door wie ik me altijd gewaardeerd heb gevoeld. En van wie enkele zich enthousiast als opponent aanboden bij de start van mijn $\mathrm{PhD}$ in 2012. Naast de commissieleden en projectleiders waren er vooral mijn collega's met wie ik veel gelachen, hard gewerkt, frustraties gedeeld maar vooral een mooie tijd mee heb gehad. Vooral met Moniek, mijn laatste kamergenootje voor de intrede van de flekplekken, met wie ik lief en leed kon, en kan delen. Ook over rijlessen. Bart, Rebecca en Ira 'mijn' programma-assistenten die inmiddels hun eigen weg buiten ZonMw gevonden hebben. Kris - samen met honden Sterling en Prya, die ik gelukkig af en toe toch mocht knuffelen -, Renata en Martijntje voor het inwerken op JPI AMR, en Thera mijn recht voor haar raap opvolger.

Bij het Zorginstituut heb ik veel korter gewerkt maar vooral het projectteam Meerjarenagenda is me bijgebleven, zonder enig morren mocht ik als hun projectleider optreden en hebben we mooie dingen in gang gezet. En kamergenoten Charles en Payam die veel konden onthullen over de ins \& outs, do's \& dont's van het Zorginstituut.

Voordat ik stil sta bij het Kennisinstituut, maak ik graag een uitstapje naar de Regieraad Kwaliteit van Zorg; de brug tussen ZonMw en het Zorginstituut. Wat een mooi team en mooie tijd was dat. Ik kijk nog steeds vol trots op deze periode terug. Jullie waren en zijn toppers: Miranda, Ira, Edmar, Madelon, Cule en Jannes. Zonder jullie had de raad niet kunnen bereiken wat hij in die korte tijd bereikt heeft. Tijdens het een na laatste jaar van de raad ben ik begonnen met mijn PhD. Wat voor raadsvoorzitter Pieter Vierhout (de kracht van het compliment) waarschijnlijk de aanleiding was om 'Denken' van Hannah Arendt als afscheid cadeau te doen (ik heb nu eindelijk tijd om het te lezen).

Het Kennisinstituut barst bijna uit zijn voegen, zoveel nieuwe mensen zijn er sinds mijn start bijgekomen. En stuk voor stuk zijn het lieve en geïnteresseerde collega's. Altijd bereid om te helpen en mee te denken. Daarnaast voel ik me vereerd dat ik Ester mag begeleiden in haar 
PhD-traject en hoop haar naast kennis ook geleerde lessen mee te kunnen geven. En zonder Debby had ik het waarschijnlijk niet gered; zij staat letterlijk bijna dag en nacht voor je klaar, zelfs om een broek om te zomen. Vertrokken collega Eva was vanaf de start mijn maatje, met een gedeeld gevoel voor humor en (zelf-)relativering, implementatie was 'ons ding' en ze had altijd een luisterend oor ook al was ze zelf druk.

Louis, Teun en Gerard; jullie zijn in mijn werkende bestaan regelmatig 'passerende individuen' van wie ik veel leer, geleerd heb en graag mee samen werk, samengewerkt heb.

Als zogeheten externe promovendus ben je niet vaak op de universiteit, maar ik heb me er geen moment minder welkom om gevoeld op de HAG/School CAPHRI. Karin, Frits, Ellen, Ine, Jochen, Huibert, Erie, Hélène, Jerôme, Sandra, Jos, Pascal, dank voor alle hulp en ondersteuning, gesprekjes, interesse, en snoepjes (op het bureau van Ine). Jako en Jany, dank dat ik op jullie kamer mocht zitten. En Albina dank voor de gezellige tijd in Lima, Peru en voor de verborgen schat Luna Rossa in Wyck.

Tevens dank aan mijn coauteurs, het was een eer met jullie te werken! A big thank you to my coauthors; it was a pleasure and honour working with you. En natuurlijk tevens aan de leden van de beoordelingscommissie en opponenten tijdens mijn verdediging.

Bijzondere dank aan Frans die bij zijn aanbod acht jaar geleden om mij te helpen met de Nederlandse samenvatting van het proefschrift vast niet doorhad wat hij zich op de hals haalde.

Zonder Lotte, Nicole en Jonne waren de interviews niet tot stand gekomen. Wat heb ik genoten van jullie energie, enthousiasme en slimheid. En wat mooi om te zien hoe jullie je plek gevonden hebben na je studie en alle drie trotse moeder inmiddels.

Dit alles was onmogelijk geweest zonder mijn promotores Eduard Verhagen, Leontien Kremer en bovenal Trudy van der Weijden; zij heeft mij deze kans geboden en het vertrouwen gehad dat ik deze klus zou klaren. Een betere promotor dan Trudy had ik me niet kunnen wensen. Eduard en Leontien dank voor jullie kritische blik en het constructief meedenken.

Dit alles was ook niet mogelijk geweest zonder mijn lieve, dierbare vrienden en familie, die er altijd voor me zijn. Winonah en haar Niels, mijn Amsterdamse basis en VIP-ticket to Haagenbasz. Sean for being there, even on the other side of the world and the one who said "nothing in life worth fighting for is easy". Jelle $(\dagger)$ voor de briljante en vermakelijke theateravonden. Justin \& Joyce voor de onvergetelijke Limburg-borrels en wat nog komen mag. Cornelia omdat je gebleven bent en onze heerlijke shopping trips. Houbert, mijn favoriete oom. Bram \& Danielle voor de spel- en filmavonden, het lekkere eten en alle steun. Sippie en Maarten, mijn (oud-) ZonMw-maatjes; effe bijkletsen om de zoveel tijd (en hopelijk binnenkort weer een balletje slaan met Maarten). Annefloor, vertrokken bij het Kennisinstituut maar gelukkig kunnen we ook daar buiten het goed vinden. Ann, Stuart, Stevie, Darren, Alan and Eamon, you came with Andy into my life and it's fun knowing you. En dat geldt ook voor Jan ( $\dagger$ ), Joe \& Bianca in Gorinchem. Otto, 'mentor' bij VWS, klankbord, mijn andere basis in Amsterdam en voor de mooiste (en 
soms onnavolgbare) films in EYE. Simon, mijn 3D Brit, vriend sinds onze randonnée naar de Alpe d'Huez, en ook het parachute springen zal ik nooit vergeten. Renske voor de wandelingen, gesprekken, alle thee, museumbezoek al dan niet met Rixt. Ubbo voor je heerlijke Friese nuchterheid en het geluk dat je Ivonne brengt. Wem \& Grainne voor de dagen in Dublin dat ik de boel de boel kon laten, een ongeëvenaarde St Paddy's en de altijd hartelijke welkom en voor de bemoedigende woorden "tegenslag kom je te boven". Sláinte! Ingeborg voor het leren drinken, kennismaking met rugby, de heerlijke weekenden in Parijs (met Marga, en nu weer terug in Nederland), het kitesurfen (toen ik dat nog mocht) en memorabele stapavonden. Taco \& Gert-Jan voor het weekendje met jullie katten (de muizen kijken er minder positief op terug vermoedelijk), het rustgevende staren naar de vissen, de jaarlijkse BBQ en kaasfondue, jullie humor, hulp en gezelligheid. Angelique, Matti \& Maleka voor de gezellige etentjes en zondochtendbrunches, bezoekjes aan Den Haag en alle lieve kaartjes. Aimée voor de films (bij dat fantastische Lumière) die ik in mijn eentje waarschijnlijk niet zou zijn gaan kijken, de wandelingen, het blijven slapen, de Haagse weekendjes en gewoon het daar zijn. Patricia, dank voor het mogen crashen bij jou, Marc, Tobias, Matthijs \& Sabien als ik weer eens in Maastricht was, de gezellige avondjes bij jullie thuis of in de stad en je luisterende oor. Babette, Romain, Nour \& Ruiz en de gezellige beestenboel, dank voor alles; het blijven slapen, het overheerlijke eten, kermis in Zichen (wauw), nooit was iets te veel.

En Tinto, mijn vrijwilligershondje, voor de broodnodige, slome zondagochtendwandelingen door weer en wind.

Anne \& Owen; Ross and Seán; Kirsty, Scott, Katie \& Sarah; Joanne, Simon, Cara \& Lily; and Paula, Adam, Beth, Ben \& Matthew thank you for welcoming me in your family and making me feel at home in your wonderful Scotland.

Karin en Ivonne, mijn paranimfen, en mijn broodnodige stukjes Maastricht in de Randstad. Door dik en dun. Ik kan met jullie naar het eind van de wereld en terug en zou jullie voor geen goud willen missen.

TuubTuub en Paco, mijn dierbare en dankbare afleidingen tijdens het typen. Die taak hebben Zoomer \& Loki sinds deze zomer overgenomen.

Pap, mam, zonder jullie zou ik niet zijn waar ik nu ben, dat laat zich niet in enkele zinnen vatten. Jullie lieten me in alle vrijheid, zelfstandigheid en onafhankelijkheid opgroeien, met respect voor de natuur, voor ouderen en anderen. Met alle Lego, autootjes, speeltuinen, zwembaden, vriendjes, boomklimmen en boeken die ik me kon wensen. Maar vooral met alle aandacht en liefde, meer was eigenlijk niet nodig.

And to Andy, my sjottepie, who preferred not too many words were being said about him, thanks for the gentle nudging once every while to keep me going ... I love you to bits.

Dit zit erop, tijd voor iets nieuws! Bedankt allemaal! x 


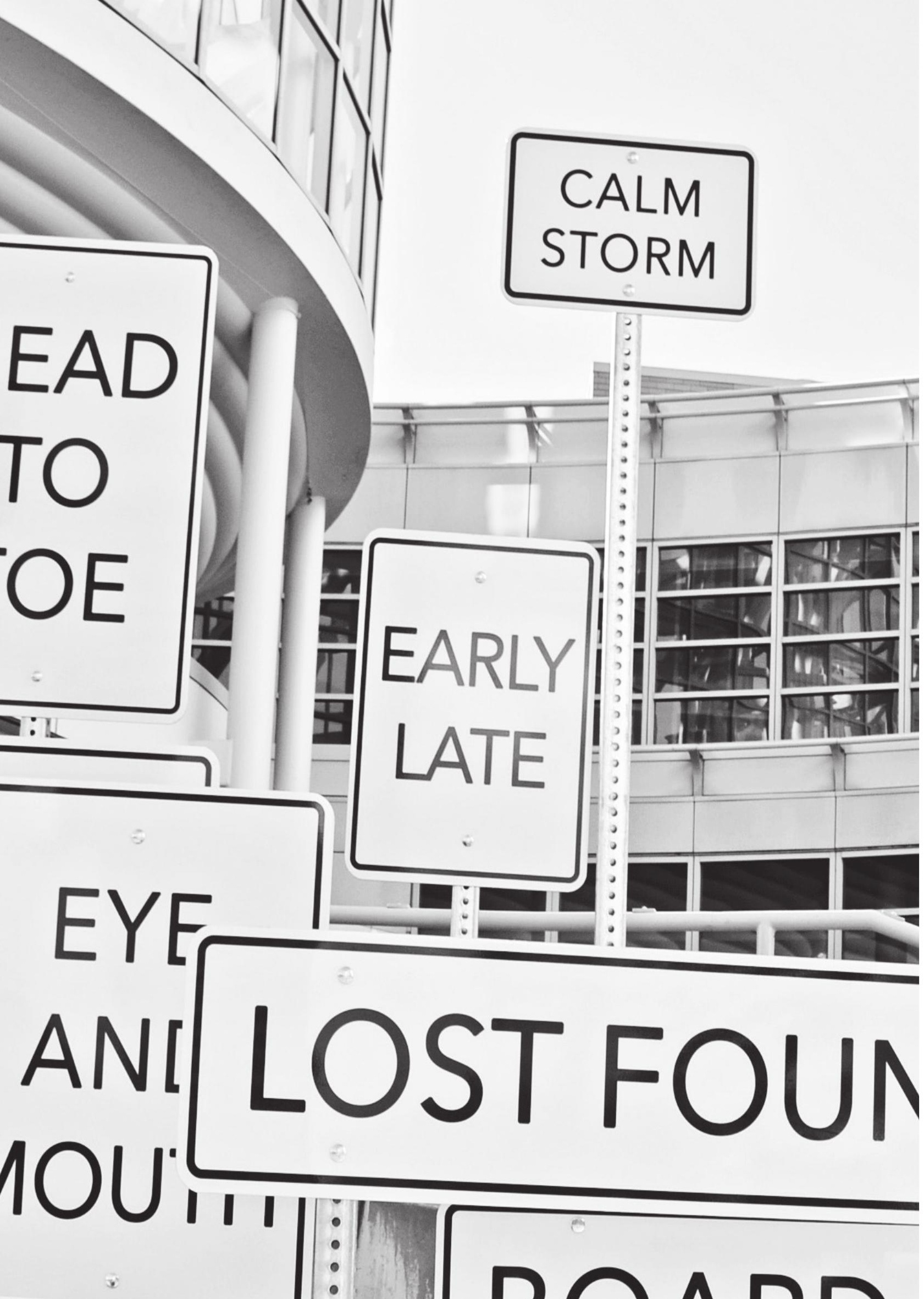




\section{About the author}

Born in Maastricht on 9th February 1972, the last day of carnival. And every eleven years, my birthday takes place on the last day of carnival. Carnival enthusiasts recognise the significance. I grew up in Maastricht except for a five year stint in Born and Sittard ('t Kleesj). After finishing Gymnasium B at 't Stedelijk, I chose to start with the brand-new studies Commerce and Business Economics at Hogeschool Zuyd (1994). Because on the one hand I was dreading the 'crowdedness' of university, and on the other hand this new study offered the opportunity to spend a year abroad. During that year abroad, I did an apprenticeship at Douwe Egberts UK (London) and got introduced to techniques retailers use to influence buying behaviour of customers. Which was also the subject of my thesis.

Triggered by the course 'intercultural communications', I decided to follow-up with a master study that was more human interest oriented: social cultural sciences at Vrije University in Amsterdam (1998). During my last year at university, I got employed by Boots the Chemist Ltd. A pharmacy/chemist chain that was seeking a foothold in continental Europe. As Merchandising \& Marketing executive health care, this was my introduction in the world of (commercial) health care. After opening five shops in the Netherlands, I switched to the Ministry of Health, Welfare and Sports where I was involved in the project pharmaceutical care. Still not having found my niche, I left the government after two years to start as a consultant with Accenture (2000). That was a rollercoaster ride, peeking into kitchens of very different organisations such as AkzoNobel, KLM, Child Welfare Council, Betuweroute (knowing quit early on that its deadline would not be met) and spending most my time with energy supplier Essent (regarding transition of the energy market). My project involvements were mainly change management.

After five years, I decided it was time to return to health care as I wanted to make sure it is in tip top shape when I'm old. However, when applying for jobs I was told that my days in health care were too long ago, so I took up a new master study at Erasmus School of Health Policy \& Management (formerly iBMG) in Rotterdam (2005). And also starting a new consulting job with CQ-procesmanagement that mainly worked with mental healthcare organisations. The subject of this thesis concerned factors influencing people choosing home care.

Preferring a job that sees to the end of the projects I was involved in, I applied with ZonMw (2006), Netherlands Organisation for Health Research and Development. My terms and discussions negotiations took place on the shores of the peninsula Snæfellsness (Iceland) waiting for the ferry. I was programme manager for three programmes: Disaster management in hospitals (Ziekenhuisrampenopvang-plannen, ZIROP), Multidisciplinary guideline development (Kwaliteit, Kennisbeleid Curatieve Zorg) and Every day diseases (Programma Alledaagse Ziekten (PAZ); programme together with the Dutch College of General Practitioners) before I was outsourced to a new advisory board for the minister of health; Councill for the Quality of Care (2009). Finally finding my niche: knowledge tools, knowledge translation and quality of care. Some feats of the Council of which I am proud: Guideline for Guidelines (working group), Glossary of quality health care, and the new edition of the 'manual' for evidence-based guideline development. 
Due to the merger of the Council with other advisory boards, I came to work with the new National Health Care Institute (Zorginstituut Nederland) (2012) and was responsible for the long-term agenda for clinical practice guideline development and implementation in the Netherlands (also known as Meerjarenagenda). Not agreeing with the direction the institute was taking, I returned to ZonMw (2014). This time, as work package lead of the EU Joint Programming Initiative Antimicrobial Resistance (JPI AMR). In this capacity I contributed to the booklet Antibiotic resistance; what if antibiotics are no longer effective? Feeling I was drifting away from my PhD subject, I asked around within my network what a suitable working place would be for a person such as me. I 'ended up' at the Knowledge Institute of Medical Specialists (2015), as senior advisor and team lead.

At the beginning of the guideline programme at ZonMw, I was interviewed and the article inadvertently referred to me as having a $\mathrm{PhD}$. When rectifying this with the programme committee, some members said that they would welcome me if I ever wanted to do a PhD with them. In 2011 an opportunity arose when committe member Trudy van der Weijden was appointed professor at Maastricht University. Coming full circle, back in my home town, I started my PhD in summer 2012 and my PhD thesis was accepted in spring 2020.

Still a proud Mestreechteneer, but living happily together with her tough Scot Andrew McBride, and kittens Zoomer \& Loki in happening The Hague. 
Het is miech gelök!

\section{Eus Mestreechter taol}

De zon sjijnt sjoen

Sjeng en dien sjeun zien erreg sjiek, bove de riviere klink dat get kemiek.

De waor steit in de kiekoet, zèt de kenkee noe mer lieg,

'n knievel op dien lip beteikent haor op die geziech.

'ne Groete bavvie is gewoen 'n groete moul,

e look in de grónd, jao dat neume veer 'n koul.

\section{Refrein:}

Ze is neet breid, ze is neet breid.

Mer ze is laank, mer ze is laank.

Eus Mestreechter taol, 't sjoens vaan allemaol.

En veer trèkke ze laank, want dat gief zjus de klaank.

Tappesere doen veer mèt tepiet,

leef medam, eur humme is te wied.

Lammentere is gewoen gezeik,

lómmele verköp ste aon 'de Reik'.

'n Kachel in de keuke hèt bijj us 'ne kwiezenjaer,

en al deez leuke wäördsjes höb iech oet d'n diksjenaer.

Teks: D. Vangarde \& J. Innemee

Melodie: "Vive le douanier Rousseau"

Zaank: De Drei Köp 




